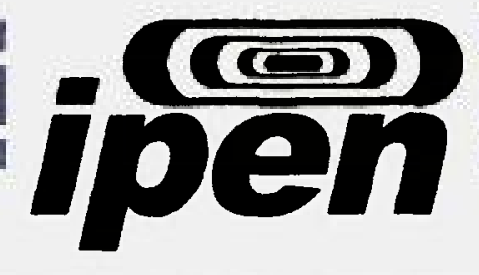

AUTARQUIA ASSOCIADA À UNIVERSIDADE DE SÃo PAULO

\title{
ESTUDO DO MECANISMO DE BLOQUEIO DA SINTERIZAÇÃO NO SISTEMA UO $\mathrm{O}_{2}-\mathrm{Gd}_{2} \mathrm{O}_{3}$
}

\section{MICHELANGELO DURAZZO}

Tese apresentada como parte dos requisitos para obtenção do Grau de Doutor em Ciências na Área de Tecnologia Nuclear-Materiais

Orientador:

Dr. Humberto Gracher Riella

\section{São Paulo}


INSTITUTO DE PESQUISAS ENERGÉTICAS E NUCLEARES

Autarquia associada à Universidade de São Paulo

ESTUDO DO MECANISMO DE BLOQUEIO DA SINTERIZAÇÃO NO SISTEMA $\mathrm{UO}_{2}-\mathrm{Gd}_{2} \mathrm{O}_{3}$

MICHELANGELO DURAZZO

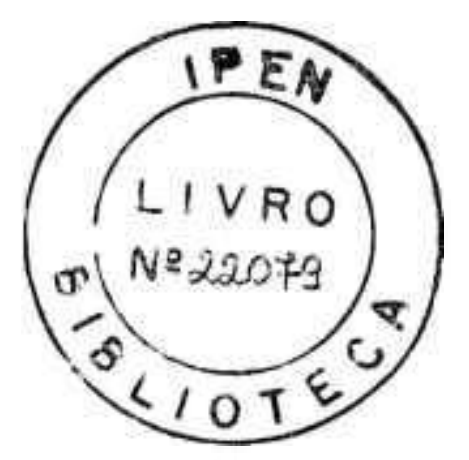

Tese apresentada como parte dos requisitos para obtenção do grau de Doutor em Ciências na Área de Tecnologia Nuclear - Materiais.

Orientador:

Dr. Humberto Gracher Riella 
Ã minha mãe, Alba, pela dedicação (in memoriam) 


\section{AGRADECIMENTOS}

Ao Instituto de Pesquisas Energéticas e Nucleares, pela possibilidade de realizar este trabalho.

À Coordenadoria de Projetos Especiais, COPESP, atual Centro Tecnológico da Marinha em São Paulo, CTMSP, pela permissão de utilização da infraestrutura do Laboratório de Materiais Nucleares, LABMAT, sem a qual não teria sido possível a realização deste trabalho.

Ao Dr. Humberto Gracher Riella, pelo estímulo, pela orientação, pelas sugestões e pelo apoio na realização deste trabalho.

A todos os colegas que trabalharam comigo no Laboratório de Materiais Nucleares do CTM/SP, os quais contribuíram decisivamente na execução da parte experimental deste trabalho.

Aos colegas do Centro de Combustíveis Nucleares do IPEN-CNEN/SP, pelo apoio na fase final deste trabalho e, em particular, à MSc. Elita Urano de Carvalho Frajndlich e ao Eng. José Antonio Batista de Souza, a quem agradeço pelo apoio sempre presente na conciliação das atividades gerenciais e de pesquisa.

Aos colegas do grupo de Caracterização Química è Isotópica do IPEN-CNEN/SP pela realização das análises químicas.

Ao MSc. Gilberto Hage Marcondes pelo apoio na realização das análises de imagens para determinação da distribuição de diâmetros de poros e pelo apoio na caracterização microestrutural por Microscopia Eletrônica de Varredura (MEV).

Ao Dr. Ricardo Mendes Leal Neto pelas incontáveis e incansáveis horas de estimulante e proveitosa discussão em várias etapas deste trabalho.

Ao Dr. Edval Gonçalves de Araújo pelo apoio na determinação de perfis de concentração por microanálise.

Ao MSc. Adonis Marcelo Saliba Silva pelo apoio e sugestões em diversas etapas deste trabalho.

Aos meus pais, que proporcionaram a oportunidade de iniciar este trabalho, e aos meus filhos, Rafael e Marina Tainá, pelo estímulo para terminá-lo.

A todos que direta ou indiretamente contribuíram para a realização deste trabalho. 


\title{
ESTUDO DO MECANISMO DE BLOQUEIO DA SINTERIZAÇÃO NO SISTEMA $\mathrm{UO}_{2}-\mathrm{Gd}_{2} \mathrm{O}_{3}$
}

\author{
Michelangelo Durazzo
}

\section{RESUMO}

A incorporação do gadolínio diretamente no combustível de reatores nucleares para geração de eletricidade é importante para compensação da reatividade e para o ajuste da distribuição da densidade de potência, permitindo ciclos de queima mais longos, com intervalo de recarga de 18 meses, otimizando-se a utilização do combustível. A incorporação do $\mathrm{Gd}_{2} \mathrm{O}_{3}$ sob a forma de pó homogeneizado a seco diretamente com o pó de $\mathrm{UO}_{2}$ é o método comercialmente mais atraente devido à sua simplicidade . Contudo, este método de incorporação conduz a dificuldades na obtenção de corpos sinterizados com a densidade mínima especificada, devido a um bloqueio no processo de sinterização. Pouca informação existe na literatura específica sobre o possível mecanismo deste bloqueio, restrita principalmente à hipótese da formação de uma fase $(\mathrm{U}, \mathrm{Gd}) \mathrm{O}_{2}$ rica em gadolínio com baixa difusividade. Este trabalho tem como objetivo a investigação do mecanismo de bloqueio da sinterização neste sistema, contribuindo para o esclarecimento da causa deste bloqueio e na elaboração de possíveis soluções tecnológicas. Foi comprovado experimentalmente que o mecanismo responsável pelo bloqueio é baseado na formação de poros estáveis devido ao efeito Kirkendall, originados por ocasião da formação da solução sólida durante a etapa intermediária da sinterização, sendo dificil a sua eliminação posterior, nas etapas finais do processo de sinterização. Com base no conhecimento deste mecanismo, possiveis propostas são apresentadas na direção da solução tecnológica do problema de densificação característico do sistema $\mathrm{UO}_{2}-\mathrm{Gd}_{2} \mathrm{O}_{3}$. 


\title{
STUDIES ON THE SINTERING BLOCKAGE MECHANISM IN THE $\mathrm{UO}_{2}-\mathrm{Gd}_{2} \mathrm{O}_{3}$ SYSTEM
}

\author{
Michelangelo Durazzo
}

\begin{abstract}
The incorporation of gadolinium directly into nuclear power reactor fuel is important from the point of reactivity compensation and adjustment of power distribution enabling thus longer fuel cycles and optimized fuel utilization. The incorporation of $\mathrm{Gd}_{2} \mathrm{O}_{3}$ powder directly into the $\mathrm{UO}_{2}$ powder by dry mechanical blending is the most attractive process because of its simplicity. Nevertheless, processing by this method leads to difficulties while obtaining sintered pellets with the minimum required density. This is due to blockages during the sintering process. There is little information in published literature about the possible mechanism for this blockage and this is restricted to the hypothesis based on formation of a low diffusivity $\mathrm{Gd}$ rich phase $(\mathrm{U}, \mathrm{Gd}) \mathrm{O}_{2}$. The objective of this investigation has been to study the blockage mechanism in this system during the sintering process, contributing thus, to clarify the cause for the blockage and to propose feasible technological solutions. Experimentally it has been shown that the blocking mechanism is based on pore formation because of the Kirkendall effect. Formation of a solid solution during the intermediate stage of sintering leads to formation of large pores, which are difficult to remove in the final stage of sintering. Based on this mechanism, technical solutions have been proposed to resolve densification problems in the $\mathrm{UO}_{2}-\mathrm{Gd}_{2} \mathrm{O}_{3}$ system.
\end{abstract}




\section{SUMÁRIO}

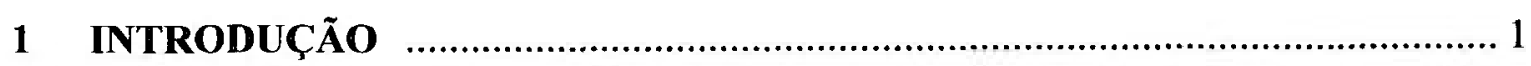

1.1 Sistemas de controle de reatores

1.1.1 Barras de controle ………………………........................... 5

1.1.2 Controle de longo prazo ………………….............................. 7

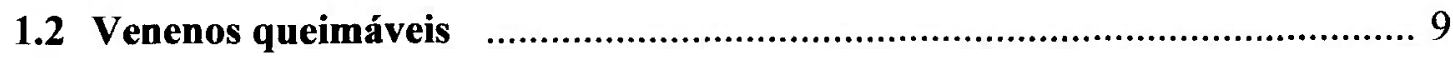

1.2.1 Considerações estratégicas $\quad$......................................................... 9

1.2.2 Aplicações dos venenos queimáveis …………………………...... 15

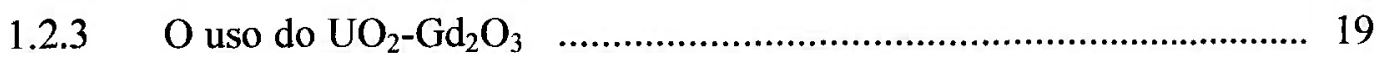

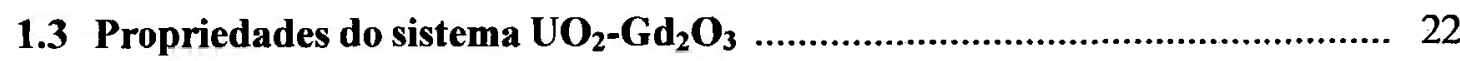

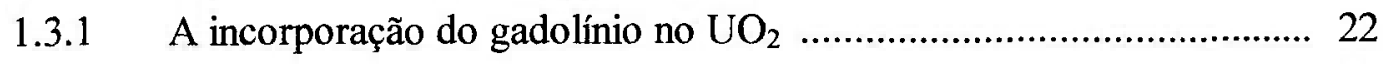

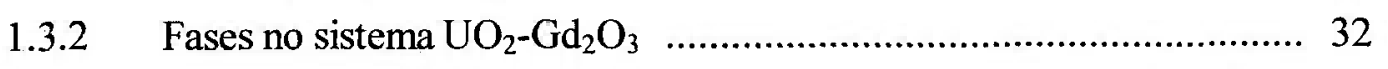

1.3.3 Outras propriedades relevantes ……………….......................... 34

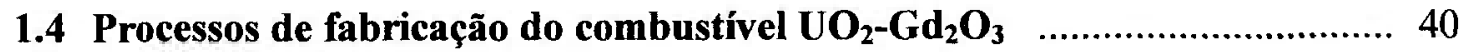

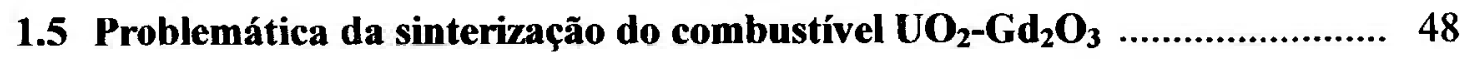

1.6 Objetivos propostos $\quad$......................................................................... 59

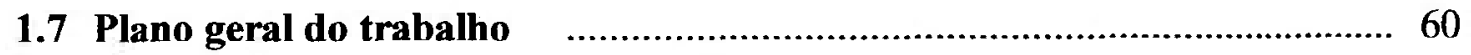

2 A HIPÓTESE DA BARREIRA DE DIFUSÃO ……...................................6 62

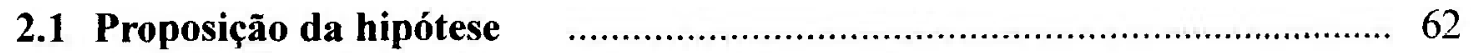

2.1.1 A influência da homogeneidade da distribuição do $\mathrm{Gd}_{2} \mathrm{O}_{3}$ no pó de

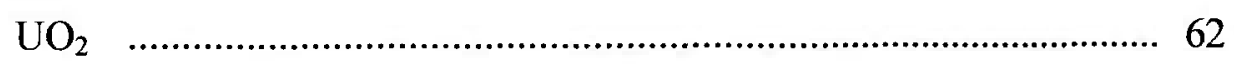

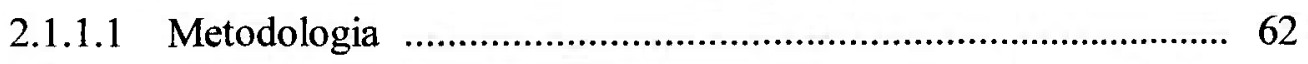

2.1.1.2 Resultados e discussão ....................................................... 71 
2.2 Desenvolvimento da hipótese f....................................................... 86

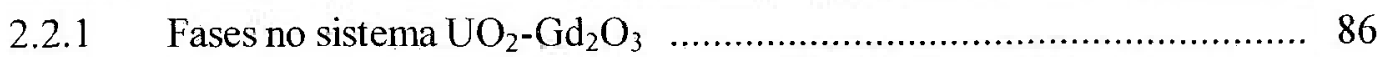

2.2.1.1 Metodologia .............................................................. 87

2.2.1.2 Resultados e discussão .................................................... 95

2.2.2 Estudos de interdifusão .......................................................... 110

2.2.2.1 Metodologia ............................................................... 110

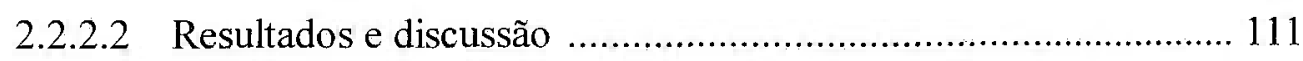

2.2.3 Fundamentação da hipótese .................................................. 118

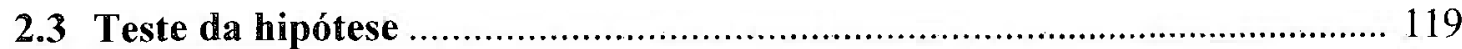

3 A HIPÓTESE DA TRANSFORMAÇÃO DE FASE DO Gd $\mathbf{G}_{2} \mathbf{O}_{3} \ldots \ldots \ldots \ldots \ldots . . \ldots \ldots$

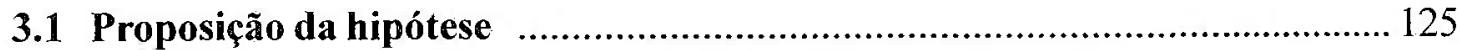

3.2 Desenvolvimento da hipótese f......................................................... 128

3.2.1 Caracterização da transformação de fase do $\mathrm{Gd}_{2} \mathrm{O}_{3} \quad \ldots \ldots \ldots \ldots \ldots \ldots \ldots . . . . . . .128$

3.2.2 Fundamentação da hipótese ................................................... 130

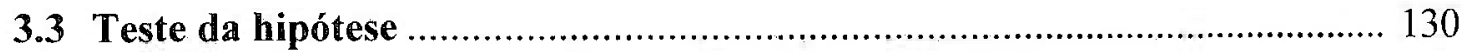

4 A HIPÓTESE DA FORMAÇÃO DE POROS ESTÁVEIS …...................... 134

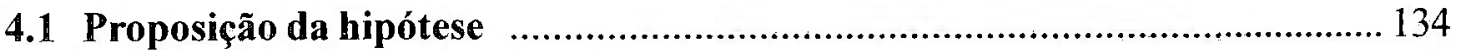

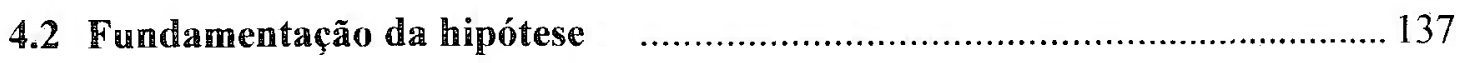

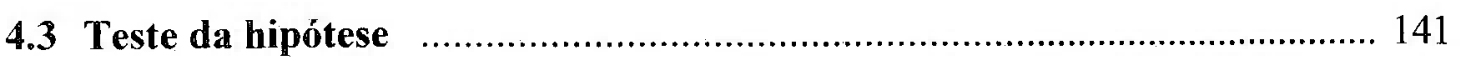

4.4 Revisão de resultados e da literatura sob a óptica da hipótese $\ldots \ldots \ldots \ldots \ldots \ldots . . . \ldots 147$ 
5.2 Ajuste da superfície específica do pó de $\mathrm{UO}_{2}$

5.3 Desenvolvimento de métodos alternativos para incorporação do pó de $\mathrm{Gd}_{2} \mathrm{O}_{3}$

6 CONCLUSÕES 161

7 PROPOSTAS PARA TRABALHOS FUTUROS 164 


\section{INTRODUÇÃO}

Desde o primeiro reator nuclear, construído por Enrico Fermi e seus colaboradores no final de 1942, numerosos métodos têm sido propostos para o controle de reatores nucleares, sendo a aplicação de materiais absorvedores de nêutrons o método universalmente adotado. Essa primeira reação nuclear em cadeia foi controlada por meio de barras de controle construídas de aço contendo boro e cádmio. Desde aquela época, imensos avanços têm sido obtidos na área de controle de reatores nucleares de potência e o uso do gadolínio tem tido uma participação decisiva, inicialmente em reatores de água fervente, tipo BWR (Boiling Water Reactor) e, mais recentemente, em reatores de água pressurizada, tipo PWR (Pressurized Water Reactor), na busca da otimização do uso do combustível e redução de rejeitos nucleares.

O projeto de reatores nucleares, e de seus sistemas de controle, é um problema complexo e exige o conhecimento dos processos físicos de interação dos nêutrons com os núcleos atômicos dos materiais que constituem o núcleo do reator nuclear e seu transporte em meios materiais. A física dos reatores é o ramo da engenharia nuclear que estuda estas interações e o transporte de nêutrons num reator nuclear. O controle do reator é projetado com base no cálculo de seus parâmetros dinâmicos durante a sua vida útil, por meio da análise da população de nêutrons no seu núcleo e, consequentemente, da distribuição de potência, definindo a estratégia operacional, o que inclui a estratégia de controle desta população de nêutrons.

A absorção de um nêutron por um núcleo atômico pesado pode ocasionar a divisão deste em dois ou mais núcleos mais leves, num processo denominado fissão nuclear. Além da fragmentação do núcleo original, formando-se os produtos de fissão, são emitidos no processo de 2 a 3 novos nêutrons que podem induzir novas 2 a 3 fissões, gerando 4 a 9 novos nêutrons que, por sua vez, podem originar outras novas fissões e de 8 a 27 novos nêutrons, e assim, numa progressão geométrica, novas fissões e novos nêutrons podem ser produzidos, caracterizando-se uma reação em cadeia. Este é o princípio de um reator nuclear, onde esta reação em cadeia ocorre de maneira controlada.

A manutenção da reação em cadeia num reator nuclear depende do balanço entre nêutrons produzidos por fissão e nêutrons que são absorvidos ou que escapam, os quais não induzem novas fissões. $O$ balanço de nêutrons no interior do sistema pode ser expresso por meio do fator de multiplicação $\mathbf{k}$, que expressa a relação entre o número de nêutrons existentes no sistema num determinado ciclo de fissão e o número de nêutrons existentes no ciclo de fissão anterior. Assim, se $\mathrm{k}>1 \mathrm{o}$ sistema é supercrítico, se $\mathrm{k}=1 \mathrm{o}$ sistema é crítico e se $\mathrm{k}<1$ o sistema é subcrítico. Vários fatores exercem influência no 
valor de k. O número médio de nêutrons emitidos numa fissão é uma constante da natureza para um determinado núcleo físsil, usualmente designada pelo símbolo $v$ (no caso do ${ }^{235} \mathrm{U}, v=2,42$ ). Como este número não pode ser controlado, o balanço de nêutrons depende de fatores que são responsáveis pela perda de nêutrons num determinado sistema, basicamente sua absorção por materiais e impurezas que são parte do sistema e seu escape sem interagir com o sistema. Esses fatores devem ser considerados no projeto do reator nuclear.

A reatividade de um reator, definida como o desvio porcentual da criticalidade que o reator possui (ou seja, expressa o quanto k é maior que 1), não é uma constante, diminuindo continuamente durante sua vida útil devido a vários fatores, principalmente consumo do combustível e formação de produtos de fissão que absorvem nêutrons, principalmente o xenônio $\left({ }^{135} \mathrm{Xe}\right)$ e o samário $\left({ }^{149} \mathrm{Sm}\right.$ e $\left.{ }^{151} \mathrm{Sm}\right)$. Além disto, a variação da temperatura do reator causa variações temporais importantes na sua reatividade (ou no fator de multiplicação), devido ao aquecimento do combustivel e do moderador. Para compensar todos estes efeitos, o reator deve ser projetado com um excesso de reatividade no início de sua vida, garantindo-se que estará crítico a qualquer instante durante toda a sua vida de operação.

Como o fluxo de nêutrons não é constante no núcleo do reator, uma vez que depende localmente das condições de geração e absorção de nêutrons, sendo, portanto, uma função da posição no núcleo, ocorre uma distribuição de potência no núcleo do reator. Esta distribuição de potência varia ao longo da vida do núcleo do reator, acompanhando variações localizadas do fluxo de nêutrons devidas à dinâmica do balanço entre geração e absorção de nêutrons, ligadas ao consumo desigual do combustível e às variações das condições de absorção de nêutrons ao longo do tempo. Esta distribuição de potência ocorre tanto na direção radial como na direção axial do núcleo e é diferente para cada projeto.

Dependendo da geometria do elemento combustível e do arranjo do núcleo do reator, ou seja, do espaçamento entre as varetas combustíveis e posições de barras de controle, ocorrem regiões onde o fluxo de nêutrons atinge valores máximos localizados. A estes picos de fluxo neutrônico correspondem picos de potência. É definido como fator de pico a relação entre a potência máxima local e a potência média do reator. Este fator é importante no projetò do reator e está relacionado ao máximo excesso de reatividade permissível, impondo as limitações térmicas do projeto.

A otimização do uso do combustível depende principalmente do aumento na sua queima, aumentando-se o intervalo entre recargas. Para isso é necessário introduzir um 
maior excesso de reatividade no início do ciclo de queima, o que é obtido aumentando-se o enriquecimento do combustivel. Esse excesso de reatividade adicional deve ser controlado e o gadolínio incorporado diretamente ao combustível $\mathrm{UO}_{2}$, na forma de $\mathrm{Gd}_{2} \mathrm{O}_{3}$, tem sido usado para exercer esse controle e também para ajuste da distribuição de potência de reatores nucleares, diminuindo os fatores de pico. No próximo item discutem-se os sistemas de controle dos reatores e a aplicação dos venenos queimáveis, como o gadolínio, no controle de longo prazo dos reatores nucleares de potência.

\subsection{Sistemas de controle de reatores}

Como foi dito anteriormente, o projeto de um reator nuclear prevê um excesso de reatividade para compensação do consumo do combustível e da formação de produtos de fissão que são fortes absorvedores de nêutrons, como o xenônio e o samário. $\mathrm{O}$ sistema de controle do reator tem a função de compensar e controlar este excesso de reatividade por meio da inserção e retirada de materiais absorvedores de nêutrons no interior do núcleo do reator, de forma a alterar os níveis de fluxo de nêutrons e, portanto, a potência, de acordo com o necessário e desejado. O sistema de controle serve também para modificar a distribuição de potência, deixando-a mais homogênea e diminuindo os fatores de pico.

Um absorvedor de nêutrons é diferenciado de outros materiais para reatores pelo fato de que ele possui uma alta seção de choque de absorção de nêutrons, sem produzir nêutrons adicionais como resultado da absorção. Um material é considerado um absorvedor de nêutrons quando possui uma seção de choque de absorção da ordem de 100 barns ou superior, considerada alta quando comparada com a seção de choque dos materiais estruturais como o Zircaloy ou o aço inoxidável, os quais possuem seção de choque de 0,2 e 2,7 barns, respectivamente. Os absorvedores mais utilizados são o boro, a prata, o índio, o cádmio, o háfnio, e as terras raras. Estes materiais são geralmente empregados na forma de ligas metálicas ou compostos, como pó compactado, pastilhas sinterizadas, dispersões e solução líquida. O boro é normalmente utilizado como carbeto de boro $\left(\mathrm{B}_{4} \mathrm{C}\right)$, na forma de pó compactado, pastilhas sinterizadas, disperso em aço inoxidável e disperso em $\mathrm{Al}_{2} \mathrm{O}_{3}$. Outra aplicação importante do boro é na forma de uma solução com o moderador (ácido bórico) e na forma de silicatos (forma vítrea). A prata, o índio e o cádmio são utilizados em conjunto, na forma de uma liga metálica com composição de $80 \% \mathrm{Ag}-15 \%$ In - $5 \% \mathrm{Cd}$ (\% em peso), o que combina a alta seção de choque de absorção de nêutrons térmicos do cádmio com as altas seções de choque de absorção de nêutrons epitérmicos (1 a $200 \mathrm{eV}$ - região de ressonâncias), o que torna este absorvedor muito eficiente. $\mathrm{O}$ háfnio é utilizado como material de controle de reatores na 
forma metálica pura ou como ligas de Hf-Ag e Hf-In-Ag. Informações mais detalhadas sobre os materiais absorvedores de nêutrons, incluindo suas propriedades, processos de fabricação, aplicações e desempenho no reator, podem ser obtidas na literatura ${ }^{(1,2)}$.

O sistema de controle do reator pode ser dividido em três categorias, a saber:

- barras de controle: é o sistema mais comum de controle de reatores nucleares, no qual barras móveis contendo material absorvedor são inseridas no núcleo do reator. Sua movimentação e posicionamento no interior do núcleo são realizados por meio de sistemas elétricos, pneumáticos ou hidráulicos. São utilizadas para ajustar a potência do reator e compensar variações de reatividade associadas com variações na temperatura do moderador e com o aparecimento de vazios. Pode-se dizer que as barras de controle exercem o controle fino do reator, isto é, providenciam a compensação de variações de reatividade de curta duração, ou seja, que ocorrem em pequenos intervalos de tempo quando comparados com a vida útil do núcleo do reator.

- barras de segurança: é o sistema de segurança do reator e garante a disponibilidade de reatividade negativa para o desligamento do reator em condições normais de operação ou de acidente. Essas barras permanecem fora do núcleo durante a operação normal do reator e, quando inseridas, o reator deve ficar subcrítico com uma margem de reatividade negativa estabelecida por normas. Essas barras são geralmente inseridas paralelamente ao eixo vertical do núcleo, o que permite, uma vez liberadas, sua rápida queda no interior do núcleo. Suas características fisicas, incluindo os materiais absorvedores utilizados e os sistemas mecânicos, são normalmente idênticas às das barras de controle.

- controle fixo de longo prazo: é o sistema que é inserido de forma fixa no núcleo do reator com a finalidade de prover ajustes de variações de reatividade causadas por processos com um ciclo de tempo longo, como o consumo do combustivel e o envenenamento pela formação de produtos de fissão com alta seção de choque de absorção de nêutrons. Pode-se dizer que este tipo de controle providencia a compensação de variações de reatividade de longa duração, ou seja, que ocorrem ao longo de toda a vida útil do núcleo do reator.

A inserção física de qualquer um dos elementos de controle apresentados acima resulta na remoção de nêutrons do sistema, introduzindo-se uma reatividade negativa. Por outro lado, sua retirada introduz reatividade positiva, de modo que, então, a sua movimentação permite o controle da reatividade do reator. A seguir estão brevemente descritos os sistemas de controle dos reatores de água leve LWR (Light Water Reactors), 
apresentando-se suas características básicas e os materiais absorvedores utilizados, com a introdução do conceito de veneno queimável, onde o gadolínio tem uma importante participação.

\subsubsection{Barras de controle}

O uso mais comum dos materiais absorvedores de nêutrons em reatores nucleares tipo LWR é na forma de barras de controle e segurança de longa duração, com vida útil superior à vida útil do combustível. A função de controle de reatividade das barras de controle varia um pouco de acordo com o projeto do reator. Nos reatores PWR elas têm sido usadas para ligar e desligar o reator, promover ajustes no nivel de potência, promover compensação de variações de reatividade associadas com variações na densidade do moderador e refrigerante (variações de temperatura) e promover compensação da variação da reatividade devida ao xenônio. Nos reatores BWR, as barras de controle, além do controle da reatividade, têm a função de controle da distribuição da potência. No sistema típico BWR, as barras de controle entram do fundo do caroço e são usadas para equilibrar os efeitos de reatividade devido à distribuição de vazios de vapor na porção superior do núcleo. Por meio do posicionamento seletivo de grupos de barras de controle em padrões prescritos, as barras de controle ajudam o aplainamento da distribuição de potência axial do caroço.

A principal característica das barras de controle é que elas podem movimentar-se no interior do núcleo do reator e, por meio de seu movimento, controlar ou interromper a reação em cadeia por meio da absorção de nêutrons. Neste caso, é desejável que a barra de controle retenha sua alta capacidade de absorção de nêutrons durante o maior tempo possivel da vida útil do reator, assegurando sempre o seu desligamento seguro, mantendose a barra de controle em operação durante o maior número possível de recargas do combustível. Portanto, para uso em barras de controle e segurança o material absorvedor de nêutrons deve reter suas propriedades absorvedoras durante um longo tempo, o que implica em que após a reação nuclear de captura de nêutrons devem ser formados isótopos que ainda possuam alta seção de choque de absorção, mantendo essa propriedade nuclear do absorvedor. As barras de controle são projetadas para suprir a reatividade negativa suficiente, designada no projeto, durante toda a sua vida nuclear. Material absorvedor suficiente deve ser provido inicialmente para impedir a degradação da sua reatividade devido aos efeitos de depleção ao longo da vida projetada de serviço. Porém, geralmente a vida nuclear das barras de controle determinada pelos efeitos de depleção é bem mais 
longa do que a sua vida mecânica, determinada pelo inchamento do absorvedor, degradação do revestimento das barras e outras considerações.

Todos os reatores PWR e BWR operacionais utilizam tanto o carbeto de boro $\left(\mathrm{B}_{4} \mathrm{C}\right)$ como a liga $80 \%$ prata - $15 \%$ índio - $5 \%$ cádmio (AgInCd) como material absorvedor para barras de controle. $\mathrm{O} \mathrm{B}_{4} \mathrm{C}$ é utilizado na forma de pó compactado nos reatores BWR e pastilhas sinterizadas nos reatores PWR. A liga AgInCd também é utilizada em barras de controle nos reatores PWR. O háfnio metálico (Hf) tem substituído tanto o $\mathrm{B}_{4} \mathrm{C}$ como a liga AgInCd nos projetos mais recentes de reatores $\mathrm{BWR}$ e PWR, respectivamente.

Os reatores PWR utilizam elementos de controle constituídos de grupos de varetas absorvedoras unidas por uma peça central denominada "aranha". Esta aranha é acoplada num sistema mecânico que movimenta o conjunto de varetas absorvedoras no interior de tubos guias existentes no elemento combustivel. As varetas absorvedoras nos atuais reatores operados pela Babcock \& Wilcox (B\&W), Fragema e Westinghouse, são varetas de AgInCd revestidas com tubos de aço inoxidável tipo 304. Um total de 16 a 24 varetas absorvedoras é usado em uma aranha. $\mathrm{O}$ absorvedor adotado pela Combustion Engineering é constituído de pastilhas sinterizadas de $\mathrm{B}_{4} \mathrm{C}$ com aproximadamente $32 \mathrm{~cm}$ de AgInCd na extremidade das varetas, as quais tem diâmetro maior e são usadas em menor número.

Os reatores BWR usam barras de controle de formato cruciforme que se ajustam entre os elementos combustíveis, sendo inseridas por baixo do núcleo. A barra de controle consiste em 4 asas; cada uma contendo de 18 a 21 tubos preenchidos com pó de $\mathrm{B}_{4} \mathrm{C}$ compactado fixados numa envoltura de aço inoxidável 304. Essa envoltura é perfurada para permitir o fluxo de refrigerante entre as varetas absorvedoras. Esta forma básica cruciforme contendo varetas com pó de $\mathrm{B}_{4} \mathrm{C}$ compactado por vibração não mudou muito desde os primeiros reatores BWR da década de 1960.

Strasser e Sheppard ${ }^{(\mathbf{3})}$ apresentam informações adicionais a respeito das barras de controle utilizadas comumente nos reatores LWR, incluindo detalhes geométricos, materiais absorvedores utilizados, experiência operacional e sistemas mecânicos de movimentação. 


\subsubsection{Controle de longo prazo}

Com o contínuo desenvolvimento dos reatores nucleares surgiu um outro importante uso para os materiais absorvedores de nêutrons, sendo introduzido de forma fixa em pontos estratégicos no núcleo do reator ou distribuído uniformemente no combustível, obtendo-se, assim, uma uniformidade na reatividade global do núcleo do reator durante sua vida útil, sendo projetado apropriadamente para ser consumido (ou queimado) a uma taxa aproximadamente igual à do combustível. Neste caso, o absorvedor é geralmente conhecido como veneno queimável e deve ter como principal característica a capacidade de absorver nêutrons gerando um isótopo que tenha baixa seção de choque de absorção, ou seja, produzir na reação de captura um isótopo que não possua capacidade de absorver nêutrons. Isto implica na gradativa perda da capacidade de absorção durante a operação do reator, acompanhando o consumo (ou queima) do combustivel, daí derivando o termo "queimável", possibilitando um controle de longa duração da reatividade do núcleo do reator.

De modo geral, do uso de venenos queimáveis no núcleo de reatores nucleares resultam as seguintes vantagens, em termos de operação e gerenciamento do combustível:

- a presença do veneno queimável possibilita o aumento da carga de combustível e seu enriquecimento, conduzindo a uma maior vida útil do núcleo do reator, pela compensação da reatividade global do núcleo inicial e das recargas;

- o veneno queimável pode ser introduzido em quantidade suficiente para reduzir a reatividade inicial do núcleo ao nível da reatividade existente no final da sua vida útil, resultando numa menor quantidade de barras de controle requeridas para o controle do reator. Além disto, as barras de controle permanecem mais retiradas do núcleo durante a operação, conduzindo a uma melhor distribuição de potência;

- o veneno queimável pode ser colocado em regiões estratégicas do núcleo, de modo a efetivamente distribuir uniformemente a potência, diminuindo os fatores de pico.

Os venenos queimáveis podem ser divididos em heterogêneos, ou discretos, e homogêneos, ou integrados. $\mathrm{O}$ veneno queimável heterogêneo é constituído por uma vareta separada da vareta combustivel e contém só o absorvedor e seu diluente. O veneno queimável homogêneo combina o absorvedor com o combustível na mesma vareta, eliminando os materiais parasitários adicionais (tubos de encamisamento e materiais diluentes) associados com o absorvedor heterogêneo e permitindo água adicional em seu espaço, resultando numa melhora na utilização do combustível. Um outro tipo de veneno 
queimável homogêneo é a solubilização de um material absorvedor queimável na água utilizada como moderador e refrigerante dos reatores PWR.

Nos reatores tipo PWR o veneno queimável heterogêneo normalmente utilizado consiste em varetas individuais de absorvedor posicionadas estrategicamente em alguns dos tubos guia das barras de controle localizados nos elementos combustíveis. O veneno queimável nos atuais reatores operacionais da Babcock \& Wilcox (B\&W) e Combustion Engineering (CE) é constituído de varetas contendo pastilhas sinterizadas de $\mathrm{Al}_{2} \mathrm{O}_{3}-\mathrm{B}_{4} \mathrm{C}$ com até aproximadamente $3 \%$ em peso de $\mathrm{B}_{4} \mathrm{C}$, posicionadas em tubos de Zircaloy. Os reatores da Westinghouse e Fragema usam tubos de vidro de borosilicato encamisados por dentro e por fora com aço inoxidável. A concentração de boro é de 3 a $5 \%$ em peso. Estes venenos queimáveis normalmente são utilizados apenas na primeira carga do reator. A Westinghouse desenvolveu um veneno queimável discreto avançado a base de boro ${ }^{\text {(4) }}, 0$ qual consiste em anéis de $\mathrm{Al}_{2} \mathrm{O}_{3}-\mathrm{B}_{4} \mathrm{C}$ sinterizados contendo mais de $20 \%$ em peso de $\mathrm{B}_{4} \mathrm{C}$, revestidos por dentro e por fora com Zircaloy, o que permitiu o preenchimento do orificio central com água. A vantagem desta configuração é a redução de residuos parasitários pela concentração do boro na pastilha anular, substituindo-se o centro com água, e pela substituição do aço inoxidável pelo Zircaloy.

$O$ veneno queimável homogêneo universalmente utilizado nos reatores PWR é o boro dissolvido na água do reator, a qual funciona como moderador e refrigerante. Ele é utilizado na forma de ácido bórico $\left(\mathrm{H}_{3} \mathrm{BO}_{3}\right)$ dissolvido em concentrações que variam de acordo com o projeto do reator e a evolução da reatividade do núcleo (da ordem de 1000 a $2000 \mathrm{ppm}$ ). Conforme o reator opera e a reatividade diminui devido ao consumo do combustível, a concentração de boro é gradualmente reduzida pela passagem da água por um sistema de troca iônica para remoção controlada do ácido bórico. A distribuição homogênea do boro numa concentração apropriada, permite o controle parcial do excesso de reatividade existente nos núcleos novos e nas recargas, minimizando a necessidade de inserção das barras de controle e a consequente distorção espacial do fluxo de nêutrons e, consequentemente, da potência. Apesar de parte do boro solubilizado ser removido por absorção de nêutrons durante a operação do reator, caracterizando-o como um veneno queimável, a diminuição da sua concentração por esta causa é relativamente pequena, sendo o controle da sua concentração primariamente realizada pelo sistema de troca iônica. Assim, pode-se dizer que sua aplicação não é basicamente como um veneno queimável. Um veneno queimável homogêneo desenvolvido pela Westinghouse para aplicação em reatores PWR é baseado na deposição de uma camada delgada de diboreto de zircônio $\left(\mathrm{ZrB}_{2}\right)$ na superficie exterior das pastilhas de $\mathrm{UO}_{2}$ do combustível. A vantagem deste projeto é a eliminação de resíduos parasitários e as vantagens genéricas dos venenos queimáveis homogêneos. Programas de desenvolvimento foram iniciados pela $\mathrm{B} \& \mathrm{~W}, \mathrm{CE}$ 
e Kraftwerk Union (KWU) na década de 1980, visando à aplicação do veneno queimável $\mathrm{UO}_{2}-\mathrm{Gd}_{2} \mathrm{O}_{3}$ nos seus reatores tipo PWR. A concentração de $\mathrm{Gd}_{2} \mathrm{O}_{3}$ no $\mathrm{UO}_{2}$ pode variar de 1 a $8 \%$ em peso, dependendo do projeto nuclear do combustível.

As varetas de veneno queimável universalmente utilizadas nos reatores BWR são do tipo homogênea constituídas de $\mathrm{UO}_{2}-\mathrm{Gd}_{2} \mathrm{O}_{3}$. Varetas de $\mathrm{UO}_{2}-\mathrm{Gd}_{2} \mathrm{O}_{3}$ são colocadas em cada elemento combustível para satisfazer as exigências de controle da reatividade do núcleo inicial e de qualquer recarga com excesso de reatividade. Alguns elementos combustíveis contêm mais varetas com $\mathrm{UO}_{2}-\mathrm{Gd}_{2} \mathrm{O}_{3}$ do que outros, otimizando-se a distribuição de potência radial. Além disto, alguns elementos combustíveis podem conter $\mathrm{Gd}_{2} \mathrm{O}_{3}$ distribuído axialmente na vareta combustível com veneno queimável, em diferentes concentrações, melhorando a distribuição de potência axial. As varetas combustíveis com veneno queimável contêm de 1 a $6 \%$ em peso de $\mathrm{Gd}_{2} \mathrm{O}_{3}$, dependendo do projeto nuclear, e de 4 a 8 varetas de veneno queimável são montadas em cada elemento combustível. Devido às características operacionais dos reatores tipo BWR, o boro solúvel não pode ser utilizado (existência da fase vapor), sendo todo o controle do excesso de reatividade realizado pelo $\mathrm{UO}_{2}-\mathrm{Gd}_{2} \mathrm{O}_{3}$.

\subsection{Venenos queimáveis}

\subsubsection{Considerações estratégicas}

A minimização do cusțo do ciclo do combustível tem sido uma preocupação desde o início da geração de energia elétrica comercial por meio da energia nuclear. A diminuição do custo de geração de eletricidade depende de estratégias de gerenciamento do combustível nuclear dentro e fora do núcleo do reator. $O$ gerenciamento do combustível dentro do núcleo do reator ("in-core fuel management"), que envolve o projeto do consumo, ou queima, do combustível e o padrão de recargas de combustível, ou seja, a retirada do combustível queimado e introdução de combustível novo, exerce influência determinante no custo da energia gerada, uma vez que influencia diretamente as atividades de gerenciamento do combustivel fora do núcleo do reator ("out-of-core fuel management"), dentre as quais pode-se citar o enriquecimento e a destinação final do combustível queimado como as mais importantes.

O objetivo principal do gerenciamento do combustível no núcleo do reator é otimizar a utilização do combustível, reduzindo o custo da eletricidade gerada. $\mathrm{O}$ 
responsável por esta tarefa tenta alcançar este objetivo alterando os parâmetros do núcleo que podem ser mudados sem violar as condições impostas por considerações operacionais e de segurança, as quais incluem:

a) as recargas devem ser programadas para um período de baixa demanda,

b) a reatividade do combustível, e portanto do núcleo, deve ser adequada para alcançar a queima projetada,

c) o caroço deve ter o controle de reatividade adequado.

A carga de combustivel e a distribuição de potência do núcleo devem ser tal que nenhum dos parâmetros de segurança exceda os valores prescritos. As condições de segurança são expressas em termos dos valores de certos parâmetros, os quais não podem exceder os limites predeterminados no projeto, tais como:

a) a relação entre a potência máxima e média, ou fator de pico,

b) a temperatura máxima no núcleo,

c) a reatividade máxima do núcleo,

d) o coeficiente de temperatura de reatividade.

A evolução da estratégia e objetivos do gerenciamento do combustível na indústria nuclear é dependente de situações políticas e sócio-econômicas conjunturais e de avanços tecnológicos. Para melhor compreensão do seu estágio atual, é interessante retomar brevemente a sua história.

No final da década de 1950, quando se iniciou a indústria nuclear civil nos Estados Unidos, havia a premissa de que o combustível queimado tinha valor comercial, com base na promessa do governo americano de comprar, num prazo máximo de 2 anos após a retirada do reator, o combustivel queimado para recuperação do plutônio gerado nos reatores civis. Assim, os responsáveis pelo gerenciamento do combustível compuseram em seus custos a futura renda a ser obtida com a venda de combustível queimado. Baseadas neste contexto, as usinas nucleares prepararam-se para o armazenamento local do combustível gasto por um período de aproximadamente cinco anos. Naquele momento, os estudos de otimização do gerenciamento do combustivel nuclear estavam baseados na suposição de que os preços do urânio seriam estáveis e baixos e de que o reprocessamento 
do combustível queimado também teria custo relativamente baixo. Nenhuma atenção particular foi dada à queima final do combustível retirado do reator.

Por volta de 1970 , o governo norte americano parecia comprometido com o reprocessamento e reciclagem do combustível queimado. Contudo, mesmo com indústrias de reprocessamento operando desde 1966, uma mudança na política norte americana levou à decisão de não mais permitir o reprocessamento nos Estados Unidos. $O$ então recentemente criado Departamento de Energia dos Estados Unidos (DOE) foi instruído a iniciar o desenvolvimento de novos projetos de combustíveis nucleares para alcançar queimas da ordem de 45.000 a $50.000 \mathrm{MWd} / T$ TonU (essa unidade de queima é dada pela energia total fornecida pela queima do combustível, em Megawatts-dia gerados por tonelada métrica de urânio consumido). Este valor era consideravelmente mais alto do que a queima típica de 28.000 a $33.000 \mathrm{MWd}$ /TonU alcançada no combustível tipo LWR naquela época. $O$ novo combustível da alta queima presumivelmente constituiria uma alternativa ao reprocessamento e reciclagem do combustível queimado. Segundo os cálculos, o aumento da queima de 33.000 para $50.000 \mathrm{MWd} / \mathrm{T}$ onU nos reatores PWR reduziria a massa de urânio na conversão em $15 \%$, o número de unidades de trabalho separativo no enriquecimento em 1 a $3 \%$ e o número de elementos combustíveis descarregadas por ano em aproximadamente $40 \%$.

Por volta de 1977, muitas centrais nucleares foram duramente pressionadas para encontrar espaço para armazenamento do seu combustível exaurido. O novo combustível de alta queima certamente ajudaria, mas sua implementação estava anos distante. Como em certas centrais era necessário alívio imediato no armazenamento do combustível queimado, foram realizados estudos por muitas centrais nucleares na busca de uma solução para o problema. Duas idéias foram consideradas, e em muitas centrais ambas foram implementadas. Uma era o redesenho do sistema de armazenamento de combustível existente em piscinas de combustíveis queimados, para prover espaço para mais elementos combustíveis. A outra era uma extensão dos intervalos de recarga, ou seja, de cada ciclo de queima, de 12 para 18 meses, onde 1/3 do combustível é substituído. Tal extensão resultou em menos elementos combustíveis utilizados durante a vida da central nuclèar e, ao mesmo tempo, numa redução do custo do ciclo do combustível, principalmente devido à diminuição no tempo médio de manutenção requerido para reabastecimento, considerandose a vida útil da central nuclear.

Em 1982, o Congresso Americano aprovou a Política de Rejeitos Nucleares, segundo o qual o governo federal, através do DOE, obrigou-se a transportar, mediante ao pagamento de uma taxa, o combustível queimado das centrais nucleares para a sua armazenagem final apropriada. Mais do que isto, se uma central necessitasse de espaço 
para armazenamento antes do governo estar pronto para levar o combustível queimado, o governo estava obrigado a providenciar o armazenamento interino. Assim, o armazenamento de combustível queimado deixou de existir como um assunto que afetasse o ciclo do combustível. Essa nova política obrigou as empresas que possuíam ou operavam centrais nucleares a pagar ao governo, a partir de abril de 1983, uma taxa de US\$ 0,001 por $\mathrm{kWh}(\mathrm{e})$ de eletricidade gerada. $\mathrm{O}$ dinheiro arrecadado seria usado para pesquisa e desenvolvimento e todos os outros custos associados com o armazenamento final do combustível queimado. Assim, um custo era oficialmente estabelecido associado ao combustível queimado, em substituição à receita da venda do plutônio produzido no curso da operação de uma central nuclear.

Como o aumento do custo de construção das centrais nucleares e com o acúmulo da experiência operacional, iniciou-se uma discussão na indústria nuclear sobre a possibilidade de estender a vida de uma central além dos 30 anos originalmente licenciados. Qualquer extensão requereria certificação pelo governo americano (US Nuclear Regulatory Commission-NRC) de que todos os componentes relacionados com a seguranç̧a operariam corretamente sob condições normais e anormais. O componente de segurança primário é o vaso de pressão, particularmente no caso dos reatores PWR. Como resultado de bombardeio de nêutrons, o aço do vaso de pressão sofre danos de irradiação, ou seja, danos diretamente relacionados à magnitude do fluxo de nêutrons, particularmente o fluxo de nêutrons rápidos, a que o material do vaso está exposto. A extensão de vida da central requereria menos danos de irradiação no vaso de pressão, o que significa menor bombardeamento por nêutrons. Como alcançar este objetivo, isto é, a redução do número de nêutrons que escapam para fora do núcleo do reator e bombardeiam o vaso de pressão, se tornou o mais recente tema no gerenciamento de combustível nuclear.

Com base no exposto acima, fica claro que os meios que se encontraram para alcançar o objetivo de minimização do custo do ciclo do combustível são o aumento da queima do combustível, a extensão do ciclo de queima (intervalos de recarga), o custo de armazenamento final dos rejeitos radioativos e o padrão adotado na distribuição de elementos combustíveis nas recargas, o qual está relacionado à vida útil do vaso de pressão do reator.

A Agência Internacional de Energia Atômica (IAEA) iniciou, em 1988, com a participação de especialistas de 11 países, um estudo de viabilidade econômica para o aumento da queima do combustivel tipo LWR dos níveis atuais de 35.000 a 45.000 $\mathrm{MWd} / \mathrm{TonU}$, para os reatores BWR, e 40.000 a $45.000 \mathrm{MWd} / \mathrm{TonU}$, para os reatores PWR. Novos níveis de queima foram considerados, na faixa de até 55.000 a $65.000 \mathrm{MWd} / \mathrm{TonU}$, ou ainda superior. As conclusões deste estudo ${ }^{(5)}$ confirmam a importância do aumento da 
queima do combustivel na redução dos custos do ciclo. Esse estudo também demonstrou que a maior parcela do custo do ciclo do combustível é referente ao armazenamento final dos rejeitos radioativos gerados, apontando para uma forte diminuição na geração destes rejeitos. Nos dias de hoje, pode-se considerar a destinação final de rejeitos radioativos como sendo o "calcanhar de aquiles" da energia nuclear, uma vez que este tema está intimamente ligado à aceitação pública do uso da energia nuclear como fonte de eletricidade neste novo século ${ }^{(6)}$.

$\mathrm{O}$ aumento da queima do combustível conduz, na maioria das circunstâncias, ao aumento do ciclo de queima e, consequentemente, ao aumento do intervalo de tempo entre as recargas de combustível. Na maioria dos casos, particularmente no caso de países como o Brasil, onde a proporção da capacidade de geração de eletricidade por centrais nucleares é pequena e a tecnologia do reprocessamento não está disponível, o aumento da queima do combustível e o intervalo de recargas são metas conjuntas, uma vez que são minimizados os problemas de armazenamento final de combustíveis queimados e outros rejeitos nucleares gerados nas centrais. $O$ menor tempo médio de paralisação da central nuclear associada aos maiores intervalos para recarga de combustível, passando de 12 meses para 18 ou 24 meses, também conduz a uma importante diminuição no custo de geração de eletricidade. Este provavelmente é o fator mais importante de diminuição de custos, principalmente no caso de centrais nucleares acopladas a sistemas que não possuem capacidade de reserva adequada e devem comprar a eletricidade que deixam de gerar durante o desligamento para a recarga. Um outro beneficio do aumento dos intervalos de recarga é a menor exposição à radiação dos operadores da central nuclear.

O padrão tradicional de gerenciamento do combustível adotado nos reatores PWR baseia-se na substituição de $1 / 3$ do combustível do núcleo a cada 12 meses. O núcleo é dividido em três regiões radiais concêntricas e, em cada recarga, os elementos combustíveis da região central são retirados e os das duas outras regiões são deslocados para o interior do núcleo, sendo a região intermediária deslocada para o centro e a região periférica deslocada para a intermediária. Os elementos combustíveis novos são posicionados na periferia do núcleo, formando-se uma nova região periférica de alta reatividade (este esquema tradicional é conhecido como carregamento "out-in"). Este padrão de recarga aumenta a produção de nêutrons rápidos na periferia do núcleo, os quais vão interagir diretamente com o vaso de pressão, causando danos de irradiação. Um padrão de recarga alternativo é o oposto ao tradicional, com a introdução dos combustíveis novos (também 1/3 dos elementos combustíveis do núcleo) em posições centrais e seu posterior deslocamento para a periferia nos seus ciclos posteriores (carregamento "in-out"). Desta forma, elementos novos com alta reatividade estão sempre "protegidos" por elementos combustíveis mais queimados, que estarão operando nos seus segundo e terceiro 
ciclos de queima, nesta ordem. Desta forma, os fluxos máximos de nêutrons rápidos incidentes no vaso de pressão são minimizados. Um aumento importante na vida útil do vaso de pressão pode ser obtido adotando-se este padrão de recarga. Adicionalmente, uma redução do enriquecimento de até $0,05 \%$ em peso de ${ }^{235} \mathrm{U}$ e um aumento na queima média do combustível podem ser obtidos com a adoção deste esquema ( ${ }^{\text {) }}$, de 200 a 500 $\mathrm{MWd} / \mathrm{TonU}$. Este padrão de recarga é denominado Padrão de Carregamento de Baixa Fuga, ou LLLP ("Low Leakage Loading Pattern").

Além destes avanços no uso do combustível nuclear, relacionados com estratégias de gerenciamento de combustíveis, outros avanços nas áreas de projeto do núcleo e do elemento combustível foram conquistados ${ }^{(\mathbf{8})}$, alguns necessários para a implantação da estratégia de alta queima, principalmente:

- a substituição do aço inoxidável pelo zircaloy, diminuindo-se a absorção parasítica de nêutrons;

- a implantação de peças removíveis no elemento combustível, as quais permitem o acesso a varetas combustíveis danificadas durante a operação para reparo ou substituição;

- o desenvolvimento de elementos combustíveis para reatores BWR contendo melhores geometrias e mais varetas, as quais possuem uma barreira de zircônio puro que inibe a propagação de trincas no zircaloy, causadas pela interação da pastilha combustível com o tubo de revestimento ("Pellet Clad Interaction - PCl").

Tecnologias inovadoras na área de combustíveis têm vindo ao encontro da diminuição do custo do ciclo do combustível pelo aumento da queima, das quais pode-se destacar:

- a montagem de pastilhas de $\mathrm{UO}_{2}$ natural nas extremidades das varetas combustíveis, com comprimento aproximado de $150 \mathrm{~mm}$, o que reduz o escape de nêutrons nas partes superior e inferior do núcleo do reator, complementando o padrão de recarga LLLP em termos de proteção do vaso de pressão e, ainda, podendo reduzir a perda de nêutrons em até $50 \%$, melhorando a utilização do combustível;

- inovações no projeto das varetas combustíveis, com aumento da capacidade de acomodação de gases de fissão, inovações para controlar a interação do combustível com o revestimento $(\mathrm{PCI})$, uso de pastilhas combustíveis anulares, e o aumento do tamanho de grão das pastilhas de combustível. 
- o desenvolvimento pela Westinghouse ${ }^{(9)}$ do combustível "VANTAGE-5";

A evolução dos procedimentos para verificação da integridade das varetas combustíveis durante as recargas também apoiam a estratégia de aumento da queima do combustível. O método mais utilizado consiste em isolar o elemento combustível a ser monitorado num recipiente fechado contendo água e, decorrido algum tempo (30 a 60 minutos), analisar a água num laboratório procurando a deteç̧ão de certos radionuclídeos. Variações deste procedimento, denominado "sipping", utilizando vácuo ou ar em substituição à água no interior do recipiente, diminuíram o tempo para a realização da monitoração e aumentaram a sua eficiência.

O veneno queimável homogêneo tem uma decisiva participação neste esforço para a diminuição do custo do ciclo do combustível. Sua presença no caroço do reator é necessária para controlar eficientemente o maior excesso de reatividade imposto pelo aumento da queima do combustível e da extensão do ciclo de queima. Além disso, sua utilização é necessária quando o padrão LLLP de recargas (in-out) é adotado, diminuindo a reatividade dos combustíveis novos. Também, com a sua utilização é minimizada a geração de rejeitos radioativos. As vantagens na sua utilização estão discutidas no próximo item.

\subsubsection{Aplicações dos venenos queimáveis}

Para atingir-se maiores queimas no combustível e intervalos de recarga mais longos, o enriquecimento inicial do combustivel deve ser aumentado para prover o núcleo com um excesso de reatividade extra necessário para manter o longo ciclo de queima. Isto significa que a quantidade adicional de material fissil no núcleo deve ser compensada pela introdução de uma maior quantidade de material absorvedor. Nos níveis de excesso de reatividade tradicionais dos reatores $L W R$, em torno de 25 a $30 \%$ acima da requerida para a criticalidade, o controle deste excesso pode ser obtido por meio das barras de controle, venenos queimáveis tradicionais a base de boro $\mathrm{e}$ boro solubilizado no moderador/refrigerante.

Contudo, o uso de boro solúvel nos reatores BWR é proibido por razões técnicas, restando apenas a opção das barras de controle. A concepção dos elementos combustíveis nos reatores BWR não apresenta os tubos guias para as barras de controle, as quais tem formato cruciforme e são inseridas entre quatro elementos combustiveis. Neste caso, a utilização isolada de barras de controle entre os elementos combustíveis causa a 
diminuição do fluxo de nêutrons nos elementos combustíveis novos, mas, como consequência, diminui também o fluxo nos elementos combustiveis mais queimados, o que evidencia a vantagem da utilização de venenos queimáveis localizados estrategicamente. Contudo, devido à alta taxa de geração de calor nas varetas combustíveis deste tipo de reator, a introdução de venenos queimáveis discretos, conduzindo à substituição de varetas combustíveis por varetas de veneno queimável, é impraticável. Por esta razão, venenos queimáveis discretos são utilizados entre elementos combustíveis (retirados depois do primeiro ciclo de queima) e, principalmente, venenos queimáveis integrados, particularmente $\mathrm{Gd}_{2} \mathrm{O}_{3}$ misturado no combustível $\mathrm{UO}_{2}$, foram introduzidos nestes reatores já em 1967 e, desde então, têm sido rotineiramente utilizados neste tipo de reator.

Nos reatores PWR, o uso de boro solúvel é aceitável e tem sido rotineiramente utilizado para atender à necessidade crescente de compensação de reatividade. Contudo, o aumento do enriquecimento do combustível e, por conseguinte, da reatividade, não pode ser indefinidamente compensado pelo aumento da concentração de ácido bórico no moderador/refrigerante. Isto ocorre porque o aumento da temperatura do moderador causa a diminuição de sua densidade, o que diminui a densidade de núcleos absorvedores de boro, diminuindo a absorção de nêutrons. Esta situação implica no fato de que um aumento na temperatura do moderador conduz a um aumento da reatividade do reator, ou seja, torna o coeficiente de temperatura do moderador positivo, o que é inaceitável. Este fenômeno é minimizado mantendo-se a concentração de boro solúvel num limite máximo aceitável, que, na prática, é de 2.000 ppm.

Com base no exposto acima, fica evidenciado que a viabilização do aumento da queima e extensão dos intervalos de recarga, o que conduz ao aumento da reatividade global do núcleo do reator, depende da introdução de venenos queimáveis sólidos nos núcleos dos reatores, introduzindo-se uma reatividade negativa que compense a, agora maior, reatividade do núcleo. Duas alternativas estão disponiveis: a utilização de venenos queimáveis discretos, principalmente varetas contendo borosilicato ou $\mathrm{Al}_{2} \mathrm{O}_{3}-\mathrm{B}_{4} \mathrm{C}$, e a utilização de venenos queimáveis integrados, onde o absorvedor é parte integrante da vareta combustível.

Com o aumento do enriquecimento do combustível, cada elemento combustível novo que entra no reator possui uma maior reatividade. Isto ocasiona maiores distorções na distribuição do fluxo de nêutrons no núcleo do reator e, portanto, na distribuição de potência. Equivale dizer que os fatores de pico tornam-se mais desfavoráveis. A situação é agravada quando a estratégia de recarga é baseada na introdução de elementos combustíveis novos na parte central do núcleo do reator (LLLP), objetivando obter maior vida útil para o vaso de pressão. Isto conduz à necessidade de introdução de venenos 
queimáveis discretos, inicialmente tendo sido usados somente na primeira carga do reator, também nas recargas e em maior quantidade. O aumento na utilização de varetas de veneno queimável discreto conduz a situações indesejáveis, muito desvantajosas, em termos de operação e desempenho do reator e gerenciamento do combustível:

- o posicionamento dos venenos queimáveis discretos é restrito a posições no núcleo não ocupadas pelas barras de controle, diminuindo a flexibilidade do projeto do ciclo de queima que prevê a sua utilização, minimizando os efeitos benéficos de sua introdução, que tem a finalidade de homogeneizar a distribuição de potência e controlar os fatores de pico.

- o aumento significativo na quantidade de venenos queimáveis discretos exauridos que devem ser gerados devido ao aumento da queima do combustível, implica num aumento do custo do ciclo do combustível, uma vez que estes rejeitos radioativos adicionais devem ser adequadamente armazenados, o que causa um impacto importante no custo do ciclo. Este impacto é tão importante que deve levar ao abandono do uso deste tipo de veneno queimável em reatores LWR.

- aos venenos queimáveis a base de boro, seja ao borosilicato ou mesmo aos mais avançados a base de pastilhas de $\mathrm{Al}_{2} \mathrm{O}_{3}-\mathrm{B}_{4} \mathrm{C}$, está associada uma alta reatividade residual no final do ciclo de queima. Como a ótima utilização do combustível impõe que o excesso de reatividade do núcleo seja zero no final do ciclo de queima e o mínimo no início do ciclo, a reatividade residual associada aos venenos queimáveis discretos a base de boro impõe que uma reserva de excesso de reatividade do núcleo no final do ciclo seja garantida para compensar a absorção residual do veneno queimável, situação que prejudica a utilização do combustível.

- a substituição de uma vareta combustivel por uma vareta de veneno queimável diminui a relação urânio/água, modificando-se a razão de moderação originalmente projetada para ser ótima. Além disto, com a diminuição da relação urânio/água, a superficie de transferência de calor entre o combustível e o refrigerante é diminuída, conduzindo a fatores de fluxo de calor e de "pontos quentes" mais desfavoráveis.

As desvantagens na utilização dos venenos queimáveis discretos, das quais as principais estão citadas acima, apontam para uma solução alternativa para a compensação do aumento do excesso de reatividade e para a uniformização da distribuição de potência nos núcleos projetados para altas queimas e longos intervalos de recarga. Esta solução é a utilização dos venenos queimáveis integrados, incorporados diretamente no combustível. Com o uso de venenos queimáveis integrados, as desvantagens do uso de venenos 
queimáveis discretos são eliminadas, ou minimizadas, e ainda, outras vantagens surgem, pelas seguintes razões:

- como são parte integrante do combustível, o posicionamento dos venenos queimáveis integrados é irrestrito, flexibilizando o projeto de queima do combustível. Esta flexibilidade permite, com base num bom projeto do ciclo, o controle eficiente da distribuição de potência no núcleo e, portanto, o controle eficiente dos fatores de pico.

- como os venenos queimáveis integrados estão presentes nas próprias varetas combustíveis, rejeitos radioativos adicionais não são gerados, uma vez que são armazenados ou reprocessados juntamente com o combustível queimado. Dessa forma, são eliminados os problemas de manuseio e armazenamento de absorvedores irradiados, minimizando-se o problema da disposição final dos rejeitos radioativos, considerado o mais sensivel na atualidade.

- aos venenos queimáveis integrados está associada uma menor reatividade residual no final do ciclo de queima, quando comparados aos venenos queimáveis discretos, já que são eliminados os tubos de revestimento que são utilizados nas varetas de venenos queimáveis discretos.

- no caso dos venenos queimáveis integrados não ocorre o deslocamento de água associado aos venenos queimáveis discretos, mantendo-se a mesma relação urânio/água, e, portanto, a razão de moderação originalmente projetada. A superfície de transferência de calor entre o combustível e o refrigerante é mantida inalterada. No caso do veneno queimável integrado, os benefícios do uso de venenos queimáveis são obtidos sem a necessidade de retirada de urânio.

- como o veneno queimável integrado é parte constituinte do combustível, ele diminui a reatividade de combustíveis novos durante o transporte $\mathrm{e}$ armazenamento, flexibilizando as considerações quanto a acidentes de criticalidade.

Atualmente, não são muitas as opções de venenos queimáveis integrados, sendo que, pelos motivos citados acima, a adoção do combustível $\mathrm{UO}_{2}-\mathrm{Gd}_{2} \mathrm{O}_{3}$ como veneno queimável integrado é a opção natural não só para uso em reatores $\mathrm{BWR}$, uma vez que já tem sido utilizado por longo tempo, como também para uso em reatores PWR. 


\subsection{3 $\mathrm{O}$ uso do $\mathrm{UO}_{2}-\mathrm{Gd}_{2} \mathrm{O}_{3}$}

As opções de veneno queimável para uso na forma integrada em reatores LWR não são muitas nos dias de hoje. Além do $\mathrm{UO}_{2}-\mathrm{Gd}_{2} \mathrm{O}_{3}$, aparecem apenas o $\mathrm{ZrB}_{2}$ e o érbio, sobre os quais algumas considerações serão apresentadas mais adiante.

Os problemas para controlar o excesso de reatividade nos combustíveis novos de reatores tipo BWR foram observados e tiveram que ser enfrentados logo no início da operação deste tipo de reator. Neste caso, devido à concepção do projeto, a solução não poderia ser a implementação do boro solúvel e varetas de veneno queimável discreto. Assim, o uso do $\mathrm{UO}_{2}-\mathrm{Gd}_{2} \mathrm{O}_{3}$ tornou-se rotina em todos os reatores BWR após a decisão da General Electric de adotá-lo no reator Dresden-2, no final da década de 1960. Desde então, todos os fornecedores têm progressivamente adotado este veneno queimável integrado. Nos dias de hoje, do total dos 442 reatores nucleares de potência operacionais ao redor do mundo, com uma capacidade instalada de mais de $350 \mathrm{GW}(\mathrm{e}), 94$ (21 \%) são do tipo BWR, com uma capacidade instalada de mais de $78 \mathrm{GW}(\mathrm{e}){ }^{\text {(10) }}$ (situação em dezembro de 1996). Portanto, a experiência com o $\mathrm{UO}_{2}-\mathrm{Gd}_{2} \mathrm{O}_{3}$ nestes anos tornou-se estatisticamente significativa, provendo confiança ao conceito. Com as crescentes preocupações em otimizar-se a utilização do combustivel nos reatores PWR, a utilização deste tipo de combustivel nestes reatores também começou a ser considerada. A boa experiência acumulada com o uso do $\mathrm{UO}_{2}-\mathrm{Gd}_{2} \mathrm{O}_{3}$ nos reatores BWR e o fato de que os fabricantes do combustível BWR também são fabricantes do combustível PWR, colocaram o $\mathrm{UO}_{2}-\mathrm{Gd}_{2} \mathrm{O}_{3}$ como a opção natural para uso nos reatores PWR. Para ilustrar a importância do $\mathrm{UO}_{2}-\mathrm{Gd}_{2} \mathrm{O}_{3}$, ele está sendo considerado para uso (ou já está sendo usado) em todos os reatores tipo BWR, na maioria dos reatores tipo PWR e, mais recentemente, nos reatores tipo WWER (Water Water Energy Reactor), que é um tipo de reator PWR russo. Estes reatores somam 347 do total de 442 reatores de potência operacionais ( $78 \%$ ), responsáveis pela geração de $302 \mathrm{GW}(\mathrm{e})$ do total de capacidade instalada mundial de $350 \mathrm{GW}(\mathrm{e})^{(6,10)}$, ou seja, mais de $86 \%$ de toda a capacidade mundial. Devido a sua importância no contexto da industria nuclear, a Agência Internacional de Energia Atômica publicou, em dezembro de 1995, um relatório que fornece uma visão geral sobre os venenos queimáveis integrados, particularmente sobre o $\mathrm{UO}_{2}-\mathrm{Gd}_{2} \mathrm{O}_{3}$, resultado de um programa de pesquisa coordenado envolvendo pesquisadores de inúmeros países ${ }^{\text {(II) }}$.

As vantagens do uso de venenos queimáveis integrados em substituição aos venenos queimáveis discretos, enumeradas no item anterior, se aplicam também ao veneno queimável $\mathrm{UO}_{2}-\mathrm{Gd}_{2} \mathrm{O}_{3}$. $\mathrm{O}$ potencial para a utilização do $\mathrm{UO}_{2}-\mathrm{Gd}_{2} \mathrm{O}_{3}$ em termos de beneficios quando comparado com os venenos queimáveis discretos a base de boro está

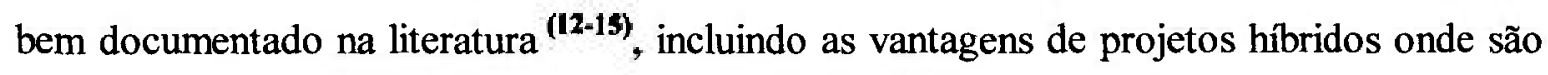


aplicados conjuntamente venenos queimáveis integrados e discretos ${ }^{(\mathbf{1 6 , 1 7})}$. Inclusive, o boro solúvel usado no controle da reatividade dos reatores PWR pode ser substituído pelo $\mathrm{UO}_{2}-\mathrm{Gd}_{2} \mathrm{O}_{3}$, o que representa uma diminuição de custos operacionais ${ }^{(18)}$.

Contudo, em contraposição a esta série de vantagens, a modelação da reatividade e da distribuição de potência do núcleo é mais complicada no caso do uso do gadolínio ${ }^{\text {(9) }}$, necessitando de técnicas analíticas mais avançadas. Esta dificuldade foi satisfatoriamente ultrapassada com o desenvolvimento e validação de métodos analíticos ${ }^{\mathbf{2 0 - 2 5})}$, os quais demonstraram suficiente precisão. Métodos sofisticados de cálculo permitem, inclusive, o cálculo de distribuições axiais ótimas na concentração de gadolinio para a obtenção de melhores distribuições axiais de potência no núcleo ${ }^{\text {(26-30). }}$.

O progressivo desenvolvimento do gadolínio como veneno queimável integrado, desde concentrações de $1 \%$ em peso de $\mathrm{Gd}_{2} \mathrm{O}_{3}$ no início de sua utilização nos reatores BWR, até as concentrações atuais de 6 a $10 \%$ em peso para uso em reatores PWR, proporcionou uma boa base de dados para este sistema. Esta considerável base de dados e o bom desempenho das varetas combustiveis de $\mathrm{UO}_{2}-\mathrm{Gd}_{2} \mathrm{O}_{3}$ foram as razões para a sua progressiva utilização pela maioria dos fabricantes de combustível nuclear. Inicialmente, devido à maior complexidade do projeto do núcleo e à influência do $\mathrm{Gd}_{2} \mathrm{O}_{3}$ nas propriedades do combustível, para manutenção de margens de segurança adequadas, a potência das varetas de $\mathrm{UO}_{2}-\mathrm{Gd}_{2} \mathrm{O}_{3}$ era reduzida. Em casos extremos, foi utilizado urânio empobrecido nas primeiras aplicações do $\mathrm{UO}_{2}-\mathrm{Gd}_{2} \mathrm{O}_{3}$ com alta concentração de gadolínio em reatores PWR, prevenindo-se das margens de incerteza do projeto. Porém, com o desenvolvimento da base de dados para altas concentrações de $\mathrm{Gd}_{2} \mathrm{O}_{3}$, estas aproximações conservativas não eram mais necessárias e os beneficios potenciais do $\mathrm{UO}_{2}-\mathrm{Gd}_{2} \mathrm{O}_{3}$ puderam ser usados em toda a sua extensão.

Contudo, altas concentrações de $\mathrm{Gd}_{2} \mathrm{O}_{3}$, superiores a $10 \%$ em peso, desejáveis para ciclos de queima com duração ainda maior do que 18 meses, causam uma absorção residual de nêutrons inaceitável no final do ciclo de queima. As dificuldades na implementação de alta concentração de $\mathrm{Gd}_{2} \mathrm{O}_{3}$ resultaram em duas outras alternativas para uso como veneno queimável, as quais têm sido aplicadas comercialmente.

A primeira alternativa foi desenvolvida pela Westinghouse e consiste na deposição de uma fina camada de $\mathrm{ZrB}_{2}(0,02 \mathrm{~mm})$ na superficie das pastilhas de $\mathrm{UO}_{2}$, a qual adere perfeitamente. Neste caso, as propriedades do material combustível, incluindo a sua condutividade térmica, não se alteram. A grande vantagem deste veneno queimável integrado é a sua menor absorção residual no final do ciclo de queima, desde que ele pode ser projetado com precisão para a total queima do ${ }^{10} \mathrm{~B}$. Apesar do processo de fabricação 
aparentemente ser mais complicado, as técnicas de fabricação foram incorporadas com sucesso numa fábrica da Westinghouse de grande capacidade. Para minimizar os fatores de pico radiais, tipicamente são utilizadas 30 a $40 \%$ de varetas deste veneno queimável nos elementos combustíveis. A utilização de boro enriquecido no isótopo ${ }^{10} \mathrm{~B}$ pode diminuir a quantidade de varetas de veneno queimável para 12 a $30 \%$. Os fatores de pico axiais são ajustados pela distribuição axial da camada de boro no comprimento da zona ativa da vareta de veneno queimável, ou seja, dos $3,7 \mathrm{~m}$ de comprimento ativo da vareta apenas 2,3 m contém a camada de boro, deixando livres as extremidades, diminuindo-se, assim, a potência no centro da vareta. Este tipo de veneno queimável vem sendo testado desde 1981 e tem sido comercializado pela Westinghouse desde 1987. Em 1990, um total de 34 recargas contendo 165.000 varetas deste veneno queimável estava sendo irradiado em 20 reatores PWR, a maioria operando em ciclos de 18 meses (31). Segundo comparações realizadas pela Westinghouse entre o $\mathrm{ZrB}_{2}$ e o $\mathrm{Gd}_{2} \mathrm{O}_{3}$, para um mesmo cenário, o $\mathrm{ZrB}_{2}$ aumenta a duração do ciclo de queima em $1 \%$ (devido à menor absorção residual) e diminui o fator de pico radial em $2,2 \%$. A única desvantagem do $\mathrm{ZrB}_{2}$ quando comparado com o $\mathrm{Gd}_{2} \mathrm{O}_{3}$ é a possibilidade potencial de ocorrência de um coeficiente de temperatura do moderador positivo no início da vida do núcleo, apesar de várias centrais estarem operando com controle apropriado deste coeficiente somente com o uso de venenos queimáveis de $\mathrm{ZrB}_{2}$. Detalhes técnicos sobre este veneno queimável estão disponíveis na literatura ${ }^{(\mathbf{3 2}-\mathbf{3 4})}$.

A segunda alternativa é a utilização de um outro elemento do grupo das terras raras. Das terras raras (Gd, Sm, Eu, Dy e Er), o samário, o disprósio e o európio possuem longas cadeias de absorção de nêutrons, nas quais vários isótopos formados participam significativamente no fenômeno da absorção, o que significa uma inaceitável absorção residual. $O$ érbio possui seção de choque de absorção de nêutrons similar à do boro e suas características de absorção permitem flexibilidade no controle do coeficiente de temperatura do moderador. Com o uso do érbio, as amplas variações do fluxo de nêutrons com a queima, observadas no caso do gadolínio, são evitadas ${ }^{(35)}$. O érbio tem sido usado nos reatores de pesquisas tipo TRIGA desde 1974 e tem se mostrado confiável e previsível. Para reatores PWR, o $\mathrm{Er}_{2} \mathrm{O}_{3}$ é diretamente homogeneizado com o $\mathrm{UO}_{2}$, porém em proporções inferiores às utilizadas no caso do $\mathrm{Gd}_{2} \mathrm{O}_{3}$ (apenas 1 a $2 \%$ em peso). A ABBCombustion Engineering adotou o érbio após a implantação de um programa experimental que demonstrou que as propriedades do combustivel com érbio são muito parecidas com as do combustível com gadolínio, podendo este combustível se beneficiar da extensa base de dados existente para o $\mathrm{UO}_{2}-\mathrm{Gd}_{2} \mathrm{O}_{3}$. A validação do projeto deste novo veneno queimável e

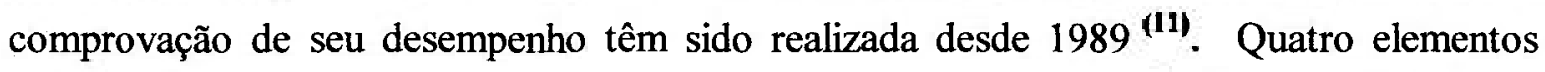
combustiveis contendo érbio foram irradiados no reator San Onofre 2 para validação da metodologia de cálculo do projeto com resultados satisfatórios ${ }^{(36)}$. Recentemente, Asou e 
Porta ${ }^{(37)}$ sugeriram que o gadolínio é mais apropriado para aplicação como veneno queimável integrado para ciclos de queima de até 18 meses, enquanto o érbio, também como veneno queimável integrado, é indicado para uso em ciclos de queima muito longos, de 24 meses ou maiores, presente em menores concentrações e distribuído num número maior de varetas. Além disto, devido ao efeito do érbio no coeficiente de temperatura do moderador, ele permite a utilização do boro solúvel em concentrações superiores à máxima admitida com o uso do gadolínio. Análises de custos indicam que o veneno queimável a base de érbio é competitivo com o $\mathrm{ZrB}_{2}{ }^{(38)}$.

Apesar destas possíveis opções, o $\mathrm{UO}_{2}-\mathrm{Gd}_{2} \mathrm{O}_{3}$ deve ser ainda o mais usado veneno queimável por longo tempo. Além da grande experiência de utilização e extensa base de dados, ele possui, ainda, vantagens importantes com relação aos outros dois candidatos, como ilustra a tabela 1 , sendo o veneno queimável integrado adotado pela grande maioria de fornecedores de combustíveis. O érbio apresenta um problema adicional, considerandose que, se todas as recargas dos reatores LWR dependerem do érbio, a atual produção mundial deste material teria que ser aumentada em 20 a $50 \%$ (11).

Cacciapouti, Weader e Malone ${ }^{(39)}$ apresentam uma interessante comparação, em termos de eficiência neutrônica e custo do ciclo do combustível, entre os três tipos de venenos queimáveis integrados disponíveis na atualidade para uso em reatores tipo PWR.

\subsection{Propriedades do sistema $\mathrm{UO}_{2}-\mathrm{Gd}_{2} \mathrm{O}_{3}$}

\subsubsection{A incorporação do gadolínio no $\mathrm{UO}_{2}$}

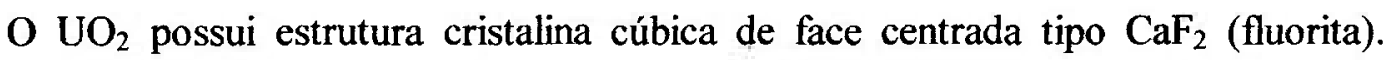
Esta estrutura consiste numa sub-rede catiônica cúbica de face centrada, no interior da qual existe a sub-rede aniônica cúbica simples. Na célula unitária cada cátion urânio possui oito primeiros vizinhos de ânions oxigênio, formando um octaedro. Os ânions oxigênio estão, por sua vez, rodeados por quatro cátions urânio, formando um tetraedro. A figura 1 apresenta um esquema desta estrutura cristalina. 
Tabela 1 - Comparação entre tipos de venenos queimáveis integrados disponíveis ${ }^{(1)}$.

\begin{tabular}{ccccc}
\hline Tipo & $\mathrm{UO}_{2}-\mathrm{Gd}_{2} \mathrm{O}_{3}$ & $\mathrm{ZrB}_{2}$ & $\mathrm{UO}_{2}-\mathrm{Er}_{2} \mathrm{O}_{3}$ \\
\hline fabricantes & (a) & $\begin{array}{c}\text { Westinghouse } \\
\text { (USA) }\end{array}$ & $\begin{array}{c}\text { Combustion } \\
\text { Eng. Co. (USA) }\end{array}$ \\
\hline concentração & $-6-10 \%$ em peso & - & $1-2,5 \%$ em peso \\
\hline
\end{tabular}

\begin{tabular}{|c|c|c|c|}
\hline $\begin{array}{c}\text { diminuição na condutividade } \\
\text { térmica }\end{array}$ & significativa & negligenciável & pequena \\
\hline redução na temperatura de fusão & significativa & negligenciável & pequena \\
\hline $\begin{array}{c}\text { proporção de varetas por elemento } \\
\text { combustivel }\end{array}$ & $3-6 \%$ & $30-40 \%$ & $20-30 \%$ \\
\hline $\begin{array}{l}\text { redução da massa de }{ }^{235} \text { U no } \\
\text { elemento combustivel }\end{array}$ & pequena & negligenciável & pequena \\
\hline velocidade de queima & alta & alta & média \\
\hline $\begin{array}{l}\text { reatividade residual no final do } \\
\text { ciclo de queima }\end{array}$ & pequena & negligenciável & significativa \\
\hline $\begin{array}{c}\text { distribuição de potência na vareta } \\
\text { de veneno queimável }\end{array}$ & boa & satisfatória (b) & boa \\
\hline pico de potência localizado & significativo & pequeno & pequeno \\
\hline $\begin{array}{l}\text { controle do coeficiente de } \\
\text { temperatura do moderador }\end{array}$ & bom & satisfatório & ótimo \\
\hline facilidade de fabricação & $\begin{array}{c}\text { pequena } \\
\text { variação na } \\
\text { linha padrão }\end{array}$ & $\begin{array}{c}\text { grande } \\
\text { equipamento } \\
\text { adicional }\end{array}$ & $\begin{array}{c}\text { pequena } \\
\text { variação na } \\
\text { linha padrão }\end{array}$ \\
\hline $\begin{array}{l}\text { reprocessabilidade do combustivel } \\
\text { com o veneno queimável }\end{array}$ & boa & questionável & boa \\
\hline
\end{tabular}

(a) Franco-Belge de Fabrication du Combustible (França e Bélgica), Siemens AG (Alemanha), Fabricazione Nucleari (Itália), Japan Nuclear Fuel (Japão), Mitsubishi Nuclear Fuel \& Nuclear Fuel Industries (Japão), Korean Nuclear Fuel Company (Koréia), Empresa Nacional del Uranio AS (Espanha), ASEA-ATOM (Suécia), British Nuclear Fuels BNFL (Inglaterra), TENEX-Novosibirsk-Ulbinskij (Rússia/Kazaquistão), Babcock\&Wilcox Fuel (USA), General Electric (USA) e Siemens Power (USA).

(b) devido à rápida queima. 
- urânio

oxigênio

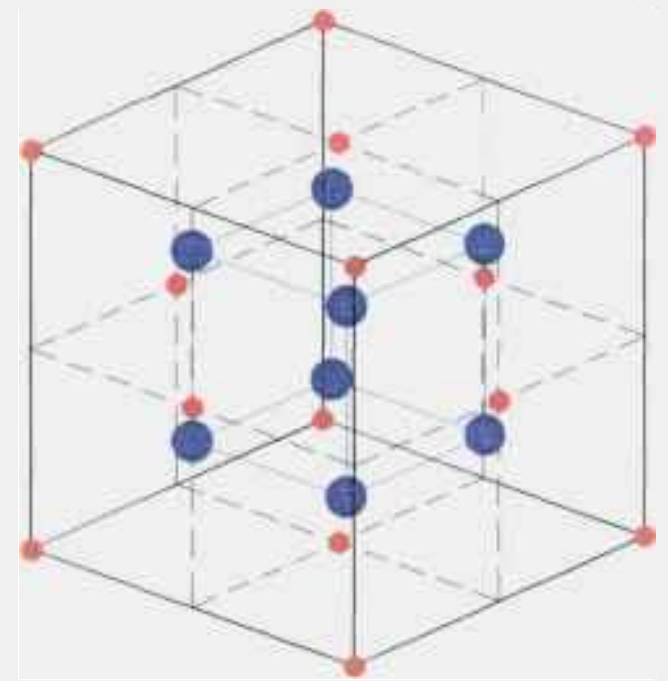

Figura 1 - Esquema ilustrativo da estrutura tipo fluorita do $\mathrm{UO}_{2}$.

Nas temperaturas de fabricação de pastilhas sinterizadas, o $\mathrm{UO}_{2}$ forma uma solução sólida substitucional com o $\mathrm{Gd}_{2} \mathrm{O}_{3}$. A solução sólida no sistema $\mathrm{UO}_{2}-\mathrm{Gd}_{2} \mathrm{O}_{3}$, também representada por $(\mathrm{U}, \mathrm{Gd}) \mathrm{O}_{2}$, é formada pela substituição de cátions $\mathrm{U}^{4+}$ por cátions $\mathrm{Gd}^{3+}$. Como o único estado de oxidação possível do gadolínio é +3 , a compensação de carga no sistema pode ser realizada de diferentes formas, dependentes do potencial de oxigênio da atmosfera na qual a solução sólida está sendo formada, ou seja, a atmosfera de sinterização. Ho e Radford ${ }^{(40)}$ propõem 9 modelos para explicar a incorporação do cátion $\mathrm{Gd}^{3+}$ na rede cristalina do $\mathrm{UO}_{2}$, apresentados a seguir:

No caso de atmosferas fortemente redutoras (pressão parcial de oxigênio muito baixa), considera-se estável a valência $4+$ do urânio $\left(U^{4+}\right)$, sendo bastante pequena a criação de cátions $U^{5+}$. Neste caso, segundo Ho e Radford, três modelos são possíveis:

MODELO 1 - cátions $\mathrm{Gd}^{3+}$ substituem cátions $\mathrm{U}^{4+}$ mantendo-se perfeita a sub-rede catiônica. A estrutura é balanceada eletricamente através da formação de vacâncias na sub-rede aniônica (perda de ânions $\mathrm{O}^{2-}$ ), resultando em hipoestequiometria. A cada dois cátions $\mathrm{Gd}^{3+}$ incorporados, um ânion $\mathrm{O}^{2-}$ é retirado.

$$
\left(\mathrm{U}^{4+}{ }_{1-\mathrm{x}} \mathrm{Gd}^{3+}{ }_{\mathrm{x}}\right) \mathrm{O}_{2-(\mathrm{x} / 2)}
$$

onde: $\mathrm{x}=$ fração de cátions $\mathrm{Gd}^{3+}$ adicionada. 
MODELO 2 - cátions $\mathrm{Gd}^{3+}$ substituem cátions $\mathrm{U}^{4+}$ mantendo-se a sub-rede aniônica perfeita. A estrutura é balanceada eletricamente através do posicionamento de cátions $\mathrm{U}^{4+}$ extras em posições intersticiais. A cada quatro cátions $\mathrm{Gd}^{3+}$ incorporados, um cátion $\mathrm{U}^{4+}$ ocupa uma posição intersticial.

$$
\left(\mathrm{U}^{4+}{ }_{1-(3 / 4 \mathrm{x})} \mathrm{Gd}^{3+}\right) \mathrm{O}_{2}
$$

MODELO 3 - supondo-se a criação de pequena quantidade de cátions $\mathrm{U}^{5+}$, quando comparada com a quantidade de cátions $\mathrm{Gd}^{3+}$ adicionada, cátions $\mathrm{Gd}^{3+}$ substituem cátions $\mathrm{U}^{4+}$ e a estrutura é balanceada eletricamente parte pela presença de cátions $\mathrm{U}^{5+}$ e parte através da formação de vacâncias na sub-rede aniônica, resultando também em ligeira hipoestequiometria.

$$
\left(\mathrm{U}^{4+}{ }_{1-(x+y)} \mathrm{U}^{5+} \mathrm{Gd}^{3+} \mathrm{x}\right) \mathrm{O}_{2-((\mathrm{x}-\mathrm{y}) / 2)}
$$

onde: $\mathrm{y}=$ fração de cátions $\mathrm{U}^{5+}$ formados e $\mathrm{x}>\mathrm{y}$.

No caso de atmosferas redutoras que apresentam maior potencial para oxidação (pressão parcial de oxigênio não desprezível), considera-se a possibilidade de que um maior número de cátions $\mathrm{U}^{4+}$ do sistema $\mathrm{UO}_{2}-\mathrm{Gd}_{2} \mathrm{O}_{3}$ passam ao estado de valência +5 $\left(\mathrm{U}^{5+}\right)$. Neste caso, dois modelos estruturais são propostos por Ho e Radford:

MODELO 4 - quando o número de cátions $\mathrm{U}^{5+}$ é igual ao número de cátions $\mathrm{Gd}^{3+}$ incorporados, cátions $\mathrm{Gd}^{3+}$ substituem cátions $\mathrm{U}^{4+}$ mantendo-se as sub-redes catiônica e aniônica perfeitas, resultando numa estrutura tipo fluorita perfeita. A estrutura é balanceada eletricamente através de cátions $\mathrm{U}^{5+}$. Para cada cátion $\mathrm{Gd}^{3+}$ incorporado, um cátion $\mathrm{U}^{5+}$ deverá estar presente.

$$
\left(\mathrm{U}^{4+}{ }_{1-2 \mathrm{x})} \mathrm{U}^{5+}{ }_{\mathrm{x}} \mathrm{Gd}^{3+} \mathrm{x}\right) \mathrm{O}_{2}
$$

MODELO 5 - este caso considera o modelo 4 com a presença de maior número de cátions $\mathrm{U}^{5+}$ do que o número de cátions $\mathrm{Gd}^{3+}$ incorporados. Neste caso o balanço elétrico se procede através da incorporação de ânions $\mathrm{O}^{2-}$ em posições intersticiais, resultando em hiperestequiometria.

$$
\left(\mathrm{U}^{4+}{ }_{1-(x+y)} \mathrm{U}^{3+} \mathrm{Gd}^{3+}\right) \mathrm{O}_{2+((\mathrm{y}-\mathrm{x}) / 2)}
$$


No caso de atmosferas oxidantes, como no caso de misturas $\mathrm{CO} / \mathrm{CO}_{2}$ ou $\mathrm{H}_{2}$ borbulhado em água quente (presença de vapor de água), torna-se favorável a formação do cátion $\mathrm{U}^{6+}$, resultando na possibilidade de outros modelos estruturais:

MODELO 6 - quando o número de cátions $\mathrm{U}^{6+}$ criados é igual à metade do número de cátions $\mathrm{Gd}^{3+}$ incorporados, o modelo estrutural proposto é semelhante ao modelo 4 , mantendo-se perfeitas as sub-redes cationnica e aniônica e, portanto, a estequiometria. A estrutura é balanceada eletricamente através de cátions $\mathrm{U}^{6+}$ e para cada dois cátions $\mathrm{Gd}^{3+}$ incorporados, um cátion $\mathrm{U}^{6+}$ deverá estar presente.

$$
\left(\mathrm{U}^{4+}{ }_{1-((3 / 2) x)} \mathrm{U}^{6+} \mathrm{Gd}^{3+}{ }_{\mathrm{x}}\right) \mathrm{O}_{2}
$$

onde: $\mathrm{z}=$ fração de cátions $\mathrm{U}^{6+}$ formados e $\mathrm{z}=\mathrm{x} / 2$.

MODELO 7 - este caso considera o modelo 6 onde o número de cátions $\mathrm{U}^{6+}$ criados excede a metade do número de cátions $\mathrm{Gd}^{3+}$ incorporados. O balanço elétrico se procede, a exemplo do modelo 5, através da incorporação de ânions $\mathrm{O}^{2-}$ em posições intersticiais, resultando em hiperestequiometria.

$$
\left(\mathrm{U}^{4+}{ }_{1-(x+\mathrm{z})} \mathrm{U}_{\mathrm{z}}^{6+} \mathrm{Gd}_{\mathrm{x}}^{3+}\right) \mathrm{O}_{2+(\mathrm{z}-(\mathrm{x} / 2))}
$$

onde: $\mathrm{z}>\mathrm{x} / 2$.

Finalmente, no caso da presença dos três estados ionizados do urânio $\left(\mathrm{U}^{4+}, \mathrm{U}^{5+} \mathrm{e}\right.$ $\mathrm{U}^{6+}$ ) são possíveis outros modelos estruturais, os quais são, basicamente, modificações dos modelos apresentados anteriormente. Os mais prováveis, segundo Ho e Radford, são:

MODELO 8 - este caso é uma combinação dos modelos 4 e 6 , onde o número de cátions $\mathrm{U}^{6+}$ criados é exatamente a metade do número de cátions $\mathrm{U}^{5+}$ criados e a soma destes dois cátions é igual ao número de cátions $\mathrm{Gd}^{3+}$ incorporados, obtendo-se o balanceamento elétrico da rede, resultando numa estrutura perfeita estequiométrica.

$$
\left(\mathrm{U}^{4+}+(x+y+z) U_{y}^{5+} U_{z}^{6+} G_{x}^{3+}\right) O_{2}
$$

onde: $x=y+2 z$ e $y=2 z$.

MODELO 9 - neste caso o balanceamento elétrico da rede é, em parte, obtido por meio da criação de vacâncias de oxigênio, uma vez que a soma de cátions $\mathrm{U}^{5+}$ e $\mathrm{U}^{6+}$ não é suficiente para compensar o número de cátions $\mathrm{Gd}^{3+}$ incorporados. A estrutura resultante é hipoestequiométrica. 


$$
\left(\mathrm{U}^{4+}{ }_{1-\mathrm{x}-\mathrm{y}-\mathrm{z}} \mathrm{U}^{5+} \mathrm{y}^{6+} \mathrm{U}_{2} \mathrm{Gd}^{3+}{ }_{\mathrm{x}}\right) \mathrm{O}_{2-(\mathrm{x}-\mathrm{y}-\mathrm{z}) / 2}
$$

onde: $x>y+2 z$ e $y \geq 2 z$.

Vários autores determinaram o parâmetro de rede do $\mathrm{UO}_{2}$ puro estequiométrico à temperatura ambiente, obtendo valores de $0,546852 \pm 0,000011^{\text {(41) }}, 0,54703 \pm 0,00002^{\text {(42) }}$ e $0.54704 \pm 0,00008^{(43)}$, todos expressos em $\mathrm{nm}$. O valor geralmente aceito é de 0,5470 $\mathrm{nm}^{(4+)}$, o que corresponde a uma densidade de $10,952 \mathrm{~g} / \mathrm{cm}^{3}$.

A incorporação do gadolínio à rede cristalina do $\mathrm{UO}_{2}$ conduz à diminuição do parâmetro de rede da estrutura. Os resultados obtidos experimentalmente apresentam muito boa concordância. A figura 2 resume os resultados obtidos por diferentes pesquisadores. Todas as amostras utilizadas para a obtenção dos dados apresentados foram obtidas por meio de sinterização sob atmosfera redutora de hidrogênio.

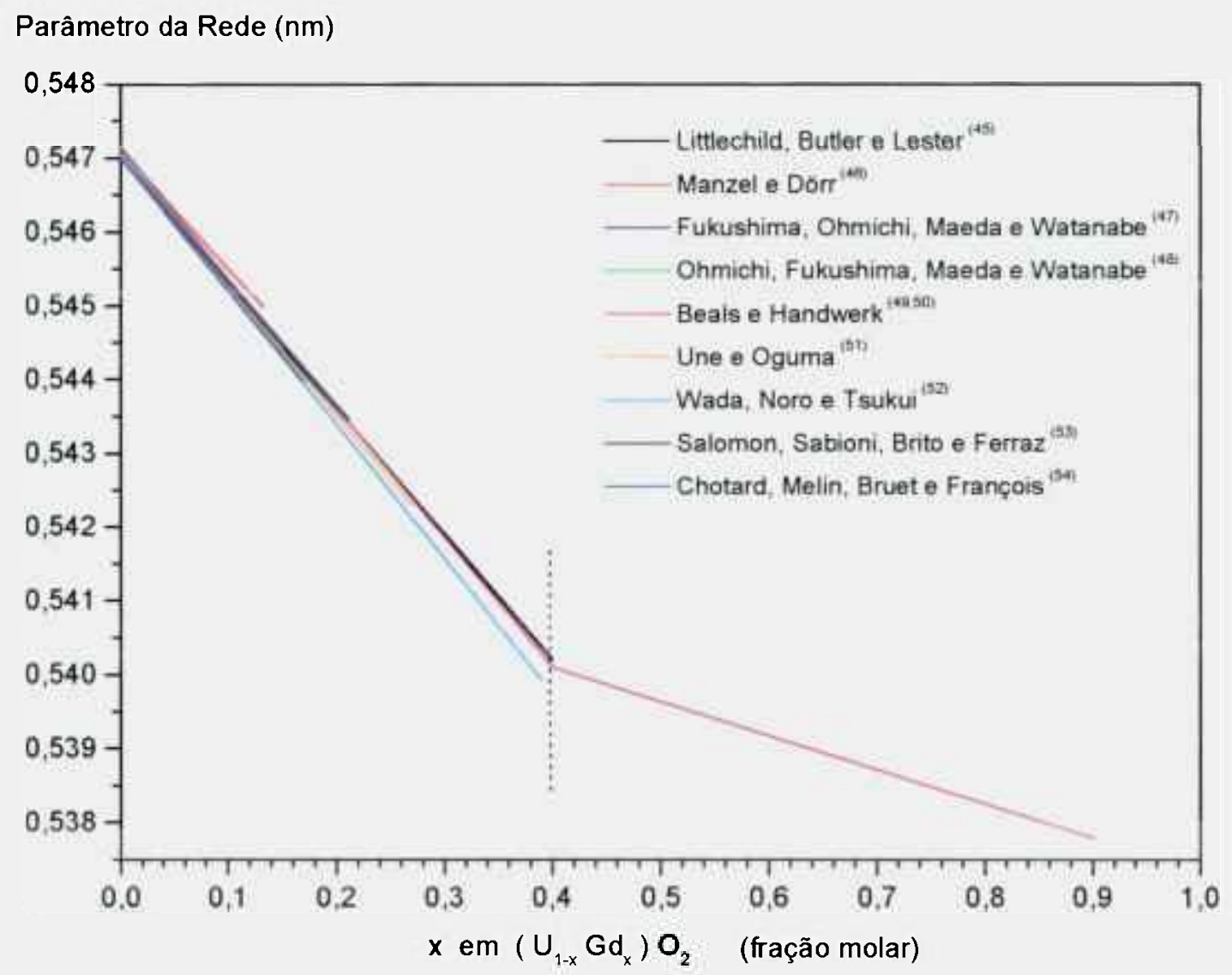

Figura 2 - Diminuição do parâmetro de rede da solução sólida $\left(\mathrm{U}_{1-\mathrm{x}} \mathrm{Gd}_{\mathrm{x}}\right) \mathrm{O}_{2}$ 
Observa-se uma diminuição linear do parâmetro de rede da estrutura fluorita com o aumento da fração de cátions $\mathrm{Gd}^{3+}$ adicionada, ou seja, com o valor de $\boldsymbol{x}$ na fórmula $\left(\mathrm{U}_{1-\mathrm{x}} \mathrm{Gd}_{\mathrm{x}}\right) \mathrm{O}_{2}$, a qual expressa a concentração de $\mathrm{Gd}$ presente no sistema, em fração molar. Esta relação pode ser expressa genericamente por meio da equação:

$$
a=a_{o}-\beta . x
$$

onde: $a$ é o parâmetro de rede da solução sólida, $a_{o}$ é o parâmetro de rede do $\mathrm{UO}_{2}$ puro, $\beta$ é a taxa de diminuição do parâmetro de rede e $x$ é a fração molar de Gd presente na estrutura cristalina do $\mathrm{UO}_{2}$. A tabela 2 resume os resultados apresentados na figura 2 .

Tabela 2 - Coeficientes da equação 1 obtidos por vários pesquisadores.

\begin{tabular}{|c|c|c|}
\hline$a_{o}(\mathrm{~nm})$ & $\beta$ & Referência \\
\hline 0,54708 & 0,0172 & Littlechild, Butler e Lester ${ }^{(45)}$ \\
\hline 0,54710 & 0,0159 & Manzel e Dörr ${ }^{(46)}$ \\
\hline 0,54704 & 0,0174 & Fukushima, Ohmichi, Maeda e Watanabe ${ }^{(47)}$ \\
\hline 0,54708 & 0,0173 & Ohmichi, Fukushima, Maeda e Watanabe ${ }^{(48)}$ \\
\hline $\begin{array}{l}0,54712 \\
0,54194\end{array}$ & $\begin{array}{l}0,0176^{\mathrm{a}} \\
0,0046^{\mathrm{b}}\end{array}$ & $\begin{array}{l}\text { Beals e Handwerk } \\
\text { idem }\end{array}$ \\
\hline 0,5470 & 0,0174 & Une e Oguma ${ }^{(51)}$ \\
\hline 0,57404 & 0,0182 & Wada, Noro e Tsukui ${ }^{(52)}$ \\
\hline 0,5471 & 0,0165 & Salomon, Sabioni, Brito e Ferraz ${ }^{\mathbf{( 5 3 )}}$ \\
\hline 0,5470 & 0,0178 & Chotard, Melin, Bruet e François ${ }^{(\mathbf{5 4})}$ \\
\hline
\end{tabular}

a) $x \leq 0,4 \quad$ e $\quad$ b) $x>0,4$

Todos os resultados apresentados na tabela 2 correspondem a amostras sinterizadas sob atmosfera de hidrogênio. Pode-se concluir destes dados que o parâmetro de rede da solução sólida $(\mathrm{U}, \mathrm{Gd}) \mathrm{O}_{2}$ diminui linearmente com o aumento da concentração de gadolínio numa taxa de aproximadamente $0,00017 \mathrm{~nm}$ a cada $1 \% \mathrm{em} \mathrm{mol} \mathrm{de} \mathrm{Gd}_{2} \mathrm{O}_{3}$ adicionado ao $\mathrm{UO}_{2}$. Estes resultados demonstram que é completa a solubilidade do gadolínio na estrutura cristalina do $\mathrm{UO}_{2}$, existindo apenas a fase tipo fluorita, com cátions 
$\mathrm{Gd}^{3+}$ substituindo cátions $\mathrm{U}^{4+}$. Esta conclusão é válida para a concentração de $\mathrm{Gd}_{2} \mathrm{O}_{3}$ de até $40 \%$ em mol. Os valores muito próximos de $\beta$ encontrados indicam que o sistema é monofásico e a solução sólida é completa e homogênea. O relativamente menor valor de $\beta$ obtido por Manzel e Dörr pode ser atribuído à observação de uma fase de $\mathrm{UO}_{2}$ virtualmente puro, contendo apenas $2 \%$ em peso de $\mathrm{Gd}_{2} \mathrm{O}_{3}$ independentemente da concentração total de $\mathrm{Gd}_{2} \mathrm{O}_{3}$ adicionado, a qual coexiste com a solução sólida.

A maioria dos trabalhos consultados abrangem uma pequena faixa de concentração de $\mathrm{Gd}_{2} \mathrm{O}_{3}$, de até cerca de $15 \%$ em mol (aproximadamente $10 \%$ em peso), que é a faixa de interesse tecnológico para o combustível $\mathrm{UO}_{2}-\mathrm{Gd}_{2} \mathrm{O}_{3}$. O trabalho de Beals e Handwerk $^{(49,50)}$ foi o mais completo encontrado na literatura, abrangendo toda a faixa de concentração no sistema $\mathrm{UO}_{2}-\mathrm{Gd}_{2} \mathrm{O}_{3}$. Estes pesquisadores observaram que acima de $40 \%$ em mol, o coeficiente angular $\beta$ assume outro valor, contudo mantendo-se a proporcionalidade, concluindo que a estrutura cristalina permanece sendo do tipo fluorita.

A relação $\mathrm{O} / \mathrm{M}$ neste sistema $(\mathrm{M}=\mathrm{U}+\mathrm{Gd})$, a qual indica a existência de vacâncias ou excesso de oxigênio na estrutura cristalina da solução sólida, foi determinada por vários pesquisadores. A figura 3 resume os resultados obtidos por diferentes pesquisadores.

Une e Oguma ${ }^{(51)}$ observaram que a relação $\mathrm{O} / \mathrm{M}$ mantém-se constante, numa faixa de 1,995 a 2,000 com média de 1,997, para concentrações de $\mathrm{Gd}_{2} \mathrm{O}_{3}$ de 0 a $27 \%$ em mol. O mesmo comportamento foi observado por Fukushima et al ${ }^{(4)}$, para concentrações de $\mathrm{Gd}_{2} \mathrm{O}_{3}$ de até $15 \%$ em mol, obtendo a média de 1,999. Para concentrações de $\mathrm{Gd}_{2} \mathrm{O}_{3}$ de até $40 \%$ em mol, Beals e Handwerk ${ }^{(49)}$ observaram valores de $\mathrm{O} / \mathrm{M}$ variando entre $1,954 \mathrm{e}$ 2,020. Este comportamento também foi observado por Ohmichi et al ${ }^{(48)}$ para concentrações de até $14 \%$ em mol de $\mathrm{Gd}_{2} \mathrm{O}_{3}$, em amostras preparadas pelo Centro de Pesquisas e Desenvolvimento da Toshiba, obtendo o valor médio da relação O/M de 1,997. Contudo, Ohmichi et al observaram uma diminuição da relação $\mathrm{O} / \mathrm{M}$ proporcional à concentração de $\mathrm{Gd}_{2} \mathrm{O}_{3}$ em amostras preparadas por eles por comoagem, como está ilustrado na figura 3. Ohmichi et al atribuem a observação de valores constantes para a relação $\mathrm{O} / \mathrm{M}$ pelos outros pesquisadores à alta susceptibilidade à oxidação das soluções sólidas ( $\mathrm{U}, \mathrm{Gd}) \mathrm{O}_{2}$ com deficiência de oxigênio, oxidando-se facilmente mesmo a baixas temperaturas, tendendo a atingir a estequiometria próxima a 2,000. Esta forte tendência à oxidação também foi observada por Une e Oguma ${ }^{(\mathbf{5 1})}$. Miyake et al ${ }^{\text {(5) }}$ observaram a presença de uma fase bem cristalizada na superficie de amostras ( $U, G d) \mathrm{O}_{2}$ sinterizadas e de uma fase de baixa cristalinidade no interior da amostra. Eles atribuem esta observação à facilidade da oxidação superficial das amostras, sendo as vacâncias de oxigênio existentes na estrutura fluorita da solução sólida fácilmente preenchidas por meio da oxidação dos 
cátions $\mathrm{U}^{4+}$ para $\mathrm{U}^{5+}$. No interior da amostra, onde oxigênio não está disponível, a presença de vacâncias de oxigênio seria a responsável pela compensação de carga, e sua presença explica a baixa cristalinidade observada.

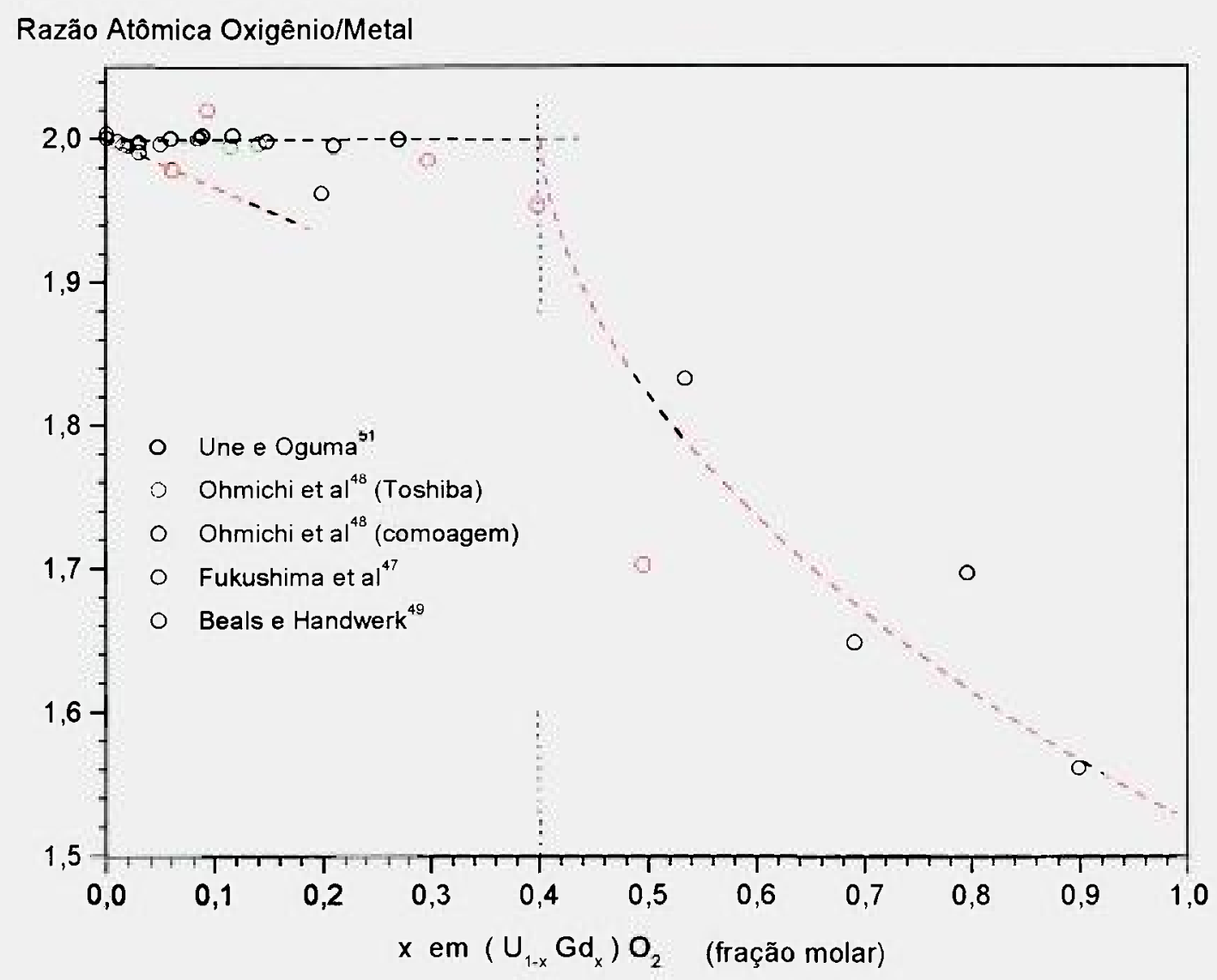

Figura 3 - Variação da razão $\mathrm{O} / \mathrm{M}$ da solução sólida $\left(\mathrm{U}_{1-\mathrm{x}} \mathrm{Gd}_{\mathbf{x}}\right) \mathrm{O}_{2}$.

Quando se comparam os raios iônicos do $\mathrm{U}^{4+}$ e do $\mathrm{Gd}^{3+}$ para o número de coordenação 8 , de $0,1001 \mathrm{~nm}$ e $0,1053 \mathrm{~nm}$, respectivamente, segundo os dados publicados por Shannon ${ }^{(56)}$, é de se esperar que a incorporação do $\mathrm{Gd}^{3+}$ na estrutura cristalina tipo fluorita do $\mathrm{UO}_{2}$ resulte no aumento do parâmetro de rede da estrutura, tendo em vista seu maior raio iônico. Portanto, a incorporação do $\mathrm{Gd}^{3+}$ deve resultar na formação de cátions $\mathrm{U}^{5+}$ ou/e $\mathrm{U}^{6+}$, os quais possuem raios iônicos de $0,084 \mathrm{~nm}$ e $0,086 \mathrm{~nm}$ para número de

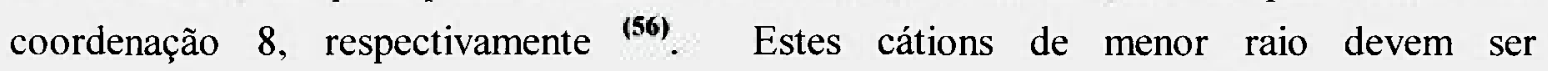
necessariamente formados para compensação do maior raio iônico do $\mathrm{Gd}^{3+}$ adicionado.

Bascando-se nas comparações dos raios iônicos dos cátions envolvidos e na ligeira hipoestequiometria do sistema $(\mathrm{U}, \mathrm{Gd}) \mathrm{O}_{2}$, independente da concentração de $\mathrm{Gd}_{2} \mathrm{O}_{3}$, 
o modelo estrutural para explicar a incorporação do $\mathrm{Gd}^{3+}$ na rede cristalina do $\mathrm{UO}_{2}$ deve prever tanto a formação de cátions urânio com estado de oxidação superior a +4 como também a presença de vacâncias de oxigênio.

Ohmichi et al ${ }^{(48)}$ compararam o valor experimental de $\beta$, determinado a partir da dependência do parâmetro de rede em função da concentração de $\mathrm{Gd}_{2} \mathrm{O}_{3}$, com os valores

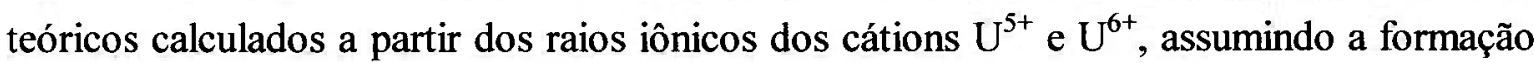
de uma solução sólida $(\mathrm{U}, \mathrm{Gd}) \mathrm{O}_{2}$ estequiométrica $(\mathrm{O} / \mathrm{M} \equiv 2)$. Utilizando o raio iônico do $\mathrm{U}^{5+}$, eles obtiveram o valor de $\beta$ calculado de $-0,0173$, igual ao valor experimental apresentado na tabela 2 , contra o valor calculado de $-0,0042$ utilizando-se o raio iônico do $\mathrm{U}^{6+}$, concluindo que o $\mathrm{U}^{5+}$ é formado preferencialmente em relação ao cátion $\mathrm{U}^{6+}$. Estes pesquisadores observaram que o parâmetro de rede da solução sólida $(\mathrm{U}, \mathrm{Gd}) \mathrm{O}_{2}$, para um determinado valor de concentração de $\mathrm{Gd}_{2} \mathrm{O}_{3}$, aumenta com a diminuição da relação $\mathrm{O} / \mathrm{M}$ ou, equivale dizer, com o aumento da concentração de vacâncias de oxigênio. Este comportamento é explicado pelo maior raio aparente da vacância de oxigênio quando comparado com o raio do ânion $\mathrm{O}^{-2}$, calculado ser $10 \%$ maior. Portanto, a substituição do ânion $\mathrm{O}^{-2}$ por uma vacância, ou seja, sua retirada da estrutura cristalina, conduz a um aumento do parâmetro de rede. Segundo estes pesquisadores, apesar da formação de vacâncias de oxigênio, as quais tem raio aparente $10 \%$ maior do que os ânions $\mathrm{O}^{-2}$, de $0,1368 \mathrm{~nm}$ (metade da distância oxigênio-oxigênio, a qual, por sua vez, é metade do parâmetro de rede do $\mathrm{UO}_{2}=0,54708 \mathrm{~nm}$ ), esta expansão é compensada pela contração causada pela formação de cátions $\mathrm{U}^{5+}$, de menor raio iônico. Ho e Radford ${ }^{(10)}$ discordam da proposta de Ohmichi et al para explicar o aumento do parâmetro de rede com a diminuição da relação $\mathrm{O} / \mathrm{M}$ para uma fixa concentração de $\mathrm{Gd}_{2} \mathrm{O}_{3}$. Segundo estes autores, o aumento do parâmetro de rede com a diminuição da relação $\mathrm{O} / \mathrm{M}$ tem pouca relação com os tamanhos do ânion $\mathrm{O}^{-2}$ ou da vacância de oxigênio, os quais são flexíveis, e o aumento do parâmetro de rede está provavelmente relacionado à diminuição do número de cátions $\mathrm{U}^{5+}$, os quais são pequenos, ou do aumento do número de cátions $\mathrm{U}^{4+}$ de maior raio iônico, com o aumento do número de vacâncias de oxigênio presentes.

Com base no exposto acima, conclui-se que o modelo para explicar a incorporação do gadolínio na rede cristalina do $\mathrm{UO}_{2}$ deve prever a formação de cátions $\mathrm{U}^{5+}$ (preferencialmente a cátions $\mathrm{U}^{6+}$ ) e vacâncias de oxigênio na sub-rede aniônica, ou seja, o modelo 3 proposto por Ho e Radford. A dúvida que persiste está relacionada às quantidades relativas de cátions $\mathrm{U}^{5+}$ e vacâncias de oxigênio formadas.

O modelo discutido acima é válido para concentrações de até $40 \% \mathrm{em} \mathrm{mol} \mathrm{de}$ $\mathrm{Gd}_{2} \mathrm{O}_{3}$ adicionado ao $\mathrm{UO}_{2}$. Beals e Handwerk ${ }^{(49)}$ observaram que a relação $\mathrm{O} / \mathrm{M}$, a qual apresenta constância com a concentração até $40 \%$ em mol de $\mathrm{Gd}_{2} \mathrm{O}_{3}$, diminui 
abruptamente para maiores concentrações de $\mathrm{Gd}_{2} \mathrm{O}_{3}$, tendendo ao limite de 1,5 , o qual corresponde à $\mathrm{GdO}_{1,5}$. Esta observação, aliada à brusca mudança no valor de $\beta$ observada por estes autores para concentrações de $\mathrm{Gd}_{2} \mathrm{O}_{3}$ acima de $40 \% \mathrm{em}$ mol, indica uma mudança estrutural nesta concentração, não sendo mais aplicável o modelo 3 proposto por Ho e Radford. Apesar de nenhuma discussão estar presente na literatura consultada, observando-se a concordância entre o valor teórico de $\beta$ calculado por Ohmichi et al (48) assumindo a presença somente de cátions $\mathrm{U}^{6+}$, de $-0,0042$, e o valor de $\beta$ obtido experimentalmente por Beals e Hadwerk ${ }^{(49)}$ para $\mathrm{x}>0,4$, de $-0,0046$ (tabela 2), pode-se assumir que quando o valor de $x$ na solução sólida $\left(\mathrm{U}_{\mathrm{I}-\mathrm{x}} \mathrm{Gd}_{\mathrm{x}}\right) \mathrm{O}_{2}$ atinge o valor de 0,4 começa a ocorrer a formação de cátions $\mathrm{U}^{6+}$ preferencialmente à formação de cátions $\mathrm{U}^{5+}$, ocasionando a mudança do valor de $\beta$ para valores menos negativos, devido ao novo raio iônico do cátion formado, o qual é maior. Além disto, a partir desta concentração, o aumento na formação de vacâncias de oxigênio, observada nos resultados obtidos por Beals e Handwerk, pode começar a exercer também influência no aumento do valor de $\beta$, assumindo-se que a teoria de Ohmichi et al quanto ao maior raio iônico da vacância de oxigênio esteja correta. Neste caso o modelo deve assumir a presença de cátions $\mathrm{U}^{6+} \mathrm{e}$ vacâncias de oxigênio, correspondendo ao modelo 3 de Ho e Radford para atmosferas redutoras, porém substituindo-se os cátions $\mathrm{U}^{5+}$ por cátions $\mathrm{U}^{6+}$.

\subsubsection{Fases no sistema $\mathrm{UO}_{2}-\mathrm{Gd}_{2} \mathrm{O}_{3}$}

Como discutido no item anterior, existe concordância quanto à existência apenas da fase tipo fluorita do $\mathrm{UO}_{2}$ até a concentração de $40 \%$ em mol de $\mathrm{Gd}_{2} \mathrm{O}_{3}$. No seu trabalho, o mais completo em termos de faixa de concentração de $\mathrm{Gd}_{2} \mathrm{O}_{3}$ estudada, Beals e Handwerk $^{(49)}$ observaram uma anomalia no parâmetro de rede para a concentração de 40 $\%$ em mol de $\mathrm{Gd}_{2} \mathrm{O}_{3}$, a qual é atribuída à variações de estequiometria que ocorrem acima dessa concentração, com a perda de ânions $\mathrm{O}^{2-}$ preferencialmente à oxidação de cátions $\mathrm{U}^{4+}$ para manutenção do balanço elétrico, como sugere o comportamento da razão $\mathrm{O} / \mathrm{M}$, a qual deixa de ser constante acima de $40 \%$ em mol de $\mathrm{Gd}_{2} \mathrm{O}_{3}$ e começa a diminuir, tendendo a assumir o valor de 1,5 para $100 \%$ de $\mathrm{Gd}_{2} \mathrm{O}_{3}\left(\mathrm{GdO}_{1,5}\right)$. Apesar desta anomalia, os resultados obtidos por difração de raios-x neste seu trabalho, complementados pelos resultados obtidos em um outro trabalho posterior, realizado em associação com Wrona ${ }^{(57)}$, mostraram apenas as linhas características da estrutura fluorita para concentrações de até $53,42 \%$ em mol de $\mathrm{Gd}_{2} \mathrm{O}_{3}$. Para a concentração estudada imediatamente superior a este valor, de $69,01 \%$ em mol de $\mathrm{Gd}_{2} \mathrm{O}_{3}$, as linhas correspondentes à estrutura fluorita ainda estavam presentes e bem definidas, mas linhas adicionais, ainda que fracas, foram evidenciadas. Estas novas linhas permaneceram, e bem definidas, para todas as 
concentrações superiores, até $89,82 \% \mathrm{em}$ mol, e foram identificadas como sendo as linhas características da forma $\mathrm{B}$ do $\mathrm{Gd}_{2} \mathrm{O}_{3}$ puro, com estrutura cristalina monoclínica. Como pode ser observado na figura 2 , mesmo para a concentração de $69,01 \% \mathrm{em} \mathrm{mol} \mathrm{e}$ superiores de $\mathrm{Gd}_{2} \mathrm{O}_{3}$, até $90 \% \mathrm{em} \mathrm{mol}$, faixa na qual já é formado o $\mathrm{Gd}_{2} \mathrm{O}_{3}$ livre, estes pesquisadores continuaram a observar o decréscimo proporcional do parâmetro de rede da estrutura fluorita, como se o sistema fosse monofásico.

Apesar de não ter sido observado nos seus difratogramas, Beals, Handwerk e Wrona ${ }^{(57)}$ incluíram no diagrama de fases $\mathrm{UO}_{2}-\mathrm{Gd}_{2} \mathrm{O}_{3}$ apresentado em seu trabalho o composto $\mathrm{Gd}_{6} \mathrm{UO}_{12}$, ou $\mathrm{UO}_{3} .3 \mathrm{Gd}_{2} \mathrm{O}_{3}$. Aitken, Bartram e Juenke ${ }^{\text {(56) }}$, a partir de estudos efetuados no sistema U-Y-O, complementando o trabalho de Chase ${ }^{\text {(59) }}$, o qual revelou pela primeira vez a existência do composto $\mathrm{UO}_{3} .3 \mathrm{Y}_{2} \mathrm{O}_{3}$, estudaram e caracterizaram uma fase de estrutura romboédrica no sistema $\mathrm{U}-\mathrm{Y}-\mathrm{O}$, de fórmula geral $\mathrm{U}_{\mathrm{m}} \mathrm{Y}_{7-\mathrm{m}} \mathrm{O}_{12}$ com valor de $\boldsymbol{m}$ variando de 1 a 3,4, ocorrendo, portanto, numa ampla faixa de concentração, de 51 a $86 \%$ em mol de $\mathrm{Y}_{2} \mathrm{O}_{3}$. Esta fase foi observada em amostras obtidas por comoagem dos pós de $\mathrm{UO}_{2}$ e $\mathrm{Y}_{2} \mathrm{O}_{3}$ e posterior sinterização sob atmosfera de $\mathrm{H}_{2}$. A partir desta fase $\mathrm{UO}_{2} .3 \mathrm{Y}_{2} \mathrm{O}_{3}$ romboédrica, estes autores prepararam uma série de compostos isoestruturais do tipo $\mathrm{R}_{6} \mathrm{UO}_{12}$, onde $\mathrm{R}$ representa o $\mathrm{La}$ e todas as terras raras do $\operatorname{Pr}$ ao $\mathrm{Lu}$, indexando-os no JCPDS-ICDD (Joint Committee of Powder Diffraction Standards - International Center for Diffraction Data). O composto com $\mathrm{Gd}\left(\mathrm{Gd}_{6} \mathrm{UO}_{12}\right)$ foi indexado no JCPDS, microficha 20-1335, como tendo estrutura cristalina romboédrica com constantes da rede hexagonal $\mathrm{a}=10,076 \AA$ e c $=9,529 \AA$ e volume da célula romboédrica de $279,26 \AA^{3}$.

Após o trabalho de Aitken, Bartram e Juenke ${ }^{(58)}$, demonstrando a existência deste novo grupo de compostos de estrutura romboédrica nos sistemas urânio-oxigênio-terras raras, outros pesquisadores também observaram esta fase nos sistemas U-La-O ${ }^{\text {(6062), }}$ U-Eu-O ${ }^{(63,64)}$, U-Ho-O ${ }^{(65)}$, U-Tm-O ${ }^{(65)}$, U-Lu-O ${ }^{(65)}$ e U-Nd-O ${ }^{(66)}$. Contudo, para o sistema U-Gd-O nenhum outro trabalho publicado menciona a observação da fase $\mathrm{Gd}_{6} \mathrm{UO}_{12}$.

Peehs, Dörr, Gradel e Maier ${ }^{(67)}$ mencionam a observação de uma fase $\left(\mathrm{U}_{0,5} \mathrm{Gd}_{0,5}\right) \mathrm{O}_{2}$ em pastilhas $\mathrm{UO}_{2}-\mathrm{Gd}_{2} \mathrm{O}_{3}$ com até $10 \%$ em peso de $\mathrm{Gd}_{2} \mathrm{O}_{3}$, para a qual, contudo, atribuíram a estrutura fluorita. Assmann, Peehs e Roepenack ${ }^{(68)}$ também sugerem a formação de fases no sistema U-Gd-O para explicar o comportamento da sinterização de pastilhas $\mathrm{UO}_{2}-\mathrm{Gd}_{2} \mathrm{O}_{3}$, muito diferente da sinterização de pastilhas de $\mathrm{UO}_{2}$ puro. Contudo, estes autores não apresentam informações sobre as características destas fases.

Além da fase romboédrica $\mathrm{Gd}_{6} \mathrm{UO}_{12}$, Ohmichi, Fukushima, Maeda e Watanabe sugerem a possibilidade da existência de uma fase ortorrômbica $\left(\mathrm{U}_{0,5} \mathrm{Gd}_{0,5}\right) \mathrm{O}_{2}$ baseados na 
observação desta fase por Bartran e Fitzsimmons ${ }^{(69)}$ no sistema U-Y-O. A partir deste trabalho, esta fase ortorrômbica, representada por $\mathrm{YUO}_{4}$, foi indexada por estes autores no JCPDS-ICDD sob o código 24-1430. Assumindo a existência desta fase ortorrômbica no sistema U-Gd-O, Ohmichi, Fukushima, Maeda e Watanabe ${ }^{(48)}$ sugerem a possibilidade da coexistência das fases $\mathrm{UO}_{2}$ fluorita e $\left(\mathrm{U}_{0,5} \mathrm{Gd}_{0,5}\right) \mathrm{O}_{2}$ ortorrômbica na faixa de concentração de $\mathrm{Gd}_{2} \mathrm{O}_{3}$ de 0 a $50 \%$ em mol, caracterizando-se um sistema bifásico.

Do exposto ạcima se conclui que muito poucos estudos básicos sobre o sistema U-Gd-O estão disponíveis. Os diagramas de equilíbrio publicados ${ }^{(57,70)}$ são incompletos, restritos a pequenas faixas de composição e temperatura, uma vez que foram construídos com o objetivo primário de determinar a temperatura de fusão do sistema $\mathrm{UO}_{2}-\mathrm{Gd}_{2} \mathrm{O}_{3}$ na faixa de concentração de interesse tecnológico para sua aplicação como combustível nuclear.

\subsubsection{Outras propriedades relevantes}

Mesmo que no combustível $\mathrm{UO}_{2}-\mathrm{Gd}_{2} \mathrm{O}_{3}$ o gadolínio esteja homogeneamente distribuído numa matriz de $\mathrm{UO}_{2}$, sua presença afeta as propriedades do combustível devido à diferença de valência do gadolínio e à forma na qual ele está disperso na matriz, a qual é dependente do processo de fabricação. A publicação resultante de um programa de pesquisa coordenado pela Agência Internacional de Energia Atômica (II) apresenta uma interessante comparação entre as propriedades dos combustíveis $\mathrm{UO}_{2}-\mathrm{Gd}_{2} \mathrm{O}_{3}$ e $\mathrm{UO}_{2}$. Neste item está apresentado um resumo sobre a influência da presença do gadolínio nas principais propriedades do combustível $\mathrm{UO}_{2}$.

Uma das propriedades químicas mais importantes numa vareta de óxido combustível é a pressão de oxigênio de equilíbrio no seu interior. O potencial de oxigênio de um óxido sólido é a diferença entre o potencial químico do oxigênio no sólido e o potencial químico do oxigênio puro gasoso à pressão de 1 atm, para uma dada temperatura. Em outras palavras, o potencial de oxigênio é uma maneira de expressar a pressão de equilíbrio do oxigênio sobre o sólido. O potencial de oxigênio do combustível determina, em grande parte, se o combustível de óxido poderá oxidar o revestimento metálico da vareta combustível. A oxidação interna do revestimento da vareta combustível reduz a sua resistência mecânica pela diminuição da sua espessura. Como o revestimento é projetado para ser o mais fino possível para diminuição do tamanho do núcleo do reator e da absorção parasítica de nêutrons, o uso de revestimento com espessura muito grande para acomodar oxidação é prejudicial. Além deste aspecto relacionado à oxidação interna do 
tubo de revestimento da vareta combustível, o potencial de oxigênio do combustível influencia suas propriedades, como sinterabilidade e liberação de gases de fissão, as quais afetam o seu desempenho sob irradiação.

Une e Oguma ${ }^{(51,71,72)}$ estudaram o potencial de oxigênio de soluções sólidas $(\mathrm{U}, \mathrm{Gd}) \mathrm{O}_{2}$ e obtiveram valores significativamente maiores do que os obtidos no caso do combustível $\mathrm{UO}_{2}$. Estes pesquisadores ${ }^{(72)}$ discutem o comportamento do combustível $\mathrm{UO}_{2}-\mathrm{Gd}_{2} \mathrm{O}_{3}$ em fenômenos controlados por difusão, com base nos resultados obtidos em seus trabalhos sobre o potencial de oxigênio de soluções sólidas $\mathrm{U}_{1-y} \mathrm{Gd}_{y} \mathrm{O}_{2}$. Por meio de um paralelo entre a dependência da difusividade catiônica no $\mathrm{UO}_{2+\mathrm{x}}$ e na solução sólida $\mathrm{U}_{0,8} \mathrm{Pu}_{0,2} \mathrm{O}_{2 \pm \mathrm{x}}$, estes autores explicam a baixa sinterabilidade observada na solução sólida $\mathrm{UO}_{2}-\mathrm{Gd}_{2} \mathrm{O}_{3}$, baseados na hipoestequiometria obtida neste sistema sob as condições usuais de sinterização em atmosfera redutora, como será discutido oportunamente, no item 1.5. Baseado neste modelo, estes autores fazem uma previsão de uma muito menor liberação de gases de fissão no combustivel $\mathrm{UO}_{2}-\mathrm{Gd}_{2} \mathrm{O}_{3}$ quando comparado ao combustível $\mathrm{UO}_{2}$ puro. Isto ocorreria devido ao fato da solução sólida (U, Gd) $\mathrm{O}_{2}$ tornar-se hipoestequiométrica sob as condições de operação do reator, onde o $\mathrm{UO}_{2}$ puro torna-se hiperestequiométrico, reduzindo, assim, a difusividade dos gases de fissão.

A solução sólida $\left(\mathrm{U}_{1-\mathrm{x}} \mathrm{Gd}_{\mathrm{x}}\right) \mathrm{O}_{2-\mathrm{x}}$ hipoestequiométrica, por exemplo com $10 \% \mathrm{em}$ peso de $\mathrm{Gd}_{2} \mathrm{O}_{3}$ e $\mathrm{O} / \mathrm{M}=1,998$, apresenta a $1500{ }^{\circ} \mathrm{C}$ um potencial de oxigênio superior ao $\mathrm{UO}_{2,00}$ estequiométrico ${ }^{(71)}$, o que poderia significar uma oxidação excessiva da parede interna do tubo de revestimento da vareta combustível. Se por um lado o combustível $\mathrm{UO}_{2}-\mathrm{Gd}_{2} \mathrm{O}_{3}$ apresenta maiores potenciais de oxigênio quando comparado com 0 combustivel $\mathrm{UO}_{2}$ sob as mesmas condições, o que é negativo em termos de oxidação interna da vareta combustível durante a irradiação, ele teria a vantagem de permitir a obtenção da hipoestequiometria, o que não é possível no combustível $\mathrm{UO}_{2}$, melhorando, segundo Une e Oguma ${ }^{(72)}$, importantes propriedades relacionadas ao desempenho no reator, como a menor taxa de liberação de gases de fissão. Avaliações pós-irradiação demonstraram que, apesar de realmente aumentar a oxidação da superficie interna do revestimento, este aumento é negligenciável em termos de desempenho do combustível ${ }^{(4)}$, A fração de gases de fissão liberada foi consideravelmente menor no caso do combustível $\mathrm{UO}_{2}-\mathrm{Gd}_{2} \mathrm{O}_{3}$, quando comparada à fração liberada no caso do combustível $\mathrm{UO}_{2}$. Estas observações apóiam o modelo proposto por Une e Oguma ${ }^{(72)}$, o qual prevê este comportamento baseado na menor difúsividade de cátions esperada num sistema hipoestequiométrico.

A condutividade térmica do combustível $\mathrm{UO}_{2}-\mathrm{Gd}_{2} \mathrm{O}_{3}$ é considerada a mais importante das suas propriedades físicas, uma vez que define a máxima taxa de 
transferência do calor gerado no combustível. A condutividade térmica é a propriedade que define o gradiente térmico do combustível durante a operação no reator, o que causa uma série de fenômenos, tais como migração de poros, redistribuição de constituintes do combustível (oxigênio, produtos de fissão), deformação plástica do combustível nas regiões de alta temperatura e seu trincamento nas regiões de baixa temperatura. Todos estes fatores devem ser considerados no projeto do reator, o que torna imprescindível o conhecimento da condutividade térmica do combustível. Como a condutividade térmica do combustível $\mathrm{UO}_{2}-\mathrm{Gd}_{2} \mathrm{O}_{3}$ é significativamente menor do que a do combustível padrão $\mathrm{UO}_{2}$, muita ênfase tem sido dada na sua determinação, uma vez que essa situação conduz a maiores temperaturas no combustível $\mathrm{UO}_{2}-\mathrm{Gd}_{2} \mathrm{O}_{3}$ durante a operação do reator, mantendose as mesmas condições de operação.

Como a condutividade térmica é derivada a partir da difusividade térmica, da capacidade calorífica e da expansão térmica, muitos trabalhos têm sido realizados com o objetivo de determinar-se estas propriedades do combustível $\mathrm{UO}_{2}-\mathrm{Gd}_{2} \mathrm{O}_{3}$, possibilitando avaliações cada vez mais precisas da condutividade térmica.

Fukushima, Ohmichi, Maeda e Watanabe (47) determinaram a condutividade térmica em amostras de $(\mathrm{U}, \mathrm{Gd}) \mathrm{O}_{2}$ contendo de 0 a $15 \% \mathrm{em} \mathrm{mol} \mathrm{de} \mathrm{Gd}_{2} \mathrm{O}_{3}$. A faixa de temperatura estudada foi de 400 a $1700{ }^{\circ} \mathrm{C}$. Os resultados obtidos mostraram uma diminuição consistente da condutividade térmica com o aumento da concentração de $\mathrm{Gd}_{2} \mathrm{O}_{3}$, de, por exemplo a $500{ }^{\circ} \mathrm{C}, 4,5 \mathrm{~W} / \mathrm{m} . \mathrm{K}$ no caso do $\mathrm{UO}_{2}$ puro para $2,5 \mathrm{~W} / \mathrm{m} . \mathrm{K}$ no caso da amostra contendo $12 \% \mathrm{em} \mathrm{mol} \mathrm{de} \mathrm{Gd}_{2} \mathrm{O}_{3}$ (aproximadamente $8,1 \%$ em peso). Mesmo para amostras com apenas $1 \%$ em peso de $\mathrm{Gd}_{2} \mathrm{O}_{3}$ a diminuição não é desprezível, de $10 \%$ a $500{ }^{\circ} \mathrm{C}$ e $8 \%$ a $1300{ }^{\circ} \mathrm{C}$. Contudo, a diferença entre as condutividades térmicas do $\mathrm{UO}_{2}$ puro e do $(\mathrm{U}, \mathrm{Gd}) \mathrm{O}_{2}$ diminui sensivelmente com o aumento da temperatura. Outros trabalhos consultados ${ }^{(54,67,73-75)}$ concordam que a presença de gadolínio no combustível $\mathrm{UO}_{2}$ diminui consistentemente a condutividade térmica do combustível. Por outro lado, existe também concordância de que a diminuição da condutividade térmica devido à presença de gadolínio no combustível pode ser considerada desprezível em altas temperaturas, superiores a $1300^{\circ} \mathrm{C}$.

Apesar de todos os resultados indicarem que a presença do $\mathrm{Gd}_{2} \mathrm{O}_{3}$ causa uma diminuição da condutividade térmica do $\mathrm{UO}_{2}$ puro e de que este efeito é menos importante em altas temperaturas, os resultados são discordantes em termos quantitativos e em relação à magnitude do efeito. Esta discrepância também é observada nos resultados obtidos para o combustível $\mathrm{UO}_{2}$ puro, a qual é refletida nos resultados obtidos para o combustível $\mathrm{UO}_{2}$ $\mathrm{Gd}_{2} \mathrm{O}_{3}$. É possível que a discrepância observada nos resultados obtidos pelos diferentes pesquisadores seja ocasionada pela utilização de diferentes valores de calor específico no 
cálculo da condutividade térmica. Alguns pesquisadores utilizaram a média ponderada dos

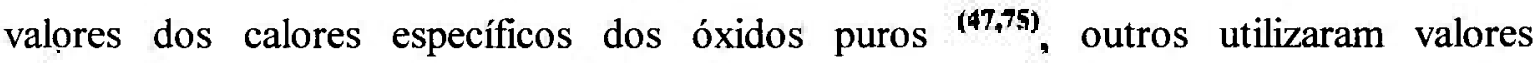
determinados experimentalmente ${ }^{(\mathbf{7 3 - 7 5 )}}$ e Chotard et al ${ }^{\text {(54) }}$ utilizaram o calor específico do $\mathrm{UO}_{2}$ puro. Outra possível explicação também poderia ser a utilização do coeficiente de expansão térmica do $\mathrm{UO}_{2}$ puro no cálculo da condutividade térmica do combustível $\mathrm{UO}_{2}$ $\mathrm{Gd}_{2} \mathrm{O}_{3}$. Contudo, esta não parece ser uma causa provável, uma vez que os resultados na determinação do coeficiente de expansão térmica do combustível $\mathrm{UO}_{2}-\mathrm{Gd}_{2} \mathrm{O}_{3}$ obtidos na literatura ${ }^{(52,54,76)}$ indicam que ele é muito próximo do determinado no combustível $\mathrm{UO}_{2}$ puro. Concluindo, pode-se observar que dados adicionais sobre a condutividade térmica do sistema $\mathrm{UO}_{2}-\mathrm{Gd}_{2} \mathrm{O}_{3}$ ainda são necessários, principalmente aqueles que relacionem as características microestruturais das amostras com a sua condutividade térmica. Amaya e Hirai (77) também sugerem que a variação nos resultados obtidos nas determinações da condutividade térmica é causada pelas diferenças na porosidade das amostras. A importância da influência da microestrutura também foi observada por Peehs et al ${ }^{\text {(bł) }}$. É recomendável, portanto, que os dados de condutividade que irão ser considerados no projeto de um combustível sejam obtidos diretamente de amostras processadas segundo os mesmos procedimentos adotados na fabricação industrial do combustível. Isto também se aplica aos dados de calor específico, tendo em vista o comportamento térmico anormal desta propriedade registrado por alguns pesquisadores ${ }^{(78,79)}$. Este é o caso do trabalho de Chotard et al ${ }^{(54)}$, que obtiveram resultados a partir de amostras $\mathrm{UO}_{2}-\mathrm{Gd}_{2} \mathrm{O}_{3}$ representativas do processo de fabricação e, além disto, complementaram a avaliação dos resultados obtidos com um teste de irradiação, cujos resultados demonstraram excelente desempenho, resultando em temperaturas na linha de centro do combustível muito próximas às observadas no caso do combustível padrão de $\mathrm{UO}_{2}$ operando sob as mesmas condições.

O conhecimento da temperatura de fusão do combustível é necessário para a definição da potência limite do elemento combustível. A temperatura de fusão do combustível $\mathrm{UO}_{2}-\mathrm{Gd}_{2} \mathrm{O}_{3}$ não está ainda definitivamente estabelecida. Contudo, os resultados obtidos por diferentes pesquisadores ${ }^{\text {(52,54,1t) }}$ apresentam boa concordância, com variação máxima de aproximadamente $170^{\circ} \mathrm{C}$, o que representa $\pm 3 \%$ a $2800{ }^{\circ} \mathrm{C}$. Esta variação pode ser explicada pela dificuldade encontrada na medição precisa das altas temperaturas envolvidas. Outra causa possível é a presença de áreas nas amostras com diferentes concentrações de $\mathrm{Gd}_{2} \mathrm{O}_{3}$. Yamanouchi, Tachibana, Tsukui e Oguma estudaram a temperatura de fusão em amostras irradiadas de $\mathrm{UO}_{2}$ e $\mathrm{UO}_{2}-\mathrm{Gd}_{2} \mathrm{O}_{3}$ com $2 \%$ em peso de $\mathrm{Gd}_{2} \mathrm{O}_{3}$. O combustível foi irradiado num reator comercial e as amostras foram obtidas a partir de fragmentos de pastilhas irradiadas com crescentes níveis de queima, de até cerca de $30 \mathrm{GWd} / \mathrm{tU}$. Estes pesquisadores concluíram que a presença do $\mathrm{Gd}_{2} \mathrm{O}_{3}$ não alterou a temperatura de fusão do $\mathrm{UO}_{2}$, nem mesmo após a irradiação, sendo a variação observada negligenciável, situando-se dentro da faixa do erro experimental. Além disto, 
seus resultados demonstraram que não ocorre diminuição da temperatura de fusão com a irradiação, tanto no caso do combustível $\mathrm{UO}_{2}$ como no caso do combustível $\mathrm{UO}_{2}-\mathrm{Gd}_{2} \mathrm{O}_{3}$ com $2 \%$ em peso de $\mathrm{Gd}_{2} \mathrm{O}_{3}$. Portanto, conclui-se que a incorporação de $\mathrm{Gd}_{2} \mathrm{O}_{3}$ ao combustível $\mathrm{UO}_{2}$ aparentemente causa uma ligeira diminuição na temperatura de fusão do combustível, contudo sem implicações importantes no seu desempenho no reator.

Apesar da importância de caracterizar-se as diversas propriedades do combustível $\mathrm{UO}_{2}-\mathrm{Gd}_{2} \mathrm{O}_{3}$, comparando-as com as propriedades do combustível padrão de $\mathrm{UO}_{2}$, os testes de irradiação são os que definitivamente definem o desempenho do combustível no reator. Os testes de desempenho do combustível $\mathrm{UO}_{2}-\mathrm{Gd}_{2} \mathrm{O}_{3}$ em reatores tipo PWR iniciaram-se em 1971 na Bélgica, no reator BR3 de 11 Mwe, de maneira bastante conservativa, elevando-se progressivamente a concentração de $\mathrm{Gd}_{2} \mathrm{O}_{3}$ e o número de varetas contendo este combustivel. Em 1984 foram introduzidas 24 varetas combustíveis contendo de 7 a $10 \%$ em peso de $\mathrm{Gd}_{2} \mathrm{O}_{3}$. Foram atingidas nas varetas combustíveis testadas taxas de geração linear de calor da ordem de $450 \mathrm{~W} / \mathrm{cm}$, obtendo-se queimas de até $71 \mathrm{GWd} / \mathrm{tU}$. $\mathrm{O}$ desempenho das varetas combustíveis contendo $\mathrm{UO}_{2}-\mathrm{Gd}_{2} \mathrm{O}_{3}$ testadas no reator $\mathrm{BR} 3$, de modo geral, foi muito similar às varetas contendo o combustível padrão $\mathrm{UO}_{2}$ (\$1). Foi observado um maior nível de interação mecânica entre as pastilhas de combustível $\mathrm{UO}_{2}$ $\mathrm{Gd}_{2} \mathrm{O}_{3}$ e o revestimento, quando comparada à interação observada no combustível $\mathrm{UO}_{2}$ de referência. Blanpain et al ${ }^{(\mathbf{8 1})}$, observando o combustível $\mathrm{UO}_{2}-\mathrm{Gd}_{2} \mathrm{O}_{3}$ irradiado, não encontraram evidências de redução na condutividade térmica do combustível e, portanto, de aumento da sua temperatura ( $3 \%$ em peso de $\mathrm{Gd}_{2} \mathrm{O}_{3}$ ), quando comparado ao combustível $\mathrm{UO}_{2}$ de referência. A liberação de gases de fissão nas varetas contendo $\mathrm{UO}_{2}$ $\mathrm{Gd}_{2} \mathrm{O}_{3}$ foi comparável à liberação encontrada nas varetas $\mathrm{UO}_{2}$ de referência. A análise microestrutural das varetas revelou uma interação química entre o combustível $\mathrm{UO}_{2}-\mathrm{Gd}_{2} \mathrm{O}_{3}$ e a superficie interna do revestimento mais pronunciada do que a observada no caso do combustível padrão $\mathrm{UO}_{2}$.

Com o objetivo de investigar as propriedades físico-químicas, termomecânicas e neutrônicas do combustível $\mathrm{UO}_{2}-\mathrm{Gd}_{2} \mathrm{O}_{3}$ e de qualificar o processo de fabricação, a Fragema francesa realizou um extenso programa de irradiação. A irradiação comercial iniciou-se em 1983 e um total de 4000 varetas combustíveis de $\mathrm{UO}_{2}-\mathrm{Gd}_{2} \mathrm{O}_{3}$ haviam sido irradiadas até o final de 1990, nos reatores franceses da série GRAVELINES, TRICASTIN e CHINON, e nos reatores suecos RINGHALS 3 e 4 . Uma grande proporção destas varetas foi irradiada sob severas condições de operação, demonstrando a flexibilidade de operação dos reatores com o uso do $\mathrm{UO}_{2}-\mathrm{Gd}_{2} \mathrm{O}_{3}$. A metodologia de cálculo neutrônico foi qualificada. Chotard et al ${ }^{\text {(5+) }}$ estudaram a condutividade térmica do combustível $\mathrm{UO}_{2}$ $\mathrm{Gd}_{2} \mathrm{O}_{3}$, contendo $8 \%$ em peso de $\mathrm{Gd}_{2} \mathrm{O}_{3}$, sob irradiação. Eles concluíram que apesar da condutividade térmica ser menor no começo do ciclo de queima, quando o combustível 
opera em menores temperaturas e não representa um problema, ela aumenta muito quando o combustível $\mathrm{UO}_{2}-\mathrm{Gd}_{2} \mathrm{O}_{3}$ opera à potência normal, resultando em temperaturas na linha de centro do combustível muito próximas às observadas no caso do combustível padrão de $\mathrm{UO}_{2}$ operando sob as mesmas condições.

Atualmente, todos os reatores PWR Coreanos, das séries KORI, ULCHIN e YONGGWANG, utilizam varetas combustíveis de $\mathrm{UO}_{2}-\mathrm{Gd}_{2} \mathrm{O}_{3}$. O primeiro carregamento deste tipo de combustível foi realizado em fevereiro de 1990 no reator KORI-2 de 605 MWe. Até outubro de 1993 um total de 3728 varetas combustíveis de $\mathrm{UO}_{2}-\mathrm{Gd}_{2} \mathrm{O}_{3}$ estavam sendo irradiadas nos reatores coreanos, tendo sido descarregadas, até esta data, 864 varetas combustíveis, das quais 228 haviam completado seu terceiro ciclo de queima (II). A avaliação do desempenho destas varetas combustíveis foi realizada por meio de inspeção no interior do vaso do reator, utilizando-se um sistema de medição das dimensões das varetas combustíveis irradiadas, comparando-as com as suas dimensões iniciais, antes da irradiação. Nenhuma anomalia foi observada nas varetas combustíveis $\mathrm{UO}_{2}-\mathrm{Gd}_{2} \mathrm{O}_{3}$, mesmo após o terceiro ciclo de queima.

A Siemens Power Company americana ${ }^{\mathbf{8 2 , 8 3 , 1 1 )}}$, antiga Exxon Nuclear Company, possuía no final de 1888 uma experiência de irradiação de 45000 varetas combustiveis $\mathrm{UO}_{2}-\mathrm{Gd}_{2} \mathrm{O}_{3}$ em 29 reatores, sendo 18 tipo BWR e 11 tipo PWR. Excelente integridade do combustivel e desempenho neutrônico foi observado. Varetas combustíveis $\mathrm{UO}_{2}-\mathrm{Gd}_{2} \mathrm{O}_{3}$ contendo $8 \%$ em peso de $\mathrm{Gd}_{2} \mathrm{O}_{3}$ foram irradiadas no reator PWR belga THIANGE-1 até queima de $50 \mathrm{GWd} / \mathrm{tU}$ sem apresentação de falhas. Exames no interior do vaso do reator concluíram que o comportamento mecânico das varetas é muito similar ao observado nas varetas combustíveis de $\mathrm{UO}_{2}$. Resultados de exame pós-irradiação em célula quente demonstraram que não ocorre redistribuição de $\mathrm{Gd}_{2} \mathrm{O}_{3}$ no combustível. $\mathrm{O}$ padrão de trincamento observado e as variações na densidade das pastilhas $\mathrm{UO}_{2}-\mathrm{Gd}_{2} \mathrm{O}_{3}$ foram similares às observadas na pastilha de $\mathrm{UO}_{2}$ puro. A Babcock \& Wilcox Fuel Company, também americana, irradiou elementos combustíveis contendo varetas de $\mathrm{UO}_{2}-\mathrm{Gd}_{2} \mathrm{O}_{3}$ no reator PWR OCONEE, de $850 \mathrm{MWe}$, até queimas da ordem de $58 \mathrm{GWd} / \mathrm{tU}$. A avaliação pós-irradiação confirmou a integridade destas varetas combustíveis, mesmo para esse elevado nível de queima ${ }^{(11)}$.

A Alemanha iniciou testes de irradiação em varetas combustíveis $\mathrm{UO}_{2}-\mathrm{Gd}_{2} \mathrm{O}_{3}$ em 1970, no reator BWR VAK KHAL de 15 MWe, e em 1972, no reator PWR OBRIGHEIM de $340 \mathrm{MWe}$, utilizando concentrações de $\mathrm{Gd}_{2} \mathrm{O}_{3}$ de 2 a $4 \%$ em peso. Foram atingidas queimas de até $18 \mathrm{GWd} / \mathrm{tU}$ e taxas de geração de calor de 140 a $180 \mathrm{~W} / \mathrm{cm}$ no reator $\mathrm{BWR}$ e queimas de até $33 \mathrm{GWd} / \mathrm{tU}$ e taxa de geração de calor de 200 a $250 \mathrm{~W} / \mathrm{cm}$ no reator PWR. A análise pós-irradiação mostrou comportamento dimensional idêntico ao 
observado em varetas combustíveis contendo $\mathrm{UO}_{2}$ puro, tanto em termos de alongamento das varetas como em termos de fluência do revestimento. A liberação de gases de fissão no combustível $\mathrm{UO}_{2}-\mathrm{Gd}_{2} \mathrm{O}_{3}$ foi menor do que a observada no combustível de referência $\mathrm{UO}_{2}$. Uma maior oxidação interna dos tubos de revestimento das varetas combustíveis $\mathrm{UO}_{2}-\mathrm{Gd}_{2} \mathrm{O}_{3}$ foi observada, sem, contudo, comprometer o desempenho da vareta

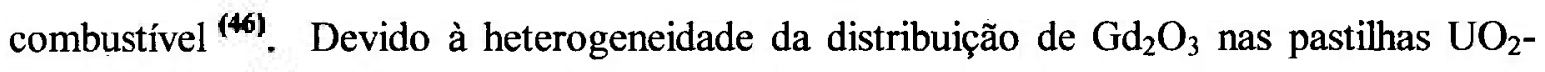
$\mathrm{Gd}_{2} \mathrm{O}_{3}$, característica do processo de fabricação alemão (mistura mecânica a seco dos pós de $\mathrm{UO}_{2}$ e $\mathrm{Gd}_{2} \mathrm{O}_{3}$ ), foi observado o desenvolvimento de grandes poros nas pastilhas combustiveis durante a irradiação, em regiões onde inicialmente existia alta concentração de $\mathrm{Gd}_{2} \mathrm{O}_{3}$. Segundo Manzel e Dörr ${ }^{(46)}$, estes poros são estáveis devido ao seu grande diâmetro, pouco susceptíveis à futura densificação, o que resulta numa menor densificação sob irradiação do combustível $\mathrm{UO}_{2}-\mathrm{Gd}_{2} \mathrm{O}_{3}$, quando comparada à densificação do combustível $\mathrm{UO}_{2}$ puro. Foi observado que o desenvolvimento destes poros no combustível $\mathrm{UO}_{2}-\mathrm{Gd}_{2} \mathrm{O}_{3}$ cessa após queimas de $30 \mathrm{GWd} / \mathrm{tU}$, o que resulta num comportamento quanto ao inchamento semelhante dos combustiveis $\mathrm{UO}_{2}-\mathrm{Gd}_{2} \mathrm{O}_{3}$ e $\mathrm{UO}_{2}$, fato verificado experimentalmente ${ }^{(46)}$. Um grande número de varetas combustíveis $\mathrm{UO}_{2}-\mathrm{Gd}_{2} \mathrm{O}_{3}$ produzidas pela KWU (Kraftwerk Union - Siemens AG) tem sido irradiado em reatores BWR desde 1974, totalizando mais de 69000 varetas até 1992, contendo 6,5\% em peso de $\mathrm{Gd}_{2} \mathrm{O}_{3}$ e atingindo queimas da ordem de $52 \mathrm{GWd} / \mathrm{tU}$. Em reatores PWR, varetas combustíveis $\mathrm{UO}_{2}-\mathrm{Gd}_{2} \mathrm{O}_{3}$ contendo de 3 a $7 \%$ em peso de $\mathrm{Gd}_{2} \mathrm{O}_{3}$ (também varetas experimentais com $12 \%$ ) tem sido irradiadas desde $1982 \mathrm{em} 7$ reatores, totalizando quase 13000 varetas até 1992 . Queimas de até $45 \mathrm{GWd} / \mathrm{tU}$ têm sido atingidas. Nenhuma falha foi registrada ${ }^{(11)}$.

Com base no exposto acima, tendo em vista a significativa quantidade de varetas combustiveis $\mathrm{UO}_{2}-\mathrm{Gd}_{2} \mathrm{O}_{3}$ irradiadas, muitas vezes sob condições bastante severas, pode-se concluir que o desempenho do combustível $\mathrm{UO}_{2}-\mathrm{Gd}_{2} \mathrm{O}_{3}$ é plenamente satisfatório, muito similar ao comportamento do combustível de referência $\mathrm{UO}_{2}$. Contudo, apesar de aceitáveis, algumas diferenças no comportamento sob irradiação dos combustíveis $\mathrm{UO}_{2}$ $\mathrm{Gd}_{2} \mathrm{O}_{3}$ e $\mathrm{UO}_{2}$ puderam ser detectadas.

\subsection{Processos de fabricação do combustivel $\mathrm{UO}_{2}-\mathrm{Gd}_{2} \mathrm{O}_{3}$}

A incorporação do $\mathrm{Gd}_{2} \mathrm{O}_{3}$ ao combustível $\mathrm{UO}_{2}$ para a obtenção de uma distribuição homogênea, finamente dispersa, de gadolínio pode ser realizada por meio de diferentes métodos de processamento. Comercialmente, o método de incorporação é 
sempre uma variante de um processo de produção industrial estabelecido para a fabricação do combustível padrão de $\mathrm{UO}_{2}$.

Os processos de fabricação do combustível $\mathrm{UO}_{2}$ para aplicação em reatores nucleares que estão industrialmente estabelecidos ${ }^{(\mathbf{8 4 , 8 5 )}}$ podem ser divididos em duas categorias, as quais diferem entre si quanto ao tipo de processo adotado para a produção do pó de $\mathrm{UO}_{2}$, também conhecido como processo de conversão:

- processo aquoso, onde um sal de urânio obtido a partir do $U_{6}$ é precipitado a partir de uma solução aquosa contendo urânio. Este sal é subseqüentemente processado para a obtenção de pó de $\mathrm{UO}_{2}$;

- processo seco, onde o $\mathrm{UF}_{6}$ é convertido a $\mathrm{UO}_{2}$ apenas por meio de reações no estado gasoso.

Dependendo da rota de obtenção do pó de $\mathrm{UO}_{2}$, o que determina suas propriedades, diferentes seqüências posteriores de processamento são necessárias para a fabricação do combustivel, particularmente aquelas que envolvem a obtenção de um pó de boa compactabilidade e sinterabilidade. A figura 4 apresenta fluxogramas simplificados dos processos de fabricação do combustível $\mathrm{UO}_{2}$ industrialmente estabelecidos. Brandberg $^{(\mathbf{8 6})}$ apresenta uma interessante comparação entre os processos de conversão.

Os dois processos industriais de conversão aquosos são designados por DUA e TCAU, diuranato de amônio $\left(\mathrm{NH}_{4}\right) \mathrm{U}_{2} \mathrm{O}_{7}$ e tricarbonato de amônio e uranilo $\left(\mathrm{NH}_{4}\right)_{4} \mathrm{UO}_{2}\left(\mathrm{CO}_{3}\right)_{3}$, respectivamente, designação que corresponde aos sais intermediários que são precipitados. Os processos industriais de conversão a seco são designados, basicamente, com relação ao tipo de equipamento utilizado, leito fluidizado ("Dry Bed ou DCFB - Direct Conversion Fluid Bed"), forno rotativo ou IDR ("Integrated Dry Route") e reator de chama ("GECO").

O processo aquoso via DUA é o mais antigo processo industrial de conversão de $\mathrm{UF}_{6}$ a $\mathrm{UO}_{2}$ e é muito utilizado em todo o mundo ${ }^{(68)}$. Como todos os processos de conversão, o processo via DUA inicia-se com a evaporação do $U_{6}$, o qual, na forma gasosa, é solubilizado em água para a formação de uma solução aquosa de $\mathrm{UO}_{2} \mathrm{~F}_{2}$, que, em seguida, reage com $\mathrm{NH}_{3}$ para formar o DUA, que precipita. Outra possibilidade é a solubilização do $\mathrm{UF}_{6}$ numa solução aquosa de $\mathrm{NH}_{4} \mathrm{OH}$, precipitando diretamente o DUA. Ainda, pode ser utilizado como material de partida uma solução de nitrato de uranilo $\mathrm{UO}_{2}\left(\mathrm{NO}_{3}\right)_{2}$. A decomposição térmica e a redução do DUA são normalmente realizadas conjuntamente em temperaturas da ordem de $600{ }^{\circ} \mathrm{C}$ sob atmosfera de $\mathrm{H}_{2} / \mathrm{H}_{2} \mathrm{O}$. O pó de 


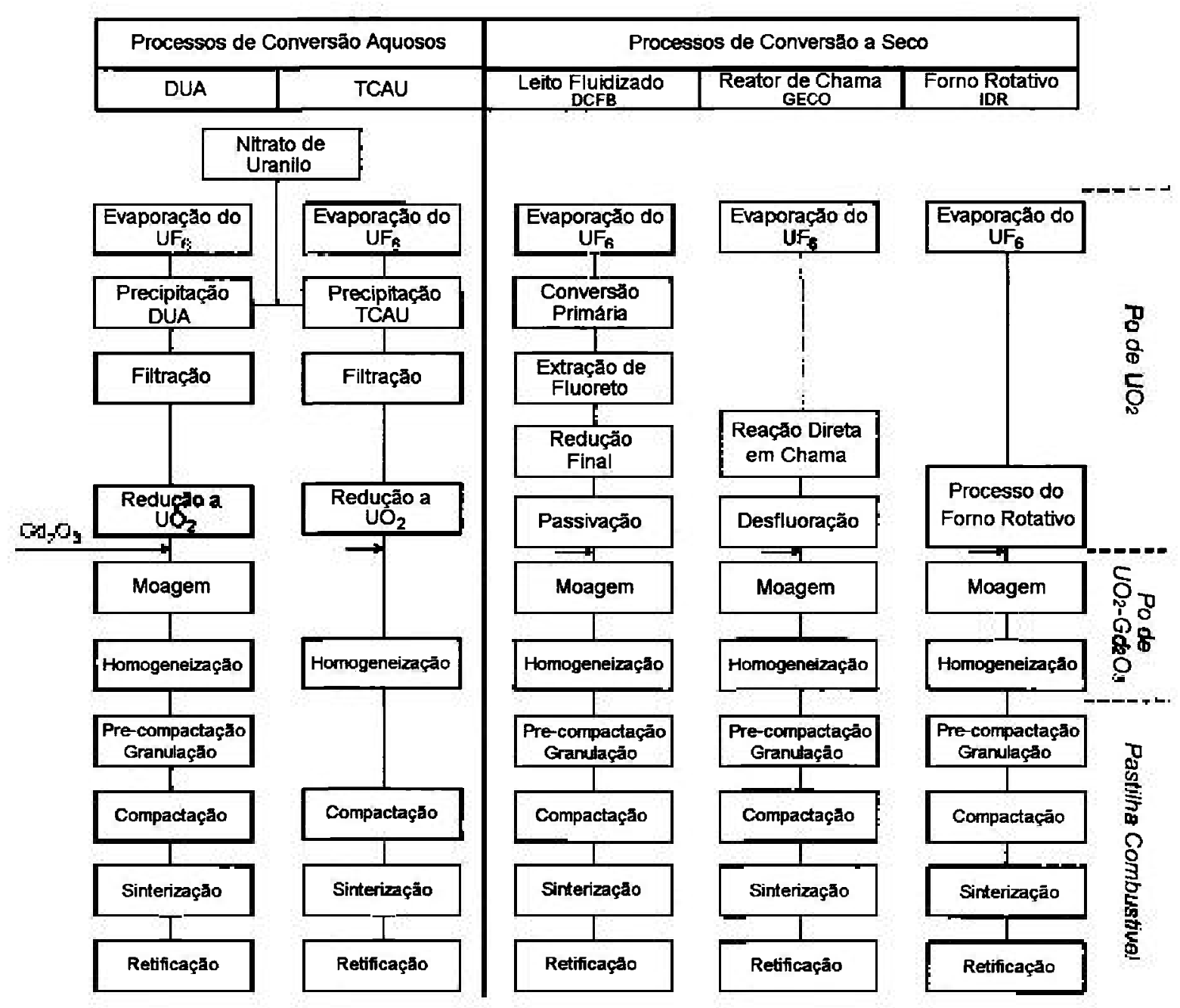

Figura 4 - Fluxogramas esquemáticos dos processos de fabricação de combustível industrialmente estabelecidos ${ }^{\text {(84,85). }}$

$\mathrm{UO}_{2}$ resultante não apresenta as características necessárias para a sua compactação direta e sinterização, etapas necessárias para a obtenção de corpos sólidos com dimensões e densidade especificadas. Por este motivo, antes da compactação devem ser realizadas etapas de condicionamento mecânico do pó, tais como adição de aglomerantes e lubrificantes numa etapa de moagem e homogeneização, pré-compactação, granulação e peneiramento. Desta forma são obtidos grânulos de tamanho controlado e com características de escoabilidade (para a alimentação automática da prensa de compactação), compactabilidade (para obtenção da densidade a verde requerida) e sinterabilidade (para obtenção da densidade final especificada) necessárias para o futuro processamento do combustivel. A sinterização, como em todas as outras rotas de processamento, é realizada sob atmosfera redutora de $\mathrm{H}_{2}$ em temperaturas ao redor de $1700^{\circ} \mathrm{C}$. 
O processo aquoso via TCAU foi desenvolvido no início dos anos 60 com o objetivo de reduzir o número de etapas de processamento envolvidas no processo aquoso via DUA, obtendo-se um precipitado com mais baixo teor de flúor e mais adequado ao

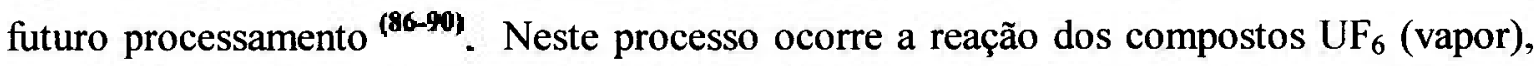
$\mathrm{NH}_{3}$ e $\mathrm{CO}_{2}$ no estado gasoso e água no estado líquido. Como no processo de conversão via DUA, o TCAU também pode ser obtido a partir de uma solução de nitrato de uranilo, a qual substitui o $\mathrm{UF}_{6}$ como material de partida. $\mathrm{O}$ precipitado obtido tem forma aproximadamente esférica e tamanho de partícula grande o suficiente para conferir ao pó de TCAU uma alta escoabilidade. Num forno de leito fluidizado, o TCAU é decomposto a $\mathrm{UO}_{3}$ e reduzido a $\mathrm{UO}_{2}$ usando-se uma atmosfera de vapor de $\mathrm{H}_{2} \mathrm{O}$ e $\mathrm{H}_{2}$. A forma do pó de $\mathrm{UO}_{2}$ obtido mantém a forma original do TCAU, possuindo, portanto, uma alta escoabilidade. $\mathrm{O}$ pó de $\mathrm{UO}_{2}$ produzido a partir do TCAU também possui uma sinterabilidade adequada. Devido a estas características, esse pó pode ser compactado diretamente, não sendo necessárias as etapas de moagem, pré-compactação, granulação e peneiramento, as quais não podem ser eliminadas na rota do DUA. A adição de aglomerantes e lubrificantes também não é necessária. A sinterabilidade é suficiente devido à alta superfície específica obtida, de cerca de $6 \mathrm{~m}^{2} / \mathrm{g}$. A adição de formadores de porosidade, usualmente utilizados para o controle da densidade final das pastilhas sinterizadas sem que seja necessário variar as condições de sinterização, pode ser facilmente realizada devido à alta escoabilidade do pó de $\mathrm{UO}_{2}$ obtido pela rota do TCAU. Também devido à alta escoabilidade, o transporte do pó de $\mathrm{UO}_{2}$ pode ser realizado pneumaticamente. A sinterização também é realizada sob atmosfera redutora de $\mathrm{H}_{2}$ em temperaturas ao redor de $1700^{\circ} \mathrm{C}$. Como dito anteriormente, devido à alta escoabilidade e compactabilidade do pó de $\mathrm{UO}_{2}$ proveniente do TCAU não é necessária a adição de aglomerantes e lubrificantes orgânicos ao pó, eliminando-se, além da moagem e granulação, a necessidade de tratamentos térmicos especiais na sinterização para retirada dos materiais orgânicos, o que é necessário nos outros processos de conversão.

Os processos a seco de conversão do $\mathrm{UF}_{6}$ foram desenvolvidos para reduzir-se a quantidade de líquidos gerados nos processos de conversão aquosos. Neste caso o UF 6 na forma gasosa é o único material de partida. Nesses processos, essencialmente, o $\mathrm{UF}_{6}$ é convertido a $\mathrm{UO}_{2} \mathrm{~F}_{2}$ sólido por meio de vapor superaquecido, o qual é posteriormente convertido a $\mathrm{UO}_{2}$ por meio de $\mathrm{H}_{2}$. As vantagens dos processos via seca são a ausência de efluentes líquidos contendo urânio, a possibilidade de processar maiores quantidades de material enriquecido ou com maior enriquecimento (diminuição de problemas de criticalidade devido à ausência de água), economia de reagentes e menor número de operações. Por outro lado, os processos via seca têm a desvantagem de necessitar materiais mais sofisticados na construção dos equipamentos, os quais operam sob altas temperaturas em presença de HF, resultando em severos problemas de corrosão. Outra 
desvantagem é a impossibilidade de processar o nitrato de uranilo, que é um material normalmente utilizado para reciclar os materiais rejeitados na linha de produção de pastilhas, implicando na necessidade de uma linha de processamento adicional via aquosa para o processamento do nitrato de uranilo, paralelamente à linha principal de conversão via seca.

No processo via leito fluidizado ${ }^{(91,92)}$, também conhecido por DCFB - Dry Direct Conversion Fluid Bed, ou simplesmente "Dry Bed", o UF 6 é introduzido na forma gasosa puro ou com o auxílio de um gás de arraste, usualmente $\mathrm{N}_{2}$, na parte inferior do forno de conversão primária (altura da placa porosa) e hidrolisado com vapor de água superaquecido. Numa segunda etapa, o $\mathrm{UO}_{2} \mathrm{~F}_{2}$ obtido é decomposto em $\mathrm{UO}_{2}$ e $\mathrm{HF}$, sendo a redução completada numa terceira etapa, obtendo-se $\mathrm{UO}_{2}$ com um menor teor de flúor. Numa última etapa, o $\mathrm{UO}_{2}$ obtido é passivado, obtendo-se $\mathrm{UO}_{2+\mathrm{x}} \operatorname{com} \mathrm{O} / \mathrm{U}$ entre 2,04 e 2,25 , para controle da sua piroforicidade. O número de etapas pode variar e elas são executadas por meio de fornos de leito fluidizado dispostos em série, nos quais os produtos da reação anterior são introduzidos juntamente com os gases de reação. Para grandes produções geralmente são necessários 4 estágios. O pó obtido possui baixa escoabilidade e deve sofrer os mesmos tratamentos de condicionamento descritos no caso de conversão via DUA.

O processo de conversão a seco conhecido como processo GECO (24,35,23) compreende dois estágios. No primeiro é realizada a conversão do UF 6 usando um gás redutor, usualmente $\mathrm{H}_{2}$, e um gás de arraste contendo oxigênio, usualmente $\mathrm{H}_{2} \mathrm{O}$ na forma de vapor. Após a introdução do $\mathrm{H}_{2}$, é injètado flúor gasoso para a ignição da reação. A reação é mantida de forma auto-sustentada pela reação do $U F_{6}$ com o oxigênio do vapor e o $\mathrm{H}_{2}$. Vários produtos intermediários são formados em conjunto com o $\mathrm{UO}_{2}$, dependendo da mistura gasosa utilizada. O teor de flúor no $\mathrm{UO}_{2}$ é muito elevado, sendo reduzido por meio dè um tratamento térmico posterior sob atmosfera de $\mathrm{H}_{2}$. O pó obtido é muito fino e também não apresenta escoabilidade suficiente para o seu posterior processamento, devendo passar pelas etapas de condicionamento descritas anteriormente.

O processo IDR produz $\mathrm{UO}_{2}$ a partir de $\mathrm{UF}_{6}$ via seca de forma contínua num único estágio ${ }^{(\mathbf{8 4 , 9 4 )}}$. O processo desenvolve-se num forno rotativo inclinado, no qual $\mathrm{UF}_{6} \mathrm{e}$ injetado juntamente com vapor de água, formando $\mathrm{UO}_{2} \mathrm{~F}_{2}$, o qual é convertido a $\mathrm{UO}_{2}$ por meio de $\mathrm{H}_{2}$ e vapor de água injetados em contra-corrente. Por meio do controle do perfil de temperatura do forno e tempo de permanência pode-se controlar o teor de flúor, tamanho de partícula, morfologia e superfície específica do pó de $\mathrm{UO}_{2}$ obtido. Devido ao pequeno tamanho das partículas do $\mathrm{UO}_{2}$ obtido, o que resulta em baixa escoabilidade, a 
granulação também se faz necessária, podendo, contudo, por meio do controle do processo de conversão, ser eliminada a adição de aglomerantes orgânicos.

Observando-se a figura 4, nota-se que o único processo de conversão no qual não são realizadas as etapas de moagem, pré-compactação, granulação e peneiramento é o processo aquoso via TCAU, o que é possível devido às características suficientes de compactabilidade, sinterabilidade e escoabilidade do pó de $\mathrm{UO}_{2}$ obtido por este método. Essas etapas são necessárias em todos os outros processos comerciais de conversão devido ao pequeno tamanho das partículas de $\mathrm{UO}_{2}$ obtidas (baixa escoabilidade $\mathrm{e}$ compactabilidade) e menor superfície específica do produto (baixa sinterabilidade).

A incorporação do $\mathrm{Gd}_{2} \mathrm{O}_{3}$ nestes processos comerciais é realizada antes da moagem, como está indicado na figura 4. No caso do processo via TCAU, o $\mathrm{Gd}_{2} \mathrm{O}_{3}$ é incorporado antes da homogeneização. Convém notar que a adição do $\mathrm{Gd}_{2} \mathrm{O}_{3}$ não perturba significativamente o processo de produção do combustível $\mathrm{UO}_{2}$ padrão. Apenas as etapas de moagem e homogeneização (ou apenas homogeneização no caso da rota do TCAU) devem ser duplicadas para o processamento paralelo dos dois tipos de combustível. Todas as etapas subseqüentes do processo de produção do combustível $\mathrm{UO}_{2}-\mathrm{Gd}_{2} \mathrm{O}_{3}$ podem ser realizadas na mesma linha de produção do combustível $\mathrm{UO}_{2}$ puro. Isto é importante por óbvias razões econômicas. Dessa forma, basicamente a mesma linha de produção pode fabricar de forma integrada os dois tipos de combustíveis.

De forma resumida, pode-se dizer que nos processos de fabricação comerciais o $\mathrm{Gd}_{2} \mathrm{O}_{3}$ é incorporado ao $\mathrm{UO}_{2}$ na forma de mistura mecânica de pós. No caso dos processos de conversão aquosa via DUA e em todos os processos de conversão via seca, esta mistura é efetuada em conjunto com uma moagem, ou, melhor dizendo, por meio de comoagèm. Esta comoagem normalmente é realizada a seco, mas também pode ser efetuada com a presença de um meio líquido, seguida por uma secagem. No caso do processo de conversão aquosa via TCAU, o pó de $\mathrm{Gd}_{2} \mathrm{O}_{3}$ é adicionado ao pó de $\mathrm{UO}_{2}$ na etapa de homogeneização, preparando-se inicialmente uma mistura matriz na proporção de $1: 1^{(\mathbf{*})}$ e, posteriormente, ajustando-se a composição requerida. Devido à boa escoabilidade do pó de $\mathrm{UO}_{2}$ proveniente da conversão via TCAU, lotes de até $2000 \mathrm{~kg}$ podem ser homogeneizados, em concentrações de até $20 \%$ em peso de $\mathrm{Gd}_{2} \mathrm{O}_{3}{ }^{(158)}$. Segundo Assmann et al ${ }^{(68)}$ até mesmo a etapa de preparação da mistura matriz pode ser omitida. No processo de conversão a seco IDR, devido à alta sinterabilidade do pó de $\mathrm{UO}_{2}$ que pode ser obtido por meio de um adequado controle do processo de conversão, pode-se eliminar a etapa de comoagem e obter-se uma boa homogeneidade entre os pós de $\mathrm{UO}_{2}$ e $\mathrm{Gd}_{2} \mathrm{O}_{3}$ apenas por meio de mistura mecânica com a preparação de mistura matriz. Contudo, na maioria dos casos se faz necessária a etapa de pré-compactação e granulação ${ }^{(95)}$. 
Nos casos necessários, a pré-compactação é realizada por meio de compressão isostática, seguida de desagregação e peneiramento. São obtidos grânulos de tamanho menor que $1 \mathrm{~mm}$. A compactação das pastilhas $\mathrm{UO}_{2}-\mathrm{Gd}_{2} \mathrm{O}_{3}$ é realizada no mesmo equipamento utilizado no caso de pastilhas de $\mathrm{UO}_{2}$ puro, utilizando-se um aditivo lubrificante (estearato de zinco) ou uma fina camada de óleo aplicada na cavidade da matriz de compactação. A compressão é uniaxial e a mesma pressão de compactação utilizada para o combustível $\mathrm{UO}_{2}$ também é utilizada para a compactação de pastilhas $\mathrm{UO}_{2}-\mathrm{Gd}_{2} \mathrm{O}_{3}$. A densidade obtida nas pastilhas compactadas (ou "a verde") de ambos os tipos de combustível é de aproximadamente $50 \%$ da densidade teórica.

Além destes processos comerciais, outras técnicas de preparação do combustível $\mathrm{UO}_{2}-\mathrm{Gd}_{2} \mathrm{O}_{3}$ são utilizadas. O método de coprecipitação é bastante utilizado em escala de laboratório para a preparação de amostras sinterizadas com alto grau de homogeneidade na distribuição de $\mathrm{Gd}_{2} \mathrm{O}_{3}{ }^{(96)}$. Neste método, pó de $\mathrm{U}_{3} \mathrm{O}_{8}{ }^{(47,97,98)}$ ou $\mathrm{UO}_{2}{ }^{(52)}$ e pó de $\mathrm{Gd}_{2} \mathrm{O}_{3}$ na proporção desejada são dissolvidos em $\mathrm{HNO}_{3}$. A partir da mistura de nitratos, é realizada a precipitação por meio da adição de uma solução de $\mathrm{NH}_{4} \mathrm{OH}$. O precipitado obtido é, então, calcinado ao ar sob temperatura de $400{ }^{\circ} \mathrm{C}$ e, finalmente, o pó calcinado é reduzido a 800 ${ }^{\circ} \mathrm{C}$ por 4 horas ${ }^{(47)}$ ou $900^{\circ} \mathrm{C}$ por 3 horas ${ }^{(52)}$ sob atmosfera redutora de $\mathrm{H}_{2}$, resultando no pó de $\mathrm{UO}_{2}-\mathrm{Gd}_{2} \mathrm{O}_{3}$.

O método sol-gel ${ }^{(99)}$ também pode ser utilizado na preparação do combustível $\mathrm{UO}_{2}-\mathrm{Gd}_{2} \mathrm{O}_{3}$. Por meio deste método é possível a obtenção de microesferas de $\mathrm{UO}_{2} \mathrm{e}$ outros compostos a base de urânio com diâmetro controlado ${ }^{(\mathbf{1 0 0 , 1 0 1 )}}$. O processo sol-gel é muito utilizado na fabricação de combustíveis para reatores de alta temperatura HTR (High Temperature Reactor), os quais empregam microesferas de $(\mathrm{U}, \mathrm{Th}) \mathrm{O}_{2}, \mathrm{UC}_{2}$ e $\mathrm{ThO}_{2}$ (102-105) O processo sol-gel também é importante no processamento de combustívieis reprocessados (reaproveitamento de combustíveis já irradiados), uma vez que é mais facilmente operável remotamente e diminui a geração de poeiras, resultando em menores níveis de radiação e menor exposição dos operadores ${ }^{(\mathbf{1 0 6})}$. O método sol-gel também tem sido estudado como alternativa para obtenção do combustível $(\mathrm{U}, \mathrm{Pu}) \mathrm{O}_{2}$ utilizado nos reatores rápidos regeneradores refrigerados a metal liquido LMFBR (Liquid Metal Fast Breeder Reactor) ${ }^{\mathbf{( 1 0 7 )}}$. No caso do combustível (U,Gd) $\mathrm{O}_{2}$, o método sol-gel também tem sido aplicado, permitindo a obtenção de amostras sinterizadas com elevada densidade ${ }^{(108,109)}$.

A especificação imposta para o combustível $\mathrm{UO}_{2}-\mathrm{Gd}_{2} \mathrm{O}_{3}$ é basicamente a mesma imposta para o combustível padrão $\mathrm{UO}_{2}$, acrescida de alguns itens que são específicos para o combustível $\mathrm{UO}_{2}-\mathrm{Gd}_{2} \mathrm{O}_{3}$ ou com algumas modificações em itens que são alterados pela presença de $\mathrm{Gd}_{2} \mathrm{O}_{3}$ e que dependem da concentração presente no combustível. Uma especificação para o pó de $\mathrm{Gd}_{2} \mathrm{O}_{3}$ utilizado também é imposta. Essas especificações 
variam de acordo com o fabricante. Exemplos de especificações típicas podem ser obtidos na literatura ${ }^{(11,68,95)}$.

As maiores diferenças entre as especificações dos combustíveis $\mathrm{UO}_{2}$ padrão e $\mathrm{UO}_{2}-\mathrm{Gd}_{2} \mathrm{O}_{3}$ residem na razão $\mathrm{O} / \mathrm{U}$, densidade e distribuição de fases nas pastilhas sinterizadas. Essas especificações variam, muitas vezes consideravelmente, de acordo com o fabricante. A razão $\mathrm{O} / \mathrm{U}$ evidentemente depende da concentração de $\mathrm{Gd}_{2} \mathrm{O}_{3}$ presente no combustível. Ela é especificada por Assmann et al ${ }^{(\mathbf{6 8 )}}$ como (válida até $12 \%$ em peso de $\left.\mathrm{Gd}_{2} \mathrm{O}_{3}\right)$ :

$$
\mathrm{O} / \mathrm{U}=\left(2,000+0,008 . \% \text { em peso de } \mathrm{Gd}_{2} \mathrm{O}_{3}\right) \pm 0,015
$$

Outras especificações para a razão $\mathrm{O} / \mathrm{U}$ ou $\mathrm{O} / \mathrm{M}$, apresentadas nas referências (11) e (95), são:

$$
\begin{gathered}
\mathrm{O} / \mathrm{U}=2,020 \pm 0,045 \\
\mathrm{O} /(\mathrm{U}+\mathrm{Gd})=2,00 \pm 0,02
\end{gathered}
$$

A densidade das pastilhas $\mathrm{UO}_{2}-\mathrm{Gd}_{2} \mathrm{O}_{3}$ sinterizadas é especificada por Assmann et al $^{(68)}$ como (válida para concentrações de até $12 \%$ em peso de $\mathrm{Gd}_{2} \mathrm{O}_{3}$ ):

$$
\rho=\rho_{o}-0,04 . \% \mathrm{Gd}_{2} \mathrm{O}_{3} \quad(+0,15 /-0,20) \mathrm{g} / \mathrm{cm}^{3}
$$

onde $\rho$ é a densidade especificada para o $\mathrm{UO}_{2}-\mathrm{Gd}_{2} \mathrm{O}_{3}$ e $\rho_{\mathrm{o}}$ é a densidade teórica do $\mathrm{UO}_{2}$ puro.

Outras especificações para a densidade das pastilhas sinterizadas, apresentadas nas referências (11) e (95), são:

$$
\frac{\rho}{\rho h}=95(+1 /-1,5) \%
$$

onde:

$$
\rho_{h h}=\frac{100}{\%_{\rho_{h} \mathrm{Gd}_{2}} \frac{\mathrm{O}_{3}}{\mathrm{O}_{3}}}+\frac{\% \mathrm{UO}_{2}}{\rho_{m} \mathrm{U} \mathrm{O}_{2}}
$$

e:

ph $\mathrm{Gd}_{2} \mathrm{O}_{3}=$ densidade teórica do $\mathrm{Gd}_{2} \mathrm{O}_{3}$.

$\rho_{h h} \mathrm{UO}_{2}=$ densidade teórica do $\mathrm{UO}_{2}$. 
A distribuição das fases $\mathrm{Gd}_{2} \mathrm{O}_{3}$ pura e $\mathrm{UO}_{2}$ presentes nas pastilhas sinterizadas deve obedecer à seguinte especificação:

$$
\text { Segundo Assmann et al }{ }^{(\mathbf{6 8})} \text { : }
$$

- $\mathrm{Gd}_{2} \mathrm{O}_{3}$ livre $\leq 15 \%$ em peso,

- $\mathrm{UO}_{2}$ livre $\leq 40 \%$ em peso,

- Óxido Misto (U,Gd) $\mathrm{O}_{2} \geq 60 \%$ em peso,

- Tamanho médio de partícula de $\mathrm{Gd}_{2} \mathrm{O}_{3}$ livre $\leq 220 \mu \mathrm{m}$,

- Tamanho médio de partícula de $\mathrm{UO}_{2}$ livre $\leq 1000 \mu \mathrm{m}$,

Segundo a referência (11):

- $\mathrm{Gd}_{2} \mathrm{O}_{3}$ livre $<6$ a $15 \%$ em volume,

- Tamanho médio de partícula de $\mathrm{UO}_{2}$ livre $<30$ a $1000 \mu \mathrm{m}$,

- Tamanho médio de partícula de $\mathrm{Gd}_{2} \mathrm{O}_{3}$ livre $<10$ a $200 \mu \mathrm{m}$,

Segundo a referência (95):

- Partículas de $\mathrm{Gd}_{2} \mathrm{O}_{3}$ livre com tamanho superior a $10 \mu \mathrm{m}$ devem representar menos do que $2,5 \%$ da massa de $\mathrm{Gd}_{2} \mathrm{O}_{3}$ presente no combustível.

\subsection{Problemática da sinterização do combustível $\mathrm{UO}_{2}-\mathrm{Gd}_{2} \mathrm{O}_{3}$}

Como pode ser observado nos fluxogramas apresentados na figura 4 , técnicas de metalurgia do pó são utilizadas no processo de fabricação do combustível a base de $\mathrm{UO}_{2}$, onde a etapa de sinterização é uma das mais importantes. É na sinterização que o pó compactado se transforma num material policristalino denso e resistente, determinando-se as propriedades físicas do produto final de modo a adequá-lo para utilização como combustível nuclear.

Segundo German (110), a "sinterização é um tratamento térmico que promove a ligação de partículas para formar uma estrutura coerente predominantemente sólida por meio de eventos de transporte de massa que freqüentemente ocorrem numa escala atômica. O processo resulta numa melhoria na resistência e num sistema de menor energia". Numa escala microestrutural, a ligação de partículas por sinterização é evidenciada pelo 
crescimento de pescoços nos contatos entre as partículas, o qual ocorre por meio de eventos num nível atômico que eliminam a alta energia superficial associada ao pó.

Em outras palavras, a força motriz da sinterização provém da tendência de um corpo compactado em reduzir sua área superficial, diminuindo a energia livre total do sistema. Num sistema que consiste em superfícies côncavas e convexas, como num corpo de partículas compactadas, ocorrem gradientes de energia na microestrutura que originam transporte de massa. Uma superfície sólida côncava tende a preencher-se e uma superficie sólida convexa tende a aplainar-se. O efeito da sinterização num corpo compactado, o qual consiste numa mistura de poros e partículas, é eliminar a curvatura superficial. Num modelo de sinterização de esferas ${ }^{(110)}$, as partículas são superficies convexas que representam fontes de massa e os poros entre as partículas recebem essa massa para preencher os vazios que têm curvatura côncava. Dessa forma, os pontos de contato entre partículas aumentam à medida que a sinterização prossegue e, a cada contato, cresce um contorno de grão que substitui a interface sólido-vapor, diminuindo a área superficial do sistema.

Devido à sua complexidade, o processo de sinterização é freqüentemente dividido em três estágios seqüenciais, de acordo com as estruturas geométricas desenvolvidas durante o processo. O estágio inicial envolve a formação e crescimento do pescoço, sendo caracterizado pelo aumento da área de contato entre as partículas originais. Neste estágio os pescoços crescem independentemente uns dos outros até que a linha de contato alcance aproximadamente $1 / 3$ do diâmetro da partícula. As partículas de pó originais ainda podem ser distinguíveis e não ocorre a migração dos contornos formados. Os centros das partículas sofrem uma pequena aproximação, mas não ocorre significante densificação no primeiro estágio.

O segundo estágio, ou estágio intermediário da sinterização, é o mais importante em termos de densificação e determina em grande parte as propriedades do corpo sinterizado. Neste estágio, as partículas originais do pó perdem sua identidade e a evolução da estrutura de poros ao redor dos pescoços passa a ser o fenômeno central do processo. $\mathrm{O}$ início do estágio intermediário é caracterizado pela formação de uma rede de poros cilíndricos interconectados (ou canais) localizados nas arestas dos pescoços formados no estágio inicial. Neste estágio ocorre a maior parte da densificação do sistema e a movimentação dos contornos de grão começa a ocorrer. A seção transversal dos poros cilíndricos diminui pela difusão de vacâncias a partir do poro para o contorno de grão. A densificação ocorre por meio de difusão pelo reticulado e pelo contorno de grão e à medida que sinterização prossegue os poros inicialmente interconectados passam a fechar-se. $O$ crescimento de grão torna-se cada vez mais ativo conforme a estrutura de poros vai sendo 
eliminada. O crescimento de grão alonga o poro e a densificação redụz o seu diâmetro, resultando no seu colapso para formação de poros discretos. Idealmente, a rede de poros interconectados torna-se instável quando a porosidade atinge o nível de $8 \%$ em volume. Contudo, na maioria dos materiais, normalmente os poros começam a fechar-se a partir de $15 \%$ em volume e estão totalmente fechados quando a porosidade atinge $5 \%$ em volume ${ }^{(110)}$.

No terceiro estágio, ou estágio final da sinterização, os poros encontram-se isolados nos cantos dos grãos como resultado da evolução da estrutura de poros inicialmente existente no estágio intermediário. Esse estágio é caracterizado como sendo um processo lento onde poros fechados contraem-se por meio de difusão pelo reticulado. Se os poros fechados possuem mobilidade suficiente para permanecer junto com os contornos de grão em movimento, então a densificação continua ocorrendo. Em baixas temperaturas, a taxa de crescimento de grão é pequena e os poros permanecem juntos com o contorno. Contudo, com a elevação da temperatura, o movimento dos contornos de grão torna-se cada vez maior e os poros devem mover-se por difusão no reticulado, difusão superficial ou por meio de mecanismos de vaporização condensação através do poro. Em temperaturas elevadas a taxa de crescimento de grão aumenta a um ponto onde os contornos destacam-se dos poros, deixando-os isolados no interior do grão. Além disto, a diferença na curvatura dos poros conduzem ao crescimento de grandes poros à custa da eliminação de poros pequenos, menos estáveis, de maneira que, com o aquecimento prolongado, o tamanho médio do poro cresce e o número total de poros diminui. Nesse caso, para que o poro seja eliminado, vacâncias devem difundir-se a partir dele até contornos de grão que estão cada vez mais distantes, o que é um processo lento. No caso da existência de gás no interior do poro, o poro cresce para diminuição da pressão interna, o que pode causar uma diminuição da densidade, ou inchamento, caso o estágio final da sinterização seja muito prolongado.

Na prática, para um aglomerado de pó, não existe uma separação nítida entre os três estágios da sinterização. Contudo, a separação do fenômeno nesses estágios permite a construção de modelos matemáticos que facilitam o estudo da sinterização e o entendimento dos mecanismos envolvidos no processo. Interessantes revisões sobre os mecanismos básicos por meio dos quais ocorre a movimentação de material durante a sinterização estão disponíveis na literatura ${ }^{\text {(III,II2). }}$.

Quanto ao processo de sinterização do combustível $\mathrm{UO}_{2}-\mathrm{Gd}_{2} \mathrm{O}_{3}$, apesar de vários pesquisadores terem publicado dados relativos à densidade final obtida na sinterização de pastilhas $\mathrm{UO}_{2}-\mathrm{Gd}_{2} \mathrm{O}_{3}$, não foram encontrados muitos estudos específicos sobre a sinterização deste sistema. Muitos dos dados publicados apontam para dificuldades na obtenção de pastilhas $\mathrm{UO}_{2}-\mathrm{Gd}_{2} \mathrm{O}_{3}$ com a mínima densidade requerida para uso como 
combustível nuclear, enquanto outros dados revelam uma boa sinterabilidade do sistema, até mesmo melhor do que a observada no combustível $\mathrm{UO}_{2}$ puro.

A figura 5 apresenta as densidades de pastilhas $\mathrm{UO}_{2}-\mathrm{Gd}_{2} \mathrm{O}_{3}$ obtidas por diferentes pesquisadores, para concentrações de $\mathrm{Gd}_{2} \mathrm{O}_{3}$ na faixa de 0 a $12 \%$ em peso. Pode-se observar nesta figura uma ampla variação nos valores de densidade obtidos na sinterização de pastilhas de $\mathrm{UO}_{2}-\mathrm{Gd}_{2} \mathrm{O}_{3}$, desde $85 \%$ da densidade teórica até $99 \%$. Observando-se as linhas que indicam a faixa especificada de densidade (93,5 a $96 \%$ da densidade teórica), verifica-se que muitos dos resultados publicados não atendem às especificações, a maioria deles na direção de densidades abaixo da mínima especificada para o combustível $\mathrm{UO}_{2}$ $\mathrm{Gd}_{2} \mathrm{O}_{3}$. Observa-se também que, em geral, mesmo pequenas adições de $\mathrm{Gd}_{2} \mathrm{O}_{3}$ já produzem um efeito negativo significativo na sinterabilidade do $\mathrm{UO}_{2}$.

A escassez de informação sobre os detalhes dos procedimentos de preparação das amostras, em termos de método de incorporação do $\mathrm{Gd}_{2} \mathrm{O}_{3}$, condicionamento do pó misto e condições de compactação e sinterização, dificultam a interpretação e discussão dos resultados de sinterização publicados. Nos trabalhos consultados, as variações no ciclo de sinterização, na superficie específica dos pós e na atmosfera de sinterização, tornam impraticável uma análise conclusiva do comportamento da sinterização do sistema $\mathrm{UO}_{2}-$ $\mathrm{Gd}_{2} \mathrm{O}_{3}$ a partir dos dados apresentados. Contudo, uma análise genérica pode ser conduzida a partir dos dados publicados, apresentados na figura 5, e algumas observações merecem ser enumeradas.

Pode-se observar na figura 5 que as amostras preparadas por meio de mistura mecânica dos pós de $\mathrm{UO}_{2}$ e $\mathrm{Gd}_{2} \mathrm{O}_{3}$ apresentam geralmente baixas densidades após a sinterização, abaixo da mínima especificada. Este é o caso dos resultados obtidos por Assmann et al ${ }^{(68)}$ e Davis e Potter ${ }^{(13)}$. Contudo, os resultados publicados por Agueda, Heredia, Amaya, Sterba e Russo ${ }^{(114)}$ obtidos em amostras preparadas por comoagem, utilizando-se pó de $\mathrm{UO}_{2}$ com alta superficie específica, também indicam baixas densidades. Apesar das altas densidades obtidas por Une e Oguma ${ }^{(72)}$ para concentrações de $\mathrm{Gd}_{2} \mathrm{O}_{3}$ de até $10 \%$ em peso em amostras preparadas por mistura mecânica, pode-se observar uma tendência de diminuição da densidade com o aumento da concentração de $\mathrm{Gd}_{2} \mathrm{O}_{3}$.

Em geral, os dados publicados obtidos a partir de amostras preparadas por comoagem dos pós de $\mathrm{UO}_{2}$ e $\mathrm{Gd}_{2} \mathrm{O}_{3}$ indicam uma melhor sinterabilidade quando comparada à obtida em pós preparados por mistura mecânica, resultando em densidades dentro da faixa especificada. Este é o caso dos resultados obtidos por Littlechild et al ${ }^{(45)} \mathrm{e}$ Agueda et al ${ }^{\text {(I14) }}$ (no caso de utilização de pó de $\mathrm{UO}_{2}$ com menor superfície específica). 
Neste caso, o resultado obtido por Ho e Radford ${ }^{(40)}$ em amostras preparadas por comoagem, o qual aponta para densidades extremamente altas, teria que ser considerado uma exceção.

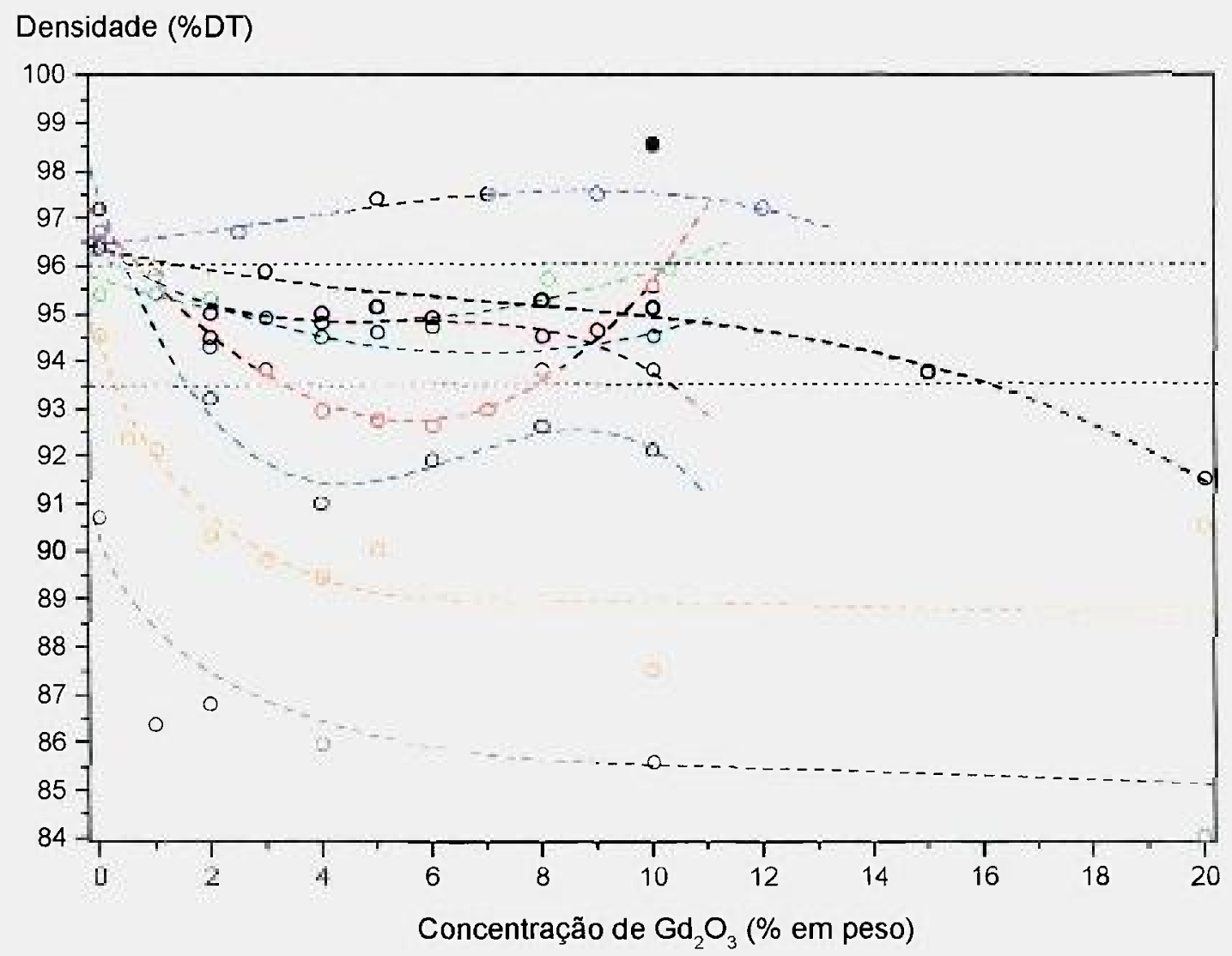

\begin{tabular}{|c|c|c|c|c|c|}
\hline & Referência & $\begin{array}{c}\text { Ciclo de } \\
\text { Sinterização }\end{array}$ & $\begin{array}{c}\text { B.E.T } \\
\text { UO } \\
\left(\mathrm{m}^{2} / \mathrm{g}\right)\end{array}$ & $\begin{array}{c}\text { Atmosfera } \\
\text { de Sinterização }\end{array}$ & $\begin{array}{l}\text { Processo de } \\
\text { Incorporação } \\
\text { de } \mathrm{Gd}_{2} \mathrm{O}_{3}\end{array}$ \\
\hline - & Hirai $^{(115)}$ & $1650^{\circ} \mathrm{C} / 4 \mathrm{~h}$ & N:I & $\mathrm{N}_{2} / 8 \% \mathrm{H}_{2} / \mathrm{H}_{2} \mathrm{O}$ & Coprecipitação \\
\hline-.0 & Fukushima et al ${ }^{(47)}$ & $1750^{\circ} \mathrm{C} / 4 \mathrm{~h}$ & N.I. & $\operatorname{Ar} / 8 \% \mathrm{H}_{2} / \mathrm{H}_{2} \mathrm{O}$ & Coprecipitação \\
\hline$-\mathrm{O}-$ & Ho e Radford ${ }^{(40)}$ & $1750^{\circ} \mathrm{C} / 6 \mathrm{~h}$ & 3,50 & $\mathrm{H}_{2} / \mathrm{H}_{2} \mathrm{O}$ & Comoagem \\
\hline-0 & Littlechild et al ${ }^{(45)}$ & $1620^{\circ} \mathrm{C} / 3 \mathrm{~h}$ & 1,60 & $\mathrm{H}_{2}$ puro & Comoagem \\
\hline$-0-$ & Agueda et al ${ }^{(114)}$ & $1700^{\circ} \mathrm{C} / 2 \mathrm{~h}$ & 6,65 & $\mathrm{H}_{2}$ puro & Comoagem \\
\hline$-\mathrm{O}-$ & Agueda et al $^{(114)}$ & $1700^{\circ} \mathrm{C} / 2 \mathrm{~h}$ & 4,37 & $\mathrm{H}_{2}$ puro & Comoagem \\
\hline$-0-$ & Assmann et $\mathrm{al}^{(68)}$ & $1750^{\circ} \mathrm{C} / 2 \mathrm{~h}$ & N.I. & $\mathrm{H}_{2}$ puro & Mistura Mecânica \\
\hline-6 & Davis e Potter ${ }^{(113)}$ (DUA) & $1650^{\circ} \mathrm{C} / 4 \mathrm{~h}$ & 3,94 & $\mathrm{~N}_{2} / 6 \% \mathrm{H}_{2}$ & Mistura Mecânica \\
\hline$-\mathrm{O}-$ & Davis e Potter ${ }^{(113)}$ (TCAU) & $1650^{\circ} \mathrm{C} / 4 \mathrm{~h}$ & N.I. & $\mathrm{N}_{2} / 6 \% \mathbb{H}_{2}$ & Mistura Mecânica \\
\hline$-0-$ & Une e Oguma $^{(72)}$ & $1700^{\circ} \mathrm{C} / 2 \mathrm{~h}$ & 3,10 & $\mathrm{H}_{2}$ puro & Mistura Mecânica \\
\hline
\end{tabular}

N.I. - Não Informado.

Figura 5 - Densidades de pastilhas $\mathrm{UO}_{2}-\mathrm{Gd}_{2} \mathrm{O}_{3}$ obtidas por diferentes pesquisadores. 
As amostras preparadas por coprecipitação dos nitratos mistos com hidróxido de amônio e posterior redução com hidrogênio demonstram alta sinterabilidade, resultando em densidades muito elevadas. Neste caso, o aumento da concentração de $\mathrm{Gd}_{2} \mathrm{O}_{3}$ na mistura aparentemente conduz ao aumento nas densidades obtidas após a sinterização. Este é o caso dos resultados obtidos por Hirai ${ }^{(115)}$ e Fukushima et al ${ }^{(47)}$.

O potencial de oxigênio da atmosfera de sinterização também poderia ser uma das causas para a grande dispersão dos resultados apresentados na figura 5. É conhecido que o aumento do potencial de oxigênio da atmosfera de sinterização aumenta a sinterabilidade do $\mathrm{UO}_{2}$ puro, deslocando a sinterização na direção de menores temperaturas e aumentando, ainda que ligeiramente, a densidade final obtida. Isto é causado pela formação de cátions $\mathrm{U}^{5+}$ de menor raio iônico, o que aumenta a difusividade do sistema ${ }^{(40)}$. Essa observação foi comprovada por Yuda e Une ${ }^{(116)}$. Neste trabalho, estes pesquisadores publicaram também os resultados obtidos com pastilhas de $\mathrm{UO}_{2}-\mathrm{Gd}_{2} \mathrm{O}_{3}$ contendo 5 e $10 \%$ em peso de $\mathrm{Gd}_{2} \mathrm{O}_{3}$, preparadas por comoagem. Os dados indicam que, como no caso do $\mathrm{UO}_{2}$ puro, o aumento do potencial de oxigênio da atmosfera de sinterização aumenta a densidade final obtida. Contudo, acima de um determinado potencial de oxigênio, o qual é característico para determinada concentração de $\mathrm{Gd}_{2} \mathrm{O}_{3}$, a densidade final obtida diminui drasticamente. $\mathrm{O}$ aumento da densidade final obtida com o aumento do potencial de oxigênio é da ordem de, no máximo, $1 \%$ da densidade teórica, para atmosfera de $\mathrm{CO} / \mathrm{CO}_{2}$ com a razão entre as pressões parciais de $\mathrm{CO}_{2}$ e $\mathrm{CO}$ de $0,04\left(\mathrm{P}_{\mathrm{CO} 2} / \mathrm{P}_{\mathrm{CO}}=0,04\right)$. Para atmosferas mais oxidantes, o efeito é contrário e o aumento do potencial de oxigênio causa uma significativa redução na densidade final obtida, podendo chegar a aproximadamente $7 \%$ da densidade teórica (116). Como as variações de densidade observadas nos dados da figura 5 são muito mais significativas do que as que poderiam ser causadas por variações no potencial de oxigênio, esta não deve ser a explicação para a discrepância dos resultados de sinterização. Além disto, nenhum pesquisador menciona especificamente a utilização de atmosfera oxidante no seu trabalho.

Com base nestas observações, pode-se concluir, ainda que com reservas, que o método de preparação das amostras $\mathrm{UO}_{2}-\mathrm{Gd}_{2} \mathrm{O}_{3}$ é quem primariamente influencia a sinterabilidade do sistema e, por conseguinte, a densidade final obtida na sinterização. Aparentemente, amostras preparadas por coprecipitação, comoagem e mistura mecânica dos pós apresentam, nesta ordem, densidades sinterizadas decrescentes. Uma conclusão mais segura quanto a este aspecto fica dificultada, uma vez que os detalhes do procedimento de comoagem não são fornecidos, o que poderia explicar os resultados contraditórios obtidos por Ho e Radford quando comparados aos resultados obtidos pelos outros pesquisadores que utilizaram a comoagem. $O$ mesmo se aplica aos resultados obtidos por coprecipitação, uma vez que os pesquisadores que utilizaram este método de 
preparação de amostras não forneceram os valores da superfície específica dos pós. As maiores densidades obtidas por Assmann et al nas amostras preparadas por mistura mecânica, quando comparadas às obtidas por Davis e Potter, poderiam ser explicadas pela maior temperatura de sinterização utilizada.

Um aspecto interessante chama a atenção nos resultados obtidos por Agueda et al ${ }^{(114)}$, os quais utilizaram pós de $\mathrm{UO}_{2}-\mathrm{Gd}_{2} \mathrm{O}_{3}$ com diferentes superfícies específicas. $\mathrm{O}$ pó com maior superficie específica $\left(6,65 \mathrm{~m}^{2} / \mathrm{g}\right)$ apresentou menores densidades após a sinterização do que o pó com menor superfície específica $\left(4,37 \mathrm{~m}^{2} / \mathrm{g}\right)$. Como as condições de sinterização e medição da densidade das pastilhas foram mantidas rigorosamente iguais, este resultado pode ser considerado inconsistente, uma vez que, mantidas as condições de sinterização, a sinterabilidade deve ser diretamente proporcional à superficie específica, ou atividade, do pó.

Manzel e Dörr ${ }^{(\mathbf{4 6 )}}$ publicaram resultados obtidos por dilatometria na sinterização de uma pastilha de $\mathrm{UO}_{2}-\mathrm{Gd}_{2} \mathrm{O}_{3}$ preparada por mistura mecânica de pós e contendo $4 \% \mathrm{em}$ peso de $\mathrm{Gd}_{2} \mathrm{O}_{3}$. Seus resultados, apresentados na figura 6, mostram que os dois tipos de combustível, $\mathrm{UO}_{2}$ e $\mathrm{UO}_{2}-\mathrm{Gd}_{2} \dot{\mathrm{O}}_{3}$, apresentam um comportamento totalmente diferente na sinterização. Comparando-se as curvas de densificação do $\mathrm{UO}_{2}$ puro e do $\mathrm{UO}_{2}-\mathrm{Gd}_{2} \mathrm{O}_{3}$ observa-se que a incorporação do $\mathrm{Gd}_{2} \mathrm{O}_{3}$ prolonga o processo de sinterização e a densidade final obtida é menor do que a observada para o $\mathrm{UO}_{2}$ puro. Pode- se verificar nas curvas de taxa de retração que as cinéticas de sinterização são completamente diferentes. Até a temperatura aproximada de $1200{ }^{\circ} \mathrm{C}$, na fase inicial da sinterização, a cinética de sinterização pode ser considerada a mesma para ambos os tipos de combustível. Acima desta temperatura, a retração da pastilha $\mathrm{UO}_{2}-\mathrm{Gd}_{2} \mathrm{O}_{3}$ é bloqueada, diminuindo a taxa de retração e deslocando a densificação na direção de maiores temperaturas. Observa-se também que a densidade final obtida na pastilha $\mathrm{UO}_{2}-\mathrm{Gd}_{2} \mathrm{O}_{3}$ é reduzida quando comparada com a pastilha de $\mathrm{UO}_{2}$ puro. A forma da curva de retração mostra que mesmo o aumento do tempo de sinterização não pode compensar esta redução na densidade final obtida.

Yuda e Une ${ }^{(116)}$ também publicaram curvas de densificação de pastilhas $\mathrm{UO}_{2}$ $\mathrm{Gd}_{2} \mathrm{O}_{3}$ obtidas por dilatometria. Os resultados obtidos tanto para pastilhas de $\mathrm{UO}_{2}$ puro como para pastilhas de $\mathrm{UO}_{2}-\mathrm{Gd}_{2} \mathrm{O}_{3}$ foram comparáveis aos obtidos por Manzel e Dörr ${ }^{(46)}$. Yuda e Une utilizaram pós preparados por comoagem e variaram o potencial de oxigênio da atmosfera de sinterização, o que ampliou significativamente a base de dados sobre a sinterização do sistema $\mathrm{UO}_{2}-\mathrm{Gd}_{2} \mathrm{O}_{3}$. Um resumo de seus resultados, obtidos para uma amostra contendo $5 \%$ em peso de $\mathrm{Gd}_{2} \mathrm{O}_{3}$ e para os casos extremos de potencial de oxigênio da atmosfera de sinterização, estão apresentados na figura 7 . 

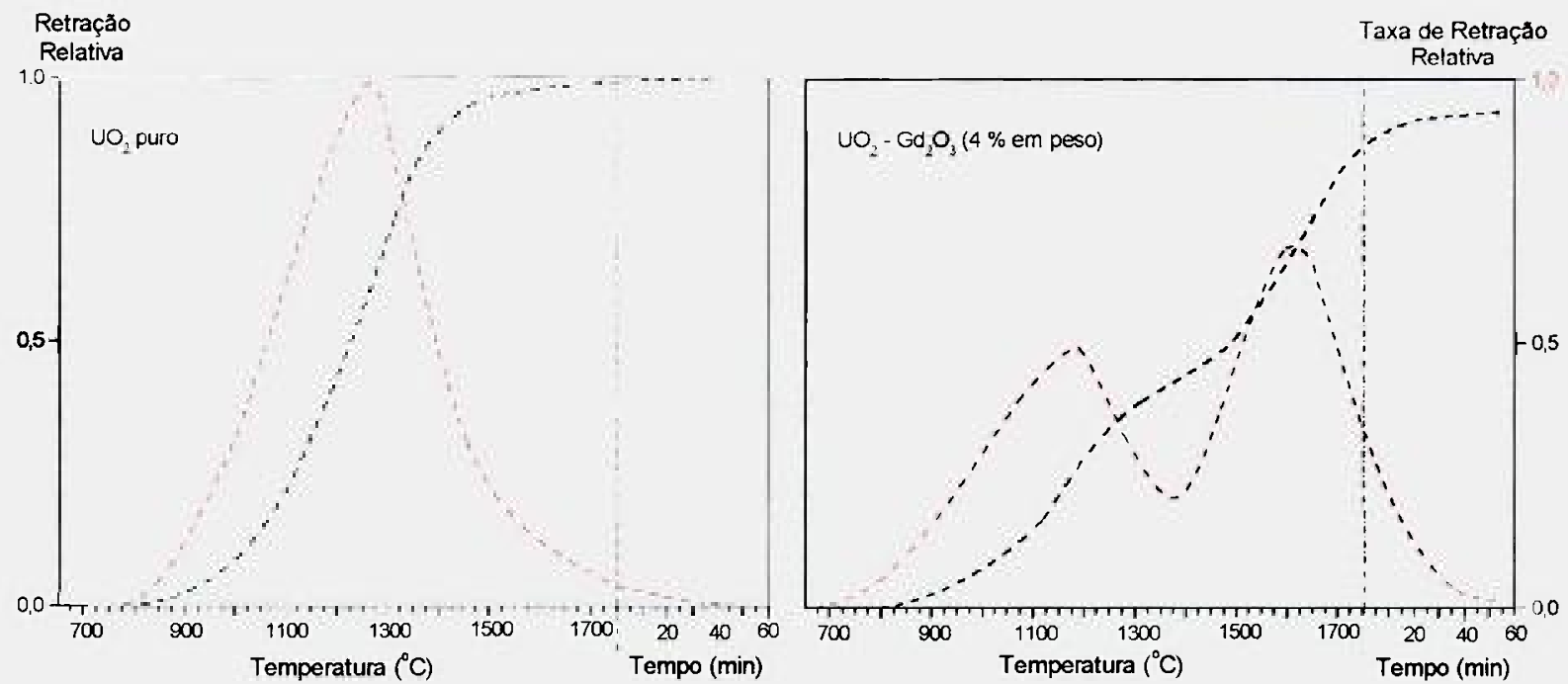

Figura 6 - Curvas de sinterização obtidas por Manzel e Dörr ${ }^{(* 6)}$ para:
A: $\mathrm{UO}_{2}$ puro e $\mathrm{B}$ : $\mathrm{UO}_{2}-\mathrm{Gd}_{2} \mathrm{O}_{3}$
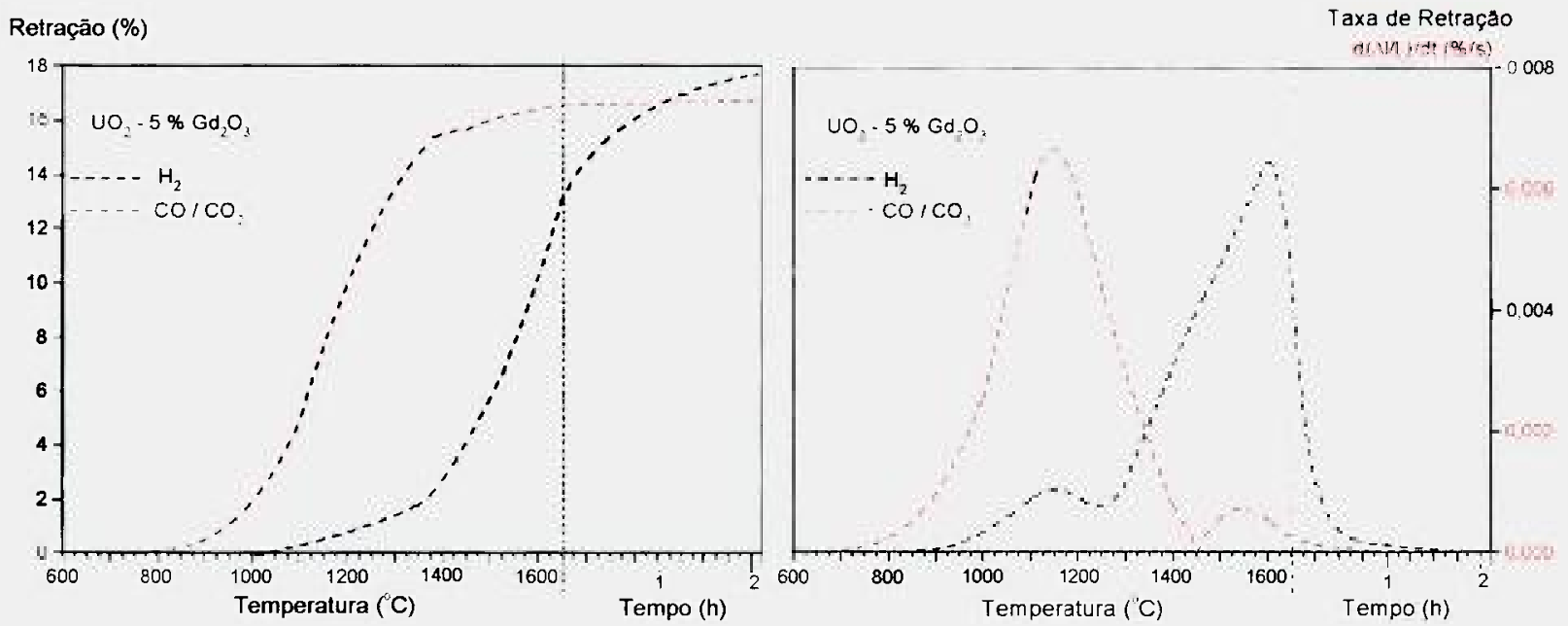

Figura 7 - Curvas de sinterização obtidas por Yuda e Une ${ }^{(116)}$ para $\mathrm{UO}_{2}-\mathrm{Gd}_{2} \mathrm{O}_{3}(5 \%$ em peso) em atmosferas redutora e oxidante.

Pode-se observar na figura 7 que a forma das curvas de retração e taxa de retração obtida sob atmosfera redutora $\left(\mathrm{H}_{2}\right)$ são similares às obtidas por Manzel e Dörr, apresentadas na figura 6 , mostrando também 2 picos na taxa de retração, evidenciando-se um bloqueio na sinterização, a qual parece ocorrer em duas etapas. A diferença básica consiste na altura do primeiro pico da curva da taxa de retração, o que poderia ser explicado por diferenças nas taxas de aquecimento adotadas nos testes. Yuda e Une 
utilizaram $7{ }^{\circ} \mathrm{C} / \mathrm{min}$, mas Manzel e Dörr não informaram a taxa de aquecimento utilizada no seu teste dilatométrico. $\mathrm{O}$ aumento do potencial de oxigênio da atmosfera de sinterização aumenta a densificação na primeira fase de sinterização do sistema $\mathrm{UO}_{2}$ $\mathrm{Gd}_{2} \mathrm{O}_{3}$, deslocando o primeiro pico da curva de taxa de retração para menores temperaturas e ampliando a integral de densificação na primeira etapa da sinterização. Neste caso, passada a primeíra etapa de sinterização, a taxa de retração é diminuída até ficar nula na temperatura de aproximadamente $1450^{\circ} \mathrm{C}$, quando a densificação volta a ocorrer, porém apenas ligeiramente.

Curvas de sinterização obtidas a partir de pós $\mathrm{UO}_{2}-\mathrm{Gd}_{2} \mathrm{O}_{3}$ preparados por coprecipitação não estão disponíveis na literatura. Contudo, comparando-se as curvas de sinterização obtidas por Manzel e Dörr em amostras preparadas por meio de mistura mecânica (figura 6) e as obtidas por Yuda e Une em amostras preparadas por comoagem (figura 7 para atmosfera redutora), pode-se observar que o método de preparação do pó misto parece influenciar a proporção de densificação relativa a cada uma das etapas de sinterização. Nas amostras obtidas por comoagem a densificação na primeira etapa é bem menor, sendo compensada por uma maior densificação na segunda etapa da sinterização. De qualquer modo, como os resultados de densidade apresentados na figura 5 , estas curvas de sinterização também indicam uma grande influência do método de preparação do pó misto na cinética de sinterização do sistema $\mathrm{UO}_{2}-\mathrm{Gd}_{2} \mathrm{O}_{3}$.

Assim como os resultados de densificação durante a sinterização do sistema $\mathrm{UO}_{2}$ $\mathrm{Gd}_{2} \mathrm{O}_{3}$ são discrepantes e contraditórios, assim também são os mecanismos propostos para explicar o comportamento da sinterização neste sistema. As proposições, muitas vezes bastante superficiais, são formuladas de acordo com os resultados obtidos e, como estes são contraditórios, assim também são os mecanismos propostos.

Une e Oguma ${ }^{(72)}$ racionalizam o comportamento da sinterização do sistema $\mathrm{UO}_{2}$ $\mathrm{Gd}_{2} \mathrm{O}_{3}$ por analogia ao sistema $\mathrm{UO}_{2}-\mathrm{PuO}_{2}$. Segundo estes pesquisadores, sob atmosfera redutora de sinterização, o sistema $\mathrm{UO}_{2}-\mathrm{Gd}_{2} \mathrm{O}_{3}$ torna-se hipoestequiométrico para compensar eletricamente a incorporação de cátions $\mathrm{Gd}^{3+}$ na rede cristalina, formando-se vacâncias de oxigênio, segundo o modelo 1 proposto por Ho e Radford ${ }^{\text {(4) }}$ (ver item 1.3.1). Nestas condições, como no caso do sistema $\mathrm{UO}_{2}-\mathrm{PuO}_{2}$, a difusividade dos cátions no sistema $\mathrm{UO}_{2}-\mathrm{Gd}_{2} \mathrm{O}_{3}$ diminui drasticamente com a hipoestequiometria, o que causa a diminuição da sinterabilidade do sistema. Davis e Potter (1/3) também atribuem as baixas densidades obtidas na sinterização do sistema $\mathrm{UO}_{2}-\mathrm{Gd}_{2} \mathrm{O}_{3}$ à hipoèstequiometria causada pela substituição do cátion $\mathrm{U}^{4+}$ pelo cátion $\mathrm{Gd}^{3+}$, o que diminui a mobilidade dos cátions e, por conseguinte, a sinterização do sistema. 
Em contraposição a esta explicação, Ho e Radford ${ }^{(40)}$ explicam seus resultados com base na formação de vacâncias de oxigênio e oxidação de cátions $\mathrm{U}^{4+}$. Segundo estes pesquisadores, a compensação de cargas devido à incorporação de cátions $\mathrm{Gd}^{3+}$ na rede cristalina do $\mathrm{UO}_{2}$ é realizada pela formação de vacâncias de oxigênio e oxidação de cátions $\mathrm{U}^{4+}$ para $\mathrm{U}^{5+}$ e/ou $\mathrm{U}^{6+}$. No caso de pequenas adições de $\mathrm{Gd}_{2} \mathrm{O}_{3}$, é formada uma solução sólida diluída na qual os defeitos formados para compensação de carga (vacâncias e oxidação de cátions) estão amplamente separados e o impacto da adição não é significativo. Acima de um determinado nível de $\mathrm{Gd}_{2} \mathrm{O}_{3}$ adicionado, a oxidação do cátion $\mathrm{U}^{4+}$ para $\mathrm{U}^{5+}$ e $\mathrm{U}^{6+}$, de menores raios iônicos, promove uma difusão mais rápida, resultando na obtenção de altas densidades. Sob atmosfera altamente redutora $\left(\mathrm{H}_{2}\right.$ seco), a formação de vacâncias de oxigênio, ao contrário do que propõe Une e Oguma ${ }^{(72)}$, é a responsável principal pelo aumento na difusividade iônica no sistema, conduzindo a altas densidades. Acima de um nível crítico de $\mathrm{Gd}_{2} \mathrm{O}_{3}$ (em torno de $8 \% \mathrm{em}$ peso) a difusividade é inibida devido à associação de cátions $\mathrm{Gd}^{3+}$ com cátions $\mathrm{U}^{5+}$ ou $\mathrm{U}^{6+}$, formando-se complexos localizados que não permitem a rápida difusão dos cátions, uma vez que somente podem se movimentar cooperativamente, portanto de baixa mobilidade, diminuindo a difusividade e a sinterabilidade. Ainda segundo Ho e Radford, o aumento do potencial de oxigênio diminui a concentração de vacâncias de oxigênio e forma oxigênio intersticial, o que contrabalanceia a formação dos cátions de menor diâmetro $\left(\mathrm{U}^{5+} \mathrm{e} \mathrm{U}^{6+}\right)$, resultando numa menor difusividade e, portanto, sinterabilidade. Esta é a explicação para a observação das baixas densidades em pastilhas $\mathrm{UO}_{2}-\mathrm{Gd}_{2} \mathrm{O}_{3}$ sinterizadas em atmosferas com maiores potenciais de oxigênio, ou mais oxidantes.

Manzel e Dörr ${ }^{(46)}$ atribuem as menores densidades observadas na sinterização de pastilhas $\mathrm{UO}_{2}-\mathrm{Gd}_{2} \mathrm{O}_{3}$ à formação da solução sólida durante o processo de densificação, de forma simultânea. A densificação é retardada devido ao início da formação da solução sólida acima de $1200^{\circ} \mathrm{C}$. Segundo estes pesquisadores, o processo de interdifusão para formação da solução sólida é o responsável pela diminuição da taxa de sinterização e deslocamento da densificação para maiores temperaturas. Assmann, Pehhs e Roepenack ${ }^{(68)}$ complementam esta proposição mencionando que os coeficientes de difusão no sistema $\mathrm{UO}_{2}-\mathrm{Gd}_{2} \mathrm{O}_{3}$ dependem de uma maneira complexa da relação $\mathrm{U}: \mathrm{Gd}: \mathrm{O}$ nas fases formadas durante a sinterização. Peehs, Dörr, Gradel e Maier ${ }^{(67)}$ detectaram em pastilhas $\mathrm{UO}_{2}$ $\mathrm{Gd}_{2} \mathrm{O}_{3}$ sinterizadas a presença de uma fase $\left(\mathrm{U}_{0,5} \mathrm{Gd}_{0,5}\right) \mathrm{O}_{2}$, sem, contudo, discutir sua possível participação no mecanismo de bloqueio da sinterização. Todos estes pesquisadores estudaram amostras preparadas por mistura mecânica de pós, as quais utilizaram $\mathrm{UO}_{2}$ proveniente do TCAU como material base. Considerando-se as afirmações de que o bloqueio ocorre durante a formação da solução sólida, o coeficiente de difusão depende das fases formadas e da observação da fase $\left(\mathrm{U}_{0,5} \mathrm{Gd}_{0,5}\right) \mathrm{O}_{2}$, pode-se deduzir que a causa proposta para o bloqueio da sinterização no sistema $\mathrm{UO}_{2}-\mathrm{Gd}_{2} \mathrm{O}_{3}$ está relacionada à 
formação de fases de baixa difusividade durante o processo de sinterização, resultando nas baixas densidades observadas.

Yuda e Une ${ }^{(116)}$ propõe que a sinterabilidade do sistema $\mathrm{UO}_{2}-\mathrm{Gd}_{2} \mathrm{O}_{3}$ não pode ser avaliada apenas do ponto de vista da difusividade dos cátions. Segundo estes pesquisadores os dois picos na taxa de sinterização observados nos seus testes dilatométricos com pastilhas $\mathrm{UO}_{2}-\mathrm{Gd}_{2} \mathrm{O}_{3}$ (ver figura 7) correspondem à reação entre partículas adjacentes $\mathrm{UO}_{2}-\mathrm{UO}_{2}$, primeiro pico, e à reação entre partículas $\mathrm{UO}_{2}-\mathrm{Gd}_{2} \mathrm{O}_{3}$, segundo pico. Devido à diferença nas taxas de sinterização entre partículas $\mathrm{UO}_{2}-\mathrm{UO}_{2} \mathrm{e}$ partículas $\mathrm{UO}_{2}-\mathrm{Gd}_{2} \mathrm{O}_{3}$, estes pesquisadores propõe a formação de poros de grande dimensão gerados por variações volumétricas localizadas e não uniformes causadas pela diferença nas taxas de densificação obtidas das reações entre partículas $\mathrm{UO}_{2}-\mathrm{UO}_{2}$ e $\mathrm{UO}_{2}$ $\mathrm{Gd}_{2} \mathrm{O}_{3}$. Estes grandes poros são formados em altas temperaturas pela reação $\mathrm{UO}_{2}-\mathrm{Gd}_{2} \mathrm{O}_{3}$, quando a estrutura de poros já está essencialmente fechada, e são, portanto, de difícil eliminação, permanecendo como poros fechados após o ciclo de sinterização, diminuindo a densidade final do sistema. Em atmosferas oxidantes, a sinterização devido às partículas $\mathrm{UO}_{2}-\mathrm{UO}_{2}$ ocorre mais rapidamente (devido à maior sinterabilidade do sistema $\mathrm{UO}_{2+\mathrm{x}}$ ), $\mathrm{o}$ que resulta numa estrutura de poros ainda mais fechada quando se inicia a reação $\mathrm{UO}_{2}-$ $\mathrm{Gd}_{2} \mathrm{O}_{3}$ e a geração de grandes poros, o que torna sua eliminação ainda mais difícil. Isto explica a drástica diminuição na densidade de pastilhas $\mathrm{UO}_{2}-\mathrm{Gd}_{2} \mathrm{O}_{3}$ sinterizadas sob atmosfera oxidante.

Foram propostas três soluções tecnológicas para as baixas densidades obtidas em pastilhas sinterizadas $\mathrm{UO}_{2}-\mathrm{Gd}_{2} \mathrm{O}_{3}$ preparadas a pàrtir de mistura de pós utilizando pó de $\mathrm{UO}_{2}$ proveniente do TCAU ${ }^{(6)}$. A primeira delas é a sinterização em atmosfera oxiredutora, a qual consiste na sinterização sob atmosfera oxidante de $\mathrm{CO} / \mathrm{CO}_{2}$ ou $\mathrm{CO}_{2}$ em baixas temperaturas $\left(800\right.$ a $1400{ }^{\circ} \mathrm{C}$, dependendo da concentração de $\mathrm{Gd}_{2} \mathrm{O}_{3}$ no combustível) com subseqüente sinterização em atmosfera redutora $\mathrm{H}_{2} / \mathrm{N}_{2}$ ou $\mathrm{NH}_{3} \mathrm{em}$ temperatura superior a $1650^{\circ} \mathrm{C}^{(\mathbf{1 1 7 , 1 1 8})}$ (processo NIKUSI ${ }^{(119)}$ ). A segunda é baseada na formação de uma barreira de difusão ao redor das partículas de $\mathrm{Gd}_{2} \mathrm{O}_{3}$, formada pela fase $\left(\mathrm{Gd}_{0,5} \mathrm{U}_{0,5}\right) \mathrm{O}_{2}$ detectada por Pehhs et al ${ }^{(67)}$, bloqueando, desta forma, a formação da solução sólida, a qual seria a responsável pelo bloqueio da sinterização no sistema $\mathrm{UO}_{2}-$ $\mathrm{Gd}_{2} \mathrm{O}_{3}{ }^{(120,121)}$. Amato et al ${ }^{(122)}$ já estudavam em 1971 a utilização de uma dispersão de microesferas de $\mathrm{Gd}_{2} \mathrm{O}_{3}$, obtidas pelo processo sol-gel, em $\mathrm{UO}_{2}$ como absorvedor queimável homogêneo. As microesferas eram recobertas com Mo para prevenção da formação da solução sólida. A terceira solução tecnológica prevê a dopagem do pó misto $\mathrm{UO}_{2}-\mathrm{Gd}_{2} \mathrm{O}_{3}$ com alumínio na forma de $\mathrm{Al}(\mathrm{OH})_{3}$. A proporção de alumínio adicionado ao pó na etapa de homogeneização é de 5 a 500 ppm, dependendo da concentração de $\mathrm{Gd}_{2} \mathrm{O}_{3}$ adicionada ao combustível ${ }^{(123)}$. Destas opções tecnológicas, a dopagem com alumỉnio foi escolhida 
para implèmentação no processo de produção industrial pela Siemens AG alemã, a qual utiliza o TCAU como matéria prima para a produção do $\mathrm{UO}_{2}{ }^{(68)}$.

\subsection{Objetivos propostos}

Na figura 4, apresentada no item 1.4, comparando-se os processos industriais de fabricação do combustivel $\mathrm{UO}_{2}-\mathrm{Gd}_{2} \mathrm{O}_{3}$, pode-se observar que o processo de conversão aquosa pela rota do tricarbonato de amônio e uranilo, ou TCAU, é a mais atraente em termos de simplicidade. Devido às boàs características de fluidez e atividade do pó de $\mathrm{UO}_{2}$ proveniente do TCAU, as etapas de moagem e granulação podem ser suprimidas. A boa fluidez permite a compactação direta do pó, evitando-se a granulação, e a sua alta atividade permite a eliminação da etapa de moagem, uma vez que o pó como reduzido possui atividade adequada para a sinterização de corpos sólidos com alta densidade. Utilizandose o pó de $\mathrm{UO}_{2}$ proveniente do TCAU para a fabricação do combustível $\mathrm{UO}_{2}-\mathrm{Gd}_{2} \mathrm{O}_{3}$, o pó de $\mathrm{Gd}_{2} \mathrm{O}_{3}$ é adicionado ao pó de $\mathrm{UO}_{2}$ na etapa de homogeneização dos vários lotes de redução, sem nenhuma etapa adicional, mantendo-se o processo tradicional de fabricação de $\mathrm{UO}_{2}$ inalterado. As etapas posteriores de fabricação do combustível, ou seja, a compactação e a sinterização, também permanecem inalteradas, podendo ser utilizados os mesmos procedimentos e equipamentos adotados na fabricação rotineira do combustível $\mathrm{UO}_{2}$ puro.

A simplicidade do processo de fabricação do combustível $\mathrm{UO}_{2}$ pela rota do $\mathrm{TCAU}$ e as comprovadas boas propriedades do combustível obtido conduziram as Indústrias Nucleares do Brásil S.A. - INB à decisão de implantar este processo industrialmente no Brasil. A Unidade II da Fábrica de Elementos Combustiveis - FEC 2 da INB tem capacidade para reconversão de $\mathrm{UF}_{6}$ a $\mathrm{UO}_{2}$ pela rota do TCAU e produção de pastilhas sinterizadas de $\mathrm{UO}_{2}$, com tecnologia alemã. A linha de produção de pastilhas foi concluída em 1998 e comissionada no início de 1999, tendo produzido 20 toneladas de combustível durante 1999 , o que representa $15 \%$ da carga completa do reator PWR ANGRA 2. A linha de produção de pó de $\mathrm{UO}_{2}$, construída integrada fisicamente com a linha de produção de pastilhas, foi concluída em 1999 e está atualmente em funcionamento. A capacidade de produção da FEC 2 é de 120 toneladas anuais de combustível, em termos de urânio.

Além da decisão de adotar-se a rota do TCAU para produção do combustivel $\mathrm{UO}_{2}$ no Brasil, o projeto do reator nuclear de potência ANGRA 2, tipo PWR, prevê a utilização do combustível $\mathrm{UO}_{2}-\mathrm{Gd}_{2} \mathrm{O}_{3}$ no seu núcleo. Portanto, no contexto do combustível nuclear tipo PWR nacional, a rota para a produção do combustível $\mathrm{UO}_{2}-\mathrm{Gd}_{2} \mathrm{O}_{3}$ será certamente a 
rota de mistura mecânica dos pós $\mathrm{UO}_{2}$ e $\mathrm{Gd}_{2} \mathrm{O}_{3}$, utilizando-se $\mathrm{UO}_{2}$ produzido a partir do TCAU, como ilustra a figura 4.

Como discutido no item anterior, se, por um lado, a rota de produção do combustível $\mathrm{UO}_{2}-\mathrm{Gd}_{2} \mathrm{O}_{3}$ via mistura mecânica dos pós de $\mathrm{UO}_{2}$ e $\mathrm{Gd}_{2} \mathrm{O}_{3}$ é a mais comercialmente atraente pela sua simplicidade, por outro lado ela apresenta dificuldade na obtenção de pastilhas combustíveis com densidade apropriada para uso como combustível nuclear, a qual está relacionada à baixa sinterabilidade do sistema $\mathrm{UO}_{2}-\mathrm{Gd}_{2} \mathrm{O}_{3}$. Tendo em vista esta dificuldade, o objetivo do presente trabalho é investigar o mecanismo responsável pelo bloqueio da sinterização do $\mathrm{UO}_{2}$ em presença do $\mathrm{Gd}_{2} \mathrm{O}_{3}$, utilizando-se como material de partida o tricarbonato de amônio e uranilo - TCAU e a rota de mistura mecânica dos pós para a obtenção do combustível. Essas são as condições prováveis que serão adotadas pela INB - FEC 2 na fabricação do combustível $\mathrm{UO}_{2}-\mathrm{Gd}_{2} \mathrm{O}_{3}$ no futuro.

Além deste objetivo primário, com base na melhor compreensão do mecanismo de bloqueio da sinterização, é também objetivo deste trabalho a proposição de outras possíveis soluções tecnológicas para o obtenção de pastilhas $\mathrm{UO}_{2}-\mathrm{Gd}_{2} \mathrm{O}_{3}$ sinterizadas com densidades adequadas para a sua utilização como combustível para reatores de potência tipo PWR, além da dopagem com alumínio adotada e patenteada pela Siemens AG alemã.

\subsection{Plano geral do trabalho}

Para facilitar o entendimento desta obra, apresenta-se a seguir um breve histórico do desenvolvimento do trabalho. Inicialmente, com base nas informações obtidas da literatura e apresentadas nos itens anteriores, foi realizado um trabalho preliminar no qual procurou-se detectar possiveis variáveis que pudessem influenciar o comportamento da sinterização do sistema $\mathrm{UO}_{2}-\mathrm{Gd}_{2} \mathrm{O}_{3}$, obtendo-se informações básicas vitais para fundamentar um ou mais mecanismos hipotéticos que pudessem explicar o comportamento da sinterização do sistema. Considerando os resultados preliminares, duas hipóteses foram simultaneamente estudadas, denominadas "Barreira de Difusão" e "Transformação de Fase do $\mathrm{Gd}_{2} \mathrm{O}_{3}$ ". Posteriormente, uma terceira hipótese, denominada "Formação de Poros Estáveis", foi amadurecida e fundamentada no decorrer dos trabalhos experimentais de desenvolvimento da hipótese da formação da Barreira de Difusão. Esta terceira hipótese é reforçada por resultados experimentais publicados na literatura, obtidos por outros pesquisadores, além de explicar a discrepância nos resultados de densificação publicados na literatura, como será discutido oportunamente. 
Com o objetivo de facilitar ao leitor o acompanhamento do desenvolvimento do trabalho, segundo o histórico apresentado acima, o trabalho foi estruturado de forma a fundamentar e discutir cada hipótese proposta, sendo, portanto, dividido em capítulos onde cada uma delas é desenvolvida, incluindo a apresentação dos materiais e métodos utilizados e discussão dos resultados obtidos (capítulos 2, 3 e 4). Após o desenvolvimento das três hipóteses propostas, foi acrescentado um quinto capítulo onde, com base no mecanismo atuante, algumas propostas de possíveis soluções tecnológicas para a baixa densificação do sistema $\mathrm{UO}_{2}-\mathrm{Gd}_{2} \mathrm{O}_{3}$ são desenvolvidas. $\mathrm{O}$ sexto capítulo conclui o trabalho e o sétimo e último capítulo apresenta propostas para trabalhos futuros que podem complementar este trabalho. A figura 8 ilustra a estrutura do trabalho.

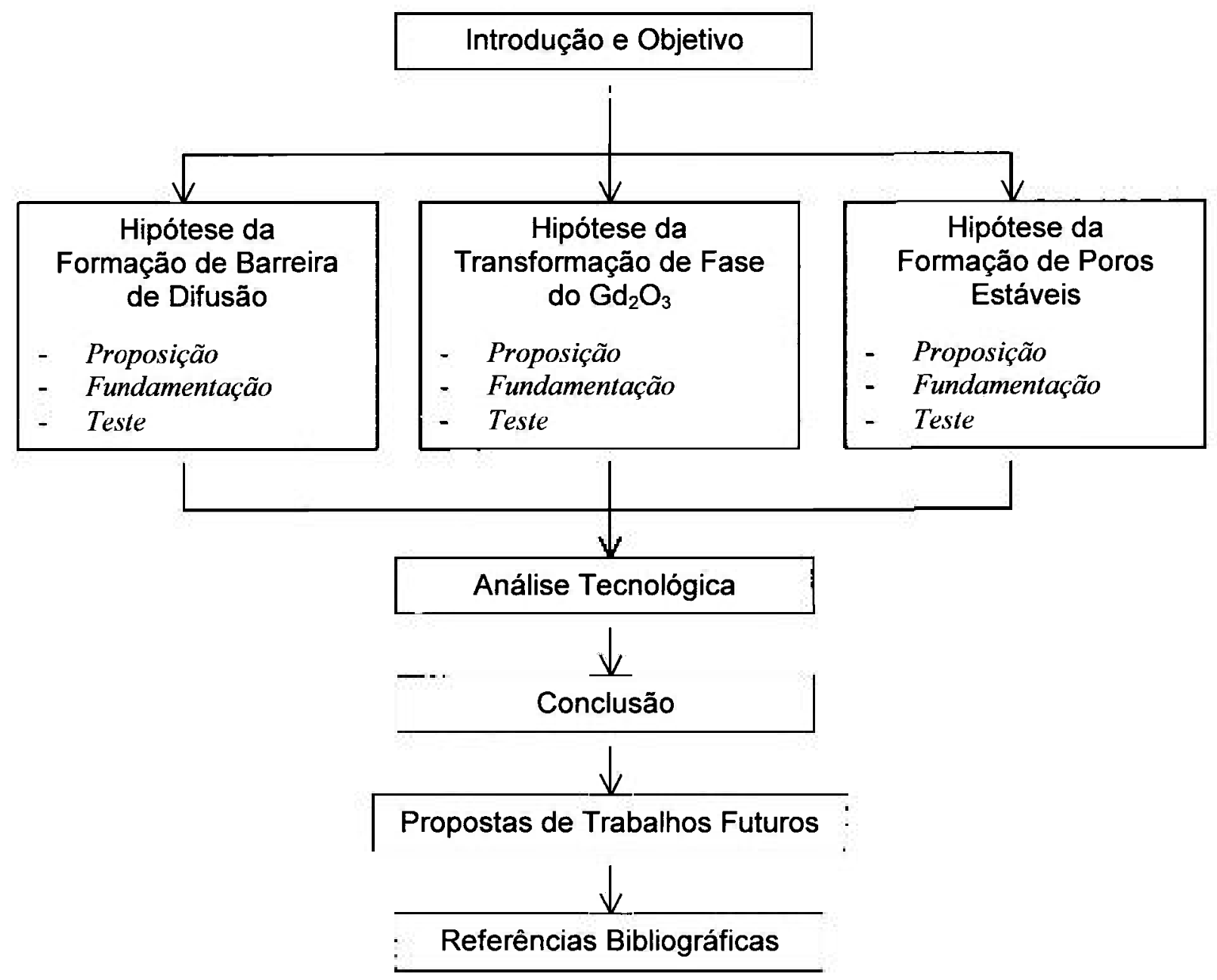

Figura 8 - Plano geral do trabalho. 


\section{A HIPÓTESE DA BARREIRA DE DIFUSÃO}

Como discutido no item 1.5 do capítulo anterior, uma análise dos resultados experimentais obtidos por diferentes pesquisadores indica que o método de preparação do pó misto $\mathrm{UO}_{2}-\mathrm{Gd}_{2} \mathrm{O}_{3}$ influencia sensivelmente a sinterabilidade do sistema $\mathrm{UO}_{2}-\mathrm{Gd}_{2} \mathrm{O}_{3}$. Assim sendo, uma investigação preliminar foi realizada com o objetivo de confirmar esta observação, além de caracterizar a forma como esta influência se manifesta. $O$ desenvolvimento deste trabalho preliminar foi iniciado, de forma exploratória, em $1991^{(124)}$ e foi retomado recentemente, sendo ampliado e reorientado, complementado-se os dados e a interpretação dos resultados ${ }^{(125)}$. Com base nos resultados obtidos foi possível a construção e a fundamentação da hipótese de que trata este capítulo, ou a Hipótese da Barreira de Difusão. A seguir estão descritos os procedimentos utilizados e estão apresentados e discutidos os resultados obtidos.

\subsection{Proposição da hipótese}

\subsubsection{A influência da homogeneidade da distribuição do $\mathrm{Gd}_{2} \mathrm{O}_{3}$ no pó de $\mathrm{UO}_{2}$}

Para verificar a influência do método de preparação do pó misto $\mathrm{UO}_{2}-\mathrm{Gd}_{2} \mathrm{O}_{3}$ no comportamento da sinterização, foram preparados pós adotando-se 3 diferentes rotas. $\mathrm{Na}$ primeira rota foi adotado o método de mistura mecânica dos pós, utilizando pó de $\mathrm{UO}_{2}$ proveniente do TCAU, o qual é o método comercial que tem interesse tecnológico diretamente relacionado a este trabalho. Na segunda rota foi adotado o método de coprecipitação de um TCAU misto, rota que teoricamente poderia resultar num pó misto com alta homogeneidade e que seria possivel de ser adotada industrialmente sem grande impacto nos procedimentos operacionais vigentes. A terceira rota adotou também a coprecipitação, porém obtendo-se um DUA misto, rota usualmente utilizada para obtenção de amostras de pó misto com alto grau de homogeneidade. Descrevem-se, a seguir, os materiais e métodos utilizados na preparação das amostras e os ensaios realizados.

\subsubsection{Metodologia}

As amostras foram preparadas por coprecipitação via DUA e TCAU, partindo-se de soluções de nitratos mistos, e por mistura dos pós de $\mathrm{UO}_{2}$ e $\mathrm{Gd}_{2} \mathrm{O}_{3}$. A faixa de composição utilizada foi de 0 a $10 \%$ em peso de $\mathrm{Gd}_{2} \mathrm{O}_{3}$, relativa à mistura $\mathrm{UO}_{2}-\mathrm{Gd}_{2} \mathrm{O}_{3}$. 
$\mathrm{O}$ pó de $\mathrm{Gd}_{2} \mathrm{O}_{3}$ foi obtido da Ventron Alfa Produkte e o pó de $\mathrm{UO}_{2}$ foi obtido a partir da conversão do $\mathrm{UF}_{6}$ via TCAU, processo implantado no IPEN desde $1984^{(126)}$. As tabelas 3 e 4 apresentam as principais características dos pós de $\mathrm{UO}_{2}$ e $\mathrm{Gd}_{2} \mathrm{O}_{3}$ utilizados, respectivamente. Observa-se que estes pós atendem às especificações adotadas na fabricação rotineira do combustível $\mathrm{UO}_{2}-\mathrm{Gd}_{2} \mathrm{O}_{3}$ pela rota do TCAU ${ }^{(68)}$. Os teores de impurezas gerais foram determinados por espectrografia de emissão óptica ${ }^{(127)}$, o teor de urânio e a relação $\mathrm{O} / \mathrm{U}$ foram determinadas por volumetria ${ }^{(\mathbf{1 2 8}, \mathbf{1 2 9 )}}$, os teores de carbono e enxofre foram determinados num analisador marca LECO, modelo CS-244 ${ }^{\text {(130) }}$, os teores de hidrogênio e nitrogênio foram determinados num determinador de gases marca LEYBOLD-HERAUS, modelo EVOLOGRAPH VH-9 ${ }^{(131)}$, os teores de fluoretos e cloretos foram determinados com eletrodos seletivos de íns ${ }^{(132)}$ e a superficie específica foi determinada pelo método de adsorção de nitrogênio (133,134) (Brunauer-EmmetTeller/BET).

A figura 9 ilustra a morfologia das partículas constituintes dos pós de $\mathrm{UO}_{2}$ e $\mathrm{Gd}_{2} \mathrm{O}_{3}$. As distribuições do tamanho de partícula dos pós, obtidas pelo método de sedimentação utilizando o etilenoglicol, estão apresentadas na figura 10. Comparando-se a figura 9B e a distribuição do tamanho de partícula do pó de $\mathrm{Gd}_{2} \mathrm{O}_{3}$ da figura 10 , pode-se observar claramente a tendência do pó de $\mathrm{Gd}_{2} \mathrm{O}_{3}$ em aglomerar-se, podendo ser observados aglomerados com tamanho superior a $50 \mu \mathrm{m}$ na figura $9 \mathrm{~B}$, enquanto o diâmetro equivalente máximo de partícula foi da ordem de $10 \mu \mathrm{m}$ (figura 10).

Na preparação das amostras por mistura mecânica e coprecipitação, os pós de $\mathrm{UO}_{2}$ e $\mathrm{Gd}_{2} \mathrm{O}_{3}$ foram pesados nas proporções desejadas para obtenção de concentrações de $\mathrm{Gd}_{2} \mathrm{O}_{3}$ na faixa de 0 a $10 \%$ em peso. Nos cálculos das proporções foram consideradas as correções na massa de pó de $\mathrm{Gd}_{2} \mathrm{O}_{3}$, referente à perda de massa no aquecimento a $1000^{\circ} \mathrm{C}$ devido à eliminação de voláteis, e na massa de pó de $\mathrm{UO}_{2}$, referente à relação $\mathrm{O} / \mathrm{U}$ de 2,149 .

No caso das amostras obtidas por mistura mecânica, inicialmente foi preparada uma mistura matriz $\mathrm{UO}_{2}-\mathrm{Gd}_{2} \mathrm{O}_{3}$ contendo $50 \%$ em peso de $\mathrm{Gd}_{2} \mathrm{O}_{3}$, adotando-se o mesmo processo proposto por Manzel e Dörr ${ }^{(46)}$. A mistura matriz foi homogeneizada por 20 minutos num misturador Turbula $\mathrm{T} 2 \mathrm{C}$, sob rotação de $42 \mathrm{rpm}$. Após a homogeneização da mistura matriz, o pó de $\mathrm{UO}_{2}$ necessário para o ajuste da composição requerida foi adicionado e a mistura foi novamente homogeneizada por 20 minutos no mesmo misturador, sob as mesmas condições. Na operação de homogeneização foi utilizado um frasco de polietileno de capacidade $300 \mathrm{~cm}^{3}$. Após a homogeneização, visualmente não foi possível perceber-se qualquer segregação de $\mathrm{Gd}_{2} \mathrm{O}_{3}$, resultando num pó homogêneo de cor cinza, tanto mais claro quanto maior o teor de $\mathrm{Gd}_{2} \mathrm{O}_{3}$ da mistura. 
Tabela 3 - Principais características químicas e fisicas do pó de $\mathrm{UO}_{2}$.

\begin{tabular}{|c|c|c|c|c|c|c|c|}
\hline \multicolumn{8}{|c|}{ Impurezas Gerais (ppm) } \\
\hline $\mathrm{Cd}$ & $<0,1$ & $\mathrm{Zn}$ & $<10$ & $\mathrm{Bi}$ & $<2$ & $\mathrm{~F}^{-}$ & $<10$ \\
\hline B & $<0,1$ & $\mathrm{Si}$ & 25 & $\mathrm{~V}$ & $<3$ & $\mathrm{Cl}^{-}$ & $<30$ \\
\hline $\mathbf{P}$ & $<55$ & $\mathrm{Al}$ & $<14$ & $\mathrm{Cu}$ & 51 & $\mathrm{C}$ & 271 \\
\hline $\mathrm{Fe}$ & 36 & $\mathrm{Mn}$ & $<2$ & $\mathrm{Ba}$ & $<1$ & $\mathbf{S}$ & 79 \\
\hline $\mathrm{Cr}$ & $<5$ & $\mathrm{Mg}$ & 30 & Co & $<10$ & $\mathbf{H}$ & 2,3 \\
\hline $\mathrm{Ni}$ & $<6$ & $\mathrm{~Pb}$ & $<1$ & $\mathrm{Ca}$ & $<2$ & $\mathrm{~N}$ & 261 \\
\hline Mo & $<2$ & $\mathrm{Sn}$ & $<1$ & & & & \\
\hline \multicolumn{3}{|c|}{ Urânio Total } & \multicolumn{3}{|c|}{$R a z a ̃ o ~ O / U$} & \multicolumn{2}{|c|}{ Densidade Solta } \\
\hline \multicolumn{3}{|c|}{$86,77 \%$ em peso } & \multicolumn{3}{|c|}{2,149} & \multicolumn{2}{|c|}{$1,75 \mathrm{~g} / \mathrm{cm}^{3}$} \\
\hline \multicolumn{4}{|c|}{ Superficie Especifica (BET) } & \multicolumn{4}{|c|}{ Diâmetro Médio Equivalente de Partícula } \\
\hline \multicolumn{4}{|c|}{$5,6 \mathrm{~m}^{2} / \mathrm{g}$} & \multicolumn{4}{|c|}{$8,7 \mu \mathrm{m}$} \\
\hline
\end{tabular}

Tabela 4 - Principais características químicas e físicas do pó de $\mathrm{Gd}_{2} \mathrm{O}_{3}$.

\begin{tabular}{|c|c|c|c|c|c|c|c|}
\hline \multicolumn{8}{|c|}{ Impurezas Gerais (ppm) } \\
\hline $\mathrm{Cd}$ & $<10$ & $\mathrm{Zn}$ & $<1500$ & $\mathrm{Bi}$ & $<15$ & $\mathrm{C}$ & 473 \\
\hline B & $<0,1$ & $\mathrm{Si}$ & $<60$ & $\mathrm{~V}$ & 30 & $\mathrm{Sm}$ & $<60$ \\
\hline $\mathbf{P}$ & 1500 & $\mathrm{Al}$ & $<600$ & $\mathrm{Cu}$ & 150 & $\mathrm{Eu}$ & $<30$ \\
\hline $\mathrm{Fe}$ & 75 & $\mathrm{Mn}$ & $<15$ & $\mathrm{Ba}$ & $<45$ & $\mathbf{L a}$ & $<100$ \\
\hline $\mathrm{Cr}$ & $<45$ & $\mathrm{Mg}$ & 300 & Co & $<45$ & $\mathrm{Nd}$ & $<100$ \\
\hline $\mathrm{Ni}$ & $<45$ & $\mathrm{~Pb}$ & $<45$ & $\mathrm{Ca}$ & 75 & $\mathrm{~Tb}$ & $<30$ \\
\hline \multirow[t]{3}{*}{ Mo } & $<1.00$ & $\mathrm{Sn}$ & $<30$ & $\mathrm{Ti}$ & 150 & $\mathbf{Y}$ & $<100$ \\
\hline & & & & $F^{-}$ & $<10$ & $\operatorname{Pr}$ & $<1000$ \\
\hline & & & & & & $\mathrm{Ce}$ & 294 \\
\hline \multicolumn{8}{|c|}{ Composição Isotópica (\% em peso) } \\
\hline \multirow{2}{*}{$\begin{array}{l}152 \\
157\end{array}$} & \multirow{2}{*}{$\begin{array}{l}-0,2044 \\
-15,6548\end{array}$} & \multirow{2}{*}{\multicolumn{2}{|c|}{$\begin{array}{l}154-2,1808 \\
158-24,8304\end{array}$}} & \multirow{2}{*}{\multicolumn{2}{|c|}{$\begin{array}{l}155-14,8054 \\
160-21,8532\end{array}$}} & \multirow{2}{*}{\multicolumn{2}{|c|}{$156-20,4709$}} \\
\hline & & & & & & & \\
\hline \multirow{2}{*}{\multicolumn{3}{|c|}{$\begin{array}{c}\text { Gadolínio Total } \\
99,9 \% \text { em peso } \\
\text { (especificaçäo do fabricante) }\end{array}$}} & \multirow{2}{*}{\multicolumn{3}{|c|}{$\begin{array}{c}\text { Perda na Ignição a } 1000{ }^{\circ} \mathrm{C} \\
0,29 \% \text { em peso }\end{array}$}} & \multicolumn{2}{|c|}{ Umidade } \\
\hline & & & & & & 0,06 & em peso \\
\hline
\end{tabular}




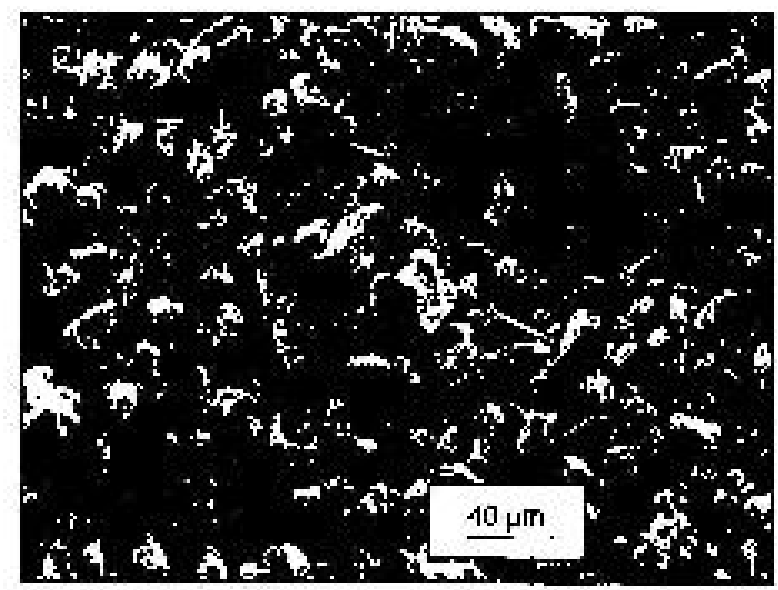

(A)
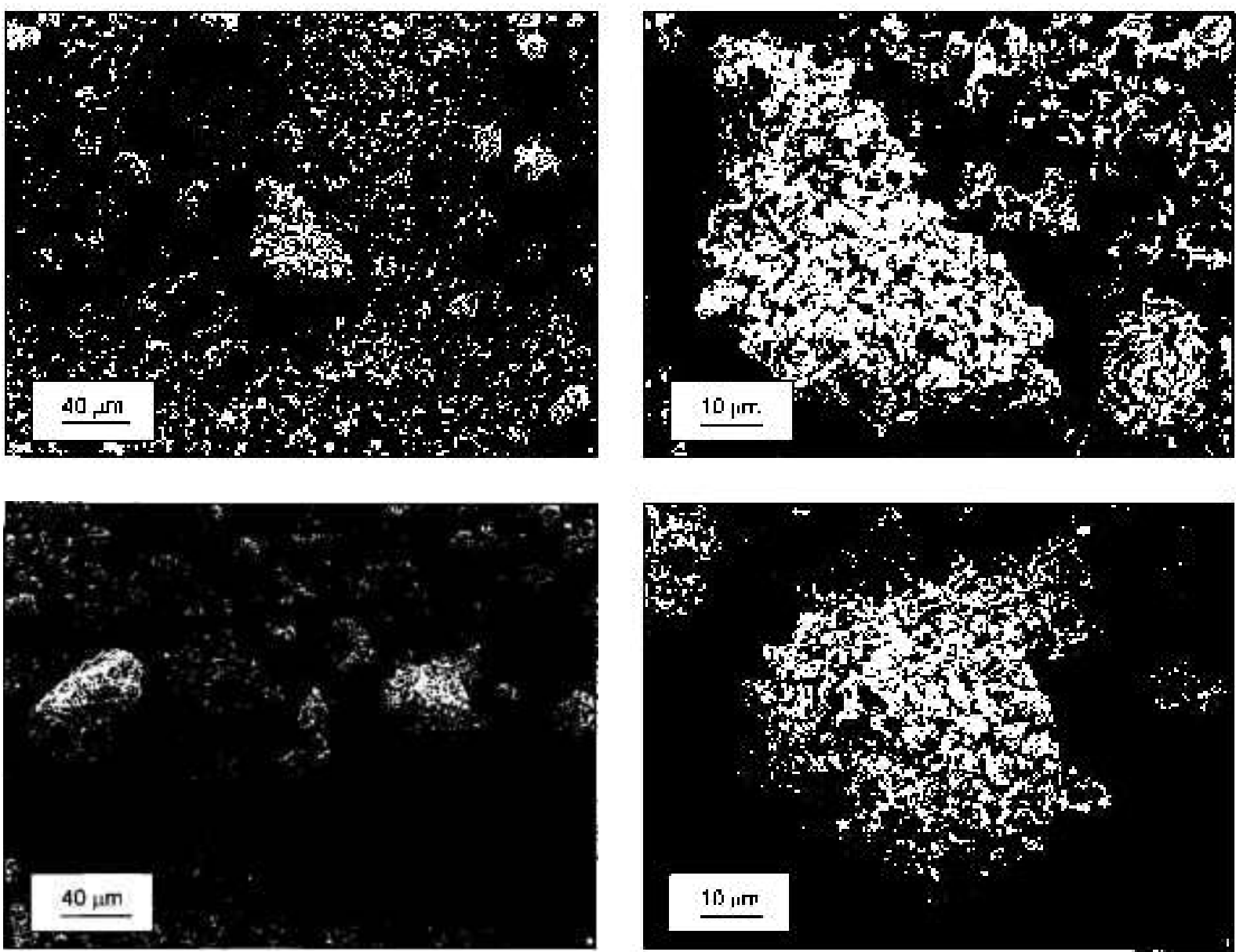

(B)

Figura 9 - Aspecto morfológico das partículas dos pós (microscopia eletrônica de varredura): (A) $\mathrm{UO}_{2} \quad$ (B) $\mathrm{Gd}_{2} \mathrm{O}_{3}$ 


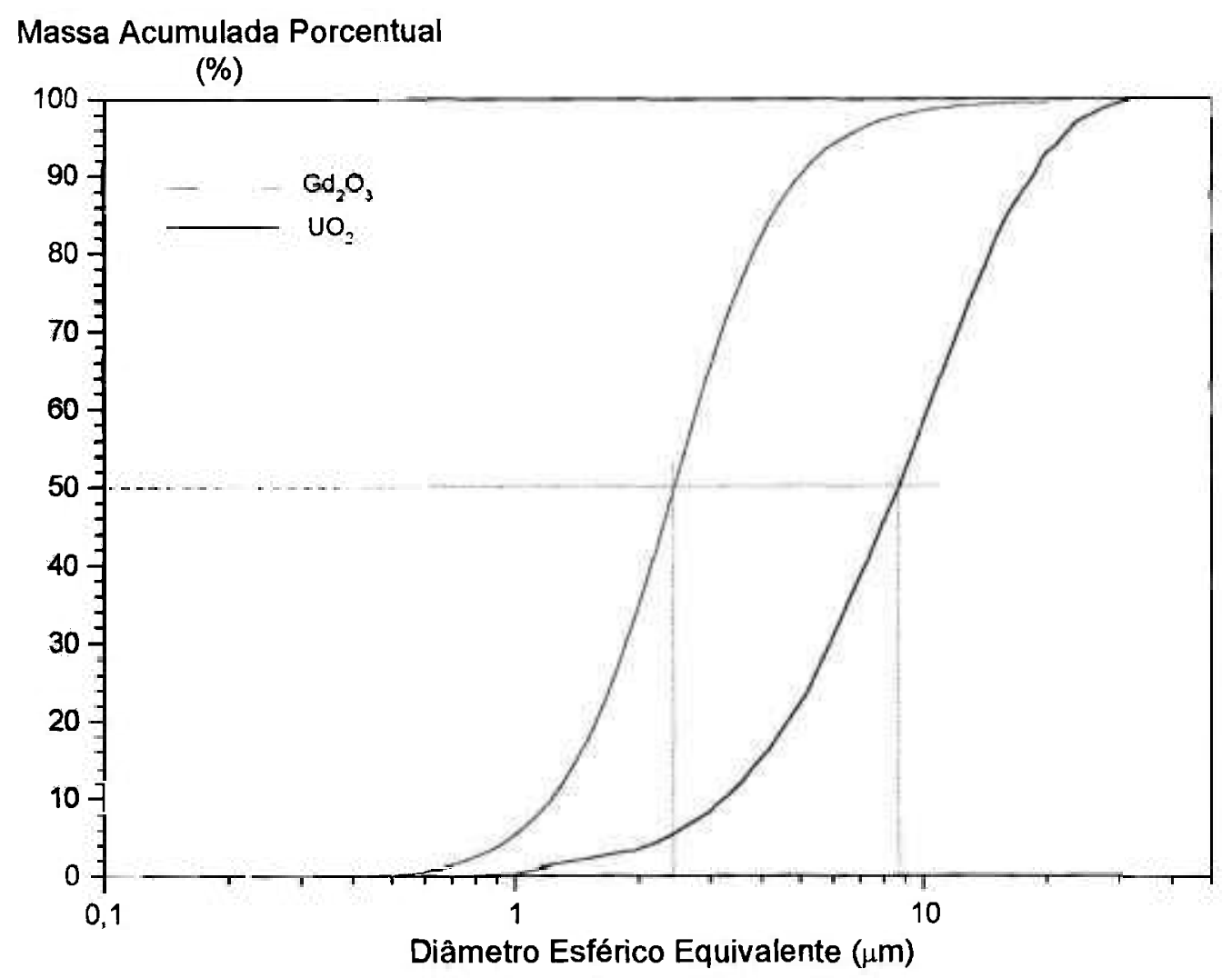

Figura 10 - Distribuição do tamanho de partícula dos pós de $\mathrm{UO}_{2}$ e $\mathrm{Gd}_{2} \mathrm{O}_{3}$.

Para verificar o grau de homogeneidade da mistura, foram retiradas 5 amostras dos pós obtidos onde o pó de $\mathrm{Gd}_{2} \mathrm{O}_{3}$ foi adicionado nas proporções nominais de $0,5,5$ e 10 $\%$ em peso. Estas amostras foram retiradas em diferentes regiões do frasco, procurando-se garantir a representatividade da amostragem. O teor de $\mathrm{Gd}_{2} \mathrm{O}_{3}$ foi determinado em cada uma das amostras por meio de fluorescência de raios-X. Os resultados demonstraram uma boa homogeneidade das amostras, como ilustra a tabela 5 .

$\mathrm{Na}$ preparação das amostras por coprecipitação via DUA, os pós de $\mathrm{UO}_{2}$ e $\mathrm{Gd}_{2} \mathrm{O}_{3}$ foram pesados individualmente, também se adotando as correções de massa mencionadas na obtenção dos pós mistos por mistura mecânica, e foram dissolvidos separadamente numa solução de $\mathrm{HNO}_{3} 7,3 \mathrm{~N}$ a $40^{\circ} \mathrm{C}$. Os pós foram lentamente adicionados à solução e durante a dissolução foi utilizada agitação por meio de um agitador magnético. $O$ término da liberação de vapores nitrosos indicou o final da dissolução, a qual ocorreu em aproximadamente 35 minutos no caso do $\mathrm{UO}_{2} \mathrm{e}$ em poucos minutos (de 1 a 2) no caso do $\mathrm{Gd}_{2} \mathrm{O}_{3}$. O aquecimento e a agitação foram mantidos por um tempo suplementar de 15 minutos para garantia de total dissolução. Apesar da maior rapidez conseguida na dissolução a temperaturas superiores a $40^{\circ} \mathrm{C}$, estas não foram utilizadas devido à violência 
Tabela 5 - Resultados da verificação da homogeneidade das misturas $\mathrm{UO}_{2}-\mathrm{Gd}_{2} \mathrm{O}_{3}$.

\begin{tabular}{|c|c|c|}
\hline $\begin{array}{c}\text { Concentração Nominal de } G d_{2} O_{3} \text { Adicionado } \\
(\% \text { em peso) }\end{array}$ & $\begin{array}{l}\text { Valor Determinado } \\
\text { (\% em peso })\end{array}$ & $\begin{array}{l}\text { Desvio } \\
(\%)\end{array}$ \\
\hline 0,5 & $\begin{array}{l}0,50 \\
0,50 \\
0,50 \\
0,49 \\
0,48\end{array}$ & $\begin{array}{c}0 \\
0 \\
0 \\
-2,0 \\
-4,0\end{array}$ \\
\hline 5 & $\begin{array}{l}5,0 \\
4,8 \\
5,0 \\
4,9 \\
5,0\end{array}$ & $\begin{array}{c}0 \\
-4,0 \\
0 \\
-2,0 \\
0\end{array}$ \\
\hline 10 & $\begin{array}{c}10,0 \\
9,8 \\
9,7 \\
9,7 \\
9,9\end{array}$ & $\begin{array}{c}0 \\
-2,0 \\
-3,0 \\
-3,0 \\
-1,0\end{array}$ \\
\hline
\end{tabular}

da reação, ocorrendo efervescência e liberação de vapores nitrosos durante a alimentação. $\mathrm{Na}$ dissolução do pó de $\mathrm{UO}_{2}$ foi utilizado um volume de $3,5 \mathrm{~cm}^{3}$ de solução de $\mathrm{HNO}_{3}$ por grama de $\mathrm{UO}_{2}$, resultando, após a diluição necessária, numa solução de nitrato de uranilo contendo $200 \mathrm{gU} / \mathrm{l}$. $\mathrm{Na}$ dissolução do pó de $\mathrm{Gd}_{2} \mathrm{O}_{3}$, o volume de solução de $\mathrm{HNO}_{3}$ utilizado foi de $5 \mathrm{~cm}^{3} / \mathrm{g}$. Após a mistura dos nitratos de uranilo e gadolínio, a solução obtida foi adicionada à uma solução de $\mathrm{NH}_{4} \mathrm{OH} 13 \mathrm{M}$, mantendo-se a temperatura de $60{ }^{\circ} \mathrm{C}$ e a vazão de alimentação aproximada de $4 \mathrm{~cm}^{3} /$ minuto. $\mathrm{O} \mathrm{pH}$ foi controlado manualmente por meio da adição simultânea da solução de $\mathrm{NH}_{4} \mathrm{OH}$, mantendo-se o seu valor entre $9 \mathrm{e}$ 10. Esta faixa de valores de $\mathrm{pH}$ foi adotada com base em testes preliminares que indicaram a precipitação do nitrato de gadolínio para o valor de $\mathrm{pH}$ de 8,5. Após o término da adição da solução de nitrato, a agitação e a temperatura foram mantidas por um tempo suplementar de 15 minutos. A suspensão obtida foi filtrada a vácuo à temperatura aproximada de $55^{\circ} \mathrm{C}$. A quantidade produzida de sal misto por concentração de $\mathrm{Gd}_{2} \mathrm{O}_{3}$ foi equivalente a $100 \mathrm{~g}$ de pó $\mathrm{UO}_{2}-\mathrm{Gd}_{2} \mathrm{O}_{3}$ após a redução. A torta obtida foi calcinada por 2 horas a $600{ }^{\circ} \mathrm{C}$ e desagregada manualmente. O material granulado obtido foi classificado em peneira de 200 mesh $(<75 \mu \mathrm{m})$ antes da sua redução. 
As amostras preparadas por coprecipitação via TCAU foram obtidas a partir de soluções mistas de nitrados preparados de maneira análoga à descrita acima, no caso da coprecipitação via DUA. Neste caso são coprecipitados o tricarbonato de amônio e uranilo e o carbonato de gadolínio. Neste tipo de coprecipitação, a concentração da solução de nitrato de uranilo foi ajustada em $400 \mathrm{gU} / 1$, concentração esta recomendada com base na experiência adquirida no IPEN na precipitação de TCAU a partir do nitrato de uranilo. À solução de nitrato misto, foi adicionada uma solução de $\mathrm{NH}_{4} \mathrm{HCO}_{3} 3,2 \mathrm{M}$ à uma vazão aproximada de $7,5 \mathrm{~cm}^{3} /$ minuto, mantendo-se a temperatura em $60^{\circ} \mathrm{C}$. O término da coprecipitação foi determinado pelo término da adição de um volume de solução de $\mathrm{NH}_{4} \mathrm{HCO}_{3}$ calculado para a obtenção de uma relação $\mathrm{C} / \mathrm{U}$ de 7,5 , o que garantiu um excesso de bicarbonato para garantia de total precipitação, uma vez que a relação $\mathrm{C} / \mathrm{U}$ estequiométrica é 6 . Durante toda a operação de precipitação manteve-se um borbulhamento de ar para impedir a redução do cátion $\mathrm{U}^{+6}$ a $\mathrm{U}^{+5}$. $\mathrm{O}$ pH variou de 8 a 8,5 . Após a coprecipitação, a suspensão obtida foi resfriada a $25^{\circ} \mathrm{C}$ sob agitação branda e filtrada a vácuo. Após a filtração, a torta obtida foi lavada com álcool etílico para diminuição da umidade. Como no caso da coprecipitação via DUA, a quantidade produzida de sal misto por concentração de $\mathrm{Gd}_{2} \mathrm{O}_{3}$ foi equivalente a $100 \mathrm{~g}$ de pó $\mathrm{UO}_{2}-$ $\mathrm{Gd}_{2} \mathrm{O}_{3}$ após a redução. A torta obtida foi diretamente reduzida a $\mathrm{UO}_{2}-\mathrm{Gd}_{2} \mathrm{O}_{3}$.

Os teores de urânio e gadolínio foram determinados nos efluentes da filtração de ambos os sais mistos obtidos por coprecipitação. Os resultados estão apresentados na tabela 6. Observando-se os valores apresentados nesta tabela, verifica-se que os teores de urânio nos filtrados são típicos dos processos de precipitação de DUA e TCAU. Também se pode observar que a perda de gadolínio no filtrado é bastante pequena, indicando a praticamente total incorporação do gadolínio ao pó misto. A variação máxima calculada da concentração de $\mathrm{Gd}_{2} \mathrm{O}_{3}$ em torno da composição nominal adicionada foi de $0,02 \%$ no caso da coprecipitação via DUA e de $0,04 \%$ no caso de coprecipitação via TCAU.

Os sais mistos obtidos por coprecipitação foram reduzidos num forno tubular sob atmosfera de hidrogênio por 3 horas a $650^{\circ} \mathrm{C}$. $\mathrm{O} \mathrm{H}_{2}$ utilizado foi do tipo comercial (pureza mínima de 99,5\%), adotando-se uma vazão de 1,2 L/min. Cada amostra, contendo as diferentes concentrações de $\mathrm{Gd}_{2} \mathrm{O}_{3}$, foi reduzida individualmente, sendo acondicionada numa bandeja de aço inoxidável 304. Após a redução e resfriamento, o gás hidrogênio foi substituído por nitrogênio e os pós reduzidos foram retirados do forno em sacos plásticos, sendo mantidos sob nitrogênio. O pós obtidos foram, então, passivados manualmente por meio do ingresso de quantidades controladas de ar no interior do saco plástico, pequena no início da passivação e aumentada progressivamente com cautela. Este procedimento foi necessário devido a piroforicidade destes pós, prevenindo-se a sua ignição. 
Tabela 6 - Concentrações de U e Gd determinadas nos filtrados da coprecipitação.

\begin{tabular}{|c|c|c|c|c|c|}
\hline \multirow[t]{2}{*}{$\begin{array}{c}\text { Material } \\
\text { Coprecipitado }\end{array}$} & \multirow[t]{2}{*}{$\begin{array}{c}\text { Concentração } \\
\text { de } \mathrm{Gd}_{2} \mathrm{O}_{3} \\
\text { (\% em peso) }\end{array}$} & \multicolumn{2}{|c|}{$\begin{array}{l}\text { Concentração no } \\
\text { Filtrado } \\
(\mathrm{mg} / \mathrm{L})\end{array}$} & \multicolumn{2}{|c|}{$\begin{array}{c}\text { Perda Total Estimada no } \\
\text { Filtrado } \\
(\mathrm{mg})\end{array}$} \\
\hline & & $\mathrm{U}$ & $\mathrm{Gd}$ & $\mathrm{U}$ & Gd \\
\hline \multirow{10}{*}{ DUA } & 0 & 4,2 & $<10$ & 8,4 & $<20$ \\
\hline & 0,5 & 2,8 & $<10$ & 5,6 & $<20$ \\
\hline & 2 & 2,5 & $<10$ & 5,0 & $<20$ \\
\hline & 3,5 & 2,3 & $<10$ & 4,6 & $<20$ \\
\hline & 4 & 2,5 & $<10$ & 5,0 & $<20$ \\
\hline & 5 & 3,1 & $<10$ & 6,2 & $<20$ \\
\hline & 6 & 2,2 & $<10$ & 4,4 & $<20$ \\
\hline & 7,5 & 3,1 & $<10$ & 6,2 & $<20$ \\
\hline & 8 & 3,7 & $<10$ & 7,4 & $<20$ \\
\hline & 10 & 2,9 & $<10$ & 5,8 & $<20$ \\
\hline \multirow{7}{*}{ TCAU } & 0 & 390 & $<10$ & 490 & 12 \\
\hline & 0,5 & 470 & 10 & 590 & 12 \\
\hline & 2 & 560 & 10 & 700 & 12 \\
\hline & 3,5 & 470 & 10 & 590 & 12 \\
\hline & 5 & 460 & 10 & 580 & 12 \\
\hline & 7,5 & 500 & 21 & 630 & 26 \\
\hline & 10 & 470 & 18 & 590 & 23 \\
\hline
\end{tabular}

Foram determinadas as superfícies específicas (BET) dos pós obtidos por coprecipitação, no estado reduzido. No caso de coprecipitação via DUA os valores determinados situaram-se na faixa de 13 a $16 \mathrm{~m}^{2} / \mathrm{g}$ e nos pós obtidos por coprecipitação via TCAU os valores determinados situaram-se na faixa de 5,5 a $8 \mathrm{~m}^{2} / \mathrm{g}$. Os resultados obtidos estão apresentados na tabela 7 .

Os pós $\mathrm{UO}_{2}-\mathrm{Gd}_{2} \mathrm{O}_{3}$ obtidos pelas diferentes rotas descritas acima foram compactados diretamente, sem que aglomerante e lubrificante fossem adicionados aos pós. A pressão de compactação variou entre 2,5 e $4,0 \mathrm{tf} / \mathrm{cm}^{2}$, dependendo do tipo de pó e da concentração de $\mathrm{Gd}_{2} \mathrm{O}_{3}$, sendo fixada de modo a obter-se pastilhas compactadas com densidade de 50,0 $\pm 0,3 \%$ da densidade teórica do sistema (\%DT), calculada a partir da composição da mistura $\mathrm{UO}_{2}-\mathrm{Gd}_{2} \mathrm{O}_{3}$ e das densidades teóricas do $\mathrm{UO}_{2}$, de $10,96 \mathrm{~g} / \mathrm{cm}^{3}$ (135), e do $\mathrm{Gd}_{2} \mathrm{O}_{3}$, de $7,62 \mathrm{~g} / \mathrm{cm}^{3}{ }^{\text {(135) }}$. Na compactação uniaxial das pastilhas foi utilizada uma prensa hidráulica e matriz cilíndrica flutuante com diâmetro de $9,3 \mathrm{~mm}$. A superfície interna da cavidade da matriz foi lubrificada com uma fina camada de óleo. A massa de pó 
misto carregada na matriz foi calculada para que fossem obtidas pastilhas com altura aproximada de $9 \mathrm{~mm}$.

Tabela 7 - Superfície específica dos pós obtidos por coprecipitação (após a redução).

\begin{tabular}{ccc}
\hline Material Coprecipitado $\begin{array}{c}\text { Composição Nominal de } \mathrm{Gd}_{2} \mathrm{O}_{3} \\
(\% \text { em peso) }\end{array}$ & $\begin{array}{c}\text { Superficie Especifica (BET) } \\
\left(\mathrm{m}^{2} / \mathrm{g}\right)\end{array}$ \\
\hline & 0 & 12,9 \\
$\mathrm{UO}_{2}$ via DUA & 0,5 & 16,0 \\
& 2 & 13,6 \\
& 3,5 & 13,5 \\
& 4 & 15,8 \\
& 5 & 14,4 \\
$\mathrm{UO}_{2}$ via TCAU & 6 & 14,6 \\
& 7,5 & 12,9 \\
& 8 & 15,5 \\
& 10 & 15,3 \\
\hline
\end{tabular}

As pastilhas compactadas, ou "a verde", foram sinterizadas a $1650{ }^{\circ} \mathrm{C}$ por 3 horas sob atmosfera de $\mathrm{H}_{2}$ de alta pureza (mínimo de 99,99\%, com $\mathrm{H}_{2} \mathrm{O}<10 \mathrm{ppm} \mathrm{e} \mathrm{O}_{2}<5 \mathrm{ppm}$ ). A taxa de aquecimento utilizada foi de $5{ }^{\circ} \mathrm{C} /$ minuto e o resfriamento foi realizado controladamente, a uma taxa de $20^{\circ} \mathrm{C} /$ minuto, até que a temperatura de $1000{ }^{\circ} \mathrm{C}$ fosse atingida, quando o forno foi desligado e o resfriamento foi natural. $\mathrm{O}$ gradiente máximo de temperatura no forno de sinterização foi de $\pm 10^{\circ} \mathrm{C}$. Após o resfriamento do forno até a temperatura ambiente, as pastilhas sinterizadas foram retiradas e suas densidades foram determinadas por imersão aplicando-se o princípio de Arquimedes, utilizando o xilol como liquido ${ }^{(136)}$.

A cinética de sinterização foi determinada por meio de dilatometria (marca NETZSCH, modelo DIL 402 C), adotando-se o mesmo ciclo de sinterização descrito 
acima. Foram realizadas análises de difração de raios-X nos pós mistos na forma oxidada e reduzida. A distribuição de gadolínio no interior da pastilha sinterizada foi caracterizada por meio de microssonda eletrônica. Os resultados obtidos estão apresentados e discutidos a seguir.

\subsubsection{Resultados e discussão}

Os pós obtidos pelas diferentes rotas de processamento, no estado reduzido, foram caracterizados por meio de difração de raios-X. Os difratogramas obtidos, apresentados na figura 11, indicam que o $\mathrm{Gd}_{2} \mathrm{O}_{3}$ está distribuído no pó misto $\mathrm{UO}_{2}-\mathrm{Gd}_{2} \mathrm{O}_{3}$ de diferentes maneiras. Apesar dos picos mais intensos do $\mathrm{UO}_{2}$ (posicionados nos valores $2 \theta$ de $28,4^{\circ}$, $32,9^{\circ}, 47,1^{\circ}$ e $56,0^{\circ}$ ) serem praticamente coincidentes com os picos mais intensos do $\mathrm{Gd}_{2} \mathrm{O}_{3}$ (posicionados nos valores $2 \theta$ de $28,7^{\circ}, 33,2^{\circ}, 47,7^{\circ}$ e $56,6^{\circ}$ ), pode-se observar na figura 11 que o difratograma obtido do pó misto preparado segundo a rota de mistura mecânica apresenta os picos característicos da estrutura cristalina cúbica de corpo centrado (CCC) do $\mathrm{Gd}_{2} \mathrm{O}_{3}$, além dos picos característicos da estrutura cúbica de face centrada (CFC) do $\mathrm{UO}_{2}$. No caso do pó preparado por coprecipitação via TCAU, a mesma observação básica é aplicável, porém com a supressão dos picos do $\mathrm{CCC} \mathrm{Gd}_{2} \mathrm{O}_{3}$ de menor intensidade, referente aos planos (111), (411), (332), (431) e (611).

Por outro lado, no difratograma do pó misto preparado por coprecipitação via DUA pode-se observar a ausência dos picos de difração referentes ao $\mathrm{Gd}_{2} \mathrm{O}_{3}$ CCC. Além disto, os picos do difratograma estão sensivelmente deslocados no sentido de maiores ângulos, o que significa uma redução no parâmetro de rede da estrutura tipo fluorita do $\mathrm{UO}_{2}$, indicando a formação de uma solução sólida, conforme discutido no item 1.3.1. Este deslocamento do difratograma no sentido de maiores ângulos também pode ser observado no caso do pó preparado por coprecipitação via TCAU, ainda que muito ligeiramente, indicando que pelo menos parte do $\mathrm{Gd}_{2} \mathrm{O}_{3}$ adicionado deve ter sido incorporado na rede cristalina do $\mathrm{UO}_{2}$.

Para evitar o problema da superposição dos picos de difração do $\mathrm{UO}_{2}$ e do $\mathrm{Gd}_{2} \mathrm{O}_{3}$ e para confirmar as observações apresentadas acima, amostras de pós mistos contendo $10 \%$ em peso de $\mathrm{Gd}_{2} \mathrm{O}_{3}$, preparadas segundo as três rotas de processamento, foram oxidadas a $800{ }^{\circ} \mathrm{C}$ por 3 horas e analisadas por difratometria de raios-X. Os resultados estão apresentados na figura 12 .

Observa-se que no pó misto preparado por mistura mecânica, o $\mathrm{Gd}_{2} \mathrm{O}_{3}$ está presente na sua forma cúbica de corpo centrado (CCC) e não podem ser observadas modificações nos picos referentes ao $\mathrm{U}_{3} \mathrm{O}_{8}$ ortorrômbico. $\mathrm{O}$ pó coprecipitado via DUA 
apresenta um comportamento inverso, com a supressão dos dubletos característicos do $\mathrm{U}_{3} \mathrm{O}_{8}$ ortorrômbico, nas posições $2 \theta$ de aproximadamente $26^{\circ}$ e $34^{\circ}$, e o acentuado alargamento dos picos de difração, não sendo visivel nenhum pico correspondente ao $\mathrm{Gd}_{2} \mathrm{O}_{3}$ cúbico.

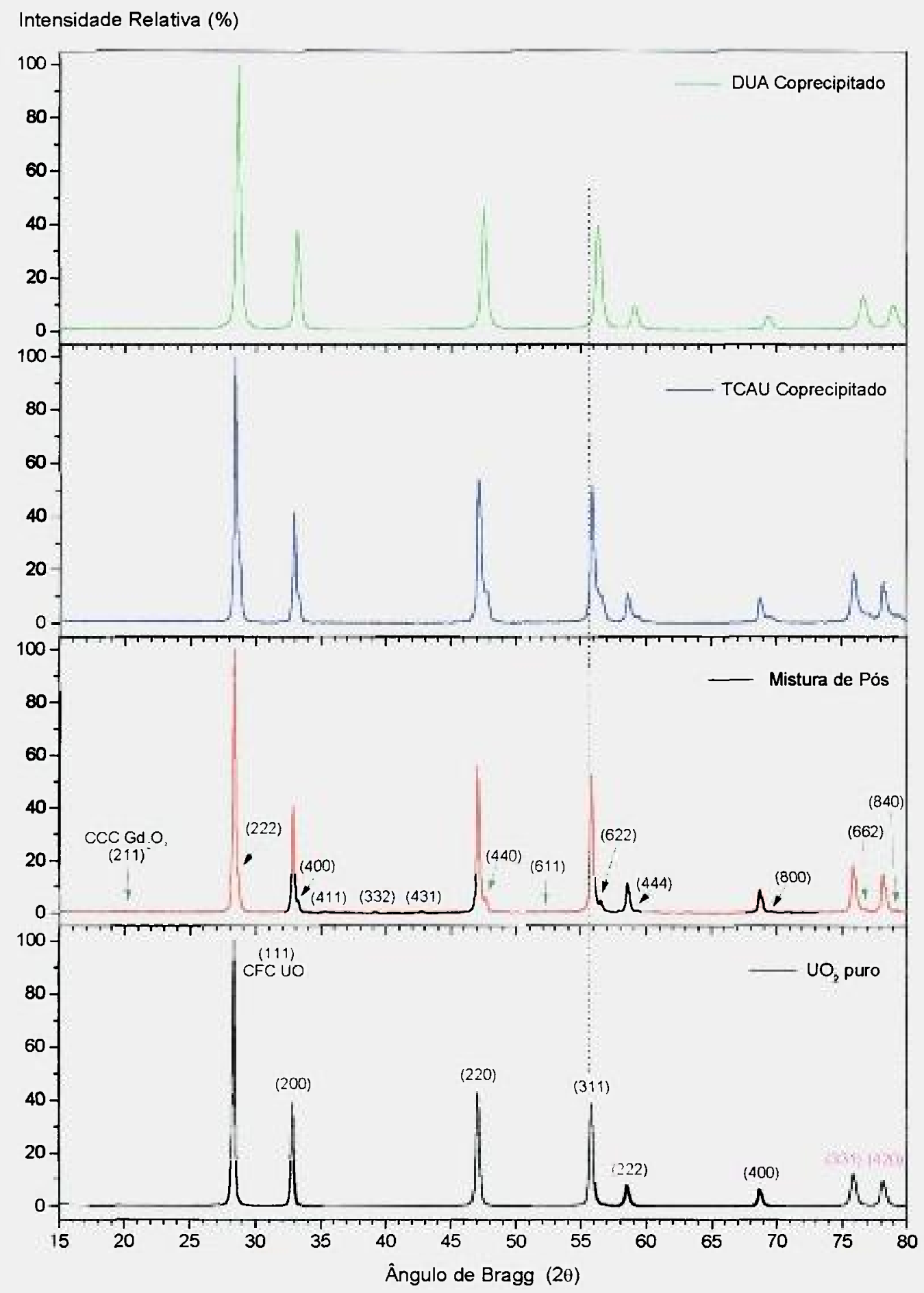

Figura 11 - Difratogramas de raios-X de pós $\mathrm{UO}_{2}-\mathrm{Gd}_{2} \mathrm{O}_{3}(10 \%$ em peso) reduzidos por 3 horas a $6500^{\circ} \mathrm{C}$, obtidos por diferentes rotas de processamento. 


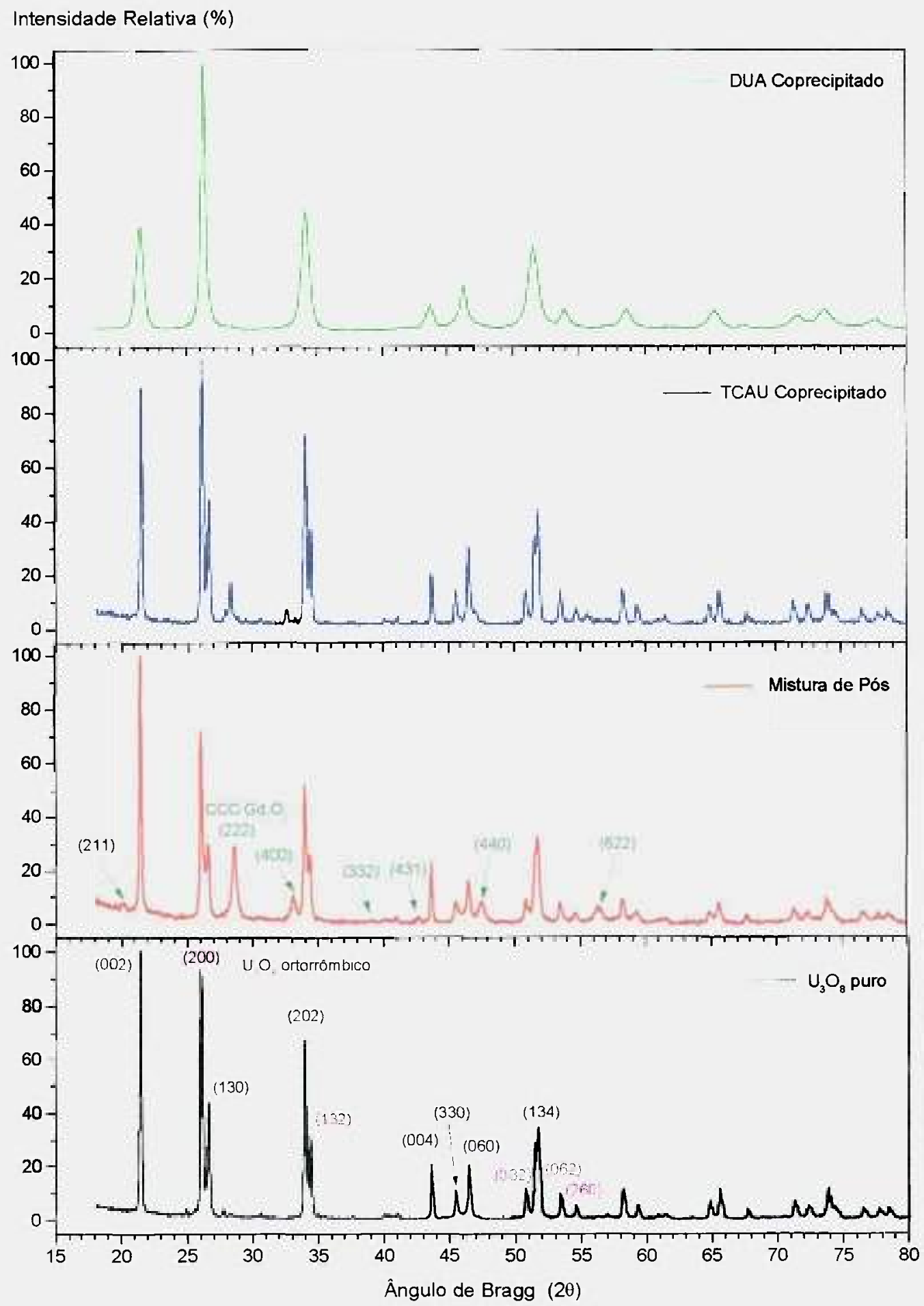

Figura 12 - Difratogramas de raios-X de pós $\mathrm{UO}_{2}-\mathrm{Gd}_{2} \mathrm{O}_{3}(10 \%$ em peso) oxidados por 3 horas a $800^{\circ} \mathrm{C}$, obtidos por diferentes rotas de processamento.

O difratograma obtido do pó preparado por coprecipitação via TCAU mostra uma aparência similar ao obtido do pó preparado por mistura mecânica, mas a diminuição da intensidade relativa dos picos de difração correspondentes ao $\mathrm{Gd}_{2} \mathrm{O}_{3} \mathrm{CCC}$ é evidente. 
Os resultados apresentados nas figuras 11 e 12 indicam que o $\mathrm{Gd}_{2} \mathrm{O}_{3}$ está presente sob diferentes formas nos pós mistos preparados segundo as diferentes rotas de processamento. No pó obtido por coprecipitação via DUA, o gadolínio incorporado deve estar presente na forma de solução sólida. No caso do pó preparado por mistura mecânica, todo o gadolínio incorporado parece estar presente como $\mathrm{Gd}_{2} \mathrm{O}_{3}$ livre, de estrutura cúbica de corpo centrado (CCC). No pó preparado por coprecipitação via TCAU parece estar ocorrendo uma situação intermediária, com a maior parte do gadolínio presente na forma de $\mathrm{Gd}_{2} \mathrm{O}_{3}$ cúbico livre, mas com uma pequena parcela na forma de solução sólida. Este resultado é confirmado pelo resultado obtido por Revindran et al ${ }^{(137)}$, que concluíram que não se forma solução sólida por meio de coprecipitação via TCAU.

A influência da concentração de $\mathrm{Gd}_{2} \mathrm{O}_{3}$ na densidade das pastilhas sinterizadas obtidas segundo os três métodos de processamento investigados está apresentada na figura 13. Como pode ser observado, três diferentes comportamentos estão evidenciados, resultando em três níveis de densificação durante a sinterização, cada um deles aparentemente relacionado à rota de preparação do pó misto $\mathrm{UO}_{2}-\mathrm{Gd}_{2} \mathrm{O}_{3}$.

Pode-se observar nessa figura que a presença do $\mathrm{Gd}_{2} \mathrm{O}_{3}$ inibe fortemente a sinterabilidade do $\mathrm{UO}_{2}$ no caso do pó preparado por mistura mecânica. Este resultado está em relativamente boa concordância com os resultados obtidos por Assmann et al ${ }^{(68)}$ e Davis e Potter ${ }^{\mathbf{( 1 1 3 )}}$, apresentados na figura 5, os quais também usaram a rota de mistura de pós na preparação das amostras. A faixa de densidades obtida situa-se entre as obtidas por Assmann et al e Davis e Potter, observando-se também a mesma queda abrupta na densificação para concentrações de $\mathrm{Gd}_{2} \mathrm{O}_{3}$ de até $4 \%$ em peso. As maiores densidades obtidas por Assmann et al podem ser explicadas pela maior temperatura de sinterização utilizada por estes pesquisadores no seu trabalho. A tendência para o aumento da densidade das pastilhas contendo teores de $\mathrm{Gd}_{2} \mathrm{O}_{3}$ superiores a $6 \%$ em peso, observada por Assmann et al, não foi confirmada pelos resultados apresentados na figura 13 .

Nas pastilhas preparadas com pó misto derivado do processo de coprecipitação via TCAU, as densidades obtidas após a sinterização parecem ser menos sensiveis à adição de $\mathrm{Gd}_{2} \mathrm{O}_{3}$. Uma ligeira tendência ao aumento da densificação com o aumento da concentração de $\mathrm{Gd}_{2} \mathrm{O}_{3}$ incorporado pode ser observada. Este resultado concorda bem com os obtidos por Littlechild et al ${ }^{(45)}$ e Agueda et al ${ }^{(114)}$ (no caso de pó de $\mathrm{UO}_{2}$ com baixa superfície específica). As amostras utilizadas por estes pesquisadores foram obtidas por meio de comoagem dos pós de $\mathrm{UO}_{2}$ e $\mathrm{Gd}_{2} \mathrm{O}_{3}$. Parece estar claro da observação destes resultados que ocorreu um segundo comportamento típico na sinterização, o qual caracteriza um segundo nível de densificação do combustível $\mathrm{UO}_{2}-\mathrm{Gd}_{2} \mathrm{O}_{3}$ durante o processo de sinterização. 
Densidade (\%DT)

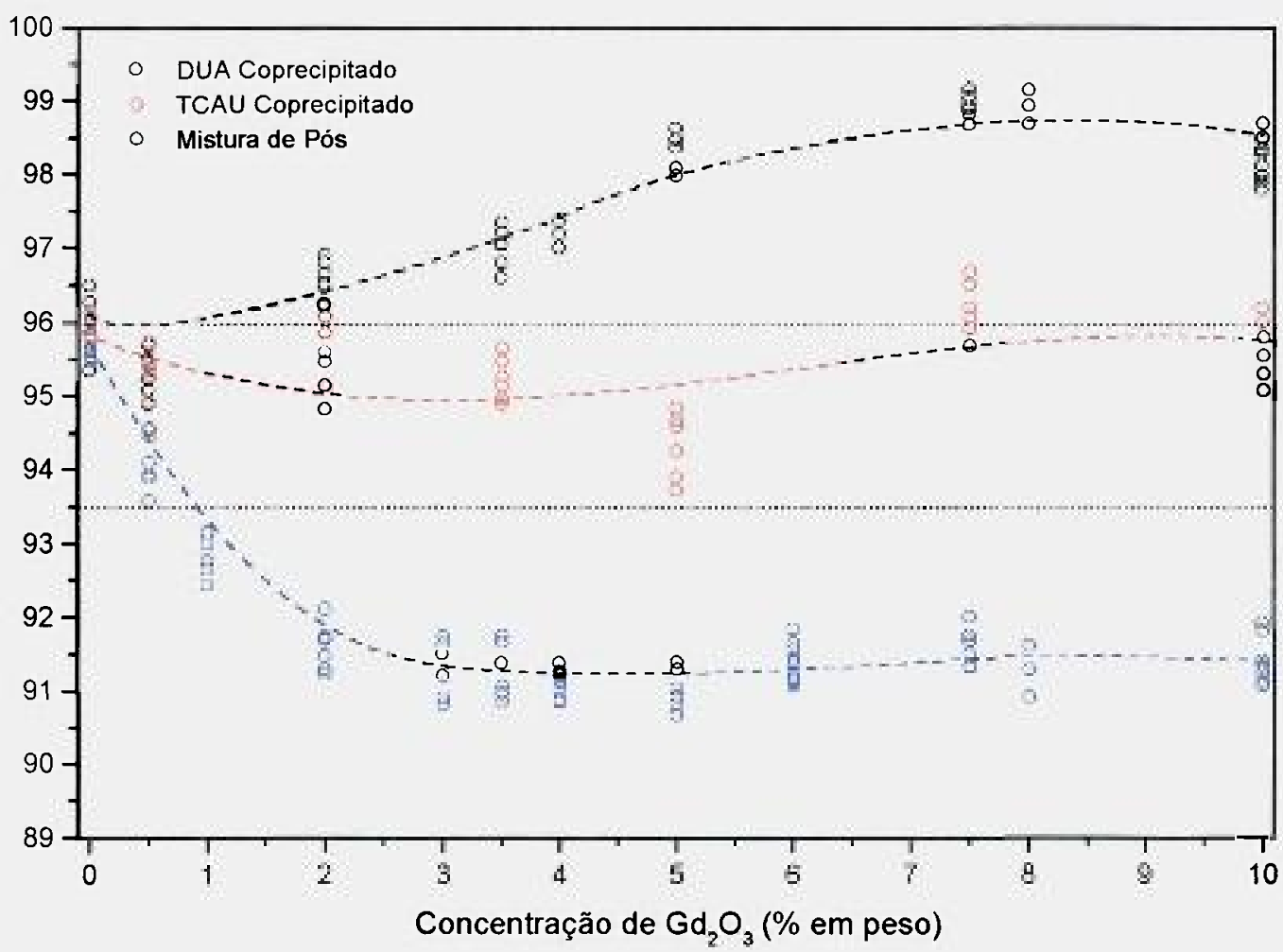

Figura 13 -Efeito da rota de preparação do pó $\mathrm{UO}_{2}-\mathrm{Gd}_{2} \mathrm{O}_{3}$ e da concentração de $\mathrm{Gd}_{2} \mathrm{O}_{3}$ na densidade de pastilhas sinterizadas.

Os resultados de sinterização das patilhas preparadas com pó obtido por coprecipitação via DUA demontraram que este tipo de pó tem uma alta sinterabilidade e que a adição de $\mathrm{Gd}_{2} \mathrm{O}_{3}$ aumenta a densificação do combustível durante a sinterização, como ilustra a figura 13. Este resultado também foi observado por Fukushima et al ${ }^{\text {(4) }} \mathrm{e}$ Hirai ${ }^{(115)}$ na sinterização de amostras derivadas de coprecipitação via DUA. As menores densidades obtidas por Fukushima et al, quando comparadas às obtidas neste trabalho, podem ser explicadas pelo uso de aglomerante no pó misto e também pela determinação da densidade da pastilha sinterizada pelo método geométrico, o qual usualmente resulta em densidades $1 \%$ (\% da densidade teórica) menor do que as determinadas pelo método de imersão.

As baixas densidades obtidas na sinterização de pastilhas $\mathrm{UO}_{2}-\mathrm{Gd}_{2} \mathrm{O}_{3}$ preparadas por mistura mecânica podem ser explicadas pela cinética de sinterização, como ilustra a figura 14. Nesta figura, pode-se observar que a adição de $\mathrm{Gd}_{2} \mathrm{O}_{3}$ por este método tem um efeito pronunciado no comportamento da sinterização do combustível. 


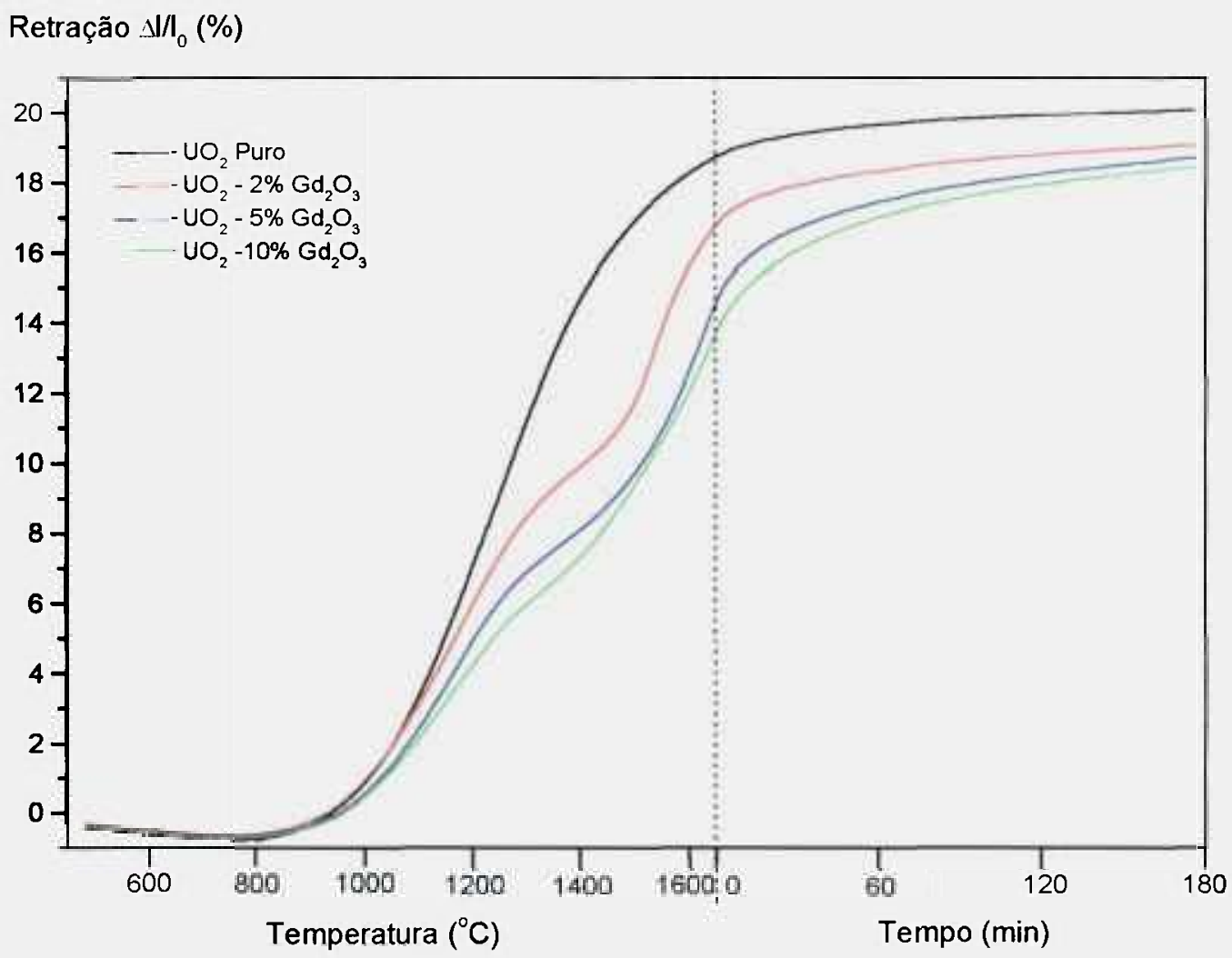

Figura 14 -Efeito da concentração de $\mathrm{Gd}_{2} \mathrm{O}_{3}$ na sinterização de pastilhas $\mathrm{UO}_{2}-\mathrm{Gd}_{2} \mathrm{O}_{3}$ preparadas por mistura mecânica de pós. $\left(5^{\circ} \mathrm{C} / \mathrm{min}, \mathrm{H}_{2}\right)$

Estes resultados são bastante concordantes com os obtido por Manzel e Dörr ${ }^{(46)}$, apresentados na figura 6 , que também utilizaram a rota de mistura de pós e $\mathrm{UO}_{2}$ proveniente do TCAU. O processo de sintcrização é bloqueado e a densificação é deslocada na direção de maiores temperaturas. A figura 15 ilustra as taxas de sinterização correspondentes às curvas da figura 14 , obtidas pelas suas derivadas.

Observa-se um comportamento da taxa de sinterização muito próximo ao obtido por Manzel e Dörr ${ }^{(46)}$, com duas etapas de sinterização. A taxa de sinterização não é afetada pela presença do $\mathrm{Gd}_{2} \mathrm{O}_{3}$ até temperaturas da ordem de $1000{ }^{\circ} \mathrm{C}$, quando uma diminuição dessa taxa, com relação à taxa observada para o $\mathrm{UO}_{2}$ puro, começa a ocorrer, diminuição esta proporcional à concentração de $\mathrm{Gd}_{2} \mathrm{O}_{3}$ presente no combustível. A 1200 ${ }^{\circ} \mathrm{C}$ é observado um máximo nas taxas de sinterização, sensivelmente menor do que a taxa máxima observada no caso do combustivel $\mathrm{UO}_{2}$ puro e tanto menor quanto maior a concentração de $\mathrm{Gd}_{2} \mathrm{O}_{3}$ presente. A partir deste valor máximo, as taxas diminuem bruscamente, atingindo um valor mínimo aproximadamente a $1400^{\circ} \mathrm{C}$, caracterizando-se $\mathrm{o}$ 
final da primeira etapa da sinterização. A partir desta temperatura, a taxa de sinterização aumenta novamente, iniciando-se uma segunda etapa de sinterização. A temperatura na qual ocorre o valor máximo da taxa de densificação na segunda etapa da sinterização é muito sensível à concentração de $\mathrm{Gd}_{2} \mathrm{O}_{3}$ presente no combustível, ao contrário do observado na primeira etapa. No caso do combustivel contendo $2 \%$ em peso de $\mathrm{Gd}_{2} \mathrm{O}_{3}$ o segundo pico ocorre a aproximadamente $1530{ }^{\circ} \mathrm{C}$, enquanto que para maiores concentrações a taxa máxima de sinterização não é obtida a $1650{ }^{\circ} \mathrm{C}$, prejudicando fortemente a densificação do combustível.

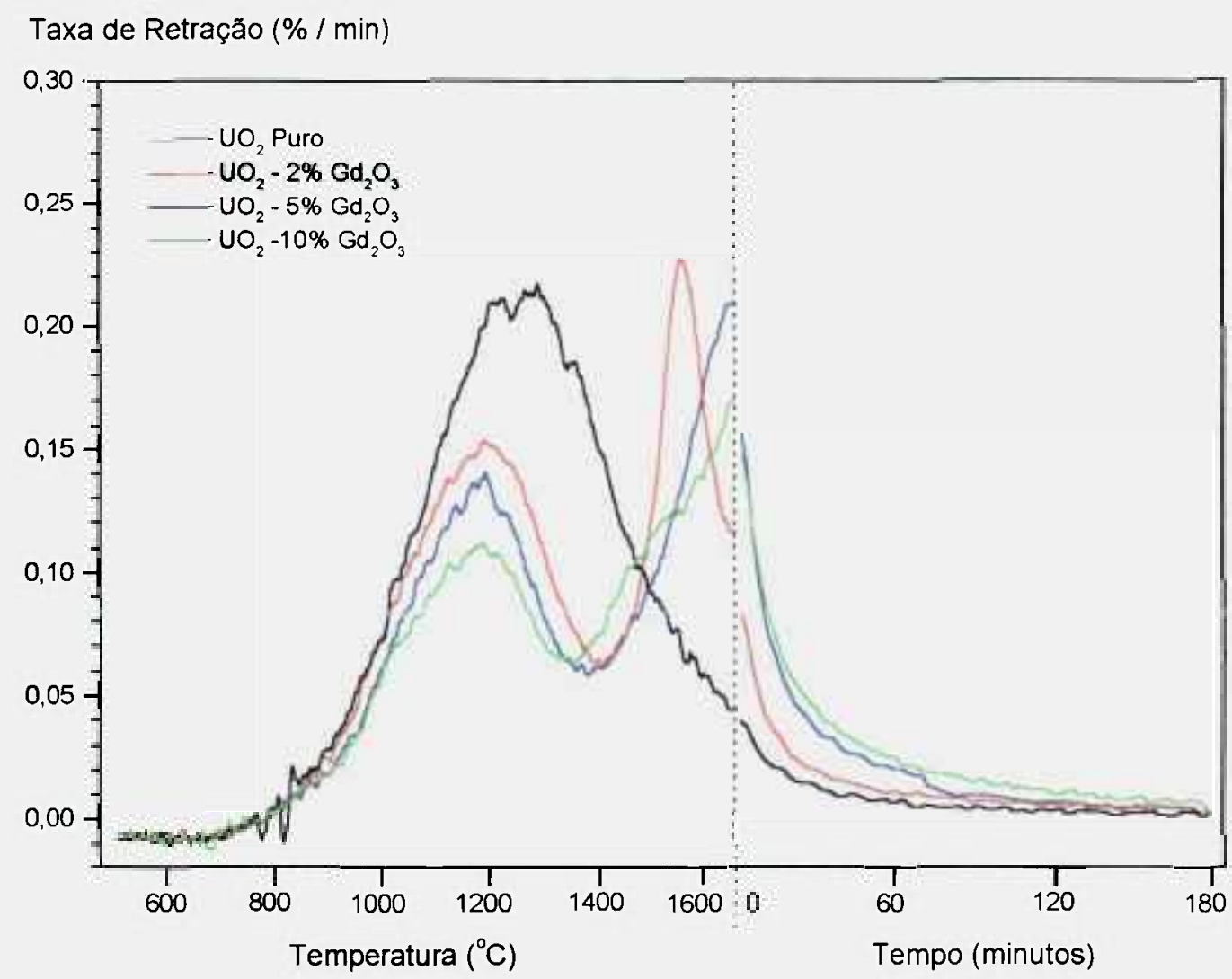

Figura 15 -Taxas de densificação derivadas das curvas apresentadas na figura 14.

Fica evidenciado, então, com base nos resultados apresentados, a ocorrência do bloqueio da sinterização do combustivel $\mathrm{UO}_{2}-\mathrm{Gd}_{2} \mathrm{O}_{3}$ quando o método de preparação do pó misto é mistura mecânica a seco, atribuído por Manzel e Dörr ${ }^{(46)}$ à formação da solução sólida $(\mathrm{U}, \mathrm{Gd}) \mathrm{O}_{2}$ a partir de $1200^{\circ} \mathrm{C}$. 
A figura 16 ilustra a influência do método de preparação do pó misto $\mathrm{UO}_{2}-\mathrm{Gd}_{2} \mathrm{O}_{3}$ na cinética de sinterização do sistema. O resultado obtido na sinterização do combustível $\mathrm{UO}_{2}$ puro, apresentado na figura 14 também está apresentado nesta figura, para efeito de comparação.

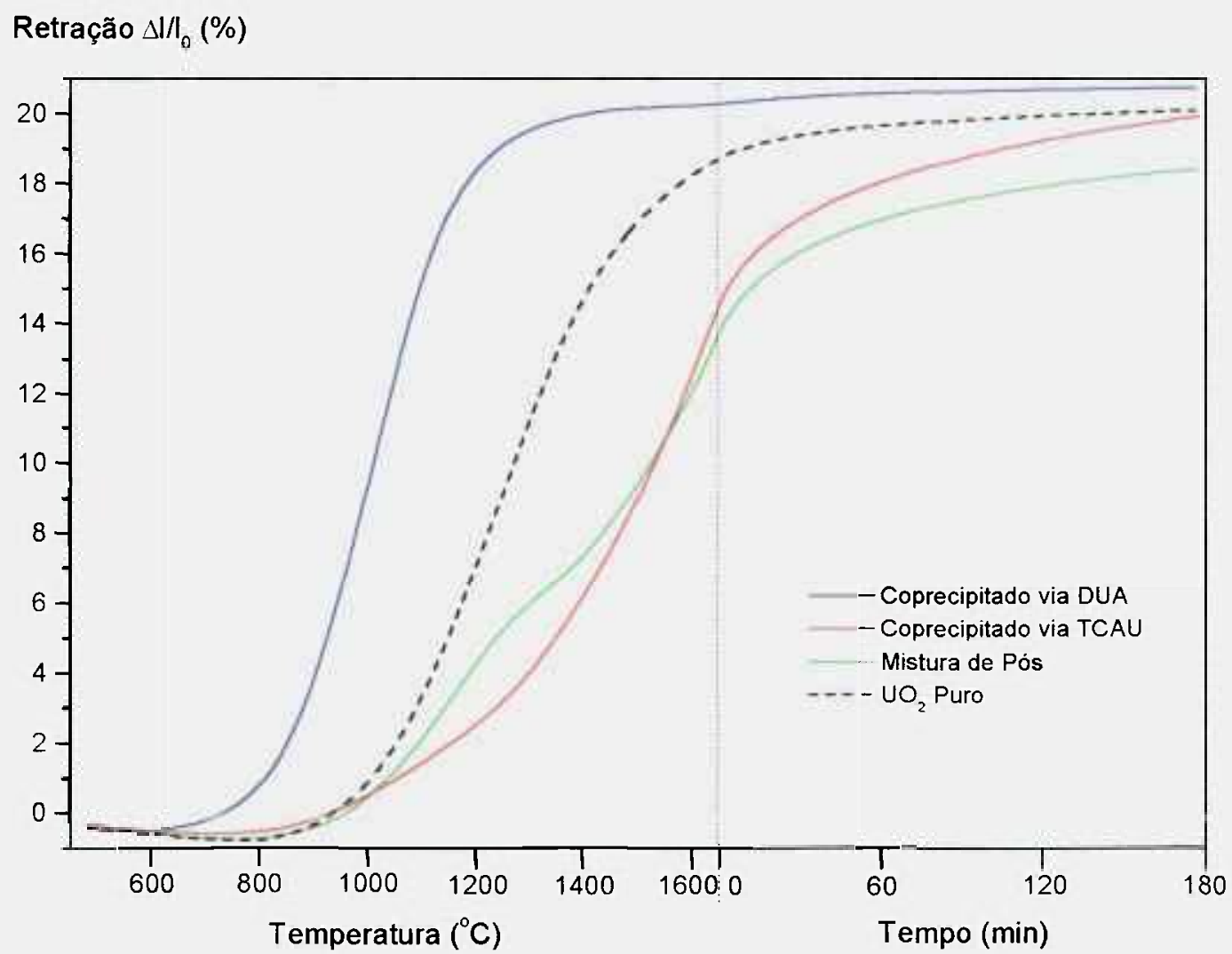

Figura 16 -Efeito do método de preparação do pó misto na sinterização de pastilhas $\mathrm{UO}_{2}-\mathrm{Gd}_{2} \mathrm{O}_{3} .\left(10 \%\right.$ em peso $\left.\mathrm{Gd}_{2} \mathrm{O}_{3}, 5^{\circ} \mathrm{C} / \mathrm{min}, \mathrm{H}_{2}\right)$

Como pode ser observado, as pastilhas preparadas pela rota de coprecipitação via DUA apresentam um comportamento na sinterização totalmente diferente do apresentado pelas amostras preparadas por mistura de pós. As amostras preparadas por coprecipitação via TCAU apresentam um comportamento que pode ser considerado, até certo ponto, similar ao apresentado pelas amostras preparadas por mistura de pós. A cinética de sinterização pode ser mais bem analisada observando-se as taxas de sinterização apresentadas na figura 17 .

As pastilhas preparadas pela rota de coprecipitação via DUA apresentam alta sinterabilidade, substancialmente superior ao combustível $\mathrm{UO}_{2}$ puro, com o início da 
sinterização ocorrendo em temperaturas inferiores e taxa máxima de sinterização sensívelmente mais elevada do que a observada para o combustivel isento de $\mathrm{Gd}_{2} \mathrm{O}_{3}$, conduzindo à obtenção de altas densidades finais. Nesta rota de preparação do pó misto $\mathrm{UO}_{2}-\mathrm{Gd}_{2} \mathrm{O}_{3}$ o comportamento da sinterização é similar ao observado para o $\mathrm{UO}_{2}$ puro, com apenas uma etapa, não sendo evidenciado o bloqueio observado no caso das amostras preparadas pela rota de mistura de pós.

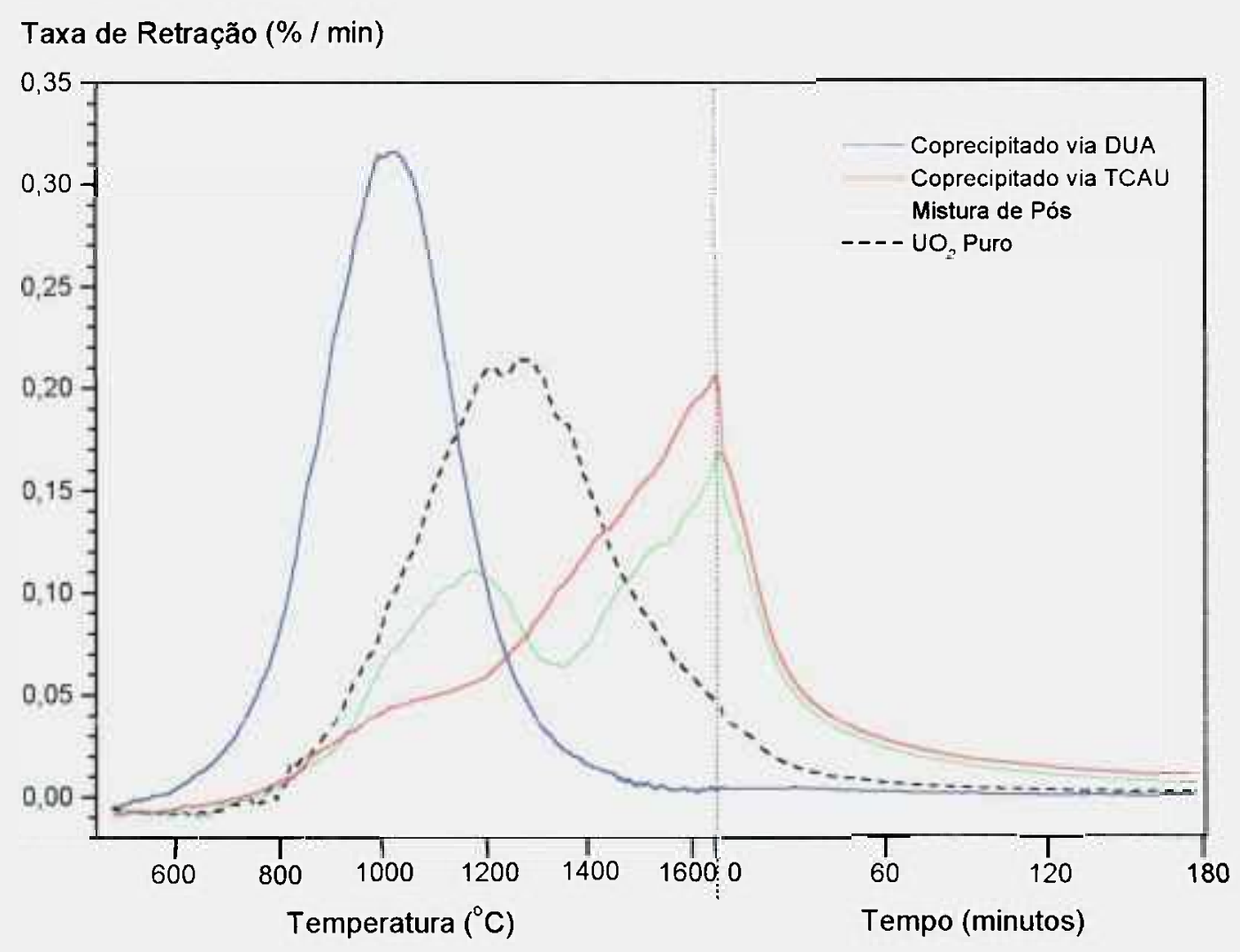

Figura 17 -Taxas de densificação derivadas das curvas apresentadas na figura 16.

As pastilhas preparadas pela rota de coprecipitação via TCAU apresentam um comportamento na sinterização que pode ser considerado intermediário entre os das pastilhas preparadas por coprecipitação via DUA e por mistura de pós, aproximando-se mais do caso de mistura mecânica. Observa-se que não ficam evidenciadas duas etapas de sinterização com os dois picos na taxa de sinterização bem definidos, como no caso de mistura de pós. Por outro lado, a sinterabilidade no caso da rota de coprecipitação via TCAU não pode ser comparada à observada no caso da rota de coprecipitação via DUA. Um bloqueio na sinterização também fica evidenciado neste caso, porém com início e final em temperaturas mais baixas, o que possibilita uma boa densificação após o bloqueio, 
recuperando-se a densificação durante o tratamento isotérmico. Isto explica a forte influência que o tempo de sinterização exerce na densidade final obtida em pastilhas preparadas pela rota de coprecipitação via TCAU, muito superior à exercida no caso de amostras preparadas pela rota de coprecipitação via DUA ${ }^{(124)}$.

A dependência do comportamento da sinterização do sistema $\mathrm{UO}_{2}-\mathrm{Gd}_{2} \mathrm{O}_{3}$ com relação à rota de preparação do pó misto, discutida acima, parece estar relacionada à forma como o gadolínio está distribuído no pó misto, discutida anteriormente. Pastilhas preparadas a partir do pó obtido por coprecipitação via DUA, o qual possui gadolínio na forma de solução sólida, caracterizando-se alto nivel de homogeneidade, apresentam uma alta sinterabilidade, sensivelmente maior do que o $\mathrm{UO}_{2}$ puro, sem evidências de bloqueio na sinterização, resultando em elevadas densidades após a sinterização. $O$ oposto é observado em pastilhas preparadas com pó misto obtido segundo a rota de mistura de pós, onde o gadolínio está presente na forma de $\mathrm{Gd}_{2} \mathrm{O}_{3}$ livre, caso em que ocorre um bloqueio na sinterização do sistema, conduzindo a baixas densidades após a sinterização. $O$ comportamento da sinterização de pastilhas preparadas segundo a rota de coprecipitação via TCAU é o caso intermediário entre os discutidos acima, estando uma parcela do gadolínio presente no pó como solução sólida e outra como $\mathrm{Gd}_{2} \mathrm{O}_{3}$ livre (maior parcela), o que conduz a um comportamento da sinterização também intermediário, mais próximo do caso de mistura de pós, evidenciando-se também o bloqueio da sinterização.

A análise da homogeneidade da distribuição de gadolínio foi realizada por microssonda eletrônica em seções polidas de pastilhas sinterizadas contendo $7,5 \% \mathrm{em}$ peso de $\mathrm{Gd}_{2} \mathrm{O}_{3}$, preparadas segundo as três rotas investigadas. Como pode ser observado na figura 18, a homogeneidade da distribuição de gadolínio nas pastilhas sinterizadas segue a mesma tendência observada nos pós mistos por difração de raios-X. Também três níveis de homogeneidade estão evidenciados após a sinterização, alto no caso de coprecipitação via DUA, baixo no caso de mistura de pós e intermediário no caso de coprecipitação via TCAU. A estes três níveis de homogenèidade na distribuição de gadolínio, observados tanto no pó misto quanto nas pastilhas sinterizadas, correspondem os três níveis de densificação durante a sinterização, com diferentes cinéticas observadas.

A homogeneidade da distribuição de gadolínio nas pastilhas sinterizadas também foi avaliada qualitativamente por meio de microscopia óptica. Secões polidas das pastilhas sinterizadas preparadas a partir de pós obtidos segundo os três diferentes métodos investigados foram atacadas segundo o procedimento desenvolvido por Hammerschmidt e Saiger ${ }^{(138)}$. Este tipo de ataque confere às regiões ricas em urânio uma coloração azul, às regiões de solução sólida uma coloração marrom a amarelo, dependendo da concentração de gadolínio, e às regiões ricas em gadolínio uma coloração amarelo claro a branco. A 
figura 19 apresenta micrografias das amostras após a aplicação do ataque. Pode-se observar os três níveis de homogeneidade na distribuição de gadolínio, correspondentes à homogeneidade existente no pó original e também à densidade obtida após a sinterização, confirmando os resultados apresentados na figura 18 .

\section{(A) Mistura de Pós}

URÂNIO

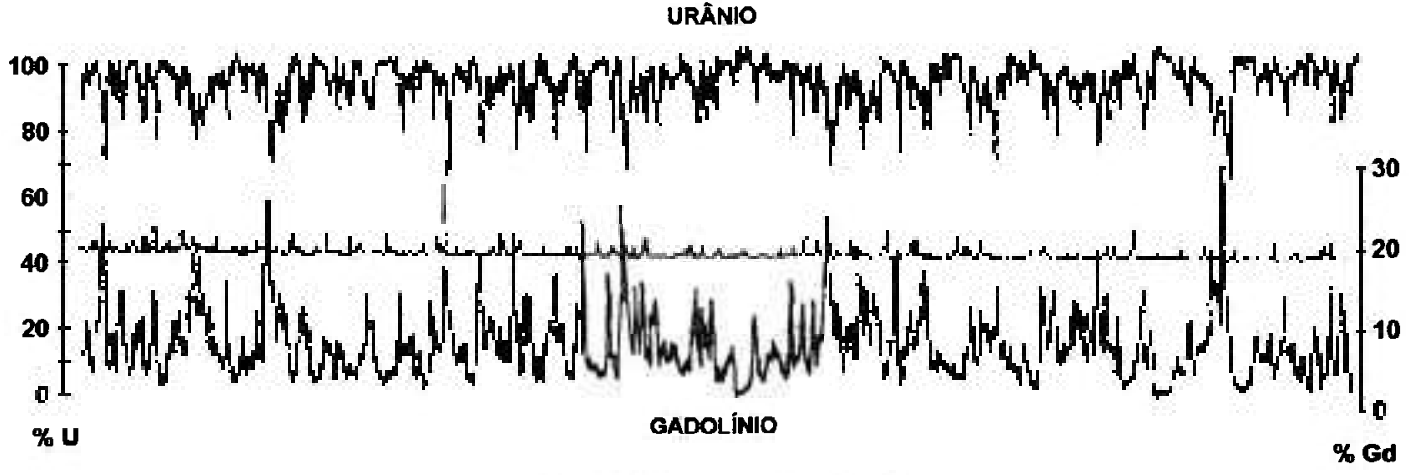

(B) Coprecipitação DUA

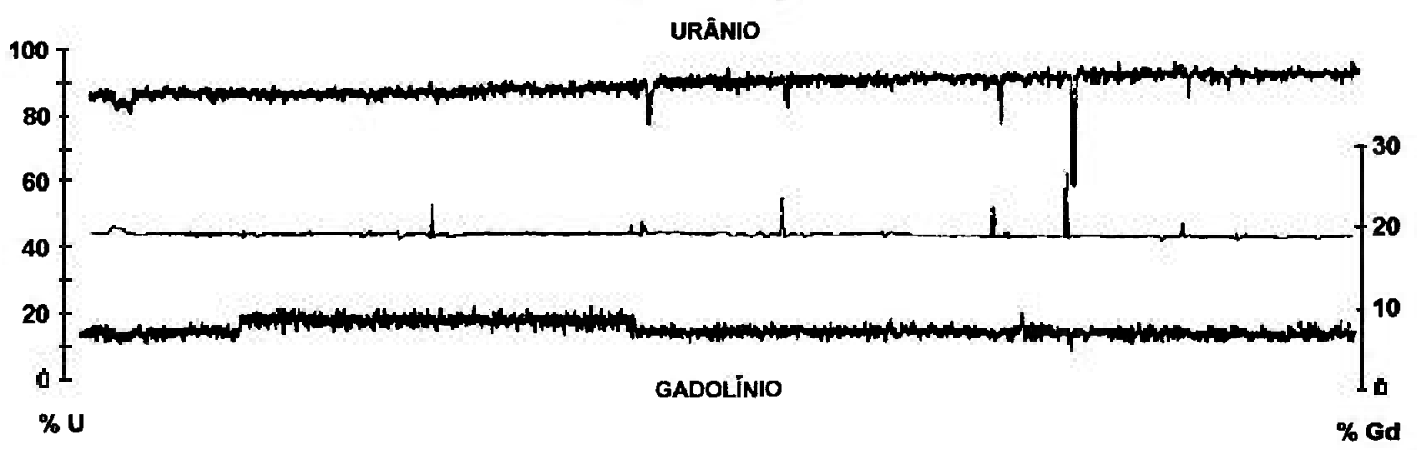

(C) Coprecipitação TCAU

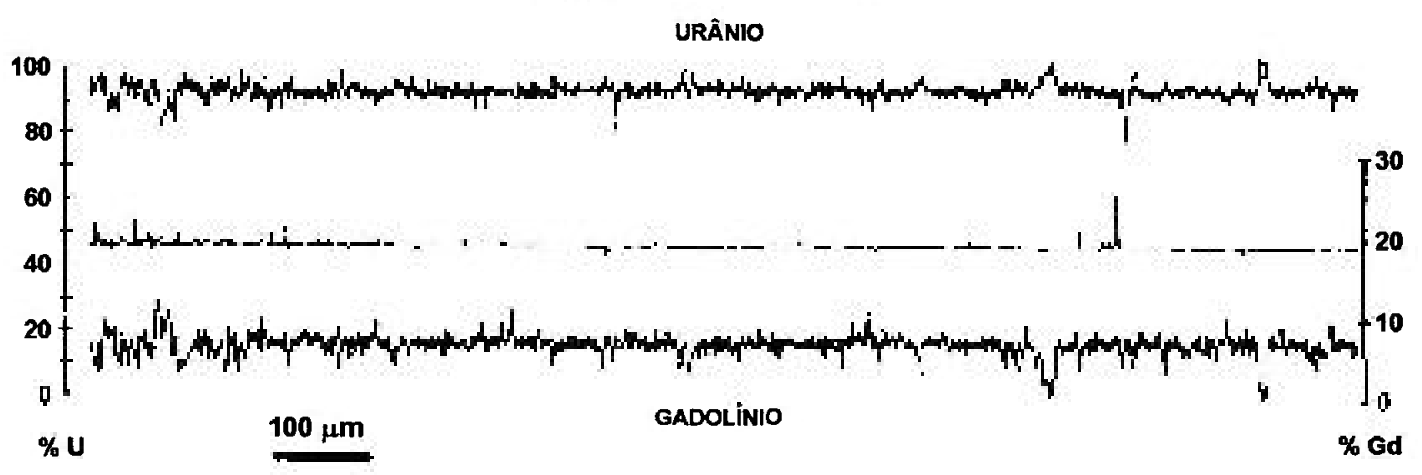

Figura 18 - Distribuição de gadolínio em pastilhas sinterizadas $\left(7,5 \%\right.$ em peso $\left.\mathrm{Gd}_{2} \mathrm{O}_{3}\right)$ : A - Mistura de pós, B - Coprecipitação DUA, C - Coprecipitação TCAU

Na figura 19A, referente à amostra obtida via coprecipitação de DUA, observa-se uma excelente homogeneidade, onde existe uma matriz homogênea de solução sólida, 
(A)

Coprecipitação via DUA
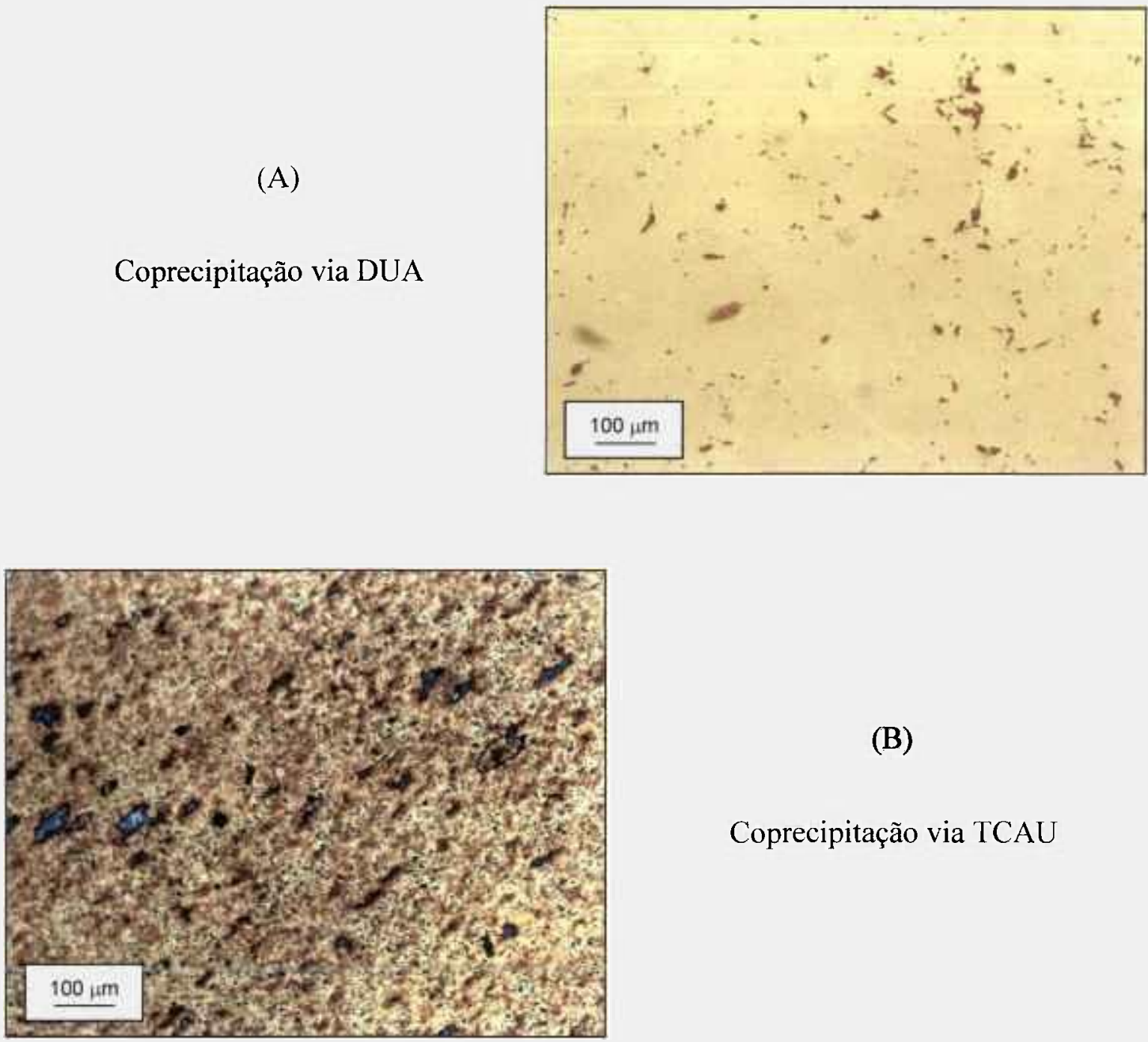

(B)

Coprecipitação via TCAU

(C)

Mistura de Pós

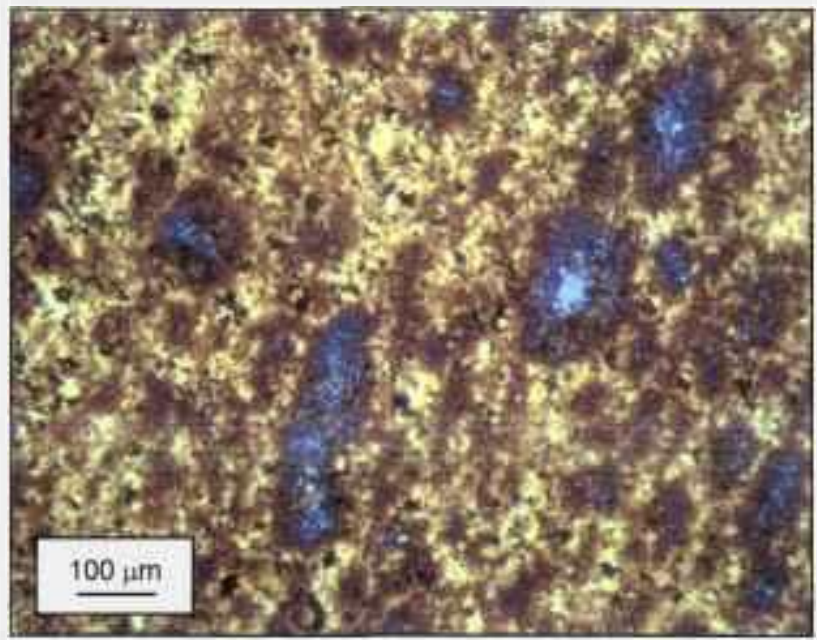

Figura 19 - Micrografias ópticas de pastilhas $\mathrm{UO}_{2}-\mathrm{Gd}_{2} \mathrm{O}_{3}$ sinterizadas ilustrando diferentes níveis de homogeneidade. $\left(7,5 \%\right.$ em peso $\left.\mathrm{Gd}_{2} \mathrm{O}_{3}\right)$ 
evidenciada pela homogeneidade da cor amarela. A amostra obtida por coprecipitação via TCAU apresenta a fase $\mathrm{UO}_{2}$ puro bem definida, na cor azul, regiões mais escuras na cor marrom, o que indica alta concentração de urânio, e regiões de cor amarelo claro, o que indica regiões com alta concentração de gadolínio. No caso da amostra preparada por mistura de pós, amplas regiões de $\mathrm{UO}_{2}$ puro e ricas em urânio podem ser observadas, assim como regiões bem claras que indicam alta concentração de gadolínio. É interessante observar que a coloração varia do azul, referente ao $\mathrm{UO}_{2}$ puro, passando pelo violeta quando algum gadolínio já está presente (ocorrendo ao redor das regiões azuis) e pelo marrom escuro. Na medida que a concentração de gadolínio sè eleva, a coloração marrom escura torna-se mais clara, atingindo uma coloração amarela, tanto mais clara quanto maior a concentração de gadolínio, até a cor branca, que indica a presença de $\mathrm{Gd}_{2} \mathrm{O}_{3}$ puro.

Os resultados obtidos indicam que a homogeneidade da distribuição do gadolínio originalmente presente no pó misto determina a homogeneidade da distribuição do gadolínio na pastilha sinterizada e, mais importante, determina o comportamento da sinterização do combustível. As curvas de sinterização mostraram que a densificação é fortemente influenciada pela homogeneidade do pó misto. Os três níveis de homogeneidade do $\mathrm{Gd}_{2} \mathrm{O}_{3}$ no pó misto correspondem diretamente aos três níveis de densificação observados na sinterização das pastilhas. Os métodos adotados para a preparação dos pós mistos resultam em diferentes nỉveis de homogeneidade na distribuição do $\mathrm{Gd}_{2} \mathrm{O}_{3}$ no pó misto, os quais podem ser descritos como segue:

Nivel Atômico: a maior parte do $\mathrm{Gd}_{2} \mathrm{O}_{3}$ originalmente adicionado ao pó de $\mathrm{UO}_{2}$ está presente no pó misto na forma de solução sólida. Após a redução, a maior parte gadolínio já está incorporado na estrutura cristalina $\mathrm{CFC}$ do $\mathrm{UO}_{2}$ (tipo fluorita, figura 1). $\mathrm{O} \mathrm{Gd}_{2} \mathrm{O}_{3}$ é homogeneizado num nível atômico. Este é o caso do pó misto preparado segundo a rota de coprecipitação via DUA.

Nível Microscópico: parte do $\mathrm{Gd}_{2} \mathrm{O}_{3}$ originalmente adicionado ao pó de $\mathrm{UO}_{2}$ está presente no pó misto na forma de solução sólida e parte permanece como $\mathrm{Gd}_{2} \mathrm{O}_{3}$ livre. Provavelmente a coprecipitação não ocorreu, mas sim é provável ter ocorrido uma precipitação simultânea. Neste caso, a homogeneização é realizada em fase líquida e uma boa homogeneidade é alcançada, num nível microscópico. Este é o caso do pó misto preparado segundo a rota de coprecipitação via TCAU. Ravindran et al ${ }^{(137)}$ também não puderam obter solução sólida pela rota de coprecipitação via TCAU. 
Nível Macroscópico: todo o $\mathrm{Gd}_{2} \mathrm{O}_{3}$ originalmente adicionado ao pó de $\mathrm{UO}_{2}$ está presente no pó misto na forma de $\mathrm{Gd}_{2} \mathrm{O}_{3} \mathrm{CCC}$ livre. Neste caso é obtido o pior nível de homogeneidade e o $\mathrm{Gd}_{2} \mathrm{O}_{3}$ está presente como uma dispersão de aglomerados no pó misto. A alta tendência do $\mathrm{Gd}_{2} \mathrm{O}_{3}$ à aglomeração foi observada neste trabalho (figura 9). Esta é a razão provável para Manzel e Dörr ${ }^{(46)}$ terem aplicado o procedimento de mistura matriz. Neste caso, uma homogeneidade ruim é alcançada, num nível macroscópico. Este é o caso do pó misto preparado segundo a rota de mistura mecânica a seco.

Baseado nos resultados obtidos na literatura ${ }^{(40,45,114)}$ e apresentados na figura 5 , uma boa homogeneidade na distribuição do $\mathrm{Gd}_{2} \mathrm{O}_{3}$ no pó misto pode ser obtida por meio do método da comoagem, ou seja, moagem conjunta de ambos os pós de $\mathrm{UO}_{2}$ e $\mathrm{Gd}_{2} \mathrm{O}_{3}$. A homogeneidade alcançada por este método aproxima-se do nível microscópico e resulta num comportamento na sinterização suficiente, conforme já foi discutido.

Com base nos resultados apresentados neste item, pode-se concluir que a má homogeneidade na distribuição do $\mathrm{Gd}_{2} \mathrm{O}_{3}$ no pó misto é a causa primária que explica as baixas densidades observadas nas pastilhas sinterizadas derivadas do pó misto $\mathrm{UO}_{2}-\mathrm{Gd}_{2} \mathrm{O}_{3}$ preparado segundo o método adotado comercialmente de mistura mecânica a seco.

O mecanismo proposto por Une e Oguma ${ }^{(72)}$ e Davis e Potter ${ }^{(113)}$ para explicar a diminuição da densificação do $\mathrm{UO}_{2}$ devido à presença do $\mathrm{Gd}_{2} \mathrm{O}_{3}$, baseado no modelo de formação de vacâncias de oxigênio, fundamentado na hipoestequiometria observada no sistema, não é sustentado pelos resultados obtidos nesta fase deste trabalho, uma vez que o pó obtido por coprecipitação via DUA, com alto grau de homogeneidade, apresentou alta sinterabilidade. Ao contrário, a presença do $\mathrm{Gd}_{2} \mathrm{O}_{3}$ aumentou sensivelmente a sinterabilidade do $\mathrm{UO}_{2}$. Apesar destes pesquisadores ${ }^{(72,113)}$ terem adotado a rota de mistura de pós na preparação de suas amostras, nenhuma menção quanto ao grau de homogeneidade obtido no pó misto foi encontrada, o que abre a possibilidade da causa das baixas densidades obtidas após a sinterização ser uma má homogeneidade na distribuição de $\mathrm{Gd}_{2} \mathrm{O}_{3}$ no pó misto.

O mecanismo proposto por Ho e Radford ${ }^{(40)}$ para explicar as altas densidades após a sinterização obtidas no seu trabalho é apoiado pelos resultados aqui apresentados. Quando o $\mathrm{Gd}_{2} \mathrm{O}_{3}$ está presente no pó misto na forma de cátions $\mathrm{Gd}^{3+}$ (nível atômico), uma alta sinterabilidade foi observada, que é o caso do pó obtido pela rota de coprecipitação via DUA. Segundo Ho e Radford, a incorporação do $\mathrm{Gd}^{3+}$ na rede cristalina do $\mathrm{UO}_{2}$ conduz à formação de cátions $\mathrm{U}^{5+}$ e $\mathrm{U}^{6+}$ de alta mobilidade, o que explica este comportamento. Neste caso não ocorre o bloqueio da sinterização, pelo contrário. Ho e Radford 
observaram altas densidades sinterizadas em seu trabalho provavelmente devido ao procedimento adotado na preparação dos pós mistos (comoagem), que resultou num bom grau de homogeneidade, certamente superior ao nível microscópico. De qualquer forma, este mecanismo proposto, apesar de apoiado pelos resultados aqui obtidos, somente é aplicável quando o $\mathrm{Gd}_{2} \mathrm{O}_{3}$ está presente no pó misto com um alto grau de homogeneidade, o que não é o caso da rota de mistura de pós, objeto deste estudo. Se a distribuição de $\mathrm{Gd}_{2} \mathrm{O}_{3}$ no pó misto não é boa, o modelo proposto por Ho e Radford não é válido e uma baixa sinterabilidade é observada. Quanto maior for a homogeneidade do pó misto, maior será a densidade final obtida na sinterização. Assim, o mecanismo que explica o bloqueio da sinterização do sistema $\mathrm{UO}_{2}-\mathrm{Gd}_{2} \mathrm{O}_{3}$ no caso da rota de mistura de pós não pode ser baseado no mecanismo proposto por Ho e Radford.

Manzel e Dörr ${ }^{(46)}$ relacionam o bloqueio da sinterização de pastilhas preparadas segundo a rota de mistura de pós ao início da formação da solução sólida (U,Gd) $\mathrm{O}_{2}$, causado pelo fato do processo de formação da solução sólida ocorrer simultaneamente com o processo de sinterização. Assmann et al ${ }^{(68)}$ complementam esta proposição sugerindo a formação de fases durante a sinterização que influenciam os coeficientes de difusão no sistema $\mathrm{UO}_{2}-\mathrm{Gd}_{2} \mathrm{O}_{3}$. Peehs et al ${ }^{(67)}$ detectaram a presença de uma fase $\left(\mathrm{U}_{0,5} \mathrm{Gd}_{0,5}\right) \mathrm{O}_{2}$ em pastilhas $\mathrm{UO}_{2}-\mathrm{Gd}_{2} \mathrm{O}_{3}$ sinterizadas. Apesar da relevância destas observações, nestes trabalhos não foi desenvolvido e comprovado um modelo que possa explicar o comportamento da sinterização observado por estes pesquisadores, o qual é muito semelhante ao observado neste trabalho. Contudo, com base nas informações obtidas destes pesquisadores e, também, nos resultados obtidos até esta fase deste trabalho, é possível propor-se um mecanismo para explicar o comportamento da sinterização do combustível preparado pela rota da mistura de pós. Se o atraso na densificação, observado nas amostras preparadas segundo a rota de mistura mecânica de pós, coìncide com o início da formação da solução sólida, pode ser proposto um modelo baseado na formação de uma fase $(\mathrm{U}, \mathrm{Gd}) \mathrm{O}_{2}$ rica em gadolinio que apresente baixa difusividade catiônica. A formação dessa fase ao redor de aglomerados de $\mathrm{Gd}_{2} \mathrm{O}_{3}$ presentes no caso de mistura mecânica (nível macroscópico de homogeneidade) atuaria como uma barreira de difusão, causando a diminuição da sinterabilidade devido à baixa difusividade catiônica. Este modelo também explicaria a alta sinterabilidade observada nas amostras preparadas por coprecipitação via DUA, uma vez que havendo alta homogeneidade na distribuição de gadolínio, não poderia ser formada esta fase de baixa difusividade, já que não ocorreriam regiões com alta concentração de gadolínio e, portanto, não poderia ser formada a barreira de difusão.

Fica então proposta a hipótese da formação de uma barreira de difusão para explicar o comportamento da sinterização do combustível $\mathrm{UO}_{2}-\mathrm{Gd}_{2} \mathrm{O}_{3}$ preparado segundo o método de mistura mecânica a seco dos pós de $\mathrm{UO}_{2}$ e $\mathrm{Gd}_{2} \mathrm{O}_{3}$, como segue: 
"Durante a sinterização do combustivel $\mathrm{UO}_{2}-\mathrm{Gd}_{2} \mathrm{O}_{3}$ preparado pelo método de mistura de pós é formada uma fase (U,Gd) $\mathrm{O}_{2}$ rica em gadolínio que apresenta baixa difusividade catiônica. Ocorrendo essa fase ao redor de aglomerados de $\mathrm{Gd}_{2} \mathrm{O}_{3}$, presentes no caso de mistura mecânica (nivel macroscópico de homogeneidade), a mesma atua como uma barreira de difusão, causando a diminuição da sinterabilidade do sistema devido diminuiçào da difusividade catiônica".

Uma vez que muito pouca informação sobre a ocorrência de fases no sistema $\mathrm{UO}_{2}-\mathrm{Gd}_{2} \mathrm{O}_{3}$ está disponível na literatura, com o objetivo de fundamentar esta hipótese, um estudo exploratório foi realizado procurando-se obter informações sobre o sistema, relativas à formação de fases e suas características de difusividade catiônica, a qual determina a sua sinterabilidade. Os resultados estão apresentados no próximo item.

\subsection{Desenvolvimento da hipótese}

\subsubsection{Fases no sistema $\mathrm{UO}_{2}-\mathrm{Gd}_{2} \mathrm{O}_{3}$}

Uma vez que o método de preparação de pós e pastilhas de $\mathrm{UO}_{2}-\mathrm{Gd}_{2} \mathrm{O}_{3}$ por coprecipitação via DUA demonstrou resultar em amostras com um alto grau de homogeneidade na distribuição de gadolínio (nível atômico), este método foi selecionado para a preparação de amostras contendo concentrações de $\mathrm{Gd}_{2} \mathrm{O}_{3}$ numa ampla faixa, de 0 a $100 \%$ em peso. Estas amostras possibilitaram a realização de uma investigação que procurou verificar a existência de fases de baixa difusividade catiônica no sistema $(\mathrm{U}, \mathrm{Gd}) \mathrm{O}_{2}$, a qual poderia fundamentar a hipótese da barreira de difusão. Descrevem-se, a seguir, os materiais e métodos utilizados na preparação das amostras e a metodologia adotada na deteç̧ão e caracterização de possíveis fases de baixa difusividade catiônica. 


\subsubsection{Metodologia}

O procedimento na preparação dos pós mistos por coprecipitação via DUA foi o mesmo descrito anteriormente, no item 2.1.1.1. Os pós de $\mathrm{UO}_{2}$ e $\mathrm{Gd}_{2} \mathrm{O}_{3}$ utilizados como material de partida também foram os mesmos, cujas características estão apresentadas nas tabelas 3 e 4. A faixa de concentração de $\mathrm{Gd}_{2} \mathrm{O}_{3}$ presente no pó misto anteriormente estudada (item 2.1.1) foi ampliada para até $100 \%$ em peso, abrangendo todo o sistema $\mathrm{UO}_{2}-\mathrm{Gd}_{2} \mathrm{O}_{3}$. As composições nominais escolhidas foram calculadas de modo a obter-se valores de $\mathrm{X}$ na fórmula $\left(\mathrm{U}_{1-\mathrm{x}} \mathrm{Gd}_{\mathrm{x}}\right) \mathrm{O}_{2}$ variando de 0,2 a 1,0 (20 a $\left.100 \% \mathrm{em} \mathrm{mol}\right)$, com valores variando igualmente espaçados em 0,1 . Numa segunda etapa, após a avaliação dos primeiros resultados, outras composições foram preparadas com o objetivo de complementar os dados obtidos, possibilitando uma interpretação mais conclusiva dos resultados. Todos os pós também foram calcinados por 2 horas a $600{ }^{\circ} \mathrm{C}$ antes da sua redução, como descrito no item 2.1.1.1. A redução e passivação dos pós calcinados foram realizadas segundo o procedimento descrito anteriormente. A tabela 8 apresenta a composição nominal dos pós preparados como descrito acima.

A variação da superfície específica em função do teor de gadolínio contido no pó está apresentada na figura 20. Nesta figura também estão incluídas as superficies específicas determinadas nos pós com concentrações de $\mathrm{Gd}_{2} \mathrm{O}_{3}$ de até $10 \%$ em peso, preparados anteriormente por coprecipitação via DUA (item 2.1.1.1), apresentadas na tabela 7 .

Observa-se na figura 20 uma ligeira tendência no aumento da superficie específica com o aumento do teor de gadolínio presente no pó misto. Este comportamento é observado até frações entre 0,7 e 0,9 , atingindo valores da ordem de $25 \mathrm{~m}^{2} / \mathrm{g}$, quando os valores começam a diminuir, atingindo pouco mais de $16 \mathrm{~m}^{2} / \mathrm{g}$ no caso de $\mathrm{Gd}_{2} \mathrm{O}_{3}$ puro $(X=1)$.

Todos os pós obtidos após a calcinação foram caracterizados por difração de raios-X com o objetivo de verificar a presença de $\mathrm{Gd}_{2} \mathrm{O}_{3} \mathrm{CCC}$ livre, garantindo-se que em todas as amostras o gadolínio está presente em solução sólida, ou seja, homogeneizado ao nível atômico. Os difratogramas estão apresentados nas figuras 21 a 24 .

Observando-se os difratogramas da figura 21, verifica-se que a presença de apenas $2 \%$ em peso de $\mathrm{Gd}_{2} \mathrm{O}_{3}$ já altera significativamente o difratograma característico do $\mathrm{U}_{3} \mathrm{O}_{8}$ ortorrômbico, com a supressão dos dubletos nas posições $2 \theta$ de $26^{\circ}$ e $34^{\circ}$ e o evidente alargamento dos picos. Os picos de difração em altos ângulos e de baixa intensidade, bem definidos no caso do $\mathrm{U}_{3} \mathrm{O}_{8}$ puro, perdem definição. Essas profundas alterações no 
Tabela 8 - Composições nominais dos pós $\mathrm{UO}_{2}-\mathrm{Gd}_{2} \mathrm{O}_{3}$ preparados por coprecipitação via DUA.

\begin{tabular}{|c|c|c|}
\hline \multirow{2}{*}{ ent } & \multicolumn{2}{|c|}{ Concentração de $\mathrm{Gd}_{2} \mathrm{O}_{3}$} \\
\hline & (\% em peso) & (\% em mol) \\
\hline $\mathrm{DC} 0$ & 0 & 0 \\
\hline $\mathrm{DC} 2$ & 2 & 2,95 \\
\hline DC4 & 4 & 5,84 \\
\hline DC6 & 6 & 8,68 \\
\hline DC8 & 8 & 11,69 \\
\hline DC10 & 10 & 14,20 \\
\hline DC14 & 14,37 & 20 \\
\hline DC22 & 22,34 & 30 \\
\hline DC30 & 30,92 & 40 \\
\hline DC40 & 40,17 & 50 \\
\hline DC50 & 50,18 & 60 \\
\hline DC53 & 53,34 & 63 \\
\hline DC56 & 56,58 & 66 \\
\hline DC61 & 61,04 & 70 \\
\hline DC66 & 66,83 & 75 \\
\hline DC70 & 70,42 & 78 \\
\hline DC71 & 71,34 & 79 \\
\hline DC72 & 72,87 & 80 \\
\hline DC74 & 74,11 & 81 \\
\hline DC75 & 75,37 & 82 \\
\hline DC80 & 80,49 & 86 \\
\hline DC85 & 85,81 & 90 \\
\hline DC90 & 89,93 & 93 \\
\hline DC92 & 92,75 & 95 \\
\hline DC95 & 95,61 & 97 \\
\hline DC100 & 100 & 100 \\
\hline
\end{tabular}

difratograma padrão do $\mathrm{U}_{3} \mathrm{O}_{8}$ demonstram que o gadolínio está interferindo fortemente na estrutura cristalina. Este comportamento ocorre até a concentração de $10 \%$ em peso de $\mathrm{Gd}_{2} \mathrm{O}_{3}$, quando, a partir dessa concentração (14,37 \% em peso ou fração molar de 0,2$)$, o pico mais intenso do $\mathrm{U}_{3} \mathrm{O}_{8}$ ortorrômbico $\left(2 \theta=26^{\circ}\right)$ diminui sensivelmente de intensidade e é detectado um novo pico de difração na posição $2 \theta$ aproximada de $28^{\circ}$, proveniente do início de formação de uma nova fase. A formação desta nova fase fica mais evidente com o aumento do teor de gadolínio. Na amostra contendo fração molar de $0,3(22,34 \% \mathrm{em}$ peso de $\mathrm{Gd}_{2} \mathrm{O}_{3}$ ), a intensidade dos picos de difração correspondentes à estrutura ortorrômbica do $\mathrm{U}_{3} \mathrm{O}_{8}$ diminui ainda mais, e um segundo pico correspondente à nova fase 
em formação ocorre na posição $2 \theta$ aproximada de $48^{\circ}$, ficando mais evidente o pico inicialmente desenvolvido na composição anterior (14,37 \% em peso ou fração molar de 0,2 ), situado na posição $2 \theta=28^{\circ}$.

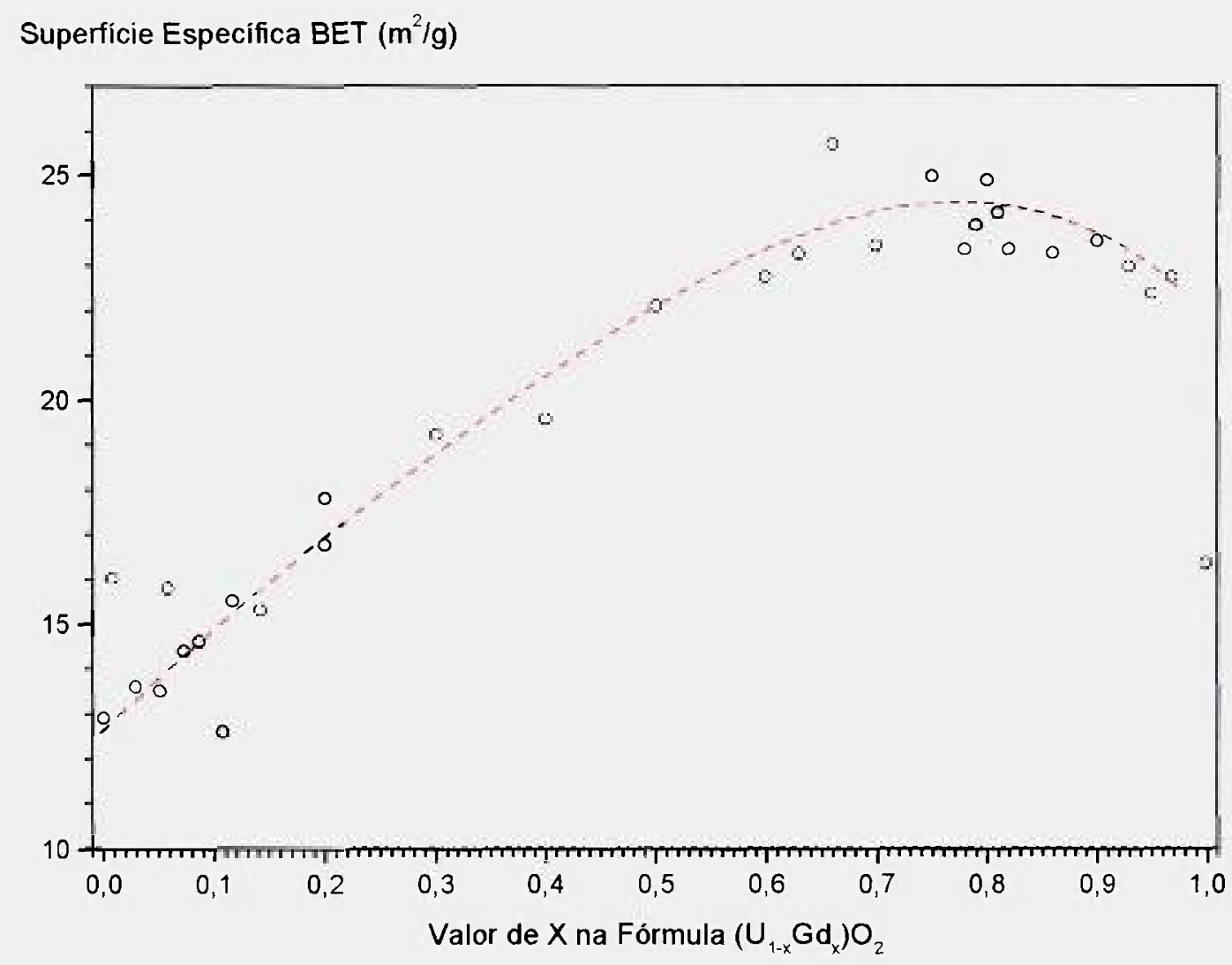

Figura 20 -Efeito do teor de gadolínio na superficie específica (BET) dos pós $\mathrm{UO}_{2}-\mathrm{Gd}_{2} \mathrm{O}_{3}$ preparados segundo o método de coprecipitação via DUA (após a redução).

A figura 22 ilustra o desenvolvimento desta nova fase. Com o aumento do teor de gadolínio, os picos de difração referentes ao $\mathrm{U}_{3} \mathrm{O}_{8}$ ortorrômbico diminuem de intensidade até desaperecer totalmente, o que ocorre para a fração molar de 0,6 $(50,18 \% \mathrm{em}$ peso deGd $\mathrm{G}_{3}$ ), quando apenas o pico mais intenso do $\mathrm{U}_{3} \mathrm{O}_{8}$ pode ser detectado com dificuldade. As caracteristicas do difratograma modificam-se inteiramente, não restando indícios da estrutura cristalina original do $\mathrm{U}_{3} \mathrm{O}_{8}$ ortorrômbico. Esta nova fase formada tem a estrutura cristalina tipo fluorita do $\mathrm{UO}_{2}$. Na figura 22 está também apresentado o difratograma do $\mathrm{UO}_{2}$ puro para comparação e facilitação da observação. Nota-se que os picos referentes à estrutura fluorita da nova fase em formação estão bastante deslocados na direção de maiores ângulos, o que significa parâmetro de rede menor do que o da estrutura do $\mathrm{UO}_{2}$ puro. 


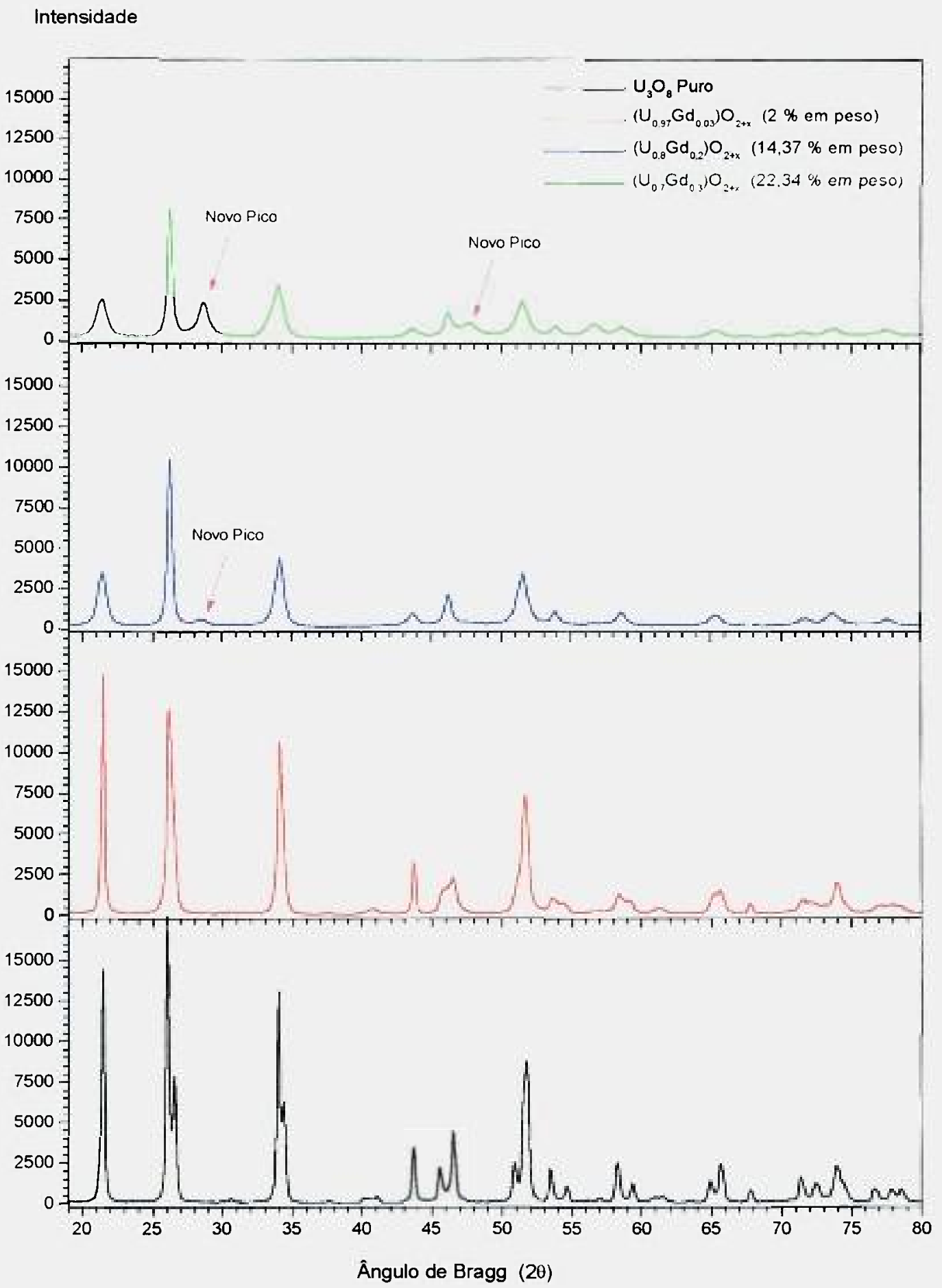

Figura 21 - Difratogramas de raios- $\mathrm{X}$ de pós $\mathrm{UO}_{2}-\mathrm{Gd}_{2} \mathrm{O}_{3}$ oxidados obtidos por coprecipitação via DUA. $\left(\mathrm{U}_{3} \mathrm{O}_{8}\right.$ a $\left.\left(\mathrm{U}_{0,7} \mathrm{Gd}_{0,3}\right) \mathrm{O}_{2}\right)\left(600^{\circ} \mathrm{C} / 2\right.$ horas $)$

$\mathrm{Na}$ figura 23, nota-se que quando desaparecem todos os picos do $\mathrm{U}_{3} \mathrm{O}_{8}$ ortorrômbico, a intensidade do pico mais intenso da nova estrutura eleva-se consideravelmente (fração molar de 0,7 ou $61,04 \%$ em peso de $\mathrm{Gd}_{2} \mathrm{O}_{3}$ ), o que indica que esta fase substituiu totalmente o $\mathrm{U}_{3} \mathrm{O}_{8}$. Contudo, para frações molares maiores do que 0,7 , 


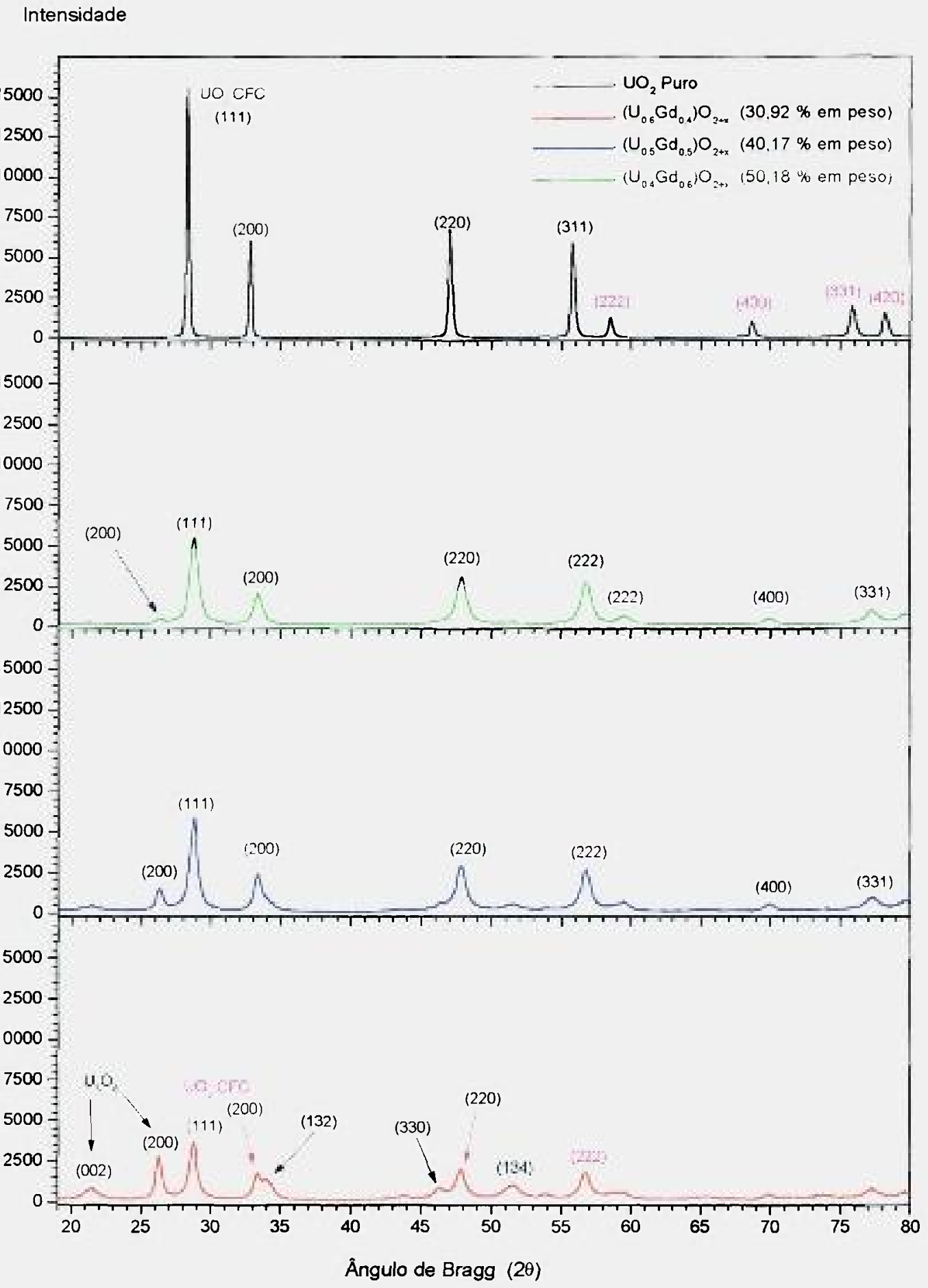

Figura 22 - Difratogramas de raios- $\mathrm{X}$ de pós $\mathrm{UO}_{2}-\mathrm{Gd}_{2} \mathrm{O}_{3}$ oxidados obtidos por coprecipitação via DUA. $\quad\left(\left(\mathrm{U}_{0,6} \mathrm{Gd}_{0.4}\right) \mathrm{O}_{2}\right.$ a $\left.\left(\mathrm{U}_{0.4} \mathrm{Gd}_{0.6}\right) \mathrm{O}_{2}\right)$ $\left(600^{\circ} \mathrm{C} / 2\right.$ horas $)$

a intensidade dos picos volta a diminuir e o alargamento fica mais acentuando, evidenciado no difratograma resultante da composição $\left(\mathrm{U}_{0,2} \mathrm{Gd}_{0,8}\right) \mathrm{O}_{2}\left(72,87 \%\right.$ em peso de $\left.\mathrm{Gd}_{2} \mathrm{O}_{3}\right)$, sugerindo a possibilidade de estar-se formando uma nova fase cujo difratograma está em 


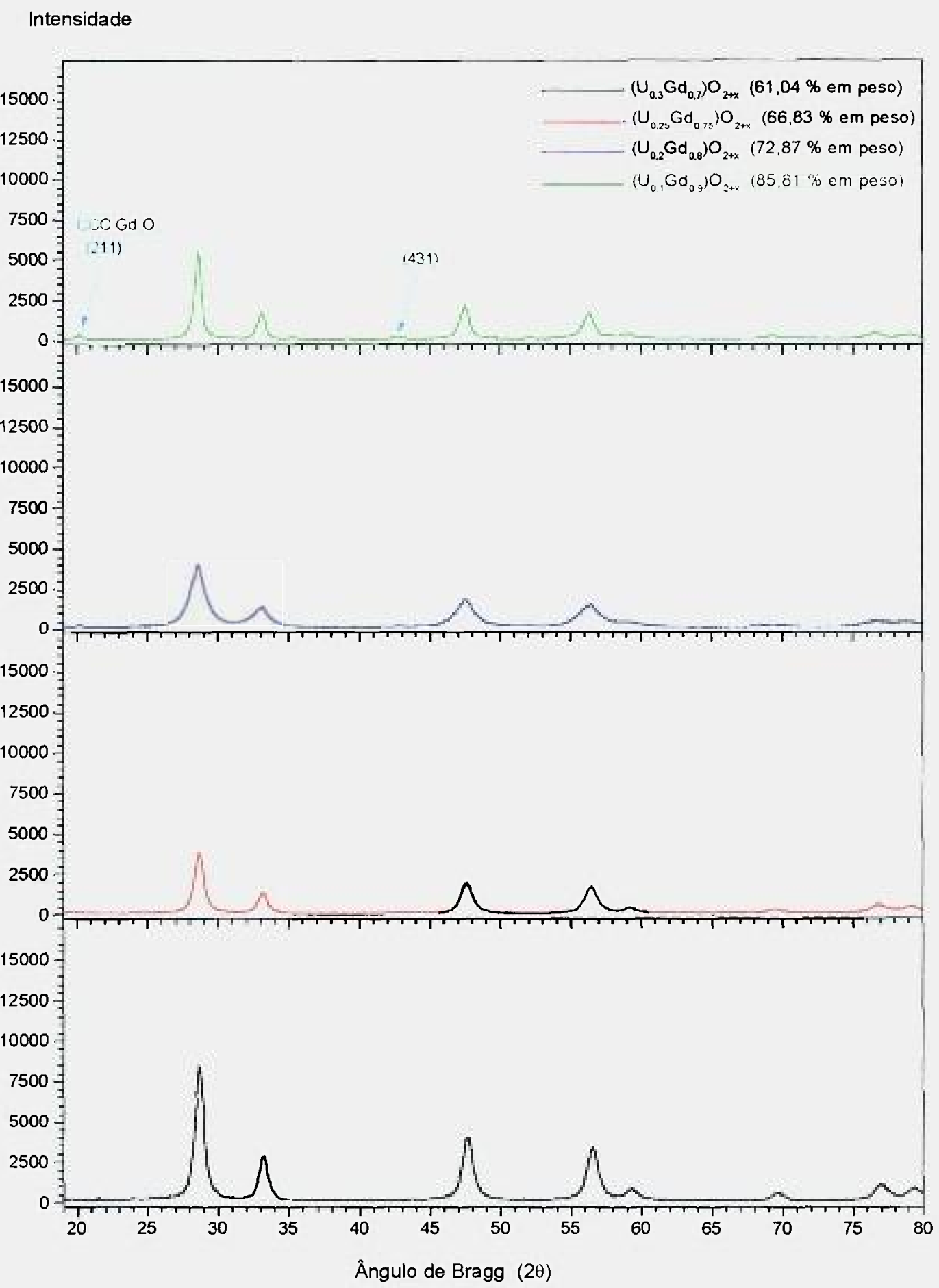

Figura 23 - Difratogramas de raios-X de pós $\mathrm{UO}_{2}-\mathrm{Gd}_{2} \mathrm{O}_{3}$ oxidados obtidos por coprecipitação via DUA. $\quad\left(\left(\mathrm{U}_{0.7} \mathrm{Gd}_{0.3}\right) \mathrm{O}_{2}\right.$ a $\left.\left(\mathrm{U}_{0.1} \mathrm{Gd}_{0.9}\right) \mathrm{O}_{2}\right)$ $\left(600^{\circ} \mathrm{C} / 2\right.$ horas $)$

coincidência com o característico da estrutura fluorita do $\mathrm{UO}_{2}$. Esta nova fase poderia ser a fase $6 \mathrm{GdUO}_{12}$ proposta por Aitken et al ${ }^{(58)}$, com estrutura cristalina romboédrica, podendo estar ocorrendo, segundo os difratogramas apresentados, para frações molares de 
gadolínio entre 0,75 e 0,86 e que possui os picos de difração muito próximos aos picos característicos da estrutura tipo fluorita, portanto, dificil de detectar-se. O aumento do teor de gadolínio conduz ao início da formação da fase cúbica de corpo centrado característica do $\mathrm{Gd}_{2} \mathrm{O}_{3}$, como pode ser observado na figura 24 .

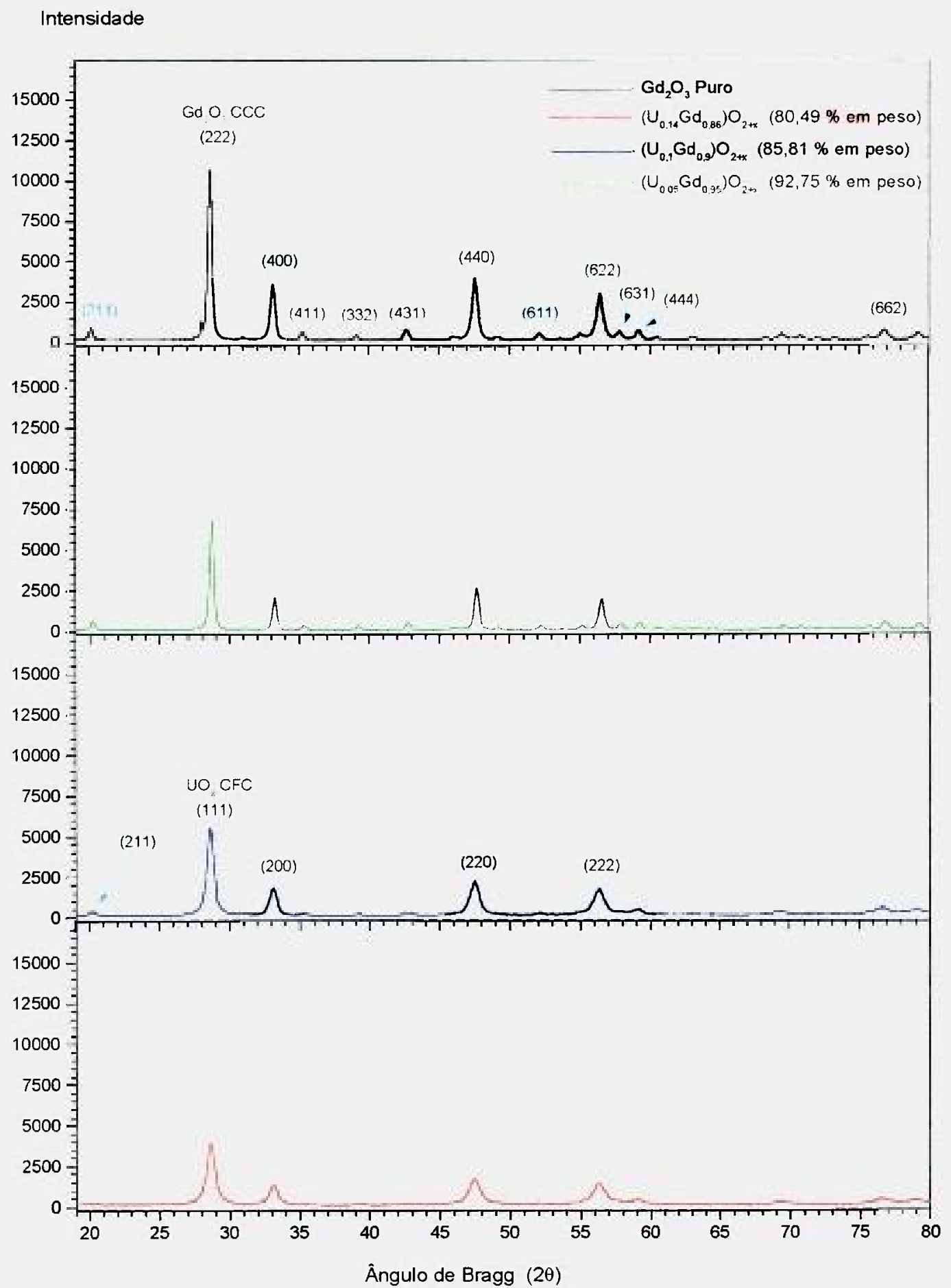

Figura 24 - Difratogramas de raios-X de pós $\mathrm{UO}_{2}-\mathrm{Gd}_{2} \mathrm{O}_{3}$ oxidados obtidos por coprecipitação via DUA. ( $\left(\mathrm{U}_{0.14} \mathrm{Gd}_{0,86}\right) \mathrm{O}_{2}$ a $\left.\mathrm{Gd}_{2} \mathrm{O}_{3}\right)$

$\left(600^{\circ} \mathrm{C} / 2\right.$ horas $)$ 
A figura 24 complementa a evolução dos difratogramas com o aumento do teor de gadolínio. Quando a fração molar de gadolínio atinge o valor de 0,9 , inicia-se a formação da estrutura cristalina cúbica de corpo centrado característica do $\mathrm{Gd}_{2} \mathrm{O}_{3}$. Pelo alargamento dos picos pode-se concluir que as fases fluorita (ou romboédrica) e CCC coexistem até que seja atingida a fração molar de 0,95 de gadolínio, quando o difratograma fica bem mais definido, com os picos característicos do $\mathrm{Gd}_{2} \mathrm{O}_{3}$. O difratograma do $\mathrm{Gd}_{2} \mathrm{O}_{3}$ puro também está apresentado nesta figura para facilitar a observação da mudança do aspecto dos difratogramas.

Os difratogramas apresentados demonstram que todo o $\mathrm{Gd}_{2} \mathrm{O}_{3}$ adicionado está presente como solução sólida em toda a faixa de composição estudada. A presença da fase cúbica de corpo centrado a partir da fração molar de gadolínio de 0,9 ocorre também com pronunciado alargamento dos picos de difração, indicando a presença de urânio em solução sólida, somente ficando mais definido o difratograma para $\mathrm{Gd}_{2} \mathrm{O}_{3}$ praticamente puro (fração molar de 0,97). Portanto, fica comprovada a qualidade da homogeneidade obtida pelo método de coprecipitação via DUA para a preparação das amostras utilizadas no estudo das fases no sistema $\mathrm{UO}_{2}-\mathrm{Gd}_{2} \mathrm{O}_{3}$.

Todos os pós obtidos após a calcinação foram reduzidos sob atmosfera de hidrogênio por 3 horas a $650{ }^{\circ} \mathrm{C}$ segundo o procedimento descrito no item 2.1.1.1. A compactação foi realizada utilizando-se os mesmos equipamentos e procedimentos anteriormente descritos, obtendo-se pastilhas com diâmetro de $9,3 \mathrm{~mm}$ e altura próxima a 9 $\mathrm{mm}$, com densidade ao redor de $50 \%$ da densidade teórica. A sinterização foi realizada no mesmo forno e segundo o mesmo procedimento descrito no item 2.1.1.1, sendo as densidades obtidas após a sinterização determinadas pelo método de imersão utilizando o xilol como líquido. Para verificação da concentração real de $\mathrm{Gd}_{2} \mathrm{O}_{3}$ nas pastilhas sinterizadas, estas foram determinadas em algumas composições por meio de uma adaptação do método de determinação de urânio total por volumetria ${ }^{(139)}$. A tabela 9 apresenta os resultados obtidos. Observa-se que a concentração de $\mathrm{Gd}_{2} \mathrm{O}_{3}$ determinada é muito próxima da composição nominal adicionada. Nas quatro composições analisadas, o máximo desvio em relação à composição nominal foi de $0,64 \%$ em peso, o que representa um desvio máximo de $1 \%$. Apesar de não terem sido analisadas as concentrações de todas as composições preparadas, os resultados obtidos são considerados suficientes para confirmar que praticamente todo o $\mathrm{Gd}_{2} \mathrm{O}_{3}$ adicionado está presente na amostra. 
Tabela 9 - Composição das pastilhas $\mathrm{UO}_{2}-\mathrm{Gd}_{2} \mathrm{O}_{3}$ sinterizadas obtidas a partir dos pós preparados por coprecipitação via DUA.

\begin{tabular}{ccc}
\hline \multirow{2}{*}{ Identificação da } & $\begin{array}{c}\text { Concentração Nominal de } \\
\text { Amostra }\end{array}$ & $\begin{array}{c}\text { Concentração de } \mathrm{Gd}_{2} \mathrm{O}_{3} \\
\text { Determinada }\end{array}$ \\
& $(\%$ em peso) & $(\%$ em peso $)$ \\
\hline \multirow{2}{*}{ DC10 } & 10 & 9,98 \\
& & 9,97 \\
& & 9,94 \\
\hline \multirow{2}{*}{ DC61 } & 61,04 & 60,6 \\
& & 60,5 \\
& & 60,4 \\
\hline \multirow{2}{*}{ DC74 } & 74,11 & 74,1 \\
& & 73,9 \\
& & 74,1 \\
\hline
\end{tabular}

\subsubsection{Resultados e discussão}

A variação das densidades obtidas após a sinterização em função da fração molar de gadolínio presente na amostra demonstra que ocorrem regiões de concentração para as quais a sinterabilidade é inequivocamente diminuída, como ilustra a figura 25.

As densidades relativas (\% da densidade teórica) apresentadas nessa figura foram calculadas assumindo-se uma dispersão de $\mathrm{Gd}_{2} \mathrm{O}_{3}$, com estrutura cristalina cúbica de corpo centrado (forma $\mathrm{C}$ dos óxidos de terras raras), e $\mathrm{UO}_{2}$, com estrutura cúbica de face centrada tipo fluorita, calculada segundo a expressão ${ }^{\text {(11,95): }}$

$$
W W=\frac{1100}{\frac{100-x}{\rho_{U O 2}}+\frac{x}{\rho_{G d 2 O 3}}}
$$


onde: $\quad D T=$ densidade teórica $\left(\mathrm{g} / \mathrm{cm}^{3}\right)$

$x=$ concentração de $\mathrm{Gd}_{2} \mathrm{O}_{3}(\%$ em peso $)$.

$\rho_{\mathrm{UO2}}=$ densidade teórica do $\mathrm{UO}_{2}$, de $10,96 \mathrm{~g} / \mathrm{cm}^{3}{ }^{(135)}$.

$\rho_{G d 2 O 3}=$ densidade teórica da forma $\mathrm{C}$ do $\mathrm{Gd}_{2} \mathrm{O}_{3}$ (cúbica), de $7,41 \mathrm{~g} / \mathrm{cm}^{3}$ (135).

Este método de cálculo da densidade teórica é utilizado numa das especificações adotadas para a densidade de pastilhas $\mathrm{UO}_{2}-\mathrm{Gd}_{2} \mathrm{O}_{3}$ sinterizadas (11,95), apresentada anteriormente no item 1.4. Como será discutido adiante, para frações molares de gadolínio acima de 0,93 , observa-se a formação da forma $\mathrm{B}$ do $\mathrm{Gd}_{2} \mathrm{O}_{3}$, de estrutura cristalina monoclínica. Portanto, na faixa de concentração de gadolínio de 0,93 a 1 , a densidade teórica do $\mathrm{Gd}_{2} \mathrm{O}_{3}$ utilizada no cálculo da densidade teórica do sistema foi de $8,352 \mathrm{~g} / \mathrm{cm}^{3}$ (140).

Observa-se na figura 25 que o aumento da sinterabilidade do $\mathrm{UO}_{2}$ com o aumento da concentração de $\mathrm{Gd}_{2} \mathrm{O}_{3}$, o qual ocorre até $10 \%$ em peso, como apresentado na figura 13 e discutido no item 2.1.1.2, atinge uma saturação a partir da composição $\left(\mathrm{U}_{0,9} \mathrm{Gd}_{0,1}\right) \mathrm{O}_{2}$, quando é mantido um alto nível de densificação até a composição $\left(\mathrm{U}_{0,5} \mathrm{Gd}_{0,5}\right) \mathrm{O}_{2}$, mantendo-se densidades na faixa de 98 a $99 \%$ da densidade teórica. Estas altas densidades obtidas podem ser explicadas segundo o modelo proposto por Ho e Radford ${ }^{\text {(*0) }}$, no qual a presença de íons $\mathrm{Gd}^{3+}$ causa um aumento na difusividade catiônica e, portanto, um aumento na sinterabilidade do $\mathrm{UO}_{2}$.

Quando o número de átomos de $\mathrm{Gd}$ supera o número de átomos de $\mathrm{U}(\mathrm{X}>0,5)$, as densidades obtidas após a sinterização diminuem drasticamente, atingindo um valor mínimo para a composição $\left(\mathrm{U}_{0,3} \mathrm{Gd}_{0,7}\right) \mathrm{O}_{2}$. $\mathrm{O}$ aumento da fração molar de gadolínio a partir dessa composição volta a elevar a sinterabilidade do sistema $(\mathrm{U}, \mathrm{Gd}) \mathrm{O}_{2}$, até atingir um máximo para a composição $\left(\mathrm{U}_{0,2} \mathrm{Gd}_{0,8}\right) \mathrm{O}_{2}$, obtendo-se densidades da ordem de $93 \%$ da densidade teórica, quando uma nova queda na sinterabilidade é observada. Outro mínimo é observado na composição $\left(\mathrm{U}_{0,18} \mathrm{Gd}_{0,82}\right) \mathrm{O}_{2}$, a partir da qual o nível de densificação se eleva até que que seja atingida a densidade típica obtida na sinterização de pastilhas de $\mathrm{Gd}_{2} \mathrm{O}_{3}$ puro, da ordem de $94 \%$ da densidade teórica.

É interessante notar o comportamento da curva da figura 25 entre as composições $\left(\mathrm{U}_{0,3} \mathrm{Gd}_{0,7}\right) \mathrm{O}_{2}$ e $\left(\mathrm{U}_{0,18} \mathrm{Gd}_{0,82}\right) \mathrm{O}_{2}$, região na qual ocorre um pico nas densidades obtidas. Este comportamento foi confirmado por meio de repetições de testes de sinterização da composição $\left(\mathrm{U}_{0,2} \mathrm{Gd}_{0,8}\right) \mathrm{O}_{2}$ e sinterização das composições intermediárias entre $\mathrm{X}=0,7$ e $\mathrm{X}=0,9$, como ilustra a figura. 


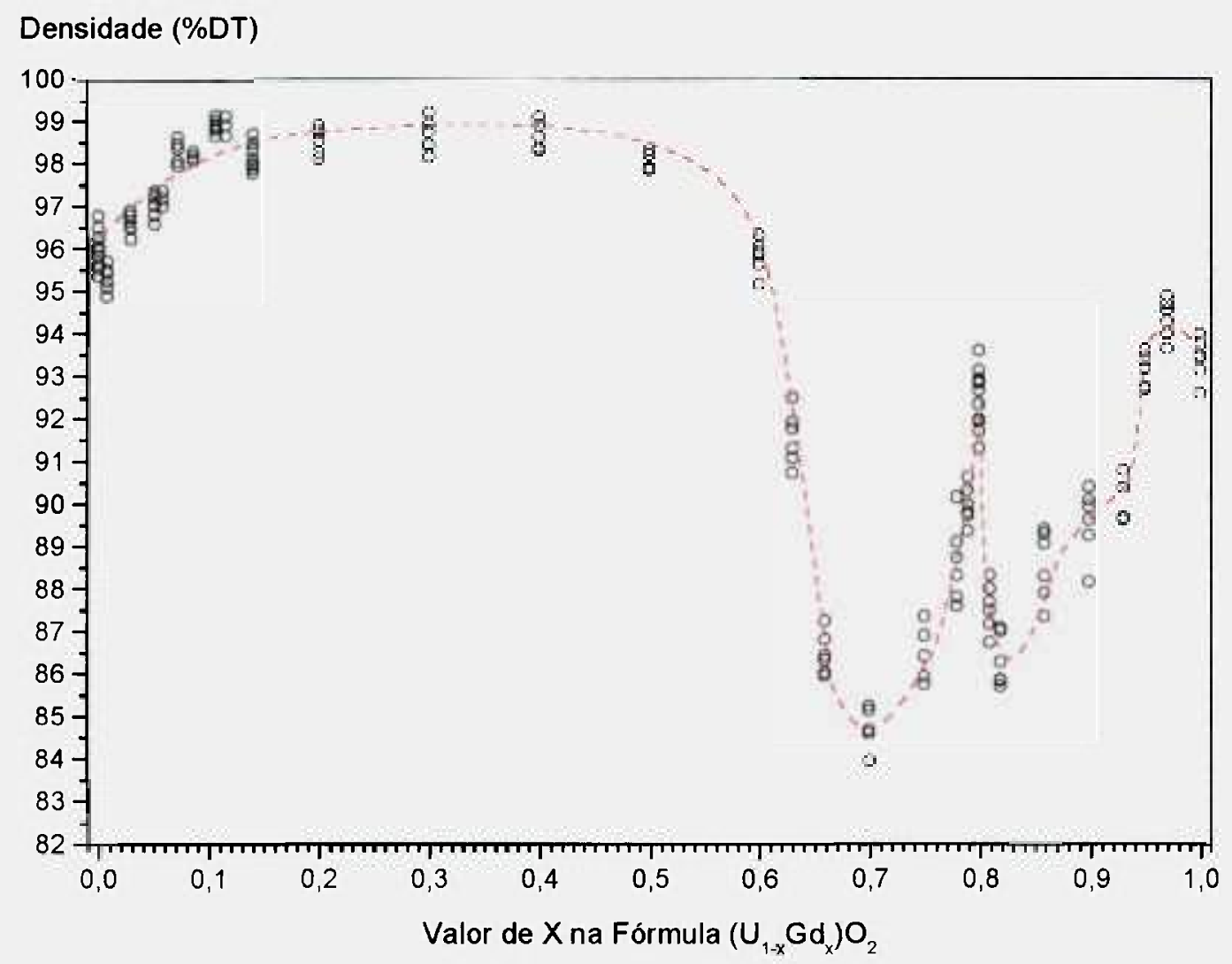

Figura 25 -Efeito do teor de gadolínio na densificação de pastilhas $\mathrm{UO}_{2}-\mathrm{Gd}_{2} \mathrm{O}_{3}$ preparadas segundo o método de coprecipitação via DUA.

Pastilhas $\mathrm{UO}_{2}-\mathrm{Gd}_{2} \mathrm{O}_{3}$ com as diferentes composições estudadas foram moídas e analisadas por meio de difração de raios-X. As condições das análises foram mantidas iguais em todos os ensaios, utilizando-se o passo $0,055^{\circ}$, tempo de contagem de 5 segundos e a radiação $\mathrm{CuK} \alpha$. Os resultados obtidos estão apresentados nas figuras 26 a 29.

$\mathrm{Na}$ figura 26 , nota-se que a estrutura fluorita do $\mathrm{UO}_{2}$ permanece até a composição $\left(\mathrm{U}_{0,5} \mathrm{Gd}_{0,5}\right) \mathrm{O}_{2}$, ocorrendo apenas o deslocamento dos picos de difração na direção de maiores ângulos, indicando a diminuição do parâmetro de rede. Nenhuma variação expressiva pode ser observada nos picos de difração, além do seu deslocamento.

$\mathrm{Na}$ figura 27 observa-se que a partir da composição $\left(\mathrm{U}_{0,5} \mathrm{Gd}_{0.5}\right) \mathrm{O}_{2}$ não ocorre mais o deslocamento dos picos de difração na direção de maiores ângulos. Uma nova fase não identificada começa a ser formada para a composição $\left(\mathrm{U}_{0.37} \mathrm{Gd}_{0.63}\right) \mathrm{O}_{2}$, evidenciada pela 
deformação dos picos de difração referentes aos planos (220) e (311). Nessa composição também pode ser observada a diminuição da intensidade dos picos de difração. Na composição $\left(\mathrm{U}_{0.34} \mathrm{Gd}_{0,66}\right) \mathrm{O}_{2}$ esta nova fase já está mais bem definida, com os picos bastante próximos dos picos característicos do $\mathrm{UO}_{2}$.

Intensidade

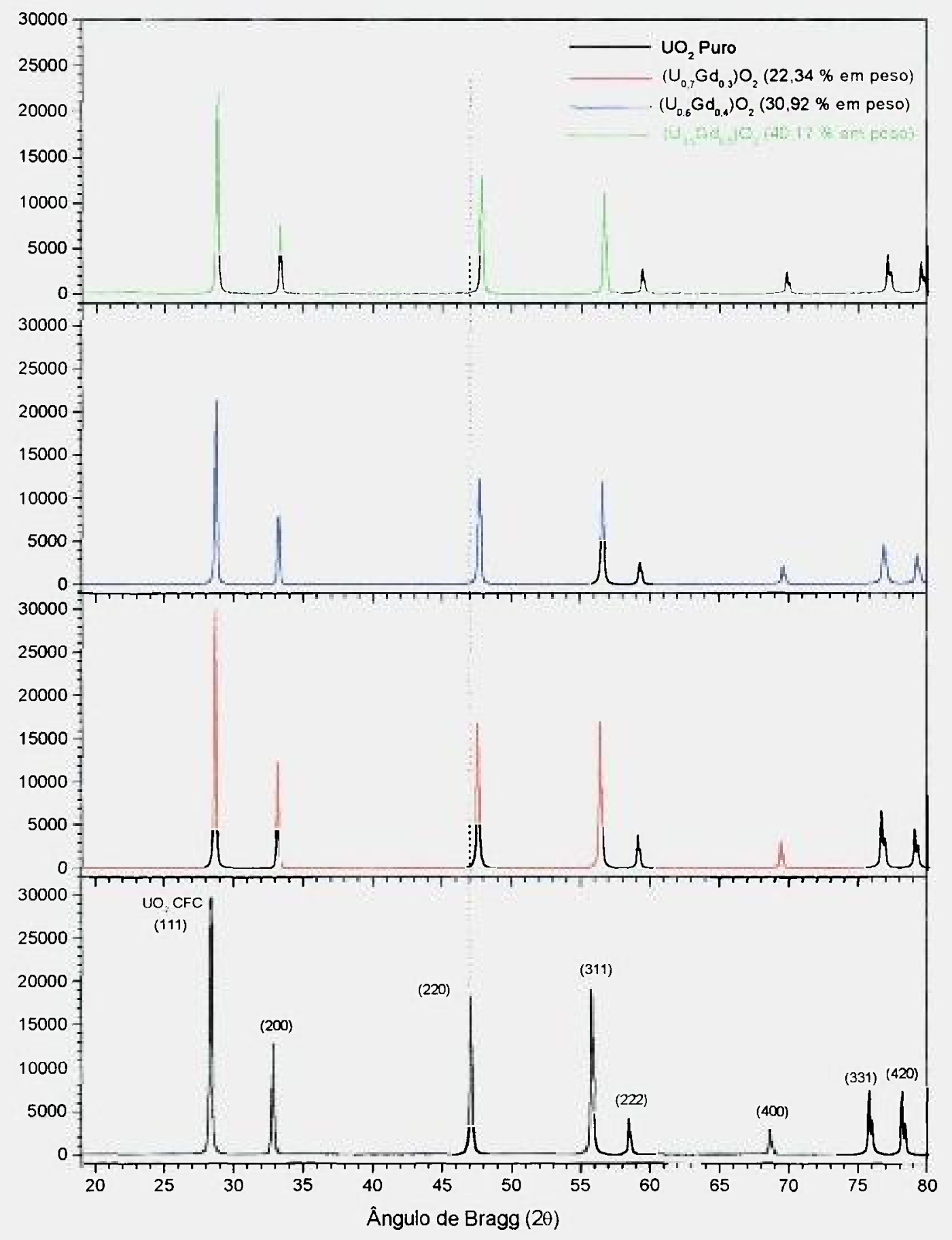

Figura 26 - Difratogramas de raios-X de pastilhas $\mathrm{UO}_{2}-\mathrm{Gd}_{2} \mathrm{O}_{3}$ sinterizadas preparadas por coprecipitação via DUA. ( $\left(\mathrm{UO}_{2}\right.$ a $\left.\left(\mathrm{U}_{0.5} \mathrm{Gd}_{0,5}\right) \mathrm{O}_{2}\right)\left(\mathrm{H}_{2} / 1650{ }^{\circ} \mathrm{C} / 3\right.$ horas) 
Intensidade

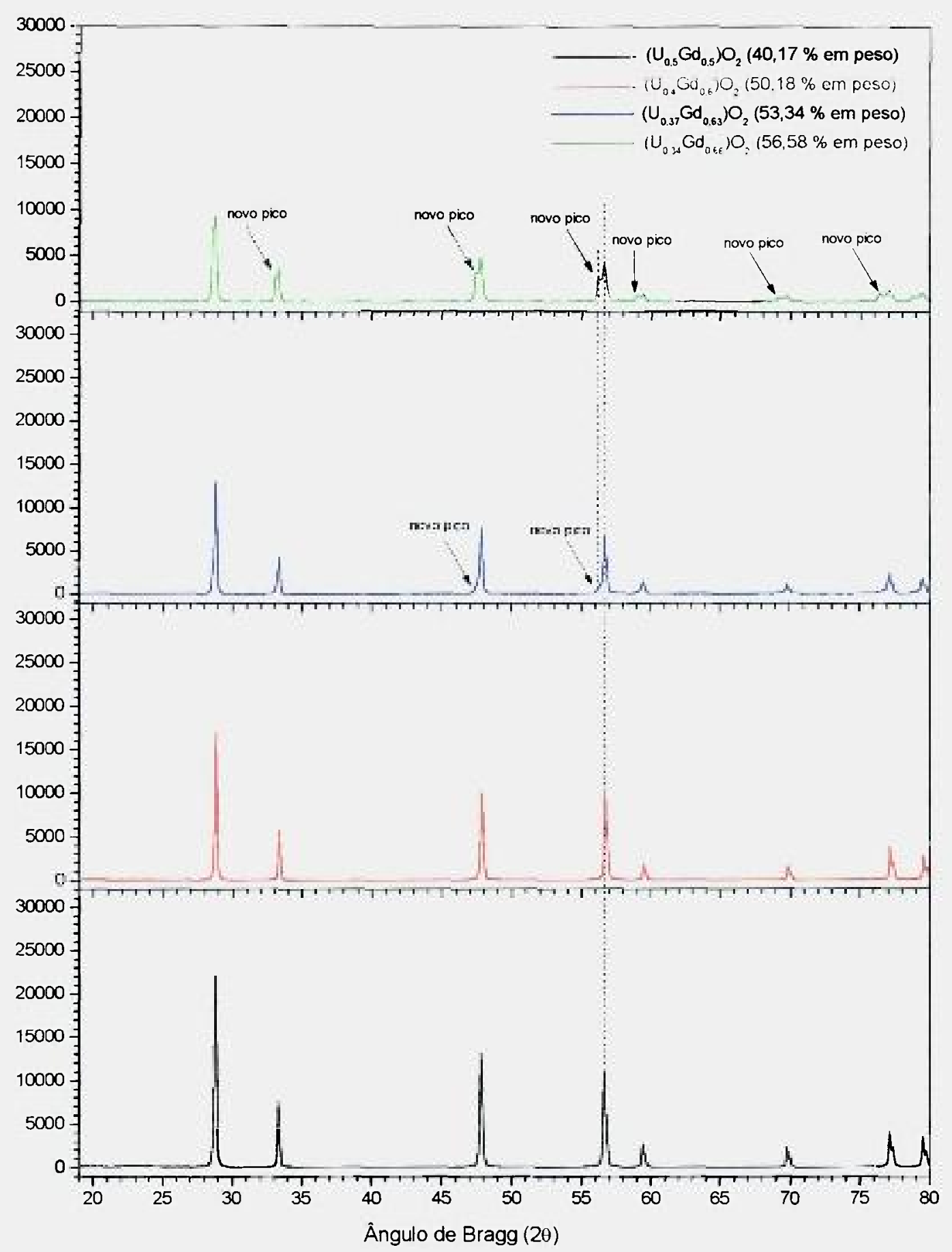

Figura 27 - Difratogramas de raios-X de pastilhas $\mathrm{UO}_{2}-\mathrm{Gd}_{2} \mathrm{O}_{3}$ sinterizadas preparadas por coprecipitação via DUA. $\left(\left(\mathrm{U}_{0.5} \mathrm{Gd}_{0.5}\right) \mathrm{O}_{2}\right.$ a $\left.\left(\mathrm{U}_{0,34} \mathrm{Gd}_{0,66}\right) \mathrm{O}_{2}\right)$ $\left(\mathrm{H}_{2} / 1650^{\circ} \mathrm{C} / 3\right.$ horas $)$

Na figura 28 observa-se que para a composição $\left(\mathrm{U}_{0,3} \mathrm{Gd}_{0,7}\right) \mathrm{O}_{2}$ a intensidade dos picos de difração volta a aumentar e os novos picos em formação, observados na 
composição anterior $\left(\mathrm{U}_{0.34} \mathrm{Gd}_{0,66}\right) \mathrm{O}_{2}$, não estão perceptíveis à identificação. Nessa composição a posição dos picos sugere uma estrutura CFC, contudo com picos alargados e não tão bem definidos. Ainda na figura 28 , observa-se que na próxima composição superior a

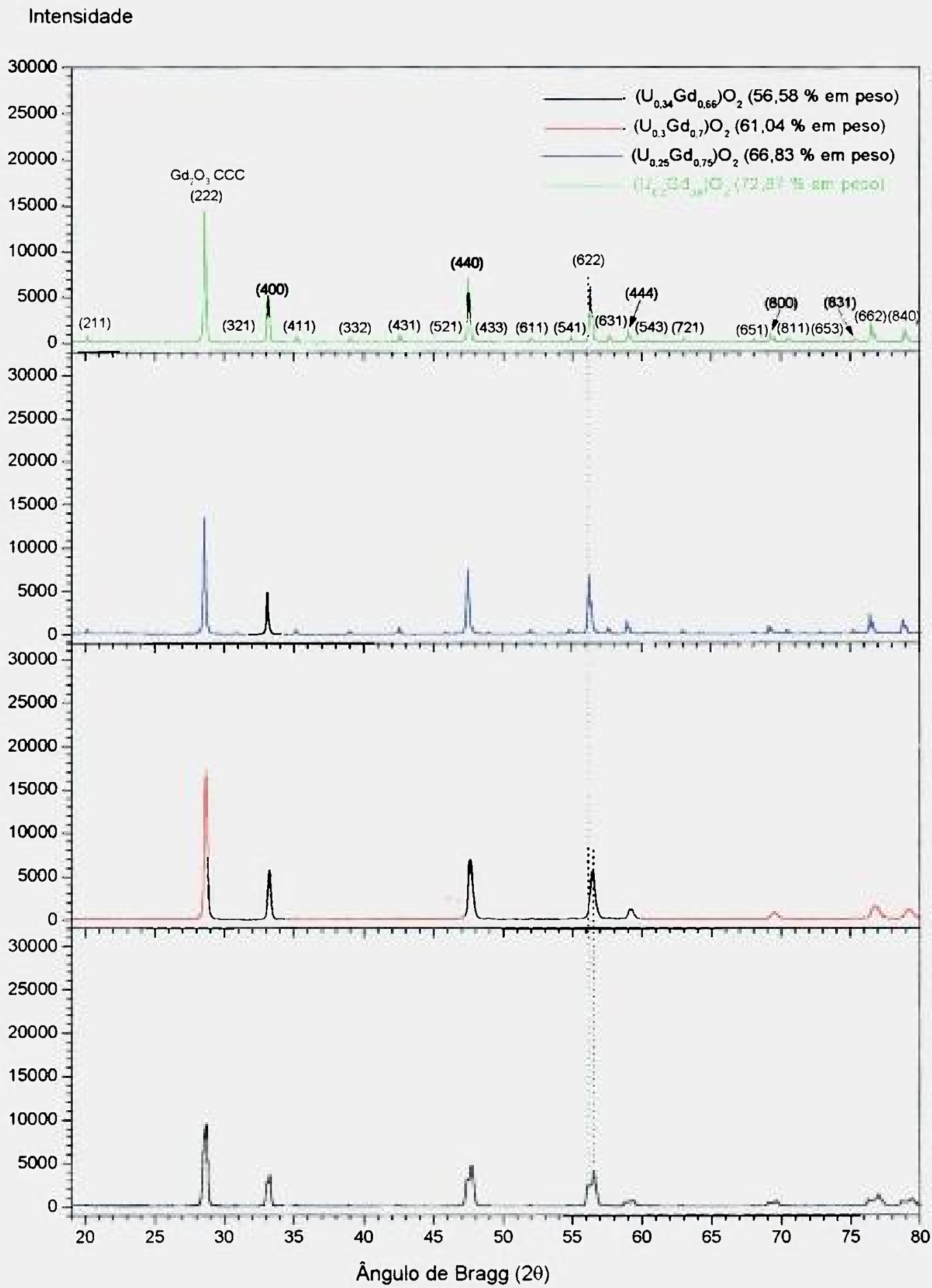

Figura 28 - Difratogramas de raios- $\mathrm{X}$ de pastilhas $\mathrm{UO}_{2}-\mathrm{Gd}_{2} \mathrm{O}_{3}$ sinterizadas preparadas por coprecipitação via DUA. $\left(\left(\mathrm{U}_{0.34} \mathrm{Gd}_{0.66}\right) \mathrm{O}_{2}\right.$ a $\left.\left(\mathrm{U}_{0.2} \mathrm{Gd}_{0.8}\right) \mathrm{O}_{2}\right)$ $\left(\mathrm{H}_{2} / 1650^{\circ} \mathrm{C} / 3\right.$ horas $)$ 
$\left(\mathrm{U}_{0,3} \mathrm{Gd}_{0.7}\right) \mathrm{O}_{2}(\mathrm{X}=0,75)$, uma série de novos picos surge no difratograma obtido, sendo possível a identificação da estrutura $\mathrm{CCC}$ do $\mathrm{Gd}_{2} \mathrm{O}_{3}$, a qual torna-se mais detinida para a composição $\left(\mathrm{U}_{0,2} \mathrm{Gd}_{0,8}\right) \mathrm{O}_{2}$.

Intensidade

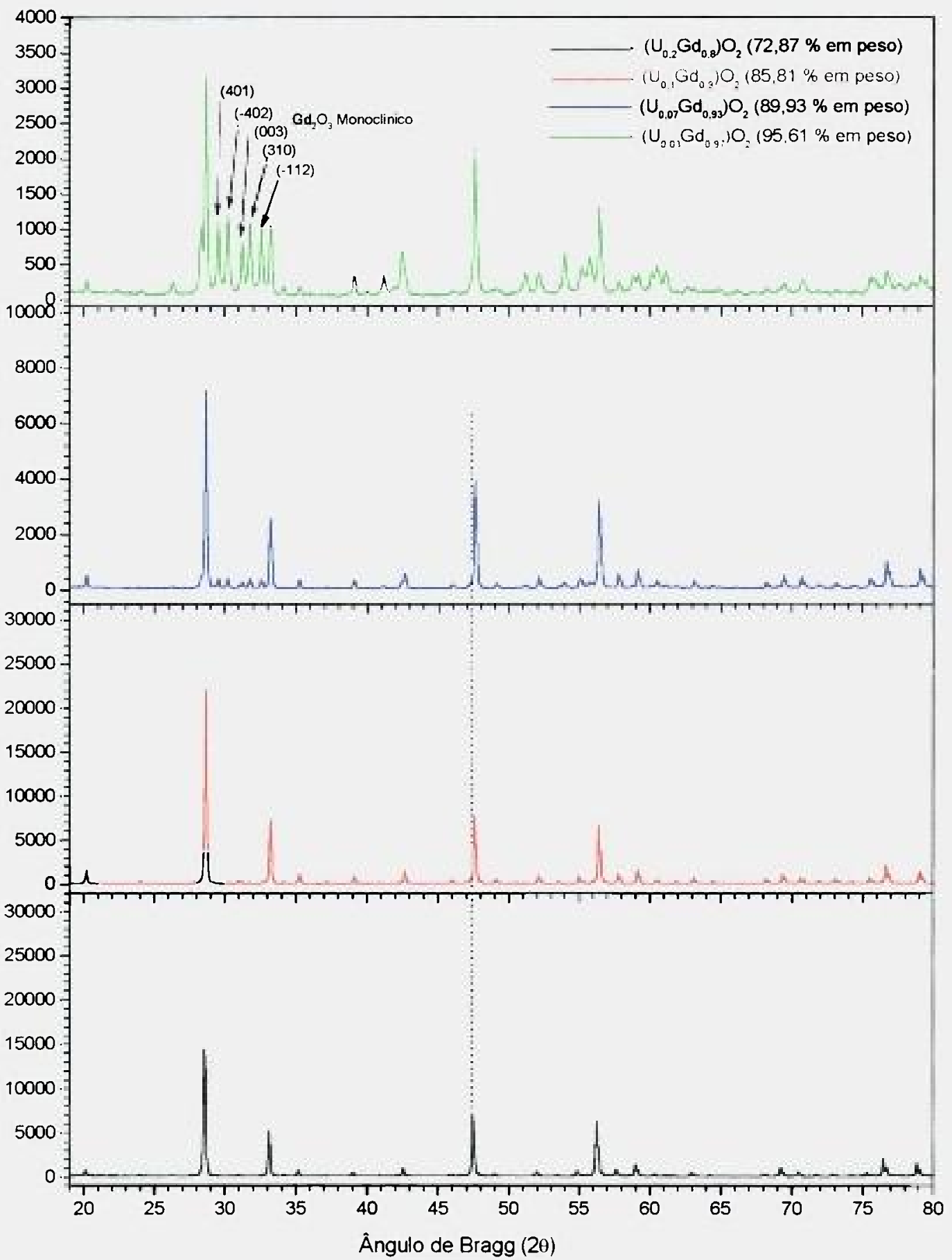

Figura 29 - Difratogramas de raios- $\mathrm{X}$ de pastilhas $\mathrm{UO}_{2}-\mathrm{Gd}_{2} \mathrm{O}_{3}$ sinterizadas preparadas por coprecipitação via DUA. $\left(\left(\mathrm{U}_{0,2} \mathrm{Gd}_{0,8}\right) \mathrm{O}_{2}\right.$ a $\left.\left(\mathrm{U}_{0,03} \mathrm{Gd}_{0,97}\right) \mathrm{O}_{2}\right)$ $\left(\mathrm{H}_{2} / 1650^{\circ} \mathrm{C} / 3\right.$ horas $)$ 
$\mathrm{Na}$ figura 29 observa-se que para as frações molares de $\mathrm{Gd}_{2} \mathrm{O}_{3}$ variando de 0,75 a 0,9 apenas a fase $\mathrm{Gd}_{2} \mathrm{O}_{3} \mathrm{CCC}$ pode ser observada. Um ligeiro deslocamento dos picos de difração na direção de maiores ângulos pode ser observado. No difratograma referente à composição $\left(\mathrm{U}_{0,07} \mathrm{Gd}_{0,93}\right) \mathrm{O}_{2}$ observa-se o início da formação de uma nova fase, identificada como $\mathrm{Gd}_{2} \mathrm{O}_{3}$ com estrutura cristalina monoclínica. A partir dessa composição, a fase cúbica do $\mathrm{Gd}_{2} \mathrm{O}_{3}$ coexiste com a fase monoclínica até que desapareça completamente, o que ocorre para composições muito próximas do $\mathrm{Gd}_{2} \mathrm{O}_{3}$ puro (a fase cúbica foi observada em amostras contendo apenas $1 \% \mathrm{em} \mathrm{mol} \mathrm{de} \mathrm{UO}_{2}$ ).

A evolução dos difratogramas com a concentração de gadolínio, dicutida acima, sugere a possibilidade da ocorrência de uma fase não identificada na faixa de composição entre 63 e $70 \%$ molar de $\mathrm{Gd}_{2} \mathrm{O}_{3}$. Na composição $\left(\mathrm{U}_{0,3} \mathrm{Gd}_{0,7}\right) \mathrm{O}_{2}$ não se pode afirmar com segurança que ocorre uma coexistência entre as fases $\mathrm{CFC}$ do $\mathrm{UO}_{2}$ e $\mathrm{CCC}$ do $\mathrm{Gd}_{2} \mathrm{O}_{3}$, considerando-se o deslocamento do pico situado na posição $2 \theta$ de aproximadamente $55,5^{\circ}$, à direita do pico (622) do $\mathrm{Gd}_{2} \mathrm{O}_{3} \mathrm{CCC}$, e o seu evidente alargamento.

Com o objetivo de complementar as observações apresentadas acima, os parâmetros de rede das estruturas cristalinas identificadas foram calculados a partir dos difratogramas apresentados. Todos os picos detectados foram considerados no cálculo dos parâmetros de rede, o que foi realizado com a ajuda de um programa de computador (141). Este programa basicamente minimiza os erros sistemáticos que inevitavelmente ocorre quando parâmetros de rede são medidos por meio de um difratômetro.

A figura 30 apresenta a variação do parâmetro de rede em função da fração molar de gadolínio presente na amostra. Para frações molares de gadolínio variando de 0 a 0,70 , os parâmetros de rede foram calculados para a estrutura CFC. Para a composição $\left(\mathrm{U}_{0,25} \mathrm{Gd}_{0,75}\right) \mathrm{O}_{2}$ e superiores os parâmetros de rede foram calculados para a estrutura CCC. Para a composição de $\left(\mathrm{U}_{0,34} \mathrm{Gd}_{0,66}\right) \mathrm{O}_{2}$ os picos novos e não identificados foram considerados como sendo resultantes de uma estrutura CCC. Para a composição $\left(\mathrm{U}_{0,3} \mathrm{Gd}_{0,7}\right) \mathrm{O}_{2}$ foi também determinado o parâmetro de rede considerando a estrutura como sendo cúbica de corpo centrado (CCC). Observa-se na figura 30 que até a composição $\left(\mathrm{U}_{0.5} \mathrm{Gd}_{0.5}\right) \mathrm{O}_{2}$ o parâmetro de rede diminui lineramente com a fração molar de gadolínio, seguindo a lei de Vegard, indicando a presença de apenas uma estrutura cristalina, com cátions $\mathrm{Gd}^{3+}$ substituindo cátions $\mathrm{U}^{4+}$, como ilustra a figura 1 . Essa observação foi comprovada pelo bom ajuste obtido numa regressão linear, cuja reta, obtida dos resultados experimentais, pode ser expressa pela equação:

$$
a=0,54636-0,01592 . x \quad\left(\mathrm{R}^{2}=0,9979\right)
$$

onde: $a$ é o parâmetro de rede (nm) e $x$ é a fração molar de gadolínio. 
Parâmetro de Rede (nm)

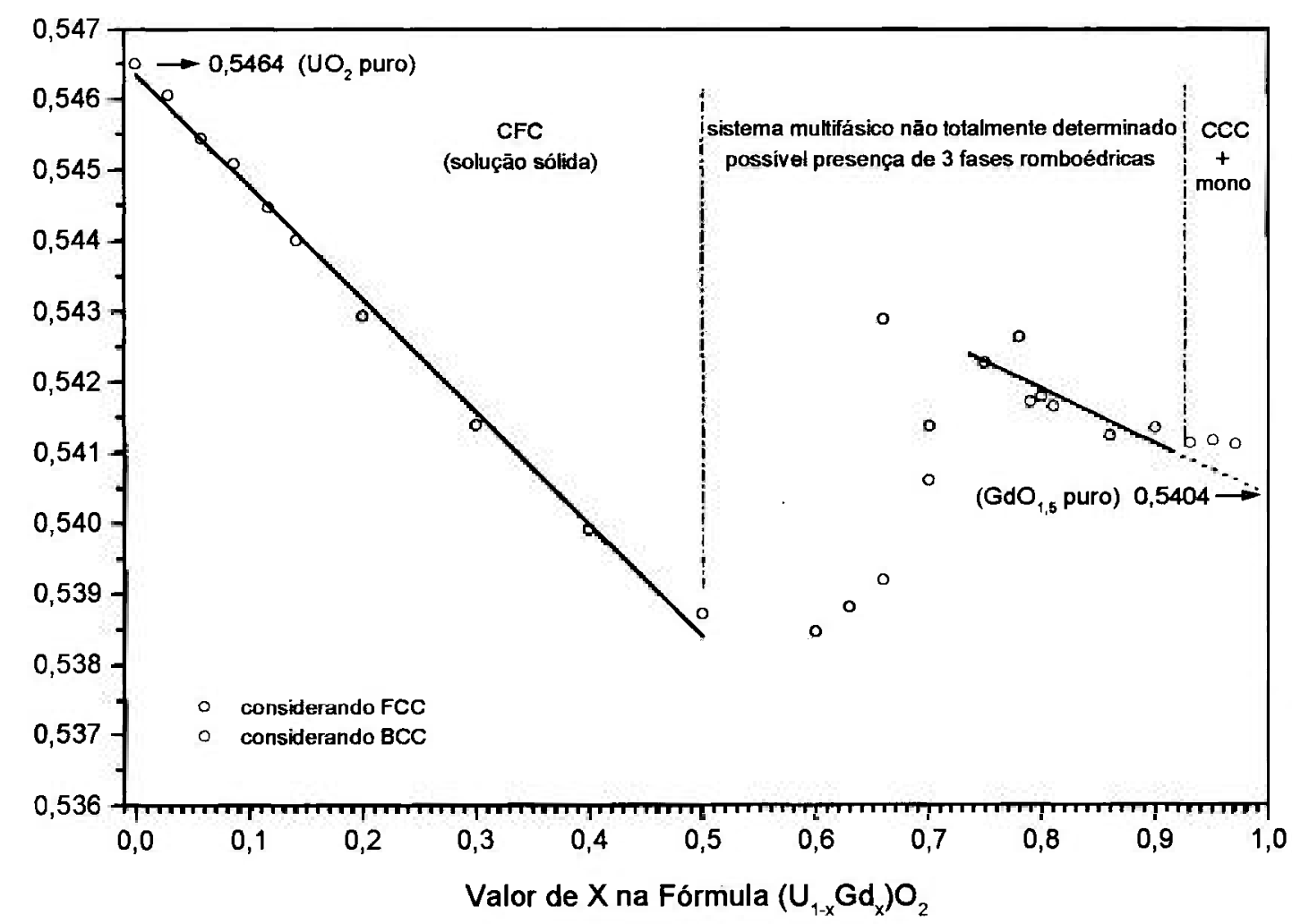

Figura 30- Evolução do parâmetro de rede das fases identificadas no sistema $(\mathrm{U}, \mathrm{Gd}) \mathrm{O}_{2}$.

Quando a fração molar de gadolínio ultrapassa o valor 0,5 , o comportamento do parâmetro de rede da estrutura fluorita não é mais linear, indicando o final da região monofásica. Para as composições entre $\left(\mathrm{U}_{0,25} \mathrm{Gd}_{0,75}\right) \mathrm{O}_{2}$ e $\left(\mathrm{U}_{0,10} \mathrm{Gd}_{0,90}\right) \mathrm{O}_{2}$, faixa na qual os difratogramas indicam somente a presença da estrutura cúbica de corpo centrado (figuras 28 e 29), pode-se observar também uma tendência à diminuição linear do parâmetro de rede com a fração molar de gadolínio. Contudo, neste caso, não se pode afirmar que a lei de Vegard é obedecida, tendo em vista a baixa qualidade do ajuste da regressão linear. Isto indica a existência de duas ou mais fases nessa faixa de composição. Uma tentativa de ajuste linear está ilustrada na figura 30 , obtendo-se a expressão:

$$
a=0,54809-0,00773 \cdot x \quad\left(\mathrm{R}^{2}=0,7981\right)
$$

$\mathrm{Na}$ faixa de composição intermediária entre $\left(\mathrm{U}_{0,5} \mathrm{Gd}_{0,5}\right) \mathrm{O}_{2}$ e $\left(\mathrm{U}_{0,25} \mathrm{Gd}_{0,75}\right) \mathrm{O}_{2}$ não pode ser afirmado a simples coexistência entre as fases CFC e CCC, uma vez que o parâmetro de rede não é constante para nenhuma das duas estruturas. Para composições entre $\left(\mathrm{U}_{0,25} \mathrm{Gd}_{0,75}\right) \mathrm{O}_{2}$ e $\left(\mathrm{U}_{0,1} \mathrm{Gd}_{0,9}\right) \mathrm{O}_{2}$ também não se pode afirmar que o sistema é monofásico com estrutura cúbica de corpo centrado, uma vez que não se pode afirmar que 
a lei de Vegard é obedecida. Portanto, nessa extensa faixa de composição, onde a fração molar de gadolínio varia de 0,5 a 0,9 , os resultados apresentados na figura 30 indicam a existência de uma ou mais fases diferentes da CFC do $\mathrm{UO}_{2}$ e $\mathrm{CCC}$ do $\mathrm{Gd}_{2} \mathrm{O}_{3}$. Para composições superiores a $\left(\mathrm{U}_{0,10} \mathrm{Gd}_{0,90}\right) \mathrm{O}_{2}$ ficou evidenciado a coexistência entre as formas $\mathrm{Ce} \mathrm{B}$ do $\mathrm{Gd}_{2} \mathrm{O}_{3}$, de estruturas CCC e monoclínica, respectivamente.

Como comentado anteriormente, Aitken, Bartran e Juenke ${ }^{\text {(58) }}$ observaram uma fase de estrutura romboédrica no sistema U-Y-O, com composição variando numa ampla faixa de concentração de ítrio, de 51 a $86 \%$ em mol. Esta fase foi designada como RI, de estrutura romboédrica. Uma segunda fase foi observada neste sistema, também com estrutura romboédrica, designada RII, com composição variando entre 68 e $75 \%$ em mol de ítrio. Estas duas fases romboédricas também foram observadas no sistema U-La-O e uma terceira fase romboédrica, designada RIII, foi detectada na faixa de concentração de 55 a $67 \%$ em mol de lantânio (142).

Estas fases romboédricas também são observadas nos compostos U-R-O $(\mathrm{R}=\mathrm{Nd}$, $\mathrm{Sm}, \mathrm{Eu}, \mathrm{Ho}, \mathrm{Er}, \mathrm{Tm}, \mathrm{Yb}$ e $\mathrm{Lu}$ ) e no sistema $\mathrm{R}-\mathrm{O}$, onde $\mathrm{R}=\mathrm{Ce}$, $\mathrm{Pr}$ e $\mathrm{Tb}$, os quais podem apresentar as valências $+3 \mathrm{e}+4$. Kang e Eyring ${ }^{(\mathbf{1 4 3})}$ observaram que essas terras raras exibem uma familia de óxidos binários nos quais coexistem as valências $+3 \mathrm{e}+4$, resultando em estruturas relacionadas à da fluorita com deficiência de oxigênio. Dentre elas, o composto $\mathrm{R}_{7} \mathrm{O}_{12}$ possui a mesma estrutura romboédrica observada no sistema U-YO. Neste trabalho e em trabalhos posteriores (144) estes pesquisadores propõem a construção da estrutura cristalina de uma série de compostos no sistema R-O a partir da montagem de módulos, os quais são células unitárias da estrutura fluorita com vacâncias de oxigênio em diferentes posições da célula unitária. $O$ total de vacâncias de oxigênio na célula unitária da estrutura montada deve sempre ser 8 , baseado na igual probabilidade das 8 posições do oxigênio tornarem-se vacância na célula unitária da fluorita. Quatro tipos de módulos podem ocorrer, dependendo do número e posição das vacâncias de oxigênio. A figura 31 auxilia a compreensão da teoria. Nessa figura, a estrutura (A) é uma célula unitária da fluorita, composta por tetraedros onde os cátions estão nos vértices e o oxigênio está no interior de cada um dos tetraedros. Este módulo é designado como do tipo F pelos pesquisadores.

A figura 31 (B) ilustra um módulo onde existe uma vacância de oxigênio. Neste caso, dois tipos de módulos podem ocorrer, o primeiro com a vacância de oxigênio num dos quatro tetraedros superiores, designado como tipo $U$ pelos pesquisadores, e o segundo com a vacância de oxigênio num dos quatro tetraedros inferiores, designado como tipo D pelos pesquisadores. Na figura o módulo ilustrado é do tipo D. 


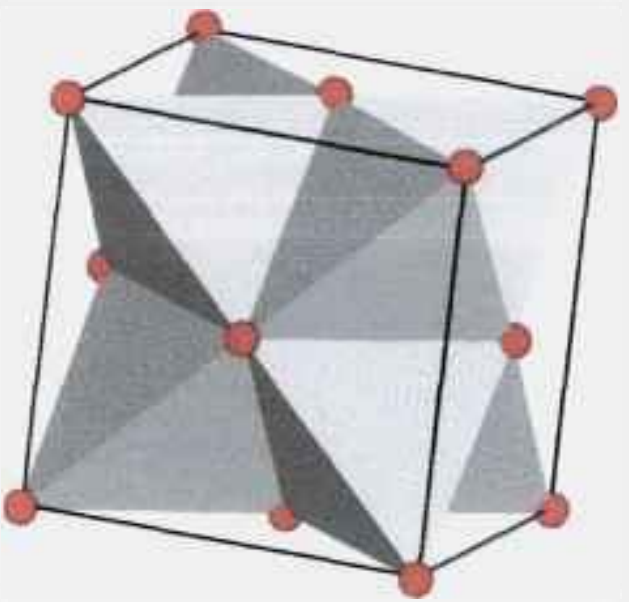

A
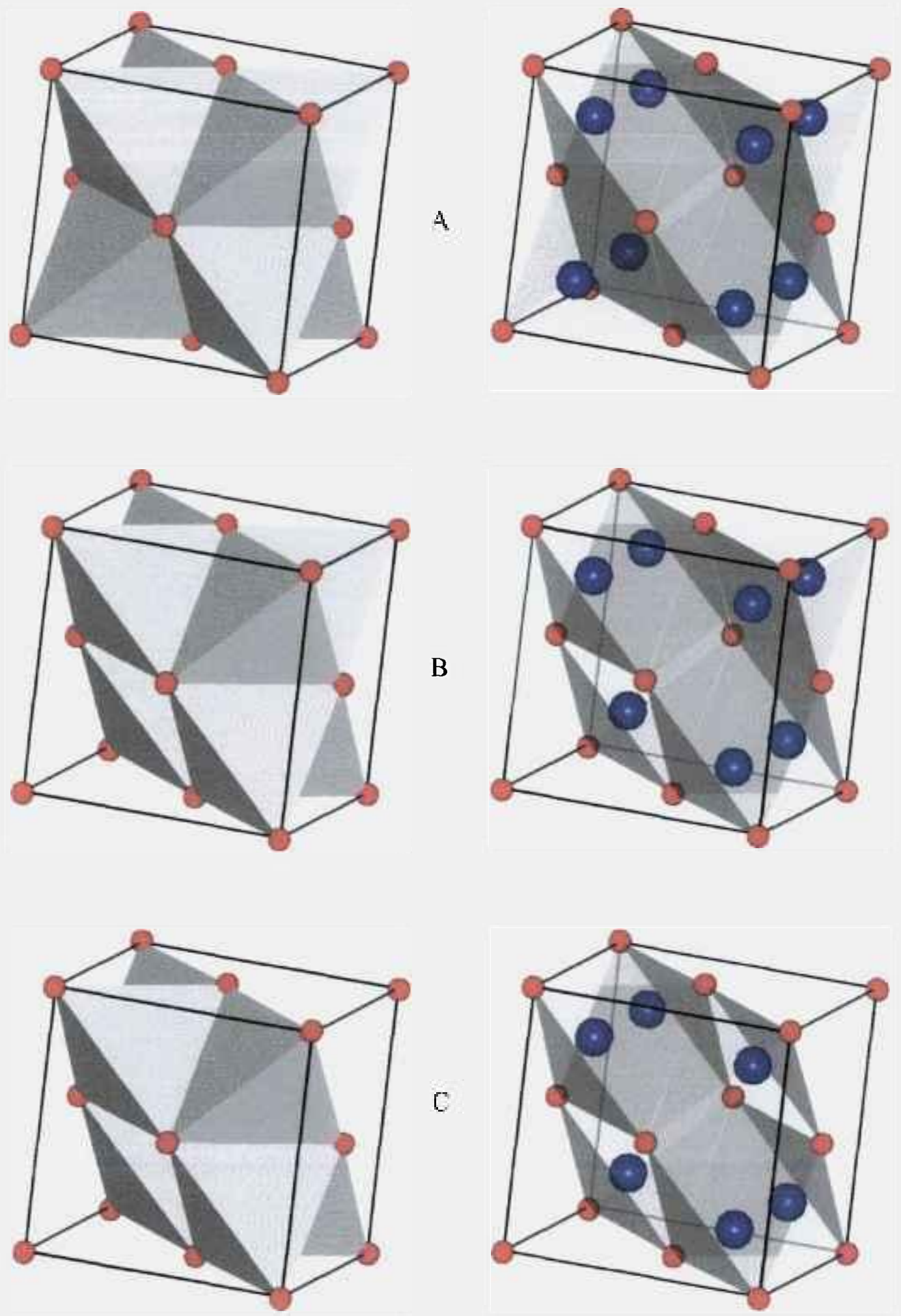

Figura 31 -Tipos de módulos fluorita usados na construção da célula unitária de compostos no sistema R-O (R=Ce, Pr, Tb ${ }^{(144)}$,

(A) - módulo tipo $\mathrm{F}$ (célula fluorita perfeita)

(B) - módulos tipo U e D (uma vacância de oxigênio) (o módulo D está ilustrado)

(C) - módulo tipo W (duas vacâncias de oxigênio opostas) 
O último tipo de módulo que pode ocorrer é aquele em que duas vacâncias de oxigênio estão presentes, sempre na diagonal do cubo que forma a célula unitária da fluorita. Este tipo de módulo está ilustrado na figura 31 (C) e é designado como tipo W.

A montagem da célula unitária da fase deve seguir algumas regras, tais como: duas vacâncias nunca podem estar mais perto do que as que ocorrem no módulo $\mathrm{W}$, sempre o número total de vacâncias na célula construída deve ser múltiplo de 8 e o número de módulos $\mathrm{U}$ deve ser igual ao número de módulos $\mathrm{D}$. A estrutura cristalina construída poderá conter qualquer número de tipos de módulos, garantindo-se apenas que o número de módulos $\mathrm{U}$ seja igual ao número de módulos $\mathrm{D}$. O módulo $\mathrm{F}$ é usualmente requerido para ajustar a composição dos membros da série.

Com base nesse mecanismo, estes pesquisadores estabeleceram e caracterizaram 14 fases diferentes no sistema R-O, como ilustra a tabela 10 . A fase $\mathrm{R}_{7} \mathrm{O}_{12}$, a qual é isoestrutural à fase romboédrica $\mathrm{UGd}_{6} \mathrm{O}_{12}$, é formada por meio da montagem sucessiva de 7 módulos, sendo 3 tipo U, 3 tipo D e um tipo W (central), ou seja, 3U3D1W. A composição é 28 íons $R(7 \times 4)$ e 48 íons oxigênio $(6 \times 7+1 \times 6)$. A figura 32 apresenta uma ilustração tridimensional da célula unitária do $\operatorname{Pr}_{7} \mathrm{O}_{12}{ }^{(143)}$.

$\mathrm{O} \mathrm{Gd}_{2} \mathrm{O}_{3}$ é formado por meio da montagem sucessiva de 8 módulos do tipo $\mathrm{W}$, resultando na composição de 32 íons $\mathrm{Gd}(8 \times 4)$ e 48 íons oxigênio ( $8 \times 6$ ), obtendo-se a fórmula $\mathrm{Gd}_{32} \mathrm{O}_{48}$, ou $\mathrm{Gd}_{2} \mathrm{O}_{3}$, ou $\mathrm{GdO}_{1,5}$. Dessa forma, a célula unitária da rede cristalina do $\mathrm{Gd}_{2} \mathrm{O}_{3}$, sendo cúbica, possui o parâmetro de rede duas vezes o valor do parâmetro do módulo pseudo-fluorita que foi usado na sua construção. Este é o valor utilizado na construção da figura 30 .

A observação experimental das fases construídas com base na metodologia proposta por Kang e Eyring, indica que pode existir uma extensa série de fases com estrutura baseada na estrutura fluorita, onde vacâncias de oxigênio são distribuídas de diferentes maneiras. Essa é uma conclusão importante, uma vez que fases isoestruturais às fases observadas por Kang e Eyring no sistema R-O (tabela 10) provavelmente também devem existir no sistema U-Gd-O. $\mathrm{O} \mathrm{U}^{4+}$ pode simplesmente estar presente nestas estruturas substituindo o cátion $\mathrm{R}^{4+}$. Ainda, com a possibilidade de ocorrência também dos cátions $\mathrm{U}^{5+} \mathrm{e} \mathrm{U}^{6+}$, a possibilidade de ocorrência de fases ainda mais complexas do que as identificadas e apresentadas na tabela 10 não pode ser descartada. Com base na discussão apresentada acima, pode-se discutir os resultados apresentados nas figuras 25 e $30 \mathrm{com}$ mais profundidade, como segue. 
Tabela 10 - Fases identificadas no sistema R-O construídas a partir da metodologia proposta por Kang e Eyring ${ }^{(\mathbf{1 4 3})}$.

\begin{tabular}{|c|c|c|c|c|}
\hline $\begin{array}{l}\text { Terra } \\
\text { Rara } \\
\text { (R) }\end{array}$ & $\begin{array}{c}\text { Número de } \\
\text { Módulos } \\
\text { Fluorita }\end{array}$ & $\begin{array}{c}\text { Esquema de } \\
\text { Montagem dos } \\
\text { Módulos }\end{array}$ & Fórmula & $\begin{array}{c}\text { Sistema } \\
\text { Cristalino }^{(\mathbf{1 4 5 )})}\end{array}$ \\
\hline $\mathrm{Ce}, \mathrm{Pr}, \mathrm{Tb}$ & 7 & $3 \mathrm{U} 3 \mathrm{D} 1 \mathrm{~W}$ & $\mathrm{R}_{7} \mathrm{O}_{12}$ ou $\mathrm{RO}_{1.714}$ & romboédrico \\
\hline $\mathrm{Ce}, \operatorname{Pr}$ & 9 & $1 F 4 U 4 D$ & $\mathrm{R}_{9} \mathrm{O}_{16}$ ou $\mathrm{RO}_{1,778}$ & triclínico \\
\hline $\mathrm{Ce}, \mathrm{Tb}$ & 11 & $3 F 4 U 4 D$ & $\mathrm{R}_{11} \mathrm{O}_{20}$ ou $\mathrm{RO}_{1.818}$ & triclínico \\
\hline $\operatorname{Pr}$ & 12 & 4F4U4D & $\mathrm{R}_{12} \mathrm{O}_{22}$ ou $\mathrm{RO}_{1,833}$ & indeterminado \\
\hline $\mathrm{Ce}, \mathrm{Pr}, \mathrm{Tb}$ & 16 & $8 \mathrm{~F} 4 \mathrm{U} 4 \mathrm{D}$ & $\mathrm{R}_{16} \mathrm{O}_{30}$ ou $\mathrm{RO}_{1,875}$ & indeterminado \\
\hline $\mathrm{Ce}$ & 19 & 3F8U8D & $\mathrm{R}_{19} \mathrm{O}_{34}$ ou $\mathrm{RO}_{1.789}$ & triclínico \\
\hline $\operatorname{Pr}$ & 24 & 8F8U8D & $\mathrm{R}_{24} \mathrm{O}_{44}$ ou $\mathrm{RO}_{1.833}$ & monoclínico \\
\hline $\mathrm{Tb}$ & 24 & $8 F 8 U 8 D$ & $\mathrm{R}_{24} \mathrm{O}_{44}$ ou $\mathrm{RO}_{1.833}$ & indeterminado \\
\hline $\mathrm{Ce}$ & 29 & $5 \mathrm{~F} 12 \mathrm{U} 12 \mathrm{D}$ & $\mathrm{R}_{29} \mathrm{O}_{52}$ ou $\mathrm{RO}_{1,793}$ & indeterminado \\
\hline $\mathrm{Ce}$ & 39 & 7F16U16D & $\mathrm{R}_{39} \mathrm{O}_{70}$ ou $\mathrm{RO}_{1,795}$ & indeterminado \\
\hline $\mathrm{Ce}, \mathrm{Pr}$ & 40 & $8 \mathrm{~F} 16 \mathrm{U} 16 \mathrm{D}$ & $\mathrm{R}_{40} \mathrm{O}_{72}$ ou $\mathrm{RO}_{1,800}$ & monoclínico \\
\hline $\mathrm{Tb}$ & 48 & 16F16U16D & $\mathrm{R}_{48} \mathrm{O}_{88}$ ou $\mathrm{RO}_{1,833}$ & indeterminado \\
\hline $\mathrm{Ce}, \mathrm{Pr}, \mathrm{Tb}$ & 62 & 14F24U24D & $\mathrm{R}_{62} \mathrm{O}_{112}$ ou $\mathrm{RO}_{1.806}$ & indeterminado \\
\hline $\operatorname{Pr}$ & 88 & 24F32U32D & $\mathrm{R}_{88} \mathrm{O}_{160}$ ou $\mathrm{RO}_{1,818}$ & indeterminado \\
\hline
\end{tabular}
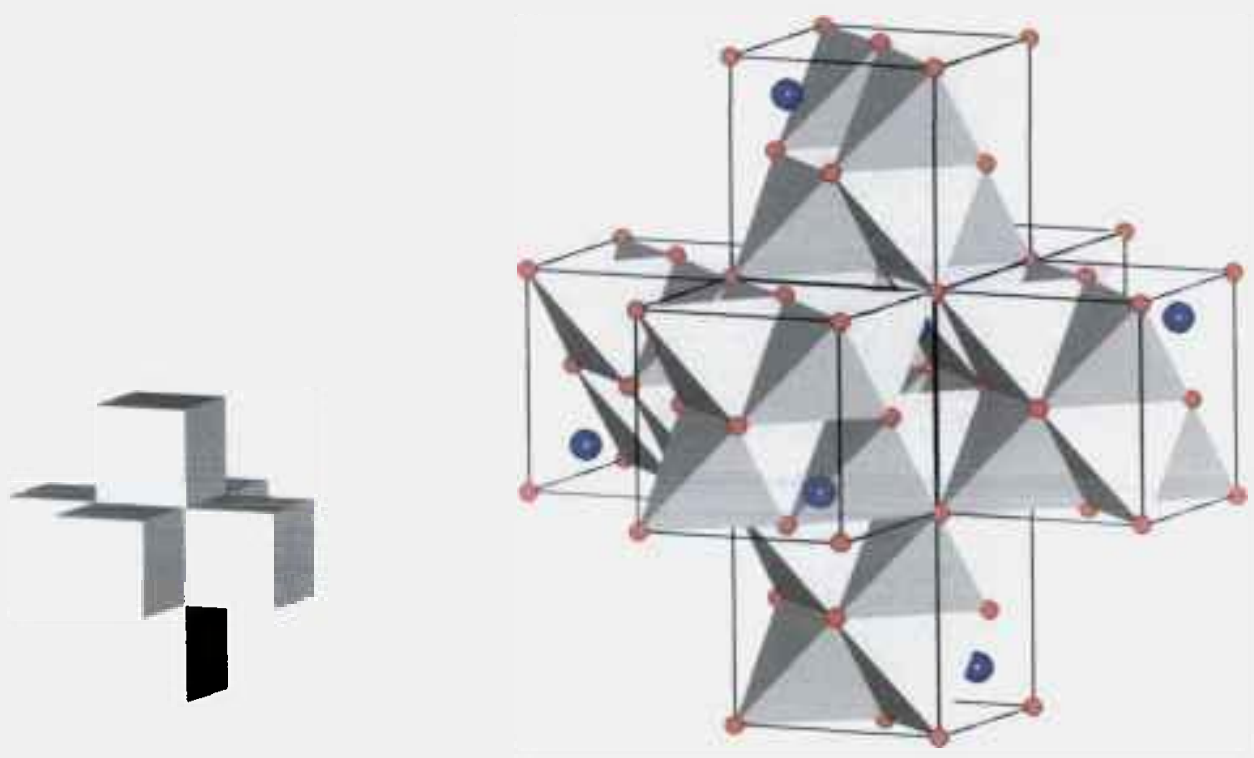

Figura 32 - Célula unitária do $\operatorname{Pr}_{7} \mathrm{O}_{12}$, isoestrutural ao $\mathrm{UGd}_{6} \mathrm{O}_{12}{ }^{(143)}$. 
Observando-se os dados referentes à variação da razão $\mathrm{O} / \mathrm{M}(\mathrm{M}=\mathrm{U}+\mathrm{Gd})$ no sistema $\mathrm{UO}_{2}-\mathrm{Gd}_{2} \mathrm{O}_{3}$ apresentados na figura 3 , verifica-se que a maioria dos pesquisadores concordam que a estequiometria permanece próxima de 2 até a concentração aproximada de pelo menos $40 \%$ em mol de $\mathrm{Gd}_{2} \mathrm{O}_{3}{ }^{(49)}$. Nota-se, também, a ocorrência de uma ligeira hipoestequiometria neste sistema nessa faixa de concentração. A partir de $40 \% \mathrm{em} \mathrm{mol} \mathrm{de}$ $\mathrm{Gd}_{2} \mathrm{O}_{3}$, Beals e Handwerk ${ }^{(49)}$ observaram uma consistente diminuição da razão $\mathrm{O} / \mathrm{M}$ com o aumento da fração molar de gadolínio, até o valor de 1,5 no caso de $\mathrm{Gd}_{2} \mathrm{O}_{3}$ puro. Apesar de não ter sido possível a determinação da razão $\mathrm{O} / \mathrm{M}$ neste trabalho, uma vez que não foi possível ajustar em tempo o método disponível para o $\mathrm{UO}_{2}$ puro, com base nos resultados obtidos da literatura pode-se considerar que à medida que cátions $\mathrm{Gd}^{3+}$ são incorporados na estrutura fluorita ocorre oxidação de cátions $U^{4+}$ para compensação de carga, formando-se preferencialmente o cátion $\mathrm{U}^{5+}$, segundo Ohmich et al ${ }^{(\mathbf{4 8})}$. A formação de uma pequena proporção de vacâncias de oxigênio também deve ocorrer (provavelmente distribuídas de forma aleatória na rede cristalina da solução sólida), o que é indicado pela ligeira hipoestequiometria observada (modelo 3 proposto por Ho e Radford ${ }^{(\mathbf{4 0})}$ ). Este mecanismo poderia ser considerado válido para concentrações de $\mathrm{Gd}_{2} \mathrm{O}_{3}$ de até $50 \% \mathrm{em} \mathrm{mol}$. Isto é confirmado pelos difratogramas apresentados na figura 26 e pela diminuição linear do parâmetro de rede da estrutura fluorita até essa composição, satisfazendo a lei de Vegard, como ilustra a figura 30 .

Acima de $50 \%$ em mol de $\mathrm{Gd}_{2} \mathrm{O}_{3}$, começa o início da formação sistemática de vacâncias de oxigênio para compensação de carga, atingindo-se um número total de vacâncias que possibilitaria o seu rearranjo de maneira a formar-se fases isoestruturais às observadas e modeladas por Kang e Eyring no sistema R-O, como discutido anteriormente, dentre elas a fase romboédrica. Dessa forma, a variação do parâmetro de rede em função da fração molar de gadolínio adicionada deixa de satisfazer a lei de Vegard. Isto é confirmado pela evolução dos difratogramas entre as composições $\left(\mathrm{U}_{0,37} \mathrm{Gd}_{0,63}\right) \mathrm{O}_{2}$ e $\left(\mathrm{U}_{0,3} \mathrm{Gd}_{0,7}\right) \mathrm{O}_{2}$ (figuras 27 e 28). Apesar dos difratogramas indicarem apenas a presença da estrutura $\mathrm{CCC}$ do $\mathrm{Gd}_{2} \mathrm{O}_{3}$ para frações molares de gadolínio entre 0,75 e 0,90 (figuras 28 e 29), não se pode afirmar que a lei de Vegard é satisfeita nessa faixa de composição. Uma vez que as fases possíveis de serem formadas têm estruturas derivadas da estrutura fluorita, os difratogramas destas fases são muito similares ao obtido para a fluorita, exceto pela formação de dubletos ou tripletos nas reflexões de alta intensidade (reflexões (111), (200), (220) e (311) no caso do difratograma do $\mathrm{UO}_{2} \mathrm{CFC}$ e reflexões (222), (400), (440) e (622) no caso do difratograma do $\mathrm{Gd}_{2} \mathrm{O}_{3} \mathrm{CCC}$ ) e de poucas reflexões adicionais fracas ${ }^{\text {(58), }}$, sendo, portanto, difícil a sua detecção. Sendo assim, estas fases podem estar presentes e não terem sido identificadas nos difratogramas. Com o continuado aumento das vacâncias de oxigênio, a estrutura cristalina evolui até obter-se a estrutura CCC do $\mathrm{Gd}_{2} \mathrm{O}_{3}$, onde 16 vacâncias de oxigênio estão presentes, duas por módulo fluorita tipo W (figura 31C). 
Nota-se que a extrapolação da reta ajustada que representa a variação do parâmetro de rede na faixa de composição 0,75 a 0,9 intercepta o eixo das ordenadas no valor $0,5404 \mathrm{~nm}$ para $\mathrm{X}=1\left(\mathrm{GdO}_{1,5}\right)$, que é muito próximo do valor padrão obtido por difração de raios-X, de $1,0813 \mathrm{~nm}$ para a célula unitária do $\mathrm{Gd}_{2} \mathrm{O}_{3}{ }^{(146)}$, ou de $0,5407 \mathrm{~nm}$ para a pseudocélula fluorita $\mathrm{GdO}_{1,5}$ (figura $31 \mathrm{C}$ ). Isto, em conjunto com o valor do parâmetro de rede determinado para o $\mathrm{UO}_{2}$ puro, de $0,5464 \mathrm{~nm}$, também muito próximo do valor padrão obtido por difração de raios-X, de $0,54682 \mathrm{~nm}{ }^{(147)}$, demonstram a confiabilidade dos dados apresentados na figura 30 , nos quais baseia-se esta discussão.

Acima de $90 \%$ em mol de $\mathrm{Gd}_{2} \mathrm{O}_{3}$ ocorre provavelmente uma mistura das fases cúbica de corpo centrado e monoclínica do $\mathrm{Gd}_{2} \mathrm{O}_{3}$, o que é evidenciado pela invariabilidade do parâmetro de rede da estrutura CCC.

Para a faixa de composição entre 0 e $50 \%$ em mol de $\mathrm{Gd}_{2} \mathrm{O}_{3}$, os resultados obtidos nesta fase do trabalho concordam bem com os obtidos por outros pesquisadores ${ }^{\text {(4s-su), }}$, observando-se somente solução sólida com estrutura fluorita, cujo parâmetro de rede diminui segundo a lei de Vegard a uma taxa aproximada de $0,00016 \mathrm{~nm}$ a cada $1 \% \mathrm{em}$ mol de $\mathrm{Gd}_{2} \mathrm{O}_{3}$ adicionado. Contudo, acima dessa concentração, os resultados obtidos se contrapõem aos obtidos por Beals e Handwerk ${ }^{(49)}$ e Wrona ${ }^{(57)}$, os quais não observaram a forma cúbica do $\mathrm{Gd}_{2} \mathrm{O}_{3}$ (forma $\mathrm{C}$ ) e, em seu lugar observaram a forma monoclínica (forma B) a partir da composição $\left(\mathrm{U}_{0,3} \mathrm{Gd}_{0,7}\right) \mathrm{O}_{2}$, ou seja, na faixa de composição onde a forma $\mathrm{C}$ foi claramente identificada neste trabalho. A estrutura monoclínica do $\mathrm{Gd}_{2} \mathrm{O}_{3}$ foi detectada no presente trabalho apenas nas amostras com concentração de $\mathrm{Gd}_{2} \mathrm{O}_{3}$ superiores a $90 \%$ em mol. A continuidade na diminuição do parâmetro de rede com a fração molar de gadolínio acima de 0,5 registrada por estes pesquisadores também não foi observada neste trabalho.

Observando-se as figuras 25 e 30 , fica evidenciado que o inicio da queda da sinterabilidade do sistema $\mathrm{UO}_{2}-\mathrm{Gd}_{2} \mathrm{O}_{3}$ corresponde ao término da região monofásica do sistema, com estrutura fluorita, na composição $\left(\mathrm{U}_{0,5} \mathrm{Gd}_{0,5}\right) \mathrm{O}_{2}$. Isto corresponde também ao início da formação de vacâncias de oxigênio, evidenciado pela diminuição da razão $\mathrm{O} / \mathrm{M}$ que era constante até aproximadamente esta composição, segundo a literatura consultada. Apesar de novas fases não puderem ter sido diretamente observadas, os resultados obtidos nesta fase do trabalho apóiam a proposição de que o início da formação de vacâncias de oxigênio possibilita a formação de fases no sistema $\mathrm{UO}_{2}-\mathrm{Gd}_{2} \mathrm{O}_{3}$, incluindo a fase romboédrica observada no sistema $\mathrm{U}-\mathrm{Y}-\mathrm{O}$, as quais devem ser isoestruturais às observadas nos óxidos de terras raras $\mathrm{CeO}_{2-\mathrm{x}}, \mathrm{PrO}_{2-\mathrm{x}}$ e $\mathrm{TbO}_{2-\mathrm{x}}$. Esta complexa estrutura de fases seria a responsável pela diminuição da difusividade catiônica do sistema, conduzindo à diminuição da sinterabilidade observada. $O$ aparecimento de alguma fase com boa 
difusividade, não detectada diretamente neste trabalho, poderia ser responsável pela forma da curva apresentada na figura 25 , a qual revelou boa sinterabilidade na composição $\left(\mathrm{U}_{0,2} \mathrm{Gd}_{0,8}\right) \mathrm{O}_{2}$.

Os resultados experimentais apresentados na figura 25 , por si só, fundamentam a hipótese proposta da Barreira de Difusão, uma vez que frações molares de gadolínio superiores a 0,5 resultam em muito baixa densidade após a sinterização. A ocorrência de fases diferentes da fluorita para frações molares de gadolínio superiores a 0,5 também foi comprovada (figura 30), o que poderia explicar a queda na sinterabilidade. Contudo, nada se pode afirmar sobre a variação do coeficiente de interdifusão no sistema $\mathrm{UO}_{2}-\mathrm{Gd}_{2} \mathrm{O}_{3} \mathrm{em}$ função da concentração de gadolínio, o qual, em última instância, é quem determina a sinterabilidade do sistema. Como não foi possível a obtenção na literatura de dados de coeficientes de interdifusão no sistema $\mathrm{UO}_{2}-\mathrm{Gd}_{2} \mathrm{O}_{3}$ em função da concentração de gadolínio, com o objetivo de complementar a fundamentação da hipótese, optou-se por realizar estudos de interdifusão no sistema $\mathrm{UO}_{2}-\mathrm{Gd}_{2} \mathrm{O}_{3}$, cujos resultados estão apresentados e discutidos no próximo item.

\subsubsection{Estudos de interdifusão}

Os estudos de interdifusão foram realizados a partir da determinação do perfil de concentração de gadolínio, ou curva de penetração, obtida a partir de um par $\mathrm{UO}_{2} / \mathrm{Gd}_{2} \mathrm{O}_{3}$ sinterizado. A partir da curva de penetração, o coeficiente de interdifusão foi determinado em função da fração molar de gadolínio, aplicando-se o método de Matano-Boltzman. Descrevem-se, a seguir, os materiais e métodos utilizados na preparação da amostra e a metodologia adotada na determinação dos coeficientes de interdifusão.

\subsubsection{Metodologia}

Os estudos de interdifusão foram desenvolvidos a partir da distribuição da concentração de gadolínio determinada num par $\mathrm{UO}_{2} / \mathrm{Gd}_{2} \mathrm{O}_{3}$ sinterizado sob as mesmas condições nas quais foram sinterizadas todas as pastilhas $\mathrm{UO}_{2}-\mathrm{Gd}_{2} \mathrm{O}_{3}$ preparadas no desenvolvimento deste trabalho, ou seja, $1650{ }^{\circ} \mathrm{C}$ por 3 horas, sempre com taxa de aquecimento de $5^{\circ} \mathrm{C}$ /minuto e sob atmosfera de $\mathrm{H}_{2}$ puro. O par $\mathrm{UO}_{2} / \mathrm{Gd}_{2} \mathrm{O}_{3}$ foi preparado a partir da compactação conjunta dos pós de $\mathrm{Gd}_{2} \mathrm{O}_{3}$ e $\mathrm{UO}_{2}$, os mesmos utilizados na preparação das pastilhas $\mathrm{UO}_{2}-\mathrm{Gd}_{2} \mathrm{O}_{3}$ pela rota de mistura mecânica de pós. 
Inicialmente, a cavidade da matriz foi preenchida com pó de $\mathrm{Gd}_{2} \mathrm{O}_{3}$, o qual foi pré-compactado a baixa pressão. Em seguida, o punção superior foi retirado e pó de $\mathrm{UO}_{2}$ foi carregado na cavidade da matriz, compactando-se o conjunto até a obtenção de um corpo sólido com densidade aproximada de $50 \%$ da densidade teórica, calculada a partir da média ponderada das densidades teóricas do $\mathrm{UO}_{2}$ e do $\mathrm{Gd}_{2} \mathrm{O}_{3}$. A pressão de précompactação do pó de $\mathrm{Gd}_{2} \mathrm{O}_{3}$ foi ajustada por meio de tentativa e erro. O uso de altas pressões conduziu, invariavelmente, a uma baixa resistência mecânia na interface. A pressão de pré-compactação do pó de $\mathrm{Gd}_{2} \mathrm{O}_{3}$ considerada adequada foi muito baixa, abaixo do limite de detecção do sistema de medição da prensa. A pastilha obtida após a sinterização apresentou boa resistência mecânica na interface, possibilitando o seu corte transversal mantendo-se a integridade da amostra. O corte foi efetuado utilizando-se um disco diamantado e a superficie da amostra foi preparada por meio de técnicas convencionais de metalografia. Adotou-se lixamento até aproximadamente $20 \mu \mathrm{m}$ e polimento sucessivo com pasta de diamante de granulometrias 9, 6, 3 e $1 \mu \mathrm{m}$.

Inicialmente foi realizada uma análise qualitativa na superficie polida, onde a aparência da interface $\mathrm{UO}_{2} / \mathrm{Gd}_{2} \mathrm{O}_{3}$ foi revelada por meio de microscopia eletrônica de varredura e a forma geral do perfil de concentração foi determinada por meio da análise qualitativa do teor de gadolínio numa linha perpendicular à interface, realizada por meio de EDS (Energy Dispersive Spectrometry). Uma vez realizada a observação da interface, foram selecionadas três regiões na mesma onde se observou a continuidade entre as fases $\mathrm{UO}_{2}$ puro e $\mathrm{Gd}_{2} \mathrm{O}_{3}$ puro, nas quais foram realizadas análises quantitativas do teor de gadolínio, por meio de WDS (Wavelength Dispersive Spectroscopy), em pontos espaçados de $0,5 \mu \mathrm{m}$. A precisão na determinação da concentração de gadolínio foi estimada ser de $0,1 \%$. A partir das curvas de penetração obtidas, o coeficiente de interdifusão foi determinado por meio de integração gráfica utilizando-se o método de Matano-Boltzmann. Os resultados obtidos estão apresentados e discutidos a seguir.

\subsubsection{Resultados e discussão}

A figura 33 apresenta uma micrografia eletrônica de varredura ilustrando a interface $\mathrm{UO}_{2} / \mathrm{Gd}_{2} \mathrm{O}_{3}$. Em geral, observou-se a presença de um vazio entre as fases, com largura entre 1 e $3 \mu \mathrm{m}$. As concentrações de urânio (vermelho) e gadolínio (verde) foram determinadas ao longo da linha analisada, indicada na figura. Os perfis de concentração indicam uma interpenetração da ordem de $16 \mu \mathrm{m}$ durante o tratamento térmico de 3 horas a $1650^{\circ} \mathrm{C}$. Observa-se, também, que a penetração de gadolínio no $\mathrm{UO}_{2}$ é sensivelmente 
maior do que a penetração do urânio no $\mathrm{Gd}_{2} \mathrm{O}_{3}$, sendo maior do que $2 / 3$ da distância total de interpenetração.

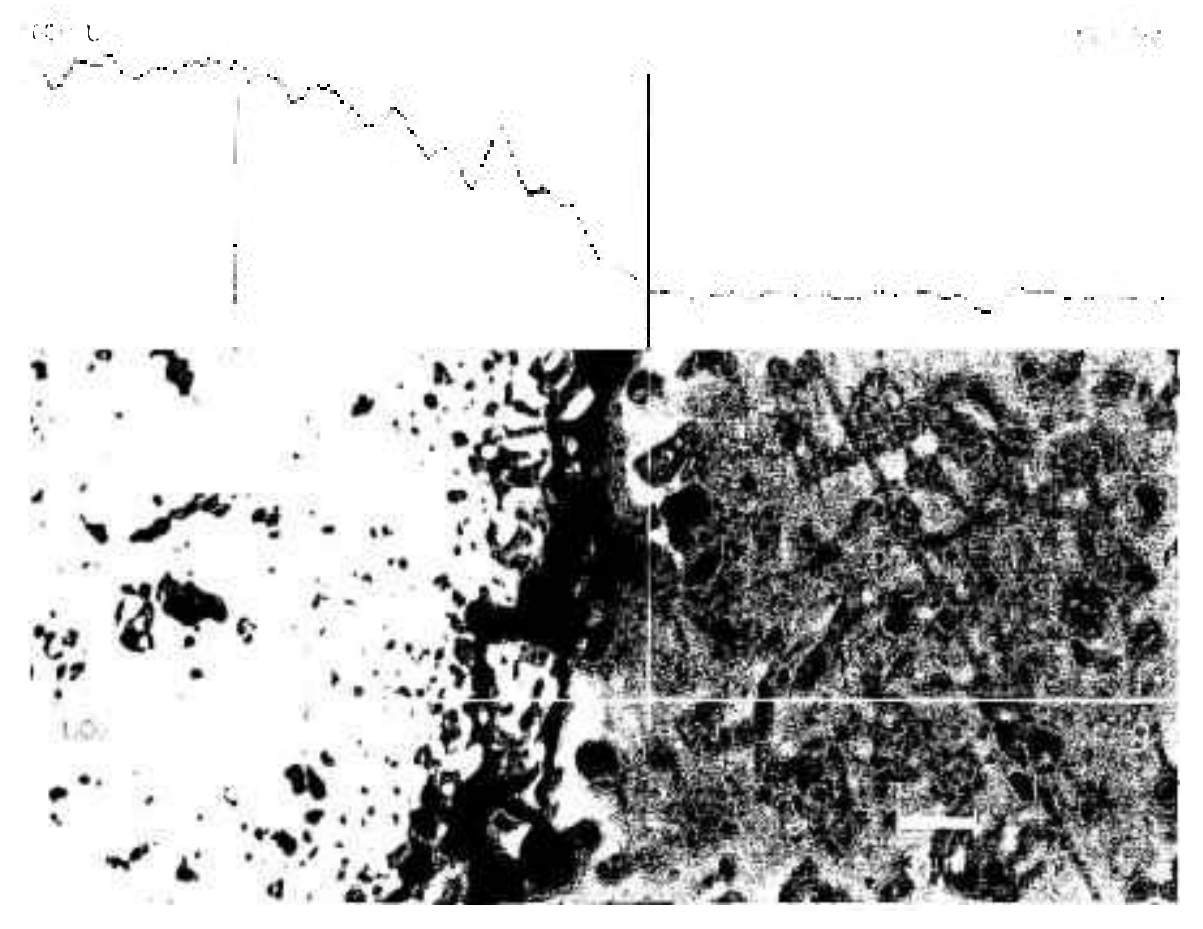

Figura 33 - Micrografia eletrônica de varredura ilustrando a interface $\mathrm{UO}_{2} / \mathrm{Gd}_{2} \mathrm{O}_{3}$.

Foi realizada uma inspeção ao longo da interface com o objetivo de selecionar regiões com boa continuidade entre as fases $\mathrm{UO}_{2}$ e $\mathrm{Gd}_{2} \mathrm{O}_{3}$, ou seja, regiões nas quais era mínima a largura do vazio que se observou existir na interface. Foram selecionadas três regiões que apresentaram uma perfeita continuidade entre as fases. Nessas regiões foram efetuadas análises quantitativas para determinação da concentração de gadolínio, em pontos espaçados de $0,5 \mu \mathrm{m}$ ao longo de uma linha normal à linha da interface $\mathrm{UO}_{2} / \mathrm{Gd}_{2} \mathrm{O}_{3}$. As curvas de penetração foram construídas a partir das concentrações de gadolínio determinadas e da posição do ponto analisado, tomando-se como referência o primeiro ponto onde a fração molar de gadolínio teve valor 1 , ou seja, não foi observada a presença de urânio. Os três perfis de concentração obtidos estão apresentados na figura 34 .

A partir dos pontos experimentais obtidos nos três perfis de concentração, foi construída uma curva de penetração média que pode representar o fenômeno de interdifusão, a qual está indicada na figura 34. Devido à forma complicada das curvas 
experimentais de penetração, não foi possível aplicar uma função para ajustar os pontos experimentais. Assim, a curva de penetração foi ajustada graficamente.

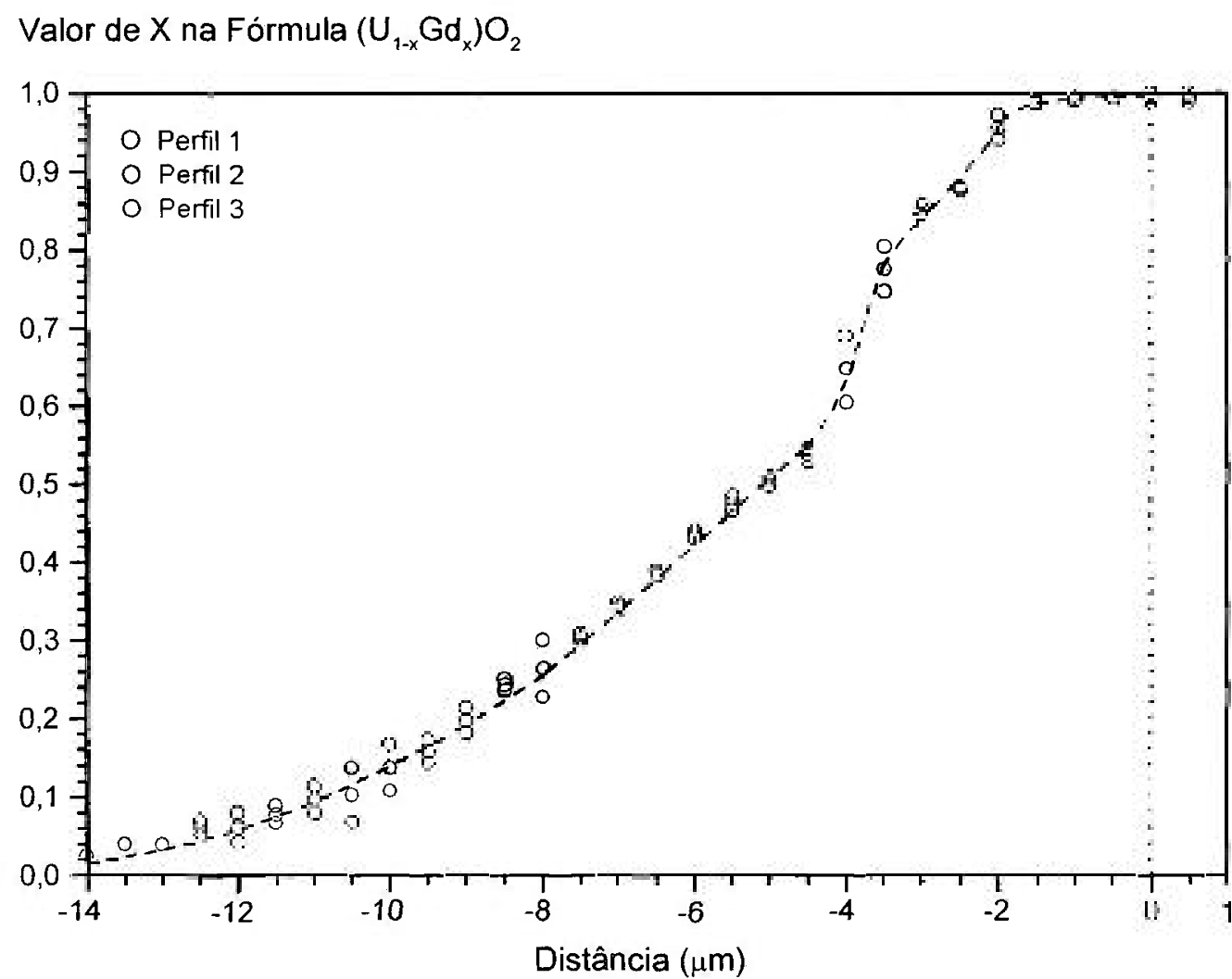

Figura 34 - Curvas de penetração obtidas em três regiões da interface $\mathrm{UO}_{2} / \mathrm{Gd}_{2} \mathrm{O}_{3}$.

A partir da construção da curva de penetração, o coeficiente de interdifusão no sistema $\mathrm{UO}_{2}-\mathrm{Gd}_{2} \mathrm{O}_{3}$ foi calculado em função da fração molar de gadolino, aplicando-se o método de análise proposto por Matano ${ }^{(148)}$, que é um método gráfico para a solução da segunda Lei de Fick, dada pela equação diferencial:

$$
\frac{\partial c}{\partial t}=\frac{\partial}{\partial x}\left(D \frac{\partial c}{\partial x}\right)
$$

onde: $c$ é a concentração, $t$ é o tempo e $x$ é a posição. 
Se o tempo de tratamento térmico $t$ é constante e é satisfeita a condição:

$$
\begin{gathered}
\int x \partial c=0 \quad \text { então o coeficiente de interdifusão é dado por: } \\
D=\frac{1}{2 t} \frac{\partial x}{\partial c} \int_{b} x \partial c
\end{gathered}
$$

Este método foi aplicado a partir da curva de penetração experimental, derivada dos dados experimentais apresentados na figura 34. A figura 35 ilustra a metodologia aplicada.

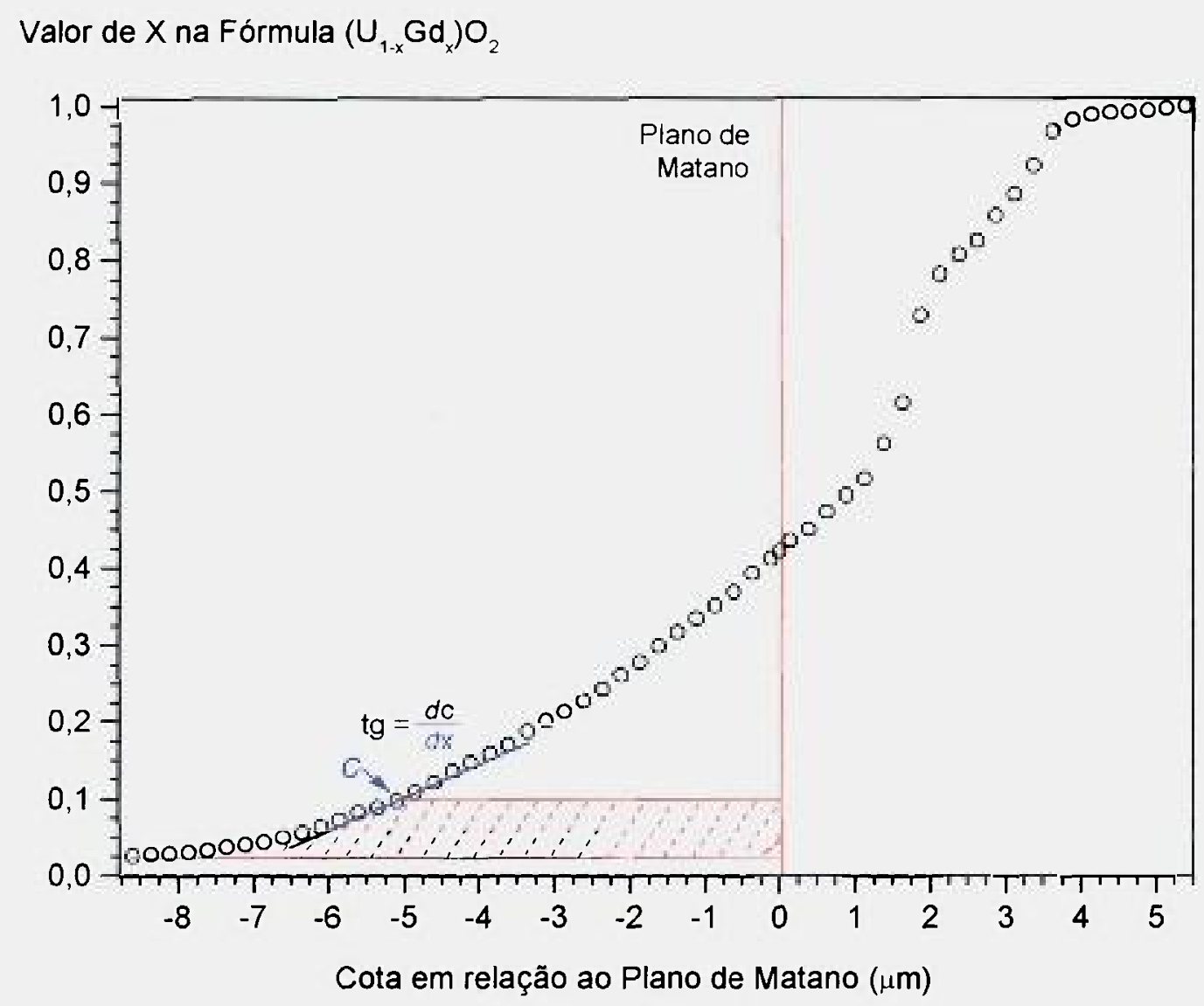

Figura 35 - Curva de penetração experimental, na qual foi aplicado o método de Matano.

Inicialmente, as áreas abaixo e acima da curva de penetração foram integradas a partir de elementos $\mathrm{x}=0,25 \mu \mathrm{m}$, totalizando 56 elementos na distância de interpenetração total de $14 \mu \mathrm{m}$. A intersecção entre as curvas da soma acumulada abaixo da curva de 
penetração (no sentido crescente de $\mathrm{x}$ ) e da soma acumulada acima da curva de penetração (no sentido decrescente de $\mathrm{x}$ ) determina a posição do plano de Matano, o qual divide a integral de concentração em duas partes iguais. Essa posição é tomada como o novo zero, como está indicado na figura 35. Essa construção satisfaz à condição $\int_{0}^{1} x \partial c=0$, imposta pelo método. Em seguida, é determinada graficamente a integral de concentração desde zero até a concentração para a qual será determinado o coeficiente de interdifusão, assim como a tangente da curva de penetração nessa concentração. $\mathrm{Na}$ figura 35 , a metodologia está indicada para uma concentração genérica $c$.

Dessa forma, a equação $D=\frac{1}{2 t} \frac{\partial x}{\partial c} \int_{0}^{c} x \partial c$ é resolvida conhecendo-se a área indicada na figura e o valor da tangente da curva na concentração $c$ :

$$
s=\frac{1}{2 t}, \frac{1}{\text { tangente no ponto } c} \mid\left(\text { área de } c_{1}=0 \text { até } c\right)
$$

Neste trabalho, o tempo de difusão foi considerado como sendo 3 horas, desprezando-se o período de aquecimento até a temperatura do teste, de $1650^{\circ} \mathrm{C}$.

Aplicando-se essa metodologia, o coeficiente de interdifusão foi calculado para toda a faixa de concentração de gadolínio, de 0 a $100 \%$ em mol. Os resultados obtidos estão apresentados na figura 36. A característica mais importante dessa figura é a queda repentina do coeficiente de interdifusão para concentrações de gadolínio acima de $50 \%$ em mol. Também é interessante o aumento do valor do coeficiente de interdifusão para concentrações de gadolínio ao redor de $80 \% \mathrm{em} \mathrm{mol}$. Estes resuldados concordam plenamente com os resultados apresentados na figura 25 , os quais foram obtidos a partir de uma metodologia totalmente diferente. Esses resultam confirmam, agora de uma forma direta, que o coeficiente de interdifusão no sistema $\mathrm{UO}_{2}-\mathrm{Gd}_{2} \mathrm{O}_{3}$ diminui abruptamente quando a fração molar de gadolínio ultrapassa o valor 0,5 , ou seja, mais da metade dos cátions presentes são cátions $\mathrm{Gd}^{3+}$. Apesar da imprecisão do método aplicado neste trabalho, refletida na considerável dispersão dos dados experimentais apresentados na figura 36, é incontestável a conclusão de que a sinterabilidade do sistema $\mathrm{UO}_{2}-\mathrm{Gd}_{2} \mathrm{O}_{3}$ diminui drasticamente a partir da composição $\left(\mathrm{U}_{0,5} \mathrm{Gd}_{0,5}\right) \mathrm{O}_{2}$ devido a uma repentina diminuição do coeficiente de interdifusão do sistema a partir dessa composição.

Outra interessante observação sobre os resultados obtidos nos estudos de interdifusão está relacionada ao deslocamento do plano de Matano em relação ao ponto 
médio da distâncial total de interpenetração das espécies urânio e gadolínio, como pode ser observado na figura 35. A metodologia aplicada neste trabalho não permite a determinação dos coeficientes de difusão individuais, uma vez que seria necessária a existência de um marcador de referência que possibilitasse a determinação do seu deslocamento em relação ao plano de Matano. Porém, a posição do plano de Matano, associado à forma da curva de penetração, indica que o fluxo de material não é homogêneo, com cátions $\mathrm{Gd}^{3+}$ penetrando preferencialmente na rede fluorita do $\mathrm{UO}_{2}$. Isso pode também ser observado, ainda que qualitativamente, na figura 33 , onde é evidente a maior penetração do gadolínio no $\mathrm{UO}_{2}$, tomando-se como referência a posição da interface $\mathrm{UO}_{2} / \mathrm{Gd}_{2} \mathrm{O}_{3}$. A partir dessas observações pode-se concluir que ocorre o efeito Kirkendall nesse sistema, conclusão esta de grande relevância para este trabalho, como será discutido oportunamente.

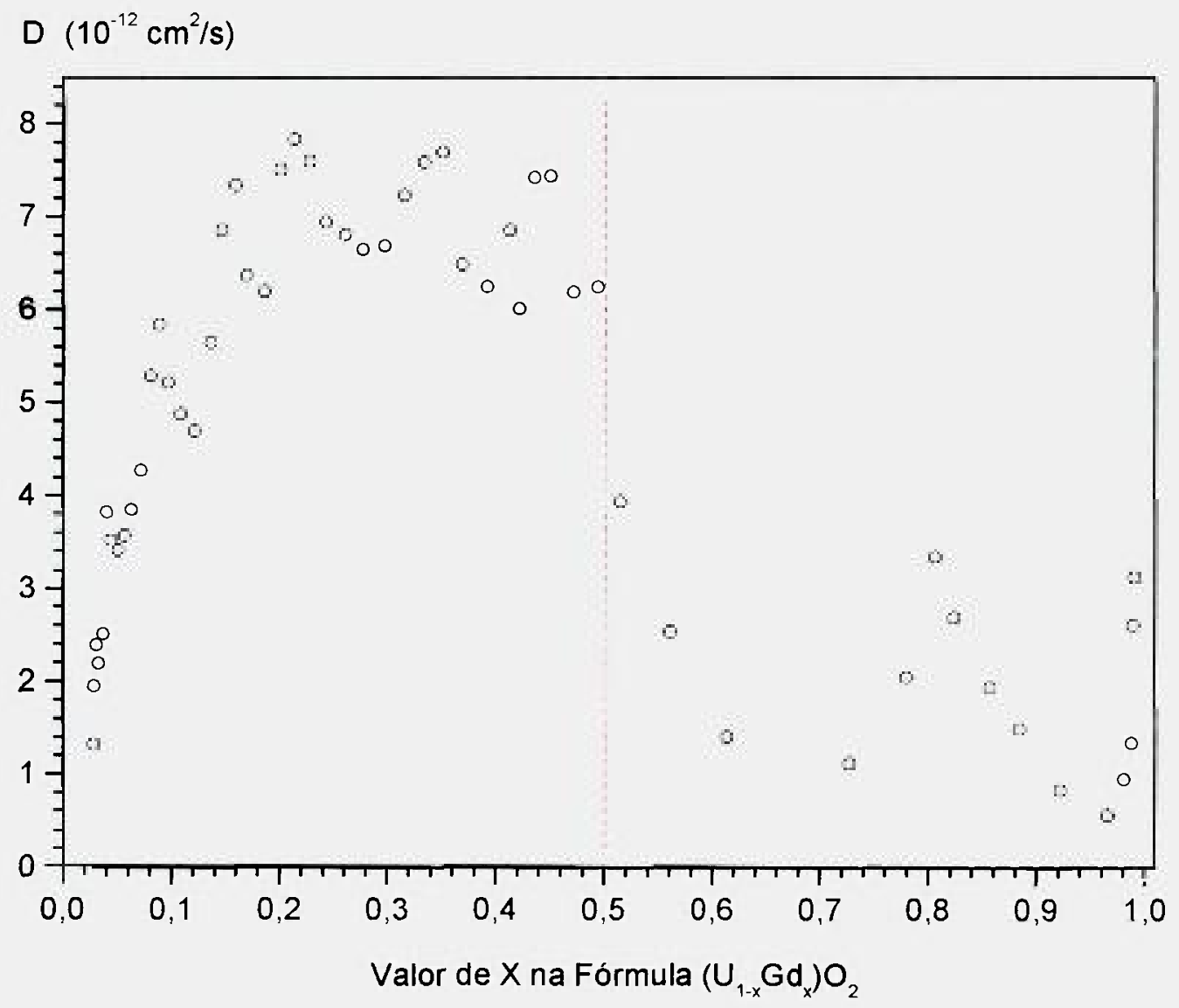

Figura 36 - Coeficiente de interdifusão no sistema $\mathrm{UO}_{2}-\mathrm{Gd}_{2} \mathrm{O}_{3}$ em função da concentração de gadolínio. 
Os resultados apresentados na figura 36 concordam, em muitos aspectos, com os resultados obtidos por outros pesquisadores, apresentados nas duas únicas publicações sobre o assunto encontradas na literatura. Loose et al ${ }^{(149)}$ estudaram a interdifusão no sistema $\mathrm{UO}_{2}-\mathrm{Gd}_{2} \mathrm{O}_{3}$ por meio de pares de interdifusão preparados a partir de uma pastilha de $\mathrm{Gd}_{2} \mathrm{O}_{3}$ compactada posisionada no interior de pó de $\mathrm{UO}_{2}$, seguindo-se uma segunda compactação simultânea. A sinterização foi efetuada em temperaturas na faixa de 1600 a $1900{ }^{\circ} \mathrm{C}$ durante 4,16 e 64 horas. As curvas de penetração foram obtidas a partir de autoradiografias impressionadas por partículas alfa emitidas pelas amostras. Nishida e Yuda ${ }^{(150)}$ também estudaram a interdifusão no sistema $\mathrm{UO}_{2}-\mathrm{Gd}_{2} \mathrm{O}_{3}$ por meio de pares de interdifusão preparados de maneira similar à adotada por Loose et al. Nesse caso a sinterização foi efetuada a $1700{ }^{\circ} \mathrm{C}$ e $1800{ }^{\circ} \mathrm{C}$ durante $100 \mathrm{~h}$ e as concentrações foram determinadas por meio de EDS.

Estes pesquisadores também obtiveram curvas de penetração complexas como as obtidas neste trabalho. A curva de penetração obtida por Loose et al em sua amostra sinterizada a $1900{ }^{\circ} \mathrm{C}$ por 64 horas tem a forma muito semelhante à curva de penetração apresentada nas figuras 34 e 35, obtida neste trabalho. Com base na forma da curva de penetração, esses autores concluíram que existe a ocorrência de outras fases diferentes da fluorita. Por outro lado, as curvas de penetração obtidas por Nishida e Yuda são consideravelmente diferentes da curva obtida neste trabalho. A razão para essa discrepância pode estar relacionada ao grande vazio observado por estes pesquisadores na interface $\mathrm{UO}_{2} / \mathrm{Gd}_{2} \mathrm{O}_{3}$, de largura ao redor de $50 \mu \mathrm{m}$.

Infelizmente, nestes dois trabalhos publicados, os autores desprezaram a forma das curvas de penetração e assumiram que o coeficiente de interdifusão é independente da concentração de gadolínio, determinando o coeficiente de interdifusão efetivo. Segundo seus resultados, o coeficiente de interdifusão no sistema $\mathrm{UO}_{2}-\mathrm{Gd}_{2} \mathrm{O}_{3}$ pode ser calculado a partir das expressões:

$$
\begin{array}{lll}
D=3,3.10^{-3} \exp (-200000 / R T) & \left(\mathrm{cm}^{2} / \mathrm{s}\right) & (\text { referência } 149) \\
D=1,0.10^{-5} \exp (-260000 / R T) & \left(\mathrm{cm}^{2} / \mathrm{s}\right) & (\text { referência } 150)
\end{array}
$$

Se a partir dessas expressões forem calculados os coeficientes de interdifusão considerando-se as condições adotadas neste trabalho, ou seja, $1650{ }^{\circ} \mathrm{C}$ e 3 horas, seriam obtidos os valores de $3,6.10^{-12} \mathrm{~cm}^{2} / \mathrm{s}{ }^{(149)}$ e $0,9.10^{-12} \mathrm{~cm}^{2} / \mathrm{s}{ }^{\text {(15)) }}$. Nota-se que o valor obtido adotando-se a expressão determinada por Loose et al concordam razoavelmente bem com 
os resultados obtidos neste trabalho, situando-se aproximadamente no centro da faixa de variação apresentada na figura 36.

Por outro lado, o valor obtido adotando-se a expressão determinada por Nishida e Yuda pode ser considerado baixo quando comparado com os resultados experimentais apresentados na figura 36. Isso pode ser inferido pela pequena interpenetração observada nos testes destes pesquisadores quando comparadas com a obtida neste trabalho. Nishida e Yuda obtiveram uma interpenetração de apenas $25 \mu \mathrm{m}$ na sinterização a $1700{ }^{\circ} \mathrm{C}$ por 100 horas. Neste trabalho, sob condições de sinterização bem menos severas, em apenas 3 horas a $1650^{\circ} \mathrm{C}$, foi obtida uma interpenetração de $14 \mu \mathrm{m}$. Esse comportamento poderia ser explicado pelo grande vazio desenvolvido na interface $\mathrm{UO}_{2} / \mathrm{Gd}_{2} \mathrm{O}_{3}$ das amostras preparadas por Nishida e Yuda, de largura ao redor de $50 \mu \mathrm{m}$, como comentado anteriormente.

\subsubsection{Fundamentação da hipótese}

Os resultados apresentados e discutidos nos itens anteriores, 2.2.1 e 2.2.2, fundamentam a hipótese da Barreira de Difusão. Essa conclusão é baseada nas seguintes observações:

1 - A sinterabilidade do sistema é drasticamente diminuída para concentrações de $\mathrm{Gd}_{2} \mathrm{O}_{3}$ superiores a $50 \% \mathrm{em} \mathrm{mol}$, como mostra inequivocamente a figura 25 ;

2 - A causa dessa queda da sinterabilidade é a repentina diminuição do coeficiente de interdifusão para concentrações de $\mathrm{Gd}_{2} \mathrm{O}_{3}$ superiores a $50 \%$ em mol, como mostra a figura 36;

3 - Apesar de não terem sido diretamente detectadas, outras fases não identificadas, com estrutura cristalina diferente da estrutura tipo fluorita do $\mathrm{UO}_{2}$, muito provavelmente ocorrem para concentrações de $\mathrm{Gd}_{2} \mathrm{O}_{3}$ superiores a $50 \%$ em mol. Essa afirmação é baseada nos difratogramas obtidos em pós $\mathrm{UO}_{2}-\mathrm{Gd}_{2} \mathrm{O}_{3}$ calcinados (figuras 21 a 24), nos difratogramas obtidos em pastilhas $\mathrm{UO}_{2}-\mathrm{Gd}_{2} \mathrm{O}_{3}$ sinterizadas (figuras 26 a 29) e, principalmente, na variação do parâmetro de rede em função da concentração de $\mathrm{Gd}_{2} \mathrm{O}_{3}$ (figura 30), o qual desvia-se da lei de Vegard para concentrações de $\mathrm{Gd}_{2} \mathrm{O}_{3}$ superiores a $50 \%$ em mol. Essa observação é uma evidência inequívoca de que outras fases diferentes da fase fluorita estão presentes no sistema. Essa afirmação é reforçada 
pela identificação de uma série de fases nos sistemas ( $\mathrm{Ce}, \operatorname{Pr}, \mathrm{Tb}$ )-O, as quais provavelmente têm a mesma estrutura cristalina de fases ainda não identificadas no sistema U-Gd-O, uma vez que o modelo de construção dessas fases nos óxidos de terras raras é inteiramente apliçável no sistema $\mathrm{UO}_{2}-\mathrm{Gd}_{2} \mathrm{O}_{3}$;

4 - A microestrutura de pastilhas sinterizadas preparadas a partir da rota de mistura mecânica de pós, apresentada na figura $19 \mathrm{C}$, revela uma fase de $\mathrm{UO}_{2}$ puro, de coloração azul, ao redor da qual observa-se um gradiente de coloração azul a amarelo, passando por violeta e vários tons de marrom. Esse gradiente de coloração indica um gradiente de concentração de gadolínio. Isto é mais uma indicação de que fases de baixa difusividade são formadas, diminuindo a sinterabilidade no sistema.

Portanto, a hipótese proposta no item 2.1 pode ser considerada fundamentada por dados experimentais e pode ser mais precisamente enunciada, complementando-se a afirmação de que "...são formadas provavelmente màis de uma fase $(U, G d) O_{2-x}$ na faixa de concentração acima de $50 \%$ em mol de $\mathrm{Gd}_{2} \mathrm{O}_{3}$, uma das quais com provável estrutura romboédrica, que apresentam baixa difusividade cationica, o que é evidenciado por um menor coeficiente de interdifusão...". Quando a formação da solução sólida é iniciada durante a sinterização, uma ou mais fases ricas em gadolinio são formadas, as quais apresentam baixo coeficiente de interdifusão, diminuindo a difusividade do sistema como um todo, conduzindo a baixa sinterabilidade e baixas densidades após o ciclo de sinterização.

\subsection{Teste da hipótese}

Para o teste da hipótese procurou-se aplicar uma metodologia a mais simples e eficaz possível, de maneira a fundamentar uma conclusão segura aplicando-se um procedimento experimental simples e rápido. A metodologia adotada baseia-se na realização de um teste de sinterização em pós mistos na qual o $\mathrm{Gd}_{2} \mathrm{O}_{3}$ seja incorporado ao $\mathrm{UO}_{2}$ de tal de maneira que se possa garantir que a barreira de difusão não seja formada, ou seja, que a concentrảção de $\mathrm{Gd}_{2} \mathrm{O}_{3}$ jamais ultrapasse o valor de $50 \% \mathrm{em} \mathrm{mol}$. Como a formação de fases diferentes da fluorita, de baixa sinterabilidade, inicia-se apenas para concentrações de $\mathrm{Gd}_{2} \mathrm{O}_{3}$ superiores a $50 \%$ em mol, como foi discutido anteriormente, foram preparadas misturas de pós onde o $\mathrm{Gd}_{2} \mathrm{O}_{3}$ foi substituído por pós coprecipitados contendo teores de $\mathrm{Gd}_{2} \mathrm{O}_{3}$ inferiores a $50 \%$ em mol. Neste caso, durante a solubilização, não é possível a formação de fases com concentração acima de $50 \% \mathrm{em} \mathrm{mol}$, não sendo possível a formação da barreira de difusão. Pelo contrário, segundo os resultados 
apresentados na figura 25 , este novo sistema deve apresentar sinterabilidade superior à do $\mathrm{UO}_{2}$ puro, uma vez que a presença de gadolínio na rede cristalina tipo fluorita comprovadamente favorece a sinterização. Além da verificação da hipótese, os resultados obtidos nestes ensaios poderiam apontar para uma possível solução tecnológica para o problema de densificação, incorporando-se ao pó de $\mathrm{UO}_{2}$ um pó misto contendo $50 \%$ em mol de $\mathrm{Gd}_{2} \mathrm{O}_{3}$ ( $25 \%$ em peso deste pó equivale a $10 \%$ em peso de $\mathrm{Gd}_{2} \mathrm{O}_{3}$ no combustível) em substituição ao pó de $\mathrm{Gd}_{2} \mathrm{O}_{3}$ puro. Este pó misto poderia substituir a mistura matriz.

Para essa verificação, pós obtidos por coprecipitação via DUA, comprovadamente de boa homogeneidade, foram homogeneizados com pó de $\mathrm{UO}_{2}$ segundo os procedimentos adotados na preparação de amostras por meio da rota de mistura de pós, descritos no item 2.1.1.1. Pós obtidos por coprecipitação com composições de $20,30,40,50,60,70,80$ e 90 $\%$ em mol de $\mathrm{Gd}_{2} \mathrm{O}_{3}$ foram adicionados ao pó de $\mathrm{UO}_{2}$ de modo a obter-se sempre o equivalente a $10 \%$ em peso de $\mathrm{Gd}_{2} \mathrm{O}_{3}(14,2 \% \mathrm{em} \mathrm{mol})$ na amostra. As amostras assim preparadas foram compactadas e sinterizadas rigorosamente sob as mesmas condições sempre utilizadas neste trabalho $\left(1650{ }^{\circ} \mathrm{C}\right.$ por 3 horas sob atmosfera de $\mathrm{H}_{2}$ ). Após a sinterização as densidades foram determinadas pelo método hidrostático utilizando-se xilol. Os resultados obtidos estão apresentados na figura 37.

Como ficou evidenciado no item 2.2, a diminuição da sinterabilidade do sistema $\mathrm{UO}_{2}-\mathrm{Gd}_{2} \mathrm{O}_{3}$, ou do coeficiente de interdifusão, devido provavelmente à formação de fases diferentes da fluorita do $\mathrm{UO}_{2}$, somente ocorre para concentrações de $\mathrm{Gd}_{2} \mathrm{O}_{3}$ acima de $50 \%$ em mol. Abaixo dessa concentração a única fase presente é uma solução sólida substitucional, onde cátions $\mathrm{Gd}^{3+}$ substituem cátions $\mathrm{U}^{4+}$, o que é benéfico em termos de sinterabilidade do sistema, como ilustra a figura 25. Portanto, quando o pó de $\mathrm{Gd}_{2} \mathrm{O}_{3}$ puro é substituído, na preparação de misturas mecânicas, por pós obtidos por coprecipitação contendo teores menores do que $50 \% \mathrm{em} \mathrm{mol} \mathrm{de} \mathrm{Gd}_{2} \mathrm{O}_{3}$, a formação da barreira de difusão fica impossibilitada de ocorrer, uma vez que se torna impossível a ocorrência de regiões onde a concentração de gadolínio exceda $50 \% \mathrm{em} \mathrm{mol} \mathrm{e,} \mathrm{portanto,} \mathrm{torna-se} \mathrm{impossível} \mathrm{a}$ formação de fases de baixa difusividade que poderiam atuar como barreira de difusão. Nestas condições, a presença de gadolínio, mesmo quando adicionado por meio de mistura mecânica de pós, deve necessariamente incrementar a sinterabilidade do sistema, obtendose um nível mínimo de densidade compatível com a densidade observada no caso da sinterização do pó contendo $10 \%$ em peso de $\mathrm{Gd}_{2} \mathrm{O}_{3}$ (ou 14,2\% em mol) preparado por coprecipitação. A mínima densidade aceitável, com base na hipótese da barreira de difusão, é a do $\mathrm{UO}_{2}$ puro (indicada na figura 37), supondo-se que a presença de gadolínio não interfira na sinterabilidade do $\mathrm{UO}_{2}$. Observando-se os resultados apresentados na figura 37 , verifica-se que não ocorreu o comportamento previsto pela hipótese da barreira de difusão. 
Densidade (\%DT)

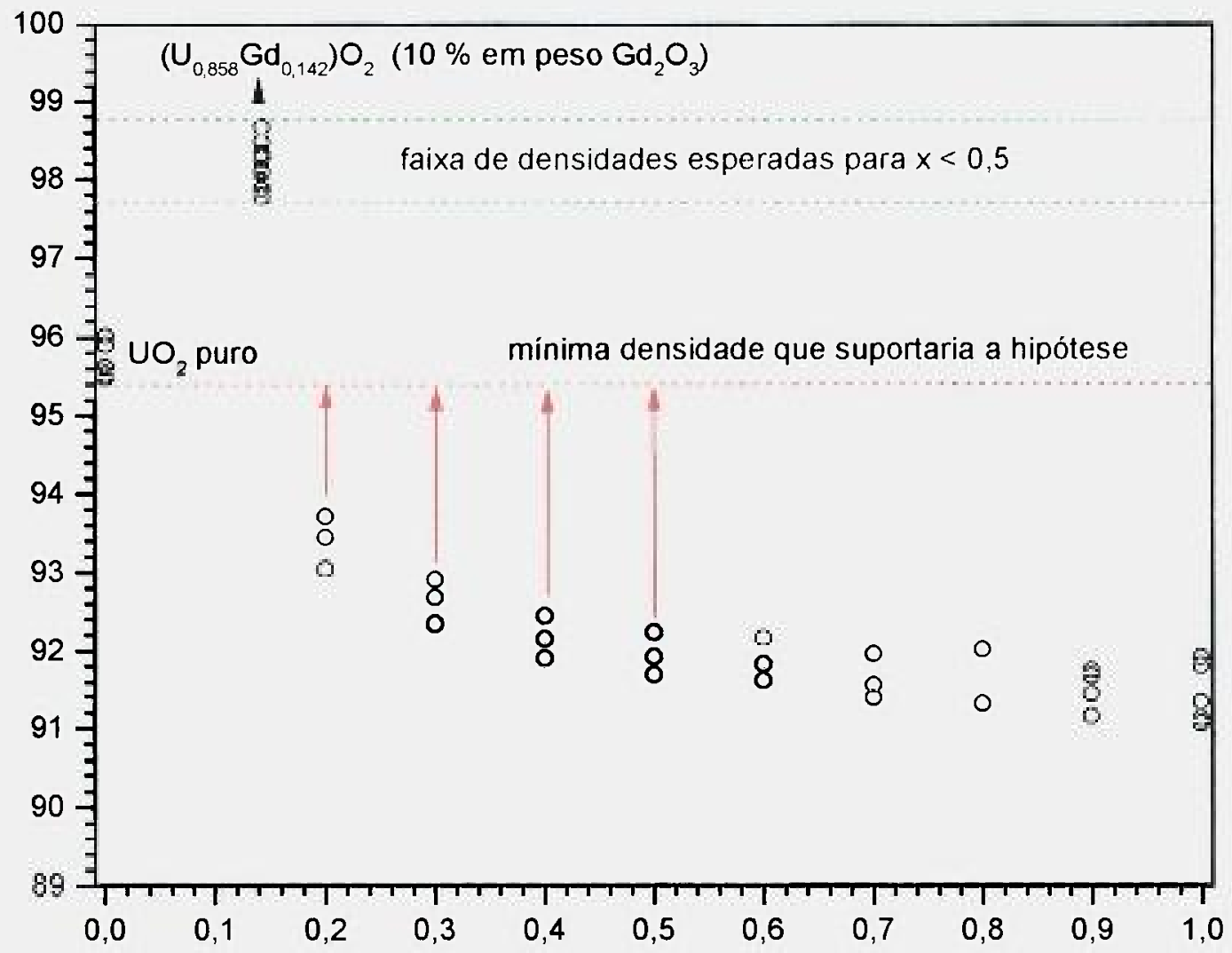

Fração molar de gadolínio $(x)$ presente no pó misto $\left(U_{1-x} G d_{x}\right) O_{2}$ adicionado ao pó de $U O_{2}$

Figura 37 - Niveis de densificação observados em pastilhas $\mathrm{UO}_{2}-\mathrm{Gd}_{2} \mathrm{O}_{3}$ preparadas por mistura mecânica utilizando-se pós $\left(\mathrm{U}_{1-\mathrm{x}} \mathrm{Gd}_{\mathrm{x}}\right) \mathrm{O}_{2}$ obtidos por coprecipitação. (base $10 \%$ em peso de $\mathrm{Gd}_{2} \mathrm{O}_{3}$ )

Como a concentração nominal de $\mathrm{Gd}_{2} \mathrm{O}_{3}$ em todas as pastilhas sinterizadas é de 10 $\%$ em peso, ou $14,2 \% \mathrm{em} \mathrm{mol}$, durante a sinterização das amostras preparadas com pós coprecipitados de composição inferior a $\left(\mathrm{U}_{0,5} \mathrm{Gd}_{0.5}\right) \mathrm{O}_{2}$ não é possivel a formação de regiões onde a concentração de $\mathrm{Gd}_{2} \mathrm{O}_{3}$ seja superior a $50 \% \mathrm{em} \mathrm{mol}$. Como os coeficientes de interdifusão mantềm-se num mesmo patamar entre as frações molares de gadolínio de 0,2 a 0,5 (figura 36), na faixa de 6 a $8.10^{-12} \mathrm{~cm}^{2} / \mathrm{s}$, pode-se dizer que a densidade final esperada após a sinterização de pós preparados com composições de gadolínio inferiores a $50 \% \mathrm{em}$ mol deve necessariamente ser compatível com o nível de densidade observada nas pastilhas contendo $10 \%$ em peso de $\mathrm{Gd}_{2} \mathrm{O}_{3}$ preparadas por coprecipitação (ao redor de 98 $\%$ da densidade teórica). Mesmo adotando-se uma hipótese extrema, a qual considera que não ocorra nenhuma redistribuição de gadolínio durante a sinterização, a mínima densidade aceitável que suportaria a hipótese da Barreira de Difusão seria a densidade típica obtida na 
sinterização do $\mathrm{UO}_{2}$ puro, ao redor de $95,5 \%$ da densidade teórica, o que também não ocorreu. Portanto, a evidência experimental que suportaria a hipótese seria um abrupto aumento da densidade final obtida nas amostras preparadas com misturas $\mathrm{UO}_{2}-\left(\mathrm{U}_{1-\mathrm{x}} \mathrm{Gd}_{\mathrm{x}}\right) \mathrm{O}_{2}$, com $\mathrm{X} \leq 0,5$. Apenas para valores de $\mathrm{X}$ na fórmula superiores a 0,5 deveria ser observado baixas densidades (o que ocorreu), uma vez que, nesse caso, a formação de fases de baixa difusividade é possível, com base nos resultados experimentais obtidos neste trabalho.

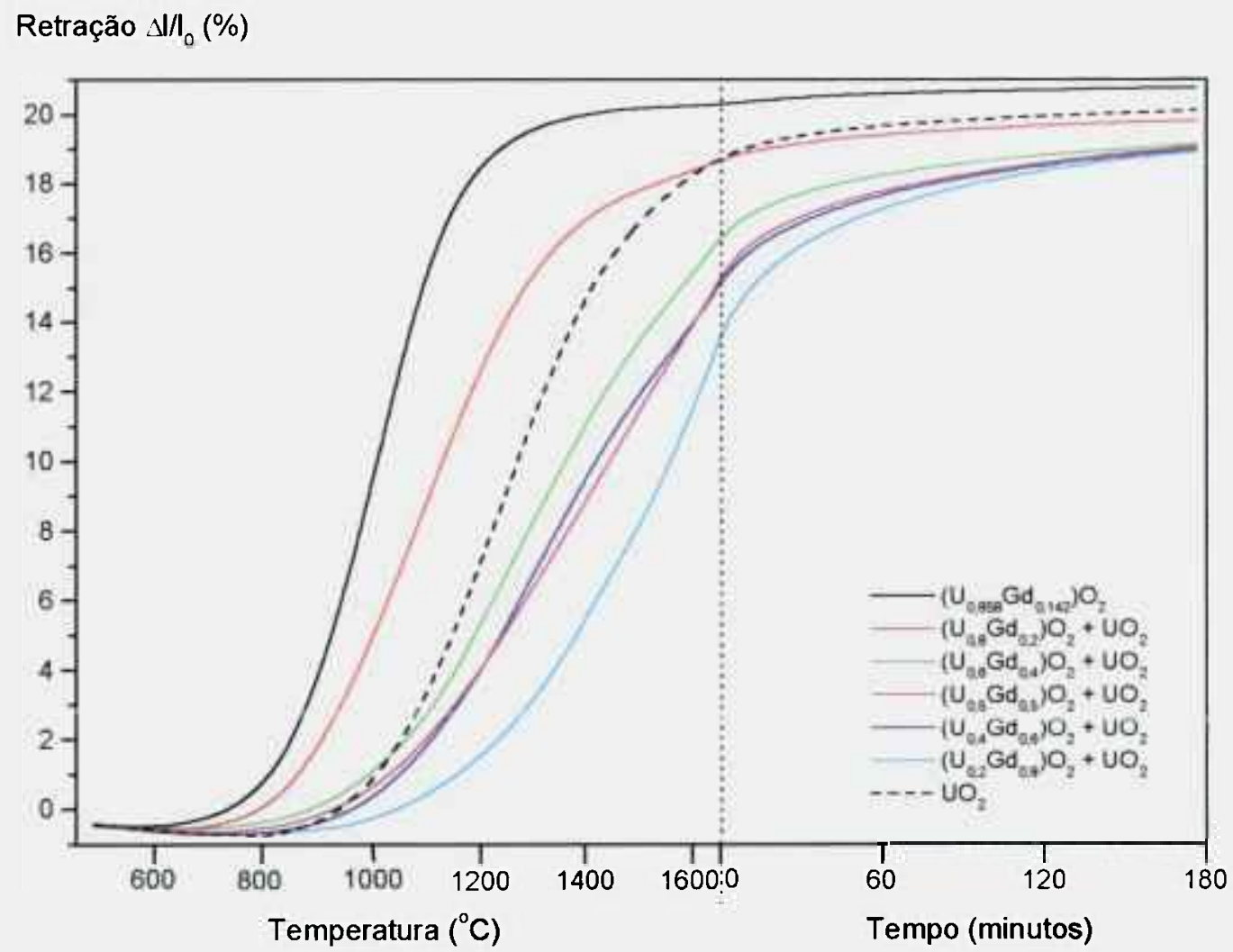

Figura 38 - Curvas de sinterização de amostras $\mathrm{UO}_{2}-\left(\mathrm{U}_{1-\mathrm{x}} \mathrm{Gd}_{\mathrm{x}}\right) \mathrm{O}_{2}$ preparadas para o teste de hipótese $\left(5^{\circ} \mathrm{C} / \mathrm{min}, \mathrm{H}_{2}\right)$.

Analisando-se a cinética de sinterização das amostras preparadas para o teste de hipótese descrito acima, cujas curvas de sinterização estão apresentadas na figura 38 , não se observa uma sensível mudança no comportamento da sinterização nas amostras preparadas a partir de misturas mecânicas $\mathrm{UO}_{2}-\left(\mathrm{U}_{1-\mathrm{x}} \mathrm{Gd}_{\mathrm{x}}\right) \mathrm{O}_{2}$ com valores de $0,4<\mathrm{X}<0,6$, o que deveria necessariamente ocorrer caso a hipótese da Barreira de Difusão fosse verdadeira. Uma melhor análise pode ser realizada observando-se as taxas de sinterização correspondentes às curvas apresentadas na figura 38 , as quais estão apresentadas na figura 39. 


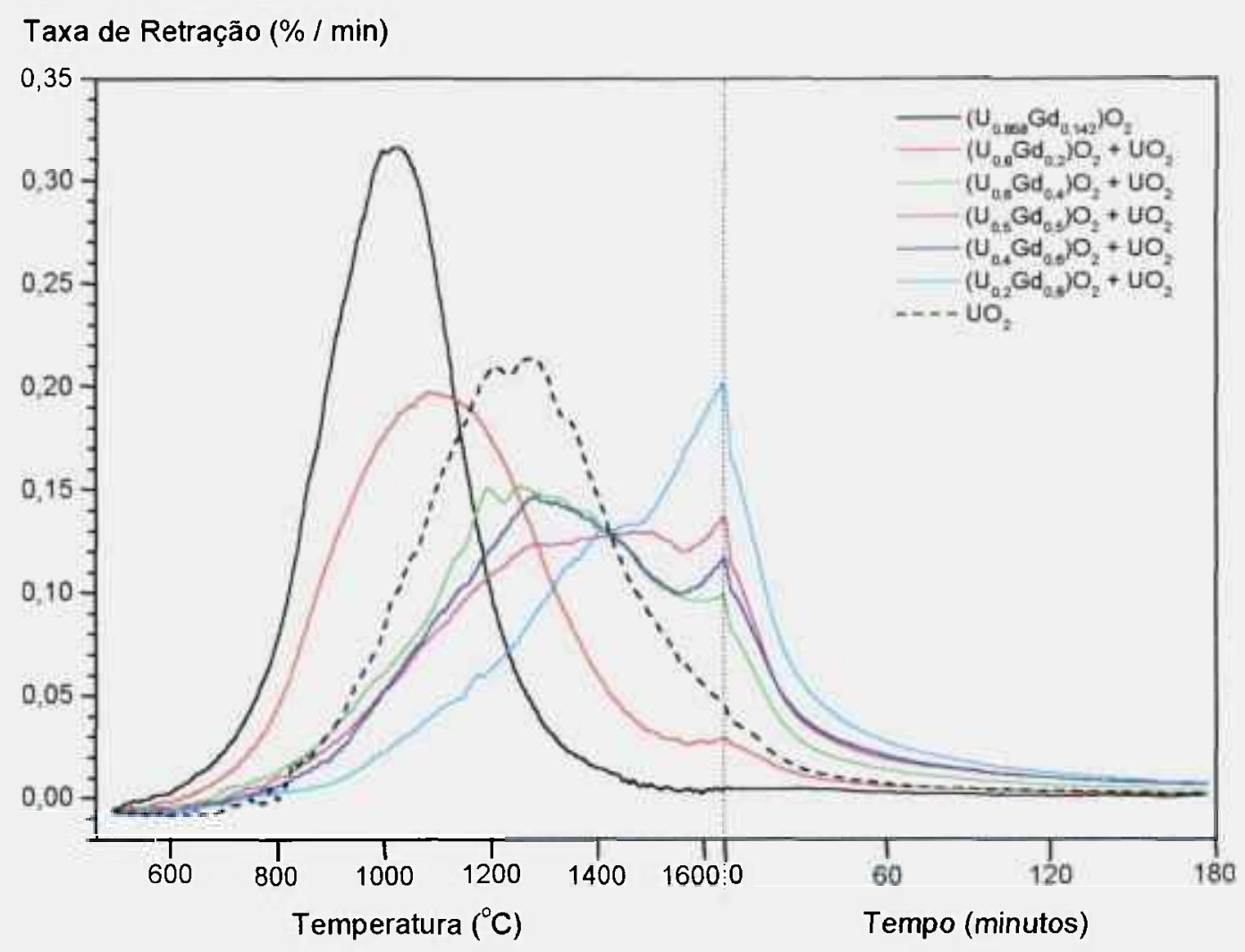

Figura 39 - Taxas de densificação derivadas das curvas apresentadas na figura 38.

Na figura 39 pode-se observar que a amostra contendo $14,2 \%$ em mol de $\mathrm{Gd}_{2} \mathrm{O}_{3}$ ( $10 \%$ em peso) preparada por coprecipitação, assim como a amostra de $\mathrm{UO}_{2}$ puro, mostra uma cinética de sinterização com apenas uma etapa, sendo que a presença de gadolínio homogeneamente distribuído antecipa a sinterização, a qual ocorre numa taxa sensivelmente maior quando comparada à sinterização do $\mathrm{UO}_{2}$ puro. Como discutido anteriormente, este comportamento é compatível com o modelo proposto por Ho e Radford ${ }^{\text {(40), }}$, baseado na formação de cátions $\mathrm{U}^{5+}$. Como a concentração equivalente de gadolínio nas amostras $\mathrm{UO}_{2}-\left(\mathrm{U}_{1-\mathrm{x}} \mathrm{Gd}_{\mathrm{x}}\right) \mathrm{O}_{2}$ também é de $14,2 \% \mathrm{em}$ mol, segundo a hipótese apresentada, a cinética de sinterização no caso de $\mathrm{X} \leq 0,5$ deve ser necessariamente muito similar à amostra preparada por coprecipitação e apresentar apenas uma etapa, uma vez que o bloqueio da sinterização não poderia ocorrer. Contudo, observando-se as curvas da figura 39 , verifica-se a presença de duas etapas na sinterização, mesmo no caso da amostra $\mathrm{UO}_{2}$ $\left(\mathrm{U}_{0.8} \mathrm{Gd}_{0,2}\right) \mathrm{O}_{2}$. Além disto, pode-se também observar que a evolução da cinética de sinterização, com o aumento do valor de $\mathrm{X}$ na fórmula do pó adicionado ao pó de $\mathrm{UO}_{2}$, é contínua, o que não suporta a hipótese da Barreira de Difusão. 
Portanto, com base nos resultados obtidos no teste da hipótese, a hipótese da formação de uma Barreira de Difusão para explicar o comportamento da sinterização do sistema $\mathrm{UO}_{2}-\mathrm{Gd}_{2} \mathrm{O}_{3}$ deve ser rejeitada. 


\section{A HIPÓTESE DA TRANSFORMAÇÃO DE FASE DO Gd $\mathrm{GO}_{3}$}

Em temperaturas inferiores a $2000{ }^{\circ} \mathrm{C}$, três tipos de óxidos de terras raras podem ser observados, designados como formas A, B e C. A forma A tem estrutura cristalina hexagonal, a forma $\mathrm{B}$ tem estrutura cristalina monoclínica e a forma $\mathrm{C}$ tem estrutura cristalina cúbica. A forma $\mathrm{C}$ é a forma de baixa temperatura, a forma $\mathrm{B}$ é observada em temperaturas intermediárias e a forma $\mathrm{A}$ ocorre em altas temperaturas. Nas temperaturas de interesse para a tecnologia do combustivel nuclear, o $\mathrm{Gd}_{2} \mathrm{O}_{3}$ pode ocorrer nas formas $\mathrm{C}$ e B. Gschneider e Eyring ${ }^{\text {(142) }}$ indicam a temperatura de transformação de fase da forma $\mathrm{C}$ para a forma $\mathrm{B}$ do $\mathrm{Gd}_{2} \mathrm{O}_{3}$ ao redor de $1250^{\circ} \mathrm{C}$. El-Houte e El-Sayed Ali ${ }^{(\mathbf{1 5 1})}$ indicam a temperatura de transformação ao redor de $1200{ }^{\circ} \mathrm{C}$. Uma vez que a transformação de fase do $\mathrm{Gd}_{2} \mathrm{O}_{3}$ ocorre numa faixa de temperatura na qual ocorre simultaneamente a sinterização no sistema $\mathrm{UO}_{2}-\mathrm{Gd}_{2} \mathrm{O}_{3}$, a possibilidade de que essa transformação de fase interfira no procesșo de sinterização não pode ser descartada. Essa foi a base para a proposição da hipótesè de que trata este capitulo, ou a Hipótese da Transformação de Fase do $\mathrm{Gd}_{2} \mathrm{O}_{3}$. A seguir estão descritos os procedimentos utilizados e estão apresentados e discutidos os resultados obtidos.

\subsection{Proposição da hipótese}

Para verificar-se o comportamento do $\mathrm{Gd}_{2} \mathrm{O}_{3}$ puro durante a sinterização, uma vez que ele é, na forma de óxido puro, parte integrante do combustível $\mathrm{UO}_{2}-\mathrm{Gd}_{2} \mathrm{O}_{3}$ durante um período do processo de sinterização, uma pastilha de $\mathrm{Gd}_{2} \mathrm{O}_{3}$ puro, na sua forma cúbica, foi sinterizada num dilatômetro sob as condições de sinterização adotas neste trabalho, ou seja, $1650{ }^{\circ} \mathrm{C}$ durante 3 horas sob atmosfera de $\mathrm{H}_{2}$ puro. A curva de sinterização obtida está apresentada na figura 40. Nesta figura estão também apresentadas as curvas de sinterização do $\mathrm{UO}_{2}$ puro e do $\mathrm{UO}_{2}-\mathrm{Gd}_{2} \mathrm{O}_{3}$ contendo $10 \%$ em peso de $\mathrm{Gd}_{2} \mathrm{O}_{3}$, para comparação.

Observa-se uma retração acentuada da pastilha de $\mathrm{Gd}_{2} \mathrm{O}_{3}$ puro na faixa de temperatura de $1250^{\circ} \mathrm{C}$ a $1300{ }^{\circ} \mathrm{C}$. Esta faixa de temperatura é próxima da faixa de temperatura onde ocorre o bloqueio da sinterização no sistema $\mathrm{UO}_{2}-\mathrm{Gd}_{2} \mathrm{O}_{3}$, de $1150{ }^{\circ} \mathrm{C}$ a $1250{ }^{\circ} \mathrm{C}$, como ilustra a figura 40 . Na figura 41 estão apresentadas as taxas de retração derivadas das curvas apresentadas na figura 40. Esta anomalia observada na curva de sinterização do $\mathrm{Gd}_{2} \mathrm{O}_{3}$ puro é, provavelmente, causada pela transformação da fase cúbica de corpo centrado (forma C) para a fase monoclínica (forma B), a qual é acompanhada de pronunciada diminuição de volume. Esta transformação de fase do $\mathrm{Gd}_{2} \mathrm{O}_{3}$ ocorre simultaneamente com o processo de sinterização do sistema, passando de uma estrutura 
cristalina cúbica, como a fluorita do $\mathrm{UO}_{2}$, para uma estrutura monoclínica, muito mais compacta. Além disto, a faixa de temperatura em que ocorre a transformação de fase é compatível com a faixa de temperatura em que ocorre o bloqueio da sinterização no sistema $\mathrm{UO}_{2}-\mathrm{Gd}_{2} \mathrm{O}_{3}$.

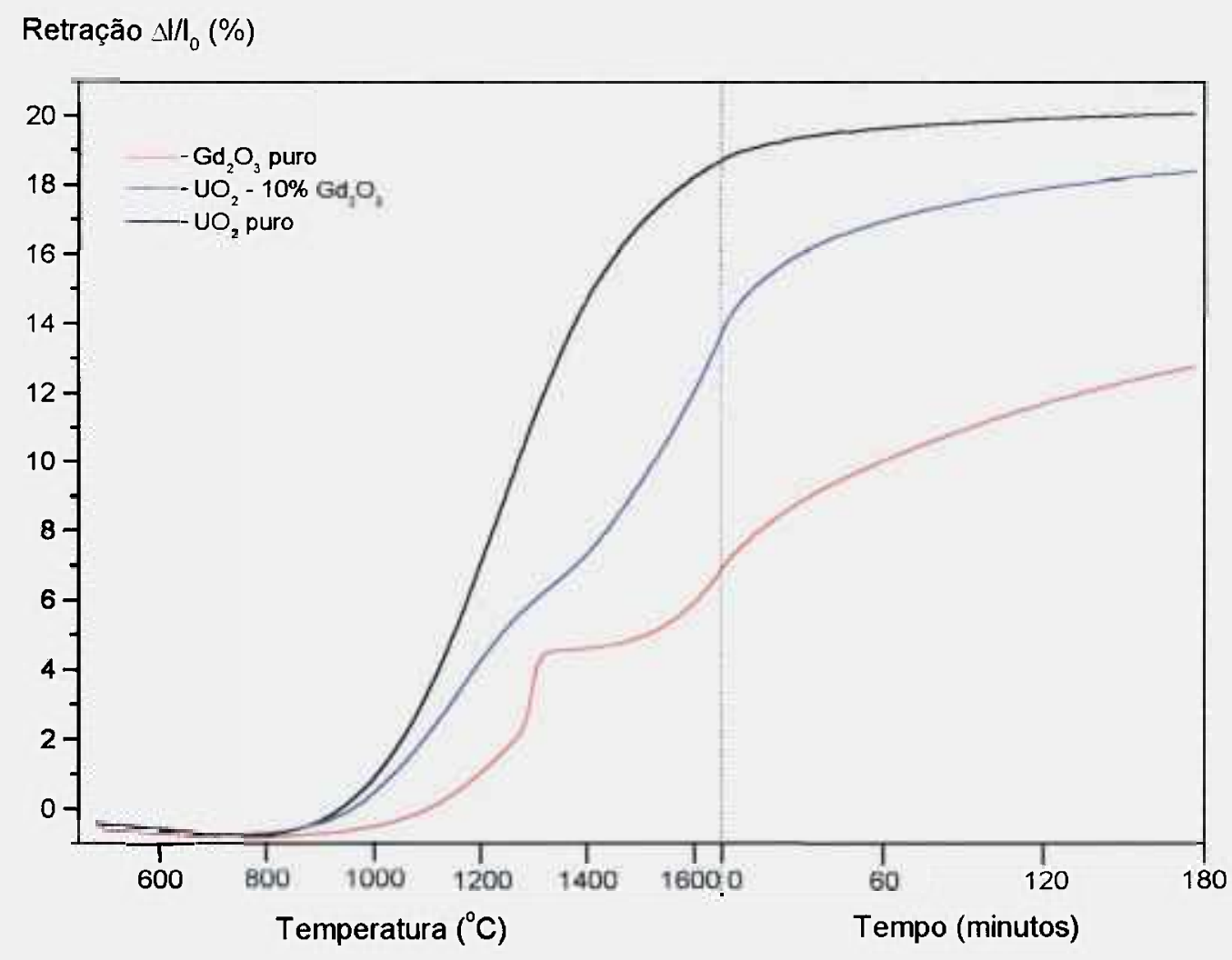

Figura 40 - Curva de sinterização de uma pastilha de $\mathrm{Gd}_{2} \mathrm{O}_{3}$ puro $\left(5^{\circ} \mathrm{C} / \mathrm{min}, \mathrm{H}_{2}\right)$.

Como discutido anteriormente, quando a rota adotada para a incorporação do $\mathrm{Gd}_{2} \mathrm{O}_{3}$ ao pó de $\mathrm{UO}_{2}$ é mistura mecânica, atinge-se um nível de homogeneidade macroscópico, onde aglomerados de $\mathrm{Gd}_{2} \mathrm{O}_{3}$ estão dispersos no $\mathrm{UO}_{2}$. Esses aglomerados possivelmente sofrem a transformação de fase durante a sinterização, passando de uma estrutura cúbica de corpo centrado muito semelhante à estrutura fluorita do $\mathrm{UO}_{2}$, como foi discutido no item 2.2.1.2, para uma estrutura monoclínica, muito mais compacta. A ocorrência dessa transformação de fase pode dificultar a formação da solução sólida devido à provavelmente maior dificuldade de cátions urânio difundir-se através da rede cristalina mais compacta do $\mathrm{Gd}_{2} \mathrm{O}_{3}$ monoclínico.

Com base nessas observações, pode ser proposta a hipótese da transformação de fase do $\mathrm{Gd}_{2} \mathrm{O}_{3}$ ser a responsável pelo comportamento da sinterização do combustível $\mathrm{UO}_{2}$ - 
$\mathrm{Gd}_{2} \mathrm{O}_{3}$ preparado segundo o método de mistura a seco dos pós de $\mathrm{UO}_{2}$ e $\mathrm{Gd}_{2} \mathrm{O}_{3}$ (existência de aglomerados de $\mathrm{Gd}_{2} \mathrm{O}_{3}$ na forma cúbica), como segue:

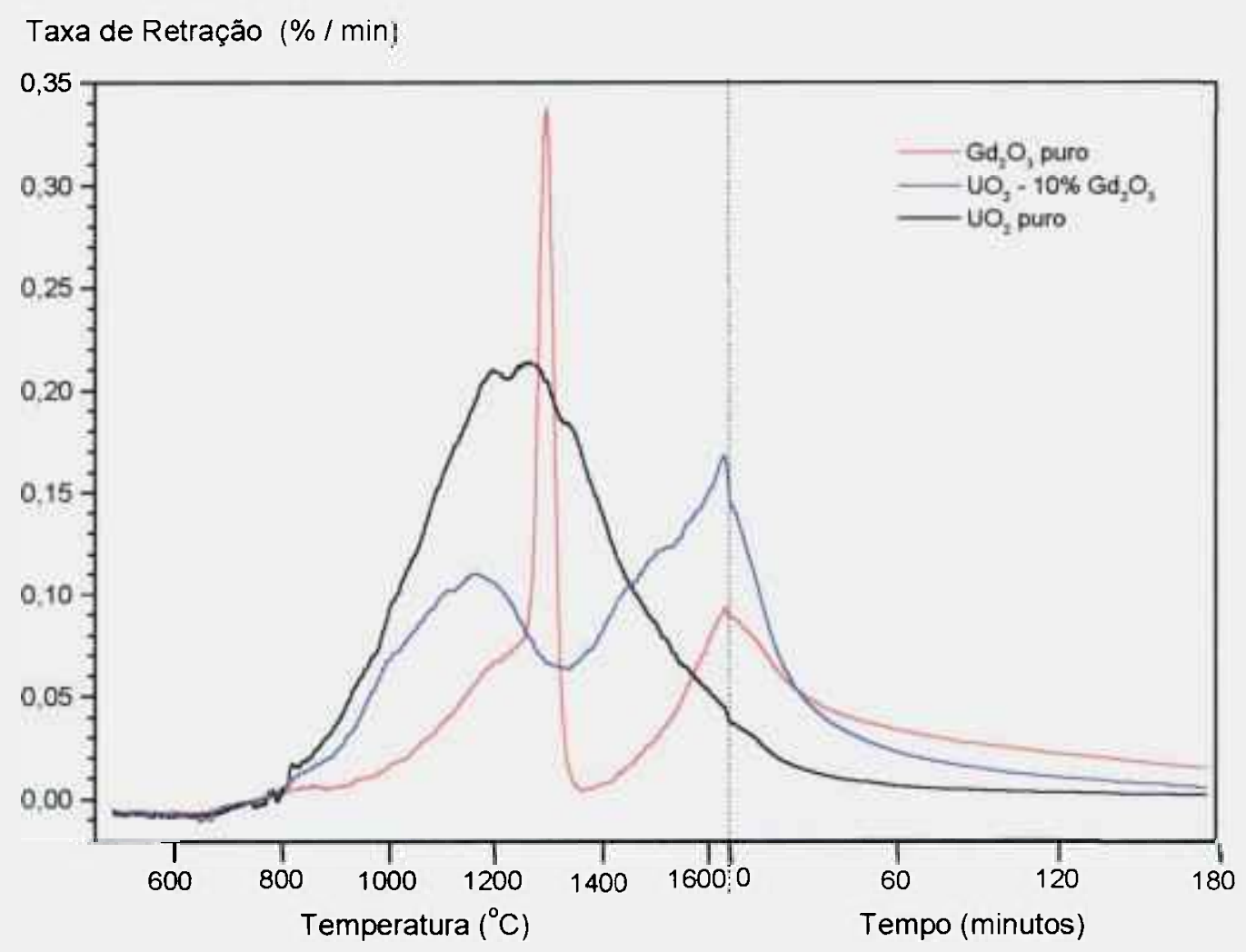

Figura 41 - Taxas de retração derivadas das curvas apresentadas na figura 40.

"Durante a sinterização do combustível $\mathrm{UO}_{2}-\mathrm{Gd}_{2} \mathrm{O}_{3}$ preparado pelo método de mistura de pós ocorre simultaneamente a transformação de fase dos aglomerados de $\mathrm{Gd}_{2} \mathrm{O}_{3}$, passando da forma cúbica, similar à estrutura tipo fluorita do $\mathrm{UO}_{2}$, para a forma monoclínica, muito mais compacta. Ocorrendo essa transformação de fase nos aglomerados de $\mathrm{Gd}_{2} \mathrm{O}_{3}$, presentes no caso de mistura mecânica (nivel macroscópico de homogeneidade), a formação da solução sólida é retardada e o processo de sinterização é influenciado negativamente, ocorrendo a diminuição da sinterabilidade do sistema".

Uma vez que muito pouca informação sobre a transformação de fase do $\mathrm{Gd}_{2} \mathrm{O}_{3}$ está disponivel na literatura, com o objetivo de fundamentar esta hipótese, um estudo foi realizado procurando-se comprovar a ocorrência da transformação de fase do $\mathrm{Gd}_{2} \mathrm{O}_{3}$ e determinar as temperaturas envolvidas no fenômeno. Os resultados estão apresentados no próximo item. 


\subsection{Desenvolvimento da hipótese}

\subsubsection{Caracterização da transformação de fase do $\mathrm{Gd}_{2} \mathrm{O}_{3}$}

A caracterização da transformação de fase foi realizada com base no teste de dilatometria e análises por difração de raios-X. A figura 42 ilustra com mais detalhes a contração repentina observada na curva de sinterização do $\mathrm{Gd}_{2} \mathrm{O}_{3}$, apresentada na figura 40. Nesta figura pode-se melhor observar as temperaturas envolvidas no fenômeno. Essa anomalia na curva de sinterização foi atribuída à transformação de fase do $\mathrm{Gd}_{2} \mathrm{O}_{3}$ por meio de tratamentos térmicos sucessivos em amostras de pó de $\mathrm{Gd}_{2} \mathrm{O}_{3}$, nas temperaturas indicadas na figura, e análise do produto obtido por meio de difração de raios-X.

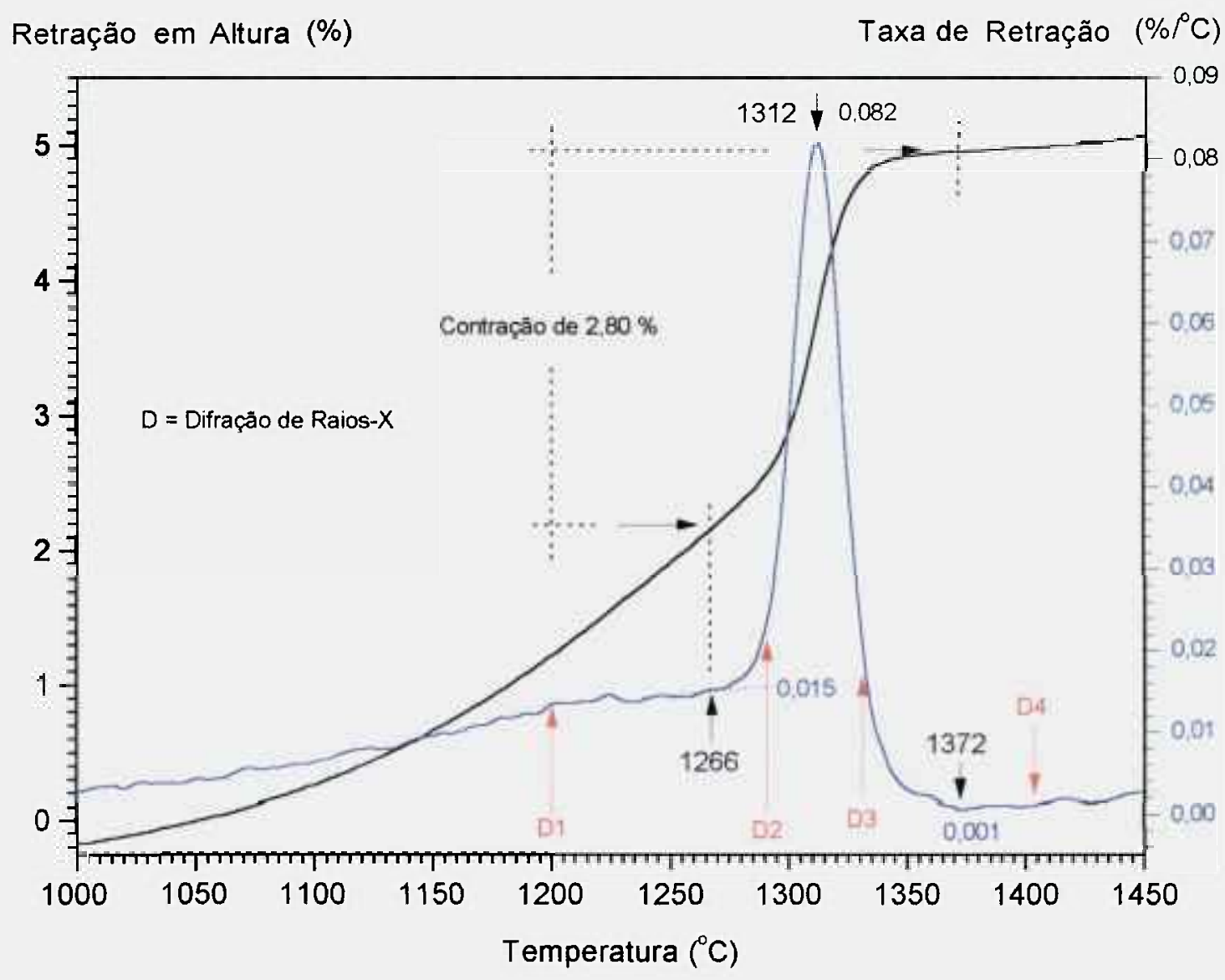

Figura 42 - Caracterização da transformação de fase do $\mathrm{Gd}_{2} \mathrm{O}_{3}$ (forma $\mathrm{C} \rightarrow$ forma $\mathrm{B}$ ).

Observa-se uma acentuada retração que se inicia a $1266^{\circ} \mathrm{C}$ e termina a $1372{ }^{\circ} \mathrm{C}$, envolvendo uma retração em altura de $2,8 \%$. A taxa de sinterização diminui mais de 10 
vezes após a ocorrência desta repentina diminuição de volume. Análises por difração de raios- $x$ demonstraram que a causa da repentina diminuição de volume é a transformação de fase do $\mathrm{Gd}_{2} \mathrm{O}_{3}$ cúbico (forma $\mathrm{C}$ ) para o $\mathrm{Gd}_{2} \mathrm{O}_{3}$ monoclínico (forma $\mathrm{B}$ ). A figura 43 apresenta os difratogramas obtidos a partir de amostras preparadas em diferentes temperaturas, indicadas na figura 42 . Fica, então, comprovada a ocorrência da transformação de fase na faixa de temperatura de 1266 a $1372{ }^{\circ} \mathrm{C}$.

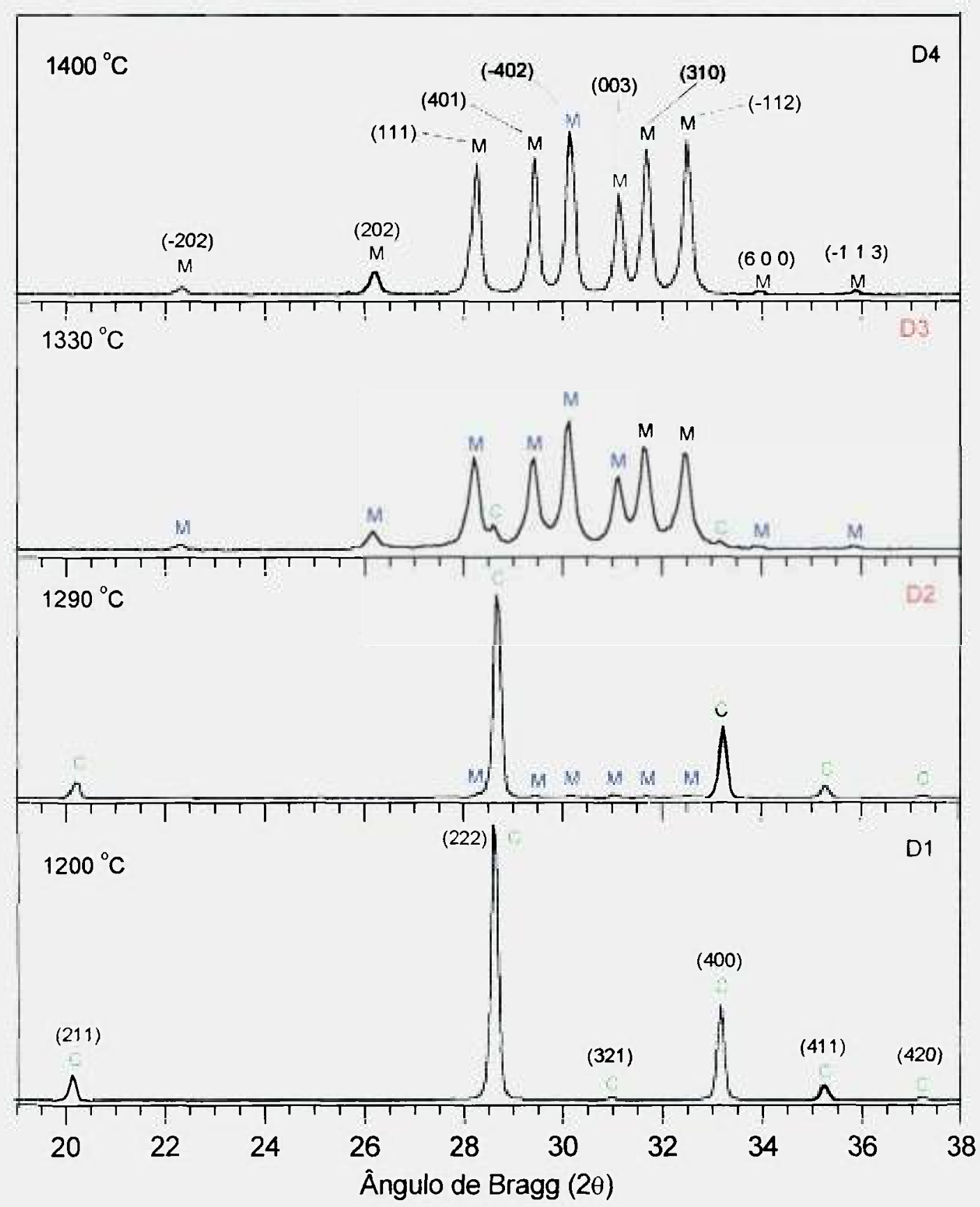

Figura 43 - Transformação de fase do $\mathrm{Gd}_{2} \mathrm{O}_{3}$ (amostras segundo indicação da figura 42). 


\subsubsection{Fundamentação da hipótese}

A transformação de fase do $\mathrm{Gd}_{2} \mathrm{O}_{3}$ sob as condições de sinterização adotadas neste trabalho, ocorre numa faixa de temperatura na qual ocorre simultaneamente o estágio principal da sinterização do sistema $\mathrm{UO}_{2}-\mathrm{Gd}_{2} \mathrm{O}_{3}$, no qual os fenômenos de difusão podem estar sendo influenciados pela mudança da estrutura cristalina do $\mathrm{Gd}_{2} \mathrm{O}_{3}$ decorrente da transformação de fase. É possível que a mudança da estrutura cristalina interfira no fenômeno de interdifusão que acompanha a formação da solução sólida, uma vez que a estrutura monoclínica da forma $\mathrm{B}$ do $\mathrm{Gd}_{2} \mathrm{O}_{3}$ é mais compacta do que a estrutura cúbica da sua forma $\mathrm{C}$, a qual é muito semelhante à estrutura cristalina do tipo fluorita do $\mathrm{UO}_{2}$.

Outro aspecto interessante é a contração que acompanha a transformação de fase, evidenciada na figura 42. Esse fenômeno deve conduzir à formação de um vazio na interface entre os aglomerados de $\mathrm{Gd}_{2} \mathrm{O}_{3}$ e a matriz de $\mathrm{UO}_{2}$ durante a sinterização. Como discutido anteriormente no item 1.5, para explicar o comportamento da sinterização do sistema $\mathrm{UO}_{2}-\mathrm{Gd}_{2} \mathrm{O}_{3}$, Yuda e Une ${ }^{(116)}$ propõem a formação de poros de grande dimensão durante a sinterização, devido a diferenças entre as taxas de sinterização de partículas adjacentes $\mathrm{UO}_{2}-\mathrm{UO}_{2}$ e UO $\mathrm{UO}_{2}-\mathrm{Gd}_{2} \mathrm{O}_{3}$. A formação desses poros, os quais são estáveis por terem sido formados em alta temperatura, poderia ser atribuída à transformação de fase do $\mathrm{Gd}_{2} \mathrm{O}_{3}$ durante a sinterização, resultado da contração dos aglomerados de $\mathrm{Gd}_{2} \mathrm{O}_{3}$.

\subsection{Teste da hipótese}

Para verificação e validação experimental da hipótese da transformação de fase do $\mathrm{Gd}_{2} \mathrm{O}_{3}$, do sistema $\mathrm{CCC}$ para o sistema monoclínico, ser a responsável pelo comportamento da sinterização do sistema $\mathrm{UO}_{2}-\mathrm{Gd}_{2} \mathrm{O}_{3}$, foram preparadas, pela técnica de mistura mecânica de pós, duas amostras contendo $10 \%$ em peso de $\mathrm{Gd}_{2} \mathrm{O}_{3}$ nas suas diferentes formas. $\mathrm{O}$ pó de $\mathrm{Gd}_{2} \mathrm{O}_{3}$ utilizado na amostra contendo a forma monoclínica foi obtido por meio do tratamento térmico do pó de $\mathrm{Gd}_{2} \mathrm{O}_{3}$ como recebido (forma $\mathrm{C}$ ) por 1 hora a $1400{ }^{\circ} \mathrm{C}$, obtendo-se a forma monoclínica, como evidencia a figura 43 . Neste teste o pó de $\mathrm{UO}_{2}$ utilizado foi proveniente de um outro lote, também obtido a partir do TCAU, uma vez que o material disponível para o desenvolvimento dos procedimentos experimentais deste trabalho havia sido esgotado, aplicado no desenvolvimento das outras duas hipóteses. Contudo, a única característica relevante deste novo lote que se mostrou diferente foi a área de superficie específica, ligeiramente menor, de $4,5 \mathrm{~m}^{2} / \mathrm{g}$. Ambas as amostras, contendo $\mathrm{Gd}_{2} \mathrm{O}_{3}$ nas suas diferentes formas, foram sinterizadas num dilatômetro sob as mesmas condições experimentais, ou seja, taxa de aquecimento de $5^{\circ} \mathrm{C} / \mathrm{min}, 3$ horas 
a $1650{ }^{\circ} \mathrm{C}$ e atmosfera de $\mathrm{H}_{2}$ puro. As curvas de sinterização obtidas podem ser observadas na figura 44 .

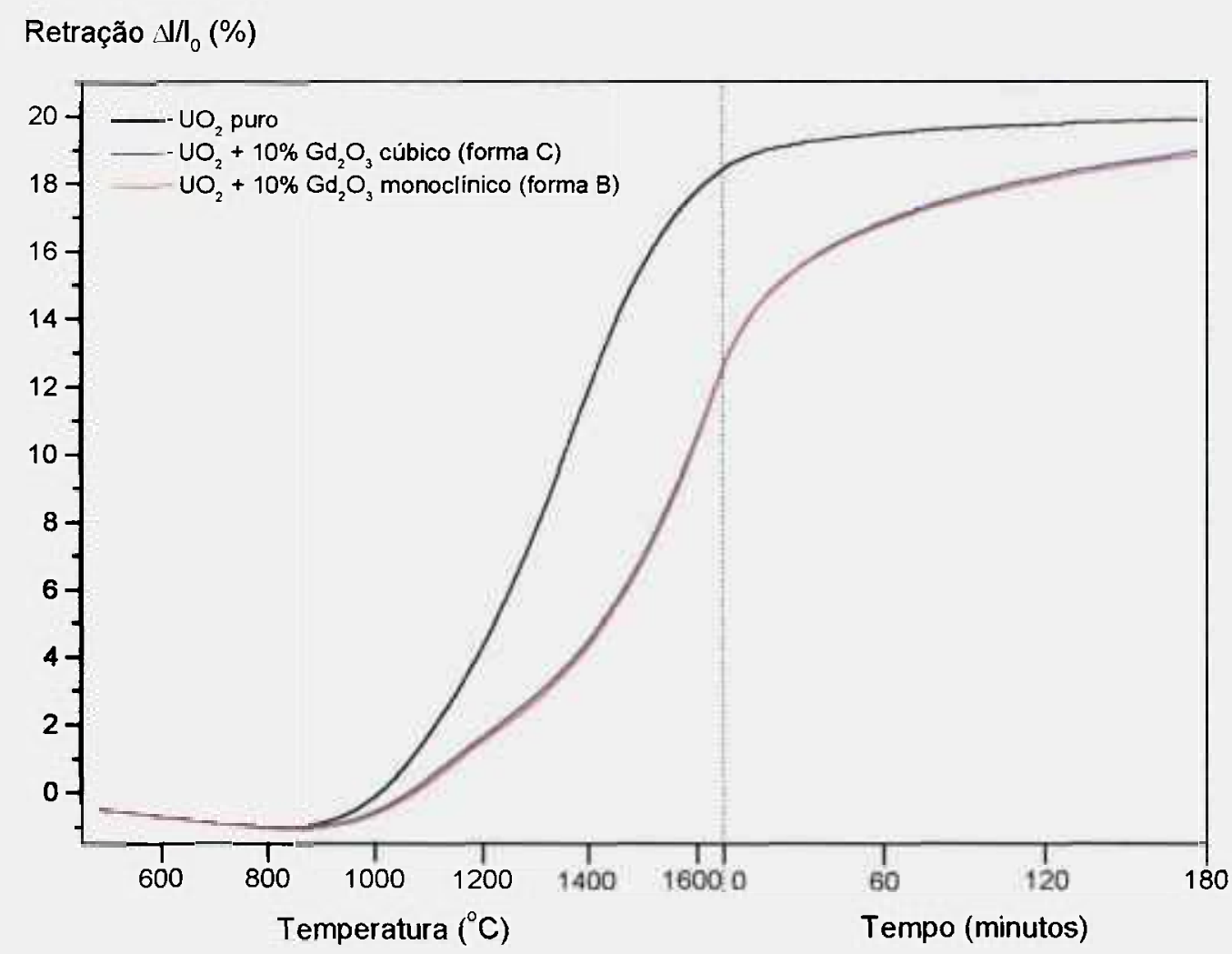

Figura 44 - Sinterização de pastilhas $\mathrm{UO}_{2}-\mathrm{Gd}_{2} \mathrm{O}_{3}$ com $\mathrm{Gd}_{2} \mathrm{O}_{3}$ nas formas $\mathrm{C}$ (cúbica) e B (monoclínica). $\left(5^{\circ} \mathrm{C} / \mathrm{min}, \mathrm{H}_{2}\right)$

As curvas de sinterização obtidas mostraram o mesmo comportamento, independente da estrutura cristalina do $\mathrm{Gd}_{2} \mathrm{O}_{3}$ adicionado. O bloqueio da sinterização no sistema continuou evidente. As curvas da taxa de retração derivadas dessas curvas de sinterização, apresentadas na figura 45 , mostram com maior clareza que o mecanismo de bloqueio da sinterização não foi alterado pela forma na qual encontrava-se o $\mathrm{Gd}_{2} \mathrm{O}_{3}$ adicionado ao pó de $\mathrm{UO}_{2}$, seja cúbica ou monoclínica.

Considerando-se um aglomerado de $\mathrm{Gd}_{2} \mathrm{O}_{3}$ aproximadamente esférico com diâmetro de $50 \mu \mathrm{m}$, como ilustra a figura 9 , com base na contração aproximada de $2,8 \%$ determinada no ensaio dilatométrico e assumindo que a contração é isotrópica, a largura do vazio formado pela contração do aglomerado de $\mathrm{Gd}_{2} \mathrm{O}_{3}$ durante a sinterização pode ser estimado como sendo menor do que $1 \mu \mathrm{m}$. Este valor não parece ser significativo, uma vez que a distribuição típica de tamanho de poros em pastilhas sinterizadas de $\mathrm{UO}_{2}$ 
provenientes do TCAU varia entre $0,5 \mu \mathrm{m}$ e pouco mais de $10 \mu \mathrm{m}{ }^{(\mathbf{8 5}, 152)}$. Como a formação deste vazio estaria ocorrendo numa estrutura de poros ainda não totalmente fechada, durante a sinterização subseqüente à sua formação ele poderia ser facilmente eliminado, não alterando significativamente o processo de densificação.

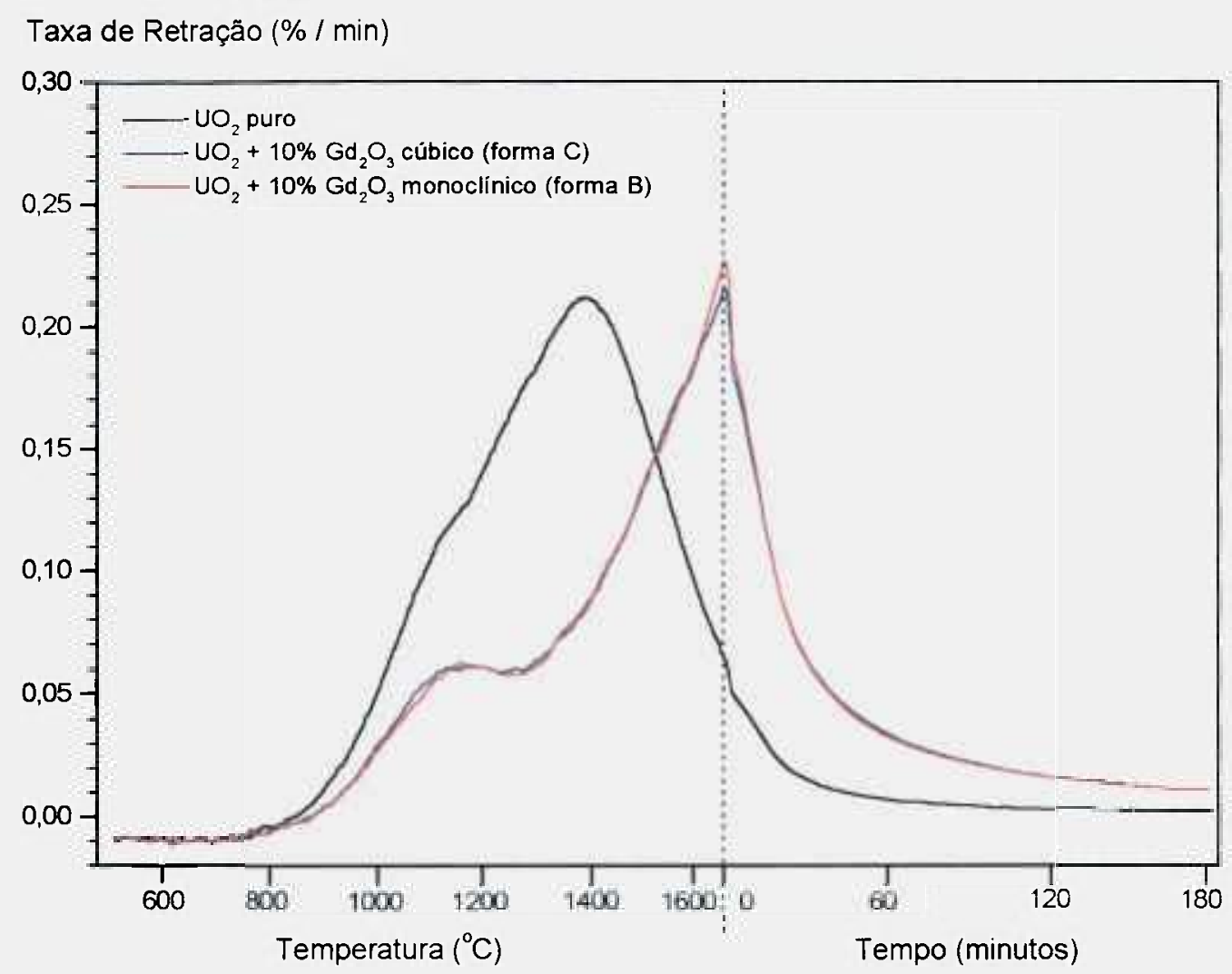

Figura 45 - Taxas de densificação derivadas das curvas apresentadas na figura 44.

Outra possibilidade é a estabilização da estrutura cúbica do $\mathrm{Gd}_{2} \mathrm{O}_{3}$ durante a sinterização em temperaturas inferiores à temperatura de início da transformação. Como pode ser observado na cinética de sinterização de pastilhas $\mathrm{UO}_{2}-\mathrm{Gd}_{2} \mathrm{O}_{3}$ (ver figuras $6,7,15$ e 45), o bloqueio da sinterização ocorre na faixa de temperatura entre 1100 e $1200{ }^{\circ} \mathrm{C}$. Assumindo-se que o bloqueio coincide com o inicio da formação da solução sólida, com o que concordam vários pesquisadores ${ }^{(46,67,68,116)}$, este estaria ocorrendo em temperaturas inferiores à da transformação de fase do $\mathrm{Gd}_{2} \mathrm{O}_{3}$, determinada neste trabalho como $1266^{\circ} \mathrm{C}$ sob condições idênticas às adotadas na sinterização das amostras $\mathrm{UO}_{2}-\mathrm{Gd}_{2} \mathrm{O}_{3}$. O estudo relativo à formação de fases no sistema, apresentado no item 2.2.1, revelou que a presença de apenas $10 \%$ em mol de urânio estabiliza a fase cúbica do $\mathrm{Gd}_{2} \mathrm{O}_{3}$, como ilustra a figura 29. Portanto, como o início da formação da solução sólida ocorre antes da transformação de fase do $\mathrm{Gd}_{2} \mathrm{O}_{3}$, parece ser grande a possibilidade de que o $\mathrm{Gd}_{2} \mathrm{O}_{3}$ contenha em solução 
sólida essa concentração de urânio antes que a temperatura de transformação de fase seja atingida. Dessa forma, a transformação de fase pode nem mesmo estar ocorrendo, permanecendo $o \mathrm{Gd}_{2} \mathrm{O}_{3}$ na sua forma cúbica.

De qualquer forma, os resultados experimentais obtidos demonstram inequivocamente que a sinterização de pastilhas $\mathrm{UO}_{2}-\mathrm{Gd}_{2} \mathrm{O}_{3}$ preparadas segundo o método de mistura mecânica de pós independe da forma em que o pó de $\mathrm{Gd}_{2} \mathrm{O}_{3}$ se encontra, seja cúbica (forma $\mathrm{C}$ ) ou monoclínica (forma $\mathrm{B}$ ). $\mathrm{O}$ fato de não ter ocorrido nenhuma variação no comportamento da sinterização comprova que a hipotese proposta não é a responsável pelo bloqueio da sinterização no sistema $\mathrm{UO}_{2}-\mathrm{Gd}_{2} \mathrm{O}_{3}$. Como conclusão, a hipótese da Transformação de Fase do $\mathrm{Gd}_{2} \mathrm{O}_{3}$ deve ser rejeitada. 


\section{A HIPÓTESE DA FORMAÇÃo DE POROS ESTÁVEIS}

Durante a sinterização do combustível $\mathrm{UO}_{2}-\mathrm{Gd}_{2} \mathrm{O}_{3}$, preparado adotando-se a rota de mistura mecânica dos pós, ocorre simultaneamente a difusão entre os componentes da mistura. Se a velocidade de difusão dos dois tipos de átomos não é a mesma, ocorre o efeito Kirkendall. Em outras palavras, se o gadolínio difunde-se mais rapidamente na matriz de $\mathrm{UO}_{2}$ do que o contrário, estabelece-se um maior fluxo de gadolínio do aglomerado de $\mathrm{Gd}_{2} \mathrm{O}_{3}$ para a matriz de $\mathrm{UO}_{2}$ do que de urânio para o interior do aglomerado de $\mathrm{Gd}_{2} \mathrm{O}_{3}$. Nesse caso a matriz de $\mathrm{UO}_{2}$ expande por receber os átomos extras de gadolínio e um vazio é gerado no local do aglomerado de $\mathrm{Gd}_{2} \mathrm{O}_{3}$ inicial. Esse fenômeno é comumente observado em sistemas de pós mistos onde existe uma difusidade ou solubilidade desbalanceada entre os pós ${ }^{(110)}$. Como a formação dos vazios devido a este efeito ocorre numa temperatura na qual a estrutura de poros pode estar já essencialmente fechada, durante o segundo estágio da sinterização, provavelmente a sua eliminação total é muito dificil. A possibilidade de ocorrência desse fenômeno no sistema $\mathrm{UO}_{2}-\mathrm{Gd}_{2} \mathrm{O}_{3}$ baseou a proposta da Hipótese de Formação de Poros Estáveis, da qual trata este capítulo. A seguir estão descritos os procedimentos utiliżados e estão apresentados e discutidos os resultados obtidos.

\subsection{Proposição da hipótese}

Os resultados obtidos nos estudos de interdifusão realizados neste trabalho, apresentados no item 2.2.2, revelaram, por meio da curva de penetração apresentada na figura 33 , que a penetração do gadolínio no $\mathrm{UO}_{2}$ é consideravelmente maior do que a penetração do urânio no $\mathrm{Gd}_{2} \mathrm{O}_{3}$. A figura 34 também demonstra que ocorre maior transporte de material na direção do $\mathrm{UO}_{2}$ do que o contrário, o que é evidenciado pelo fato do Plano de Matano estar posicionado mais próximo do lado do $\mathrm{Gd}_{2} \mathrm{O}_{3}$ puro no par de interdifusão. A observação de um sensivelmente menor coeficiente de interdifusão para frações molares de gadolínio maiores do que 0,5 demonstra que a movimentação catiônica é desfavorecida em regiões onde é alta a concentração de $\mathrm{Gd}_{2} \mathrm{O}_{3}$ e, pelo contrário, é favorecida no lado pobre em gadolínio, também favorecendo o transporte preferencial do gadolínio no $\mathrm{UO}_{2}$.

Apesar de não ter sido possível neste trabalho a determinação dos coeficientes individuais de difusão, como comentado anteriormente no item 2.2.2, e não terem sido encontrados na literatura dados relativos aos coeficientes de difusão do gadolínio no $\mathrm{UO}_{2} \mathrm{e}$ do urânio no $\mathrm{Gd}_{2} \mathrm{O}_{3}$, é conhecido que o urânio difunde-se pouco na forma cúbica do $\mathrm{Gd}_{2} \mathrm{O}_{3}$ e a difusão do urânio na forma $\mathrm{B}$ do $\mathrm{Gd}_{2} \mathrm{O}_{3}$ (monoćlínica) é praticamente nula. No sistema 
$\mathrm{UO}_{2}-\mathrm{Y}_{2} \mathrm{O}_{3}$ a máxima solubilidade do urânio na forma cúbica do $\mathrm{Y}_{2} \mathrm{O}_{3}$ (forma $\mathrm{C}$ ) é 7-8 \% em mol ${ }^{(142)}$. A máxima solubilidade do urânio na forma $\mathrm{B}$ do $\mathrm{Gd}_{2} \mathrm{O}_{3}$ (monoclínica) é de 2 $\%$ em mol ${ }^{(57,153)}$. Tudo indica, portanto, uma baixa solubilidade do urânio no $\mathrm{Gd}_{2} \mathrm{O}_{3}$, seja na sua forma cúbica ou monoclínica. Por outro lado, o gadolínio difunde-se facilmente na estrutura fluorita do $\mathrm{UO}_{2}$, tendo em vista a ampla faixa de concentrações na qual pode-se obter a solução sólida, como ilustra a figura 30 .

Portanto, os resultados experimentais obtidos neste trabalho e as informações obtidas na literatura indicam que existe uma considerável diferença entre os coeficientes de difusão do gadolínio no $\mathrm{UO}_{2}$ e do urânio no $\mathrm{Gd}_{2} \mathrm{O}_{3}$ (seja nas formas $\mathrm{C}$ ou $\mathrm{B}$ ), o que pode conduzir a um desbalanceamento no transporte de material por ocasião da formação da solução sólida durante a sinterização do combustível $\mathrm{UO}_{2}-\mathrm{Gd}_{2} \mathrm{O}_{3}$ preparado pela técnica de mistura mecânica de pós, onde aglomerados de $\mathrm{Gd}_{2} \mathrm{O}_{3}$ estão dispersos numa matriz de $\mathrm{UO}_{2}$ antes da sinterização. Nesta situação é provável a ocorrência do efeito Kirkendall.

A estrutura de poros desenvolvida em pastilhas sinterizadas $\mathrm{UO}_{2}-\mathrm{Gd}_{2} \mathrm{O}_{3}$ preparadas pela técnica de mistura de pós, apóia esta hipótese. Neste trabalho, em pastilhas sinterizadas de $\mathrm{UO}_{2}-\mathrm{Gd}_{2} \mathrm{O}_{3}$, preparadas por mistura mecânica de pós, observa-se a existência de poros com diâmetros sensivelmente maiores do que os tipicamente observados em pastilhas de $\mathrm{UO}_{2}$ puro, deslocando a curva de distribuição de diâmetro de poros na direção de maiores diâmetros. Este efeito está ilustrado na figura 46. As distribuições dos diâmetros de poros foram obtidas por meio de análise de imagens, aplicando-se o método Saltikov ${ }^{(154)}$, o qual permite o cálculo do diâmetro em três dimensões a partir de informações bidimensionais obtidas em superficies polidas. Observa-se que a distribuição determinada na pastilha combustível de $\mathrm{UO}_{2}$ puro concorda bem com a distribuição de diâmetros de poros típica do combustível $\mathrm{UO}_{2}$ obtido a partir do TCAU, variando entre $0,5 \mu \mathrm{m}$ e pouco mais de $10 \mu \mathrm{m}$ e com média entre 3 e $4 \mu \mathrm{m}{ }^{(85,152)}$. No caso da amostra contendo $10 \%$ em peso de $\mathrm{Gd}_{2} \mathrm{O}_{3}$, observa-se poros com até $25 \mu \mathrm{m}$ de diâmetro, sendo a média deslocada para aproximadamente $8 \mu \mathrm{m}$. Este resultado também suporta a proposição da hipótese, uma vez que os aglomerados de $\mathrm{Gd}_{2} \mathrm{O}_{3}$ existentes no sistema (ver figura 9B) podem conduzir à formação de poros devido à ocorrência do efeito Kirkendall durante a formação da solução sólida, os quais não podem ser eliminados, pelo menos não totalmente, durante os estágios de sinterização posteriores à sua formação.

Com base no exposto acima, o que por si só já fundamenta a hipótese, é possível a proposição da hipótese da formação de poros estáveis durante a sinterização (efeito Kirkendall) como sendo a responsável pelo comportamento da sinterização do combustível $\mathrm{UO}_{2}-\mathrm{Gd}_{2} \mathrm{O}_{3}$ preparado segundo o método de mistura mecânica dos pós de $\mathrm{UO}_{2}$ e $\mathrm{Gd}_{2} \mathrm{O}_{3}$ (existência de aglomerados de $\mathrm{Gd}_{2} \mathrm{O}_{3}$ ), como segue: 
"Durante a sinterização do combustivel $\mathrm{UO}_{2}-\mathrm{Gd}_{2} \mathrm{O}_{3}$ preparado pelo método de mistura mecânica de pós ocorrem simultaneamente a formação da solução sólida $(U, G d) \mathrm{O}_{2}$ e a sinterização. Durante a formação da solução sólida, pela solubilização preferencial do gadolinio na rede cristalina tipo fluorita do $\mathrm{UO}_{2}$, ocorre o desenvolvimento de vazios devido ao efeito kirkendall. Estes vazios, uma vez formados em alta temperatura, são de dificil eliminação nas etapas de sinterização posteriores à sua formação, permanecendo no corpo sinterizado na forma de poros estáveis, o que ocasiona a diminuição da densidade final obtida".

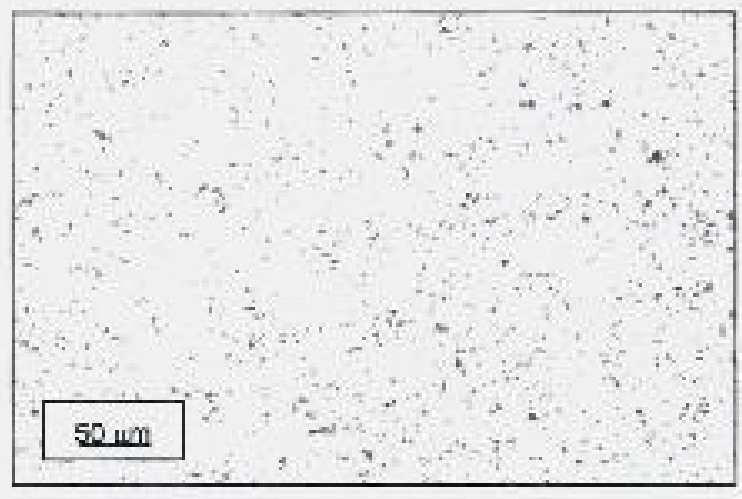

(A)

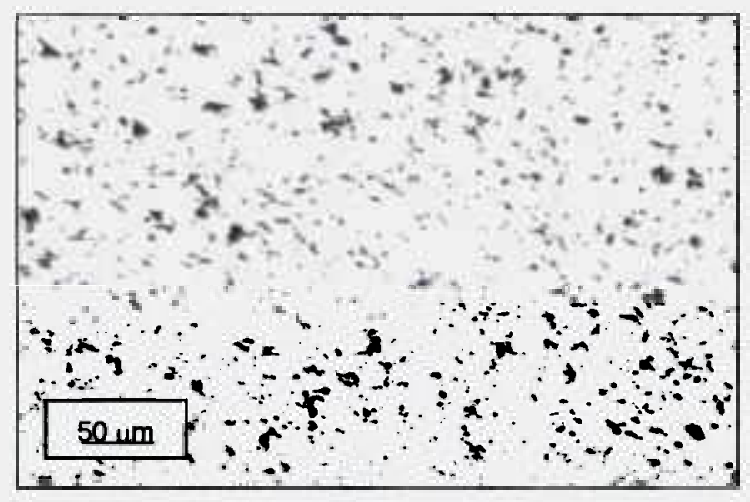

(B)

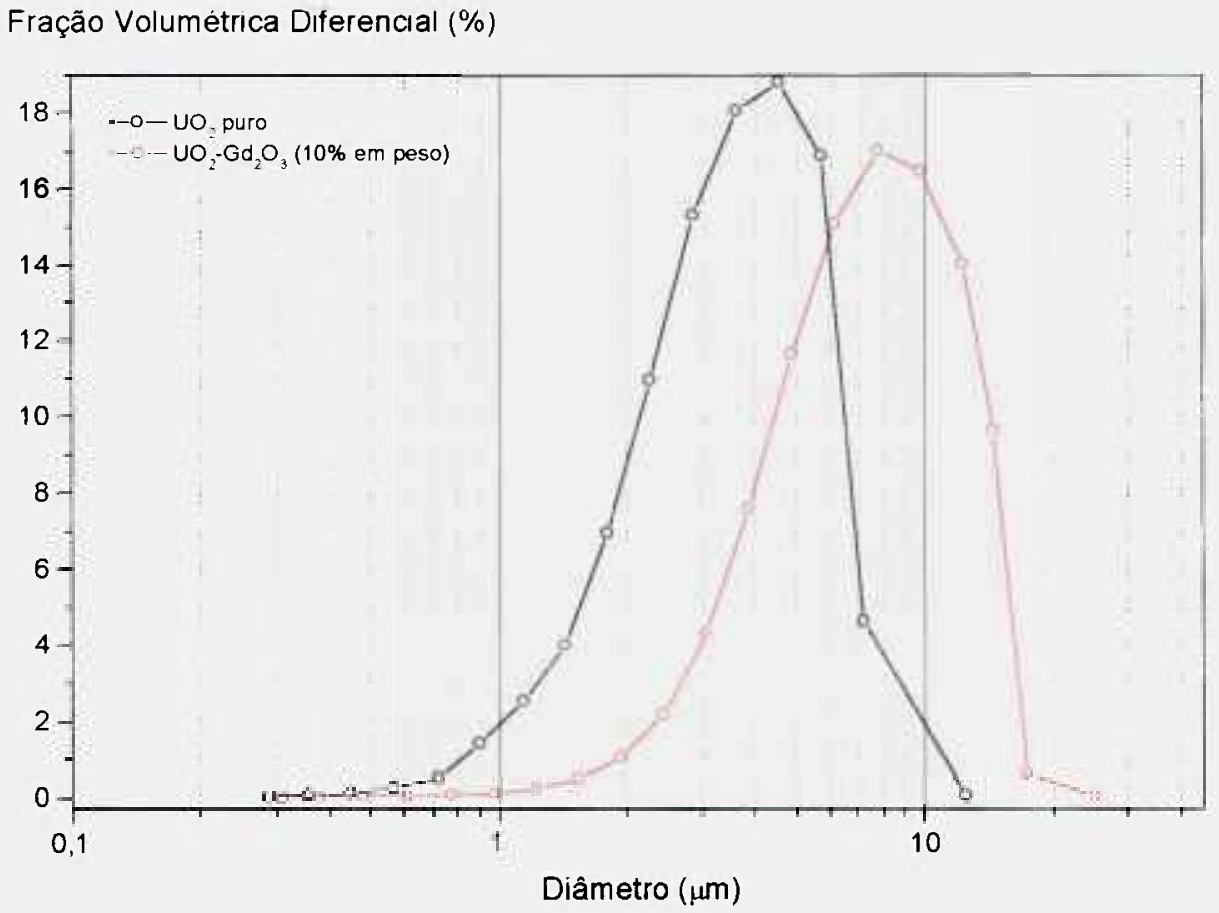

Figura 46 - Micrografias ópticas e curvas de distribuição de tamanho de poros.
(A) $-\mathrm{UO}_{2}$ puro
(B) $-\mathrm{UO}_{2}-\mathrm{Gd}_{2} \mathrm{O}_{3}(10 \%$ em peso $)$ 


\subsection{Fundamentação da hipótese}

As observações e evidências experimentais apresentadas no item anterior permitem não só a proposição da hipótese como também a fundamenta. Contudo, buscouse uma evidência experimental que pudesse relacionar diretamente a formação da solução sólida, ou seja, a ocorrência do efeito Kirkendall, com o bloqueio da sinterização no sistema $\mathrm{UO}_{2}-\mathrm{Gd}_{2} \mathrm{O}_{3}$, evidenciado nas curvas de sinterização. Se o efeito Kirkendall realmente está ocorrendo, durante a solubilização dos aglomerados de $\mathrm{Gd}_{2} \mathrm{O}_{3}$ na matriz de $\mathrm{UO}_{2}$ deve ocorrer um inchamento da matriz ao mesmo tempo em que os poros são formados, como é característico do efeito Kirkendall. Portanto, segundo a hipótese proposta, durante a sinterização do sistema $\mathrm{UO}_{2}-\mathrm{Gd}_{2} \mathrm{O}_{3}$ devem ocorrer dois fenômenos simultâneos. Um deles é a retração da pastilha como resultado da sinterização. O outro é o inchamento que acompanha a formação da solução sólida, a qual gera vazios nos locais onde originalmente estavam aglomerados de $\mathrm{Gd}_{2} \mathrm{O}_{3}$, resultado do efeito Kirkendall. Sendo assim, o bloqueio da sinterização não deve ser compreendido como um bloqueio, e sim como uma competição entre dois fenômenos independentes e opostos (retração e dilatação) que ocorrem simultaneamente durante o processo de sinterização.

Essa evidência experimental pôde ser obtida por meio da separação dos dois fenômenos opostos, a retração devido à sinterização e a dilatação devido à formação de poros decorrente do efeito Kirkendall. Isso pôde ser realizado por meio de um teste dilatométrico onde se utilizou uma atmosfera de argônio, em substituição à atmosfera redutora de $\mathrm{H}_{2}$. Como a razão $\mathrm{O} / \mathrm{U}$ do pó de $\mathrm{UO}_{2}$ utilizado na preparação das pastilhas $\mathrm{UO}_{2}-\mathrm{Gd}_{2} \mathrm{O}_{3}$ pela rota de mistura mecânica de pós é de 2,15 (ver tabela 3 ), a quantidade de cátions $U^{5+}$ presentes é considerável. Se a atmosfera de sinterização é fortemente redutora, esses cátions são reduzidos a $U^{4+*}$ em temperaturas bastante baixas, da ordem de $400{ }^{\circ} \mathrm{C}$, antes do início do processo de sinterização. Por outro lado, se a atmosfera é inerte os cátions $\mathrm{U}^{5+}$ originalmente presentes no pó de $\mathrm{UO}_{2,15}$ permanecem neste estado de oxidação durante a sinterização. Como a difusividade dos cátions $\mathrm{U}^{5+}$ é muito maior do que a dos cátions $\mathrm{U}^{4+}$, devido ao menor raio iônico, o processo de sinterização é beneficiado, iniciando em temperaturas mais baixas e terminando, também, em temperaturas mais baixas. Dessa forma, toda a curva de sinterização é deslocada na direção de menores temperaturas. Seguindo essa linha de raciocínio, foi possível obter-se um resultado onde a separação da retração devido à sinterização e a dilatação devido ao efeito Kirkendall ficou evidenciada. O resultado pode ser observado na curva apresentada na figura 47. Nessa figura também está apresentada a curva de sinterização de uma pastilha $\mathrm{UO}_{2}-\mathrm{Gd}_{2} \mathrm{O}_{3}$ sinterizada sob atmosfera redutora de $\mathrm{H}_{2}$. A figura 48 apresenta as taxas de retração derivadas das curvas apresentadas na figura 47. 


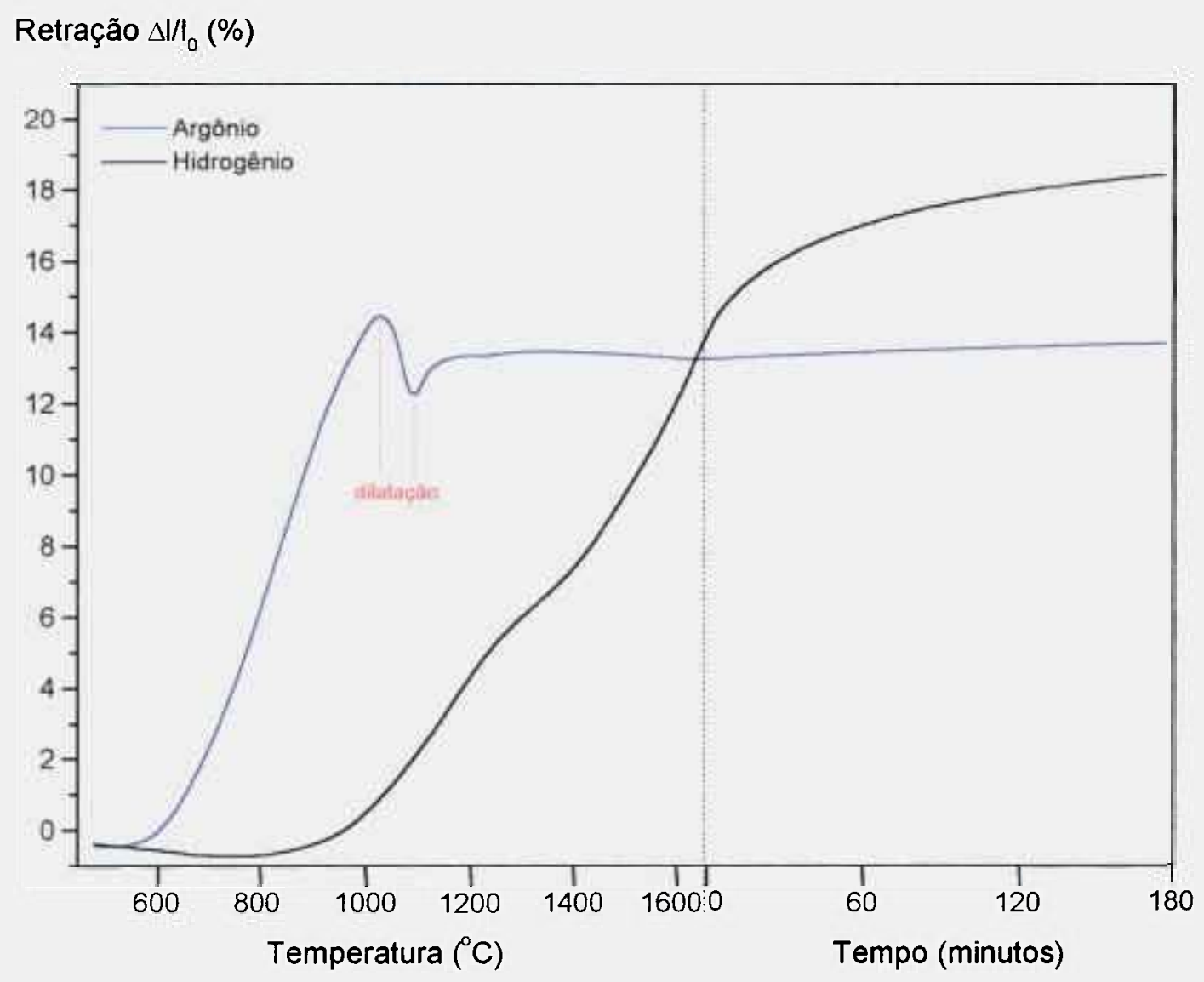

Figura 47 - Curvas de sinterização de pastilhas $\mathrm{UO}_{2}-\mathrm{Gd}_{2} \mathrm{O}_{3}$ sob argônio e hidrogênio. (10\% em peso de $\mathrm{Gd}_{2} \mathrm{O}_{3}, 5^{\circ} \mathrm{C} / \mathrm{min}$ )

Observa-se na figura 47 que pouco acima de $1000{ }^{\circ} \mathrm{C}$ inicia-se um processo de dilatação na pastilha sinterizada sob atmosfera de argônio. Nessa atmosfera, como se podia antecipar, a sinterização é iniciada numa temperatura significativamente inferior àquela correspondente à atmosfera redutora de $\mathrm{H}_{2}$. Isso ocorre devido à presença de cátions $\mathrm{U}^{5+}$ no sistema. Pelo mesmo motivo, todo o processo de sinterização é deslocado na direção de menores temperaturas. Assim, quando é iniciada a formação da solução sólida a componente de retração devida à sinterização é menor do que a componente de dilatação devida à formação de poros decorrente do efeito Kirkendall, resultando numa dilatação que pôde ser detectada. Nota-se que quando cessa a formação de vazios devido à formação da solução sólida, ou ao efeito Kirkendall, novamente é observada uma retração de aproximadamente $1 \%$. Isto pode significar que parte dos vazios formados devido ao efeito Kirkendall, pelo menos os de menor diâmetro, está sendo eliminada juntamente com a complementação da sinterização da matriz de $\mathrm{UO}_{2}$, que ainda não havia sido completada. Esse resultado demonstra que não ocorre um bloqueio na sinterização, e sim, uma 
concorrência entre retração e dilatação. No caso de atmosferas redutoras, a componente de dilatação é muito menor do que a componente de retração, que é muito significativa na temperatura na qual ocorre o efeito Kirkendall, de maneira que a resultante é de retração. Portanto, em atmosferas redutoras, o efeito Kirkendall não resulta em dilatação e sim numa diminuição da taxa de retração durante o período no qual ele ocorre, o que explica a forma das curvas de sinterização observadas neste trabalho e nos resultados obtidos por Manzel e Dörr ${ }^{(46)}$. Quando a formação da solução sólida é completada, a taxa de retração aumenta novamente. Esse mecanismo pode também ser percebido nos resultados obtidos por Yuda e Une (116) na sinterização de pastilhas de $\mathrm{UO}_{2}-\mathrm{Gd}_{2} \mathrm{O}_{3}$ sob atmosfera de $\mathrm{CO} / \mathrm{CO}_{2}$, apresentados na figura 7 . Nesse caso a concentração de cátions $U^{5+}$ é menor do que no caso de sinterização sob argônio, o que resulta numa situação intermediária, ou seja, não ficou evidenciada a dilatação mas a taxa de retração diminuiu até zero, ou seja, igualaramse as componetes de retração e dilatação, quando a retração voltou a ocorrer após a formação da solução sólida e a conseqüente formação de vazios devido ao efeito Kirkendall.

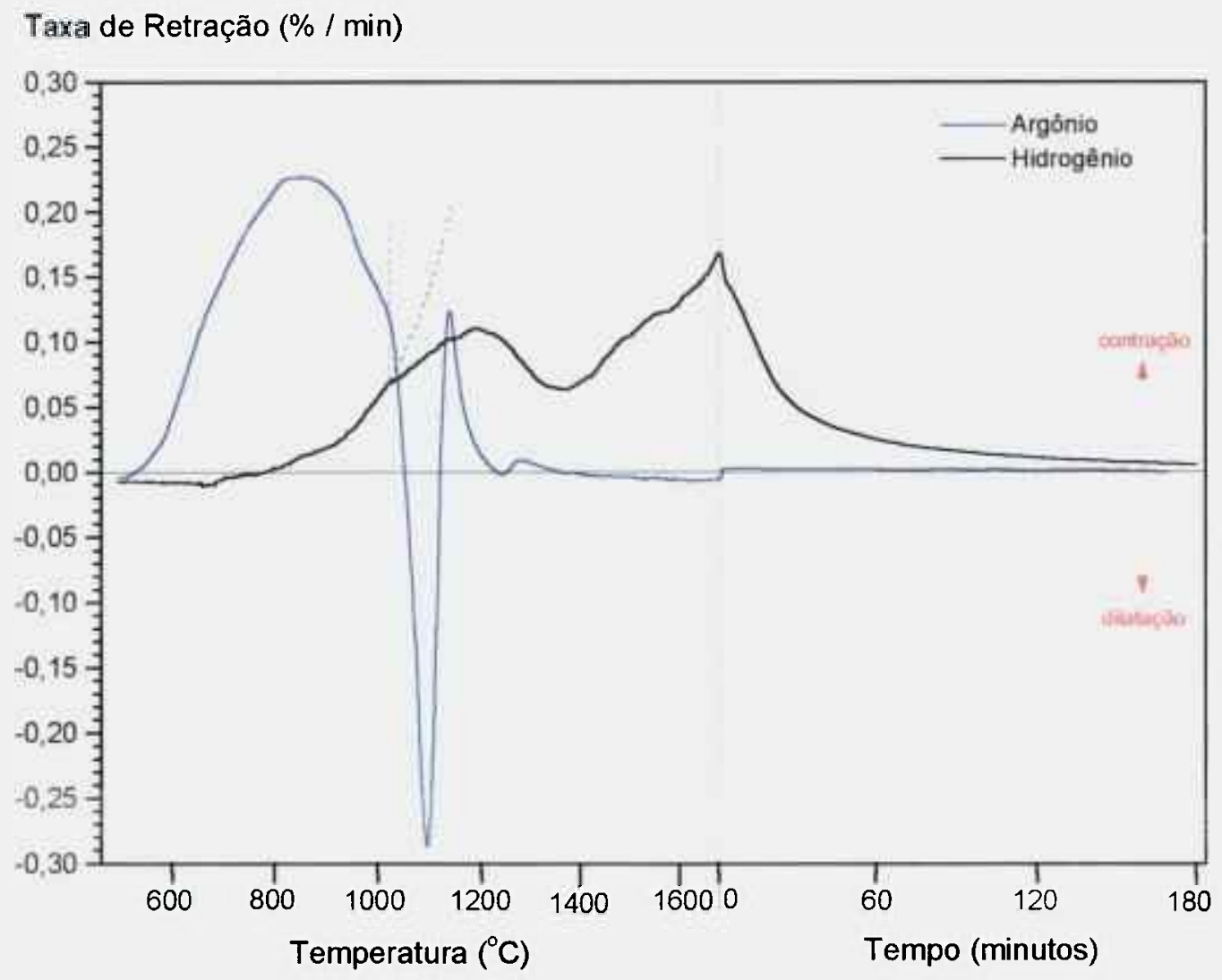

Figura 48 - Taxas de retração derivadas das curvas apresentadas na figura 47. 
Nota-se na figura 48 , que o início da queda repentina na taxa de retração da pastilha $\mathrm{UO}_{2}-\mathrm{Gd}_{2} \mathrm{O}_{3}$ sinterizada sob atmosfera de argônio, ou o início da dilatação devida à formação de poros, corresponde ao início da diminuição da taxa de retração observada na curva de sinterização da pastilha sinterizada sob atmosfera de $\mathrm{H}_{2}$. Contudo, o término da formação da solução sólida em atmosfera de argônio, e, portanto, de poros, não coincide com a retomada do aumento da taxa de retração na amostra sinterizada sob $\mathrm{H}_{2}$. Isso indica que a presença de cátions $\mathrm{U}^{5+}$, além de favorecer a sinterização, favorece também o processo de solubilização do gadolínio na rede cristalina do $\mathrm{UO}_{2}$, ou seja, da formação da solução sólida. Isso poderia também ser explicado com base na maior difusividade dos cátions $\mathrm{U}^{5+}$ quando comparada com a dos cátions $\mathrm{U}^{4+}$, o que poderia estar favorecendo a cinética de formação da solução sólida.

Os resultados apresentados acima evidenciam a formação de porosidade simultaneamente à sinterização do sistema $\mathrm{UO}_{2}-\mathrm{Gd}_{2} \mathrm{O}_{3}$. Estabelece-se, então, durante o processo de sinterização, uma concorrência entre formação e eliminação de poros no processo. Contudo, visando complementar a fundamentação e verificação da hipótese, considerou-se necessária a obtenção de evidências experimentais que demonstrassem que a formação de poros observada no sistema, ou dilatação, é resultante da formação da solução sólida, quando ocorre o efeito Kirkendall. Para isso foi realizado um experimento de termoanálise (DSC - "Differential Scaning Calorimetry") utilizando-se fragmentos de uma pastilha $\mathrm{UO}_{2}-\mathrm{Gd}_{2} \mathrm{O}_{3}$ compactada, preparada segundo a rota de mistura mecânica de pós. A composição também foi de $10 \%$ em peso de $\mathrm{Gd}_{2} \mathrm{O}_{3}$. O ensaio também foi conduzido sob atmosfera de argônio. Devido às baixas energias envolvidas na reação de formação da solução sólida, a taxa de aquecimento não pôde ser de $5{ }^{\circ} \mathrm{C} / \mathrm{min}$, a qual foi utilizada no teste dilatométrico e mantida como padrão neste trabalho. Optou-se, então, por uma taxa de aquecimento de $15{ }^{\circ} \mathrm{C} / \mathrm{min}$, o que resultou numa boa resposta. A curva termoanálitica obtida está apresentada na figura 49. Nesta figura também está apresentada a curva de sinterização, o que facilita a visualização da existência de uma correspondência direta entre a formação de vazios, ou dilatação, e a formação da solução sólida.

O resultado apresentado na figura 49 comprova que a formação da solução sólida, evidenciada pelos picos endotérmicos da curva termoanalítica, ocorre na mesma faixa de temperatura na qual observa-se a formação de vazios decorrente do efeito Kirkendall. O pequeno deslocamento entre o início do pico endotérmico da curva termoanalítica e o início da formação de poros, ou da dilatação, na curva de sinterização, deve ser atribuída à maior taxa de aquecimento adotada no ensaio termoanalítico, o que ocasiona o ligeiro deslocamento da deteç̧ão da reação na direção de maiores temperaturas. Covém notar que picos de caráter endotérmico correspondem a reações de formação, que é o caso da formação da solução sólida 
Diferença de Temperatura $(\mu \mathrm{V})$

Retração $.1 / I_{0}(\%)$

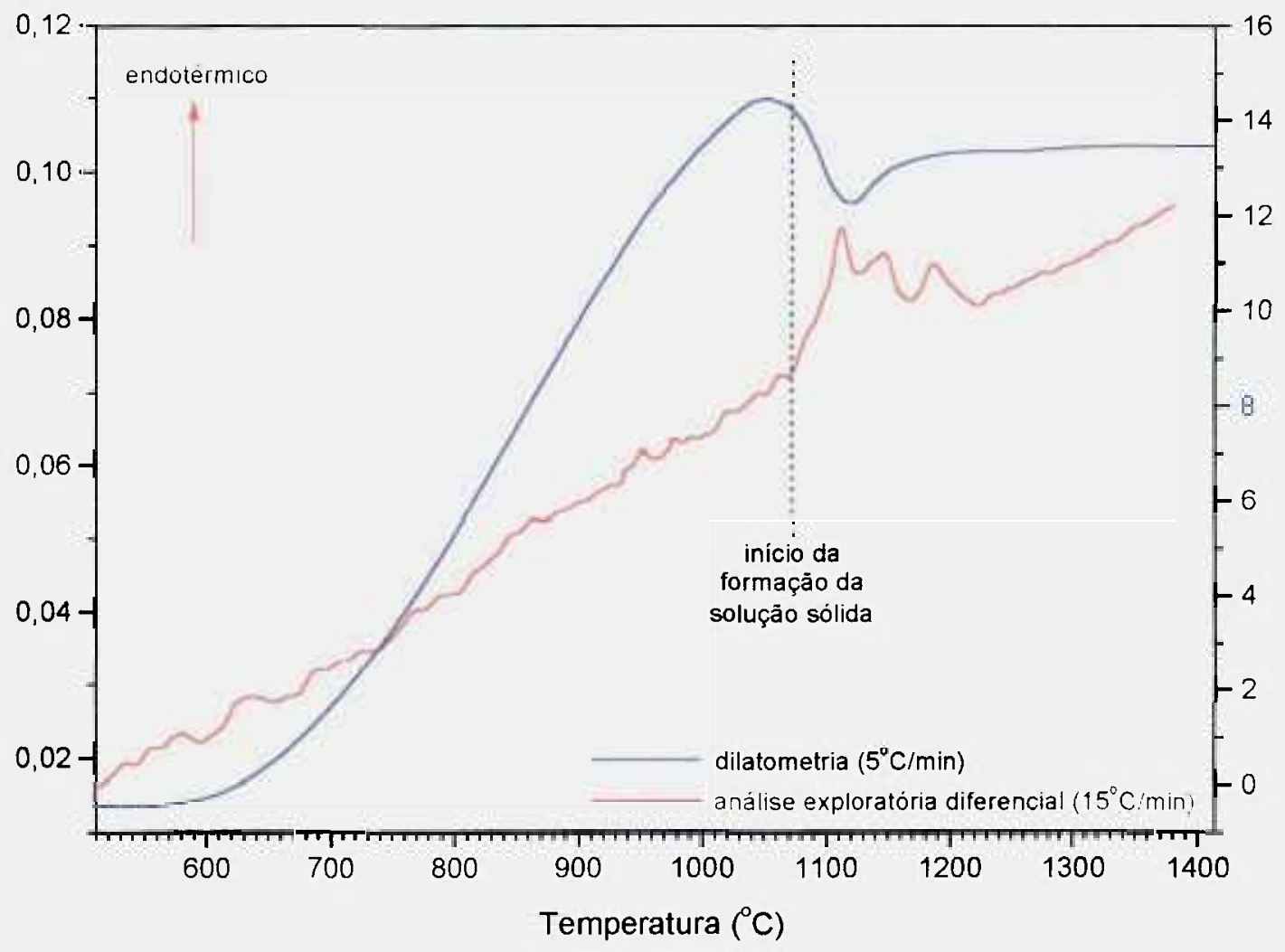

Figura 49 - Curva termoanalítica (análise exploratória diferencial) de amostra $\mathrm{UO}_{2}-\mathrm{Gd}_{2} \mathrm{O}_{3}$. ( $10 \%$ em peso de $\mathrm{Gd}_{2} \mathrm{O}_{3}$, atmosfera de argônio)

Os resultados apresentados neste item não só fundamentam a hipótese proposta como também são considerados como evidências experimentais suficientes para a sua aceitação como responsável pelo comportamento da sinterização no sistema $\mathrm{UO}_{2}-\mathrm{Gd}_{2} \mathrm{O}_{3}$. Porém, para o teste da hipótese procurou-se obter evidências diretamente observáveis de que a hipótese é verdadeira. Os resultados obtidos estão apresentados no próximo item.

\subsection{Teste da hipótese}

$\mathrm{O}$ teste desta hipótese foi realizado por meio da preparação de pastilhas $\mathrm{UO}_{2}$ $\mathrm{Gd}_{2} \mathrm{O}_{3}$ onde ao pó de $\mathrm{UO}_{2}$ foi adicionado, por meio de mistura mecânica de pós, aglomerados de $\mathrm{Gd}_{2} \mathrm{O}_{3}$ de tamanho controlado. Esses aglomerados foram obtidos por meio de compactação e granulação, seguidas de classificação granulométrica. Os pós de $\mathrm{Gd}_{2} \mathrm{O}_{3}$ e $\mathrm{UO}_{2}$ foram os mesmos utilizados anteriormente na preparação de amostras $\mathrm{UO}_{2}-\mathrm{Gd}_{2} \mathrm{O}_{3}$ 
pela técnica de mistura de pós. A concentração de $\mathrm{Gd}_{2} \mathrm{O}_{3}$ adotada foi $10 \%$ em peso. Os grânulos obtidos foram classificados nas faixas granulométricas $<37 \mu \mathrm{m}$, entre $37 \mu \mathrm{m}$ e 45 $\mu \mathrm{m}$, entre $45 \mu \mathrm{m}$ e $53 \mu \mathrm{m}$ e entre $53 \mu \mathrm{m}$ e $62 \mu \mathrm{m}$. As misturas preparadas utilizando-se os grânulos de $\mathrm{Gd}_{2} \mathrm{O}_{3}$ nas diferentes faixas de tamanho foram compactadas e sinterizadas a $1650{ }^{\circ} \mathrm{C}$ por 3 horas sob atmosfera de $\mathrm{H}_{2}$ puro. A taxa de aquecimento foi de $5{ }^{\circ} \mathrm{C} / \mathrm{min}$. Seções polidas das pastilhas sinterizadas foram observadas em microscópio óptico e a distribuição do diâmetro de poros foi determinada num analisador de imagens, utilizandose o método Saltikov ${ }^{(\mathbf{1 5 4})}$. Em cada amostra foram analisados entre 15 e 20 mil poros e foram adotados os aumentos de 50 e 200 vezes. Os resultados estão apresentados na figura 50.

As estruturas de poros ilustradas nas micrografias da figura 50 apresentam poros com diâmetros sensivelmente superiores à faixa de diâmetros tipicamente observada no combustível padrão de $\mathrm{UO}_{2}$ fabricado a partir do TCAU, entre $0,5 \mu \mathrm{m}$ e pouco mais de 10 $\mu \mathrm{m}{ }^{(\mathbf{8 5}, 152)}$. Nessas micrografias é possível se observar um consistente aumento do diâmetro desses grandes poros com o aumento do diâmetro dos grânulos de $\mathrm{Gd}_{2} \mathrm{O}_{3}$ adicionados. Nas micrografias correspondentes à faixa granulométrica superior a $45 \mu \mathrm{m}$ (figura $50 \mathrm{C}$ e D) é possível observar grânulos de $\mathrm{Gd}_{2} \mathrm{O}_{3}$ que não foram totalmente solubilizados na matriz de $\mathrm{UO}_{2}$, desenvolvendo-se um vazio ao seu redor. Isso demonstra que os grandes poros observados nas micrografias da figura $50 \mathrm{~A}$ e B foram realmente formados em locais onde inicialmente existiam grânulos de $\mathrm{Gd}_{2} \mathrm{O}_{3}$. Esses poros são os responsáveis pela forma bimodal das distribuições de diâmetros apresentadas na figura 50 , ao lado das respectivas micrografias. Ao contrário da típica distribuição monomodal característica do combustível padrão de $\mathrm{UO}_{2}$ preparado a partir do TCAU, observa-se que todas as distribuições de diâmetros de poros obtidas são do tipo bimodal. Observa-se, também, que a posição do segundo pico das distribuições está relacionada com a faixa granulométrica do $\mathrm{Gd}_{2} \mathrm{O}_{3}$ adicionado. Quanto maiores são os grânulos $\mathrm{Gd}_{2} \mathrm{O}_{3}$ adicionados, maiores são os diâmetros de poros correspondentes ao segundo pico da distribuição bimodal.

Para facilitar a visualização da evolução da distribuição de diâmetros de poros em função do tamanho dos grânulos de $\mathrm{Gd}_{2} \mathrm{O}_{3}$ adicionados, a figura 51 apresenta, em conjunto, as distribuições apresentadas na figura 50. Também estão apresentadas nessa figura as distribuições de diâmetros de poros presentes em pastilhas sinterizadas de $\mathrm{UO}_{2}$ puro e $\mathrm{UO}_{2}-\mathrm{Gd}_{2} \mathrm{O}_{3}$ que utilizou pó de $\mathrm{Gd}_{2} \mathrm{O}_{3}$ como recebido. Observando-se a figura 51 fica evidenciada a correlação entre a segunda moda da distribuição bimodal e a faixa de tamanho dos grânulos de $\mathrm{Gd}_{2} \mathrm{O}_{3}$ adicionados. 


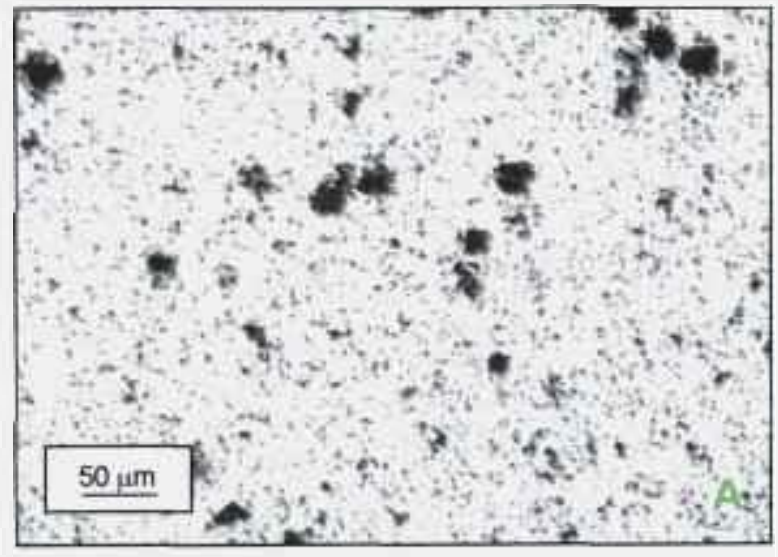

Fraçăo Volumétrica Diferencial (\%)
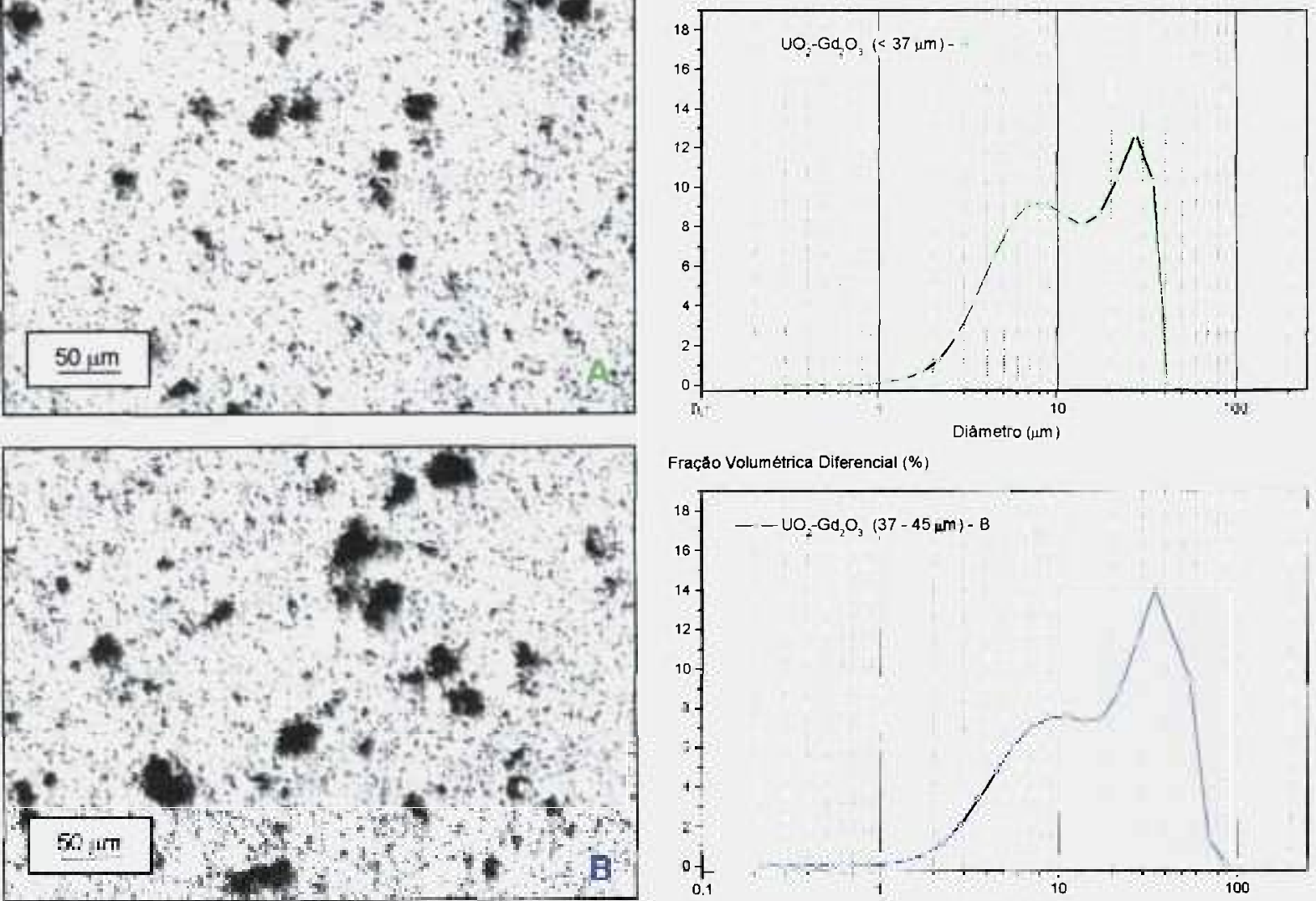

Fraçăo Volumetrica Diferencial (\%)
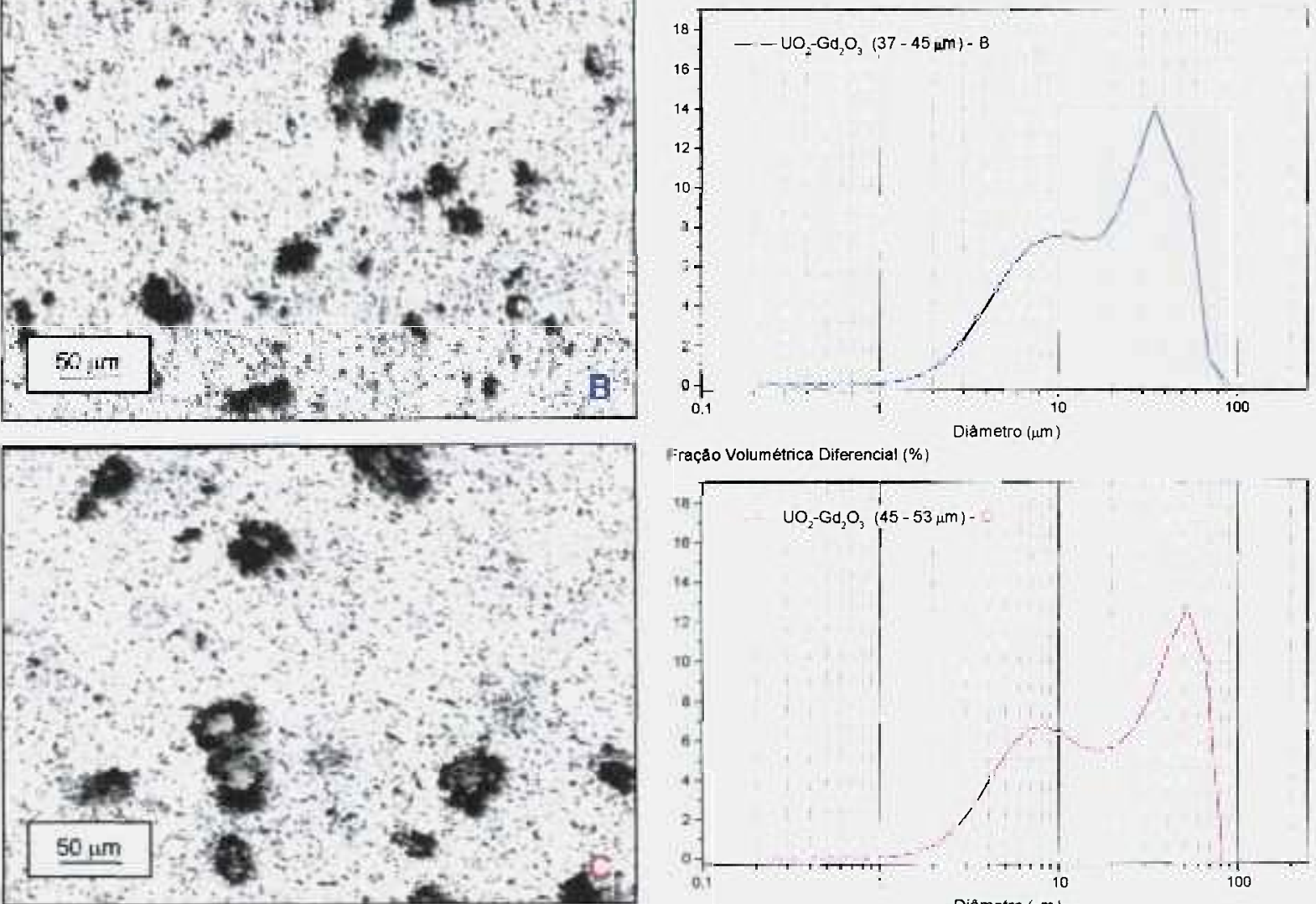

F:raçåo Volumétrica Diferencial (\%)
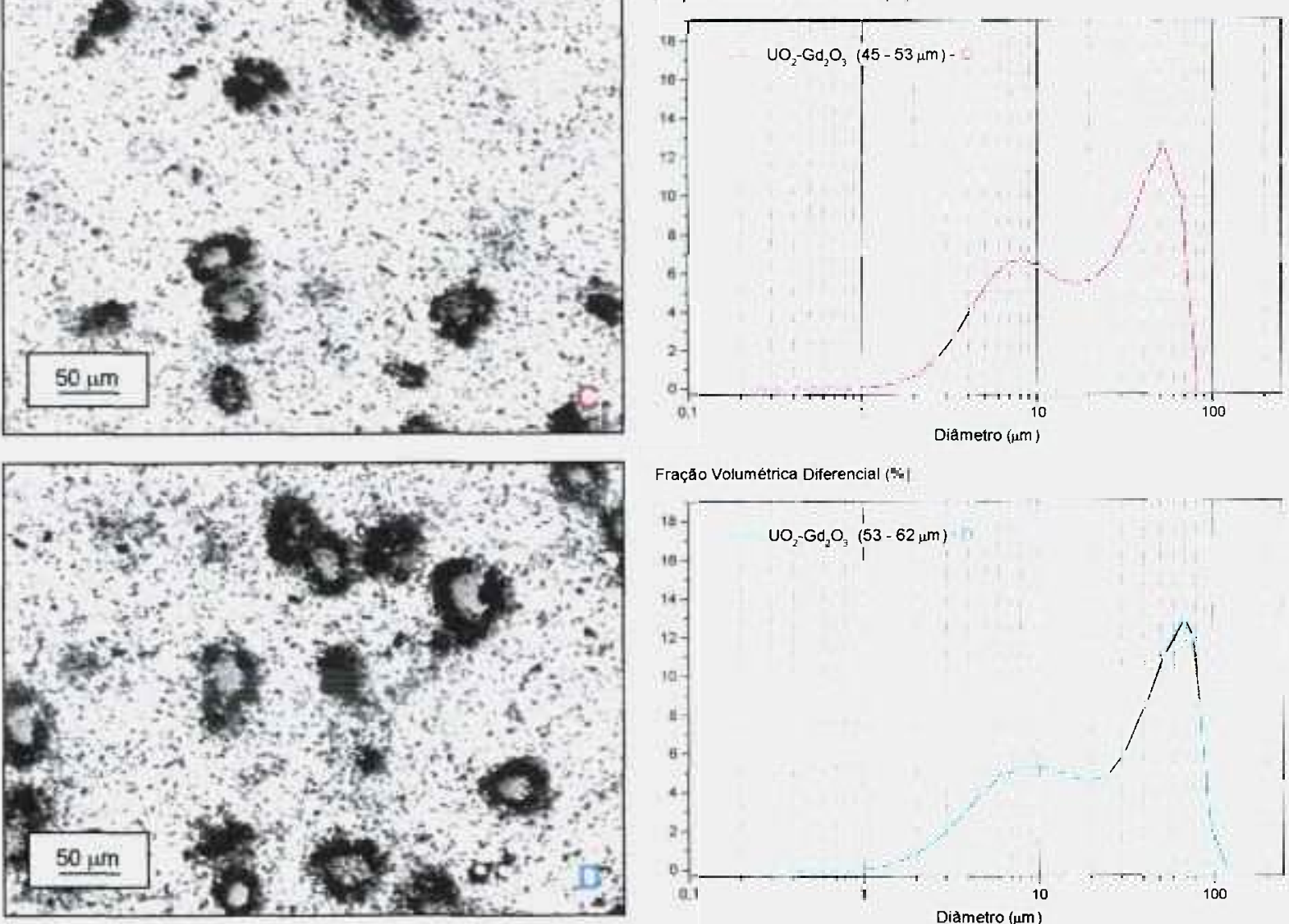

Figura 50 - Estrutura de poros de pastilhas $\mathrm{UO}_{2}-\mathrm{Gd}_{2} \mathrm{O}_{3}$ sinterizadas ( $10 \%$ em peso). 


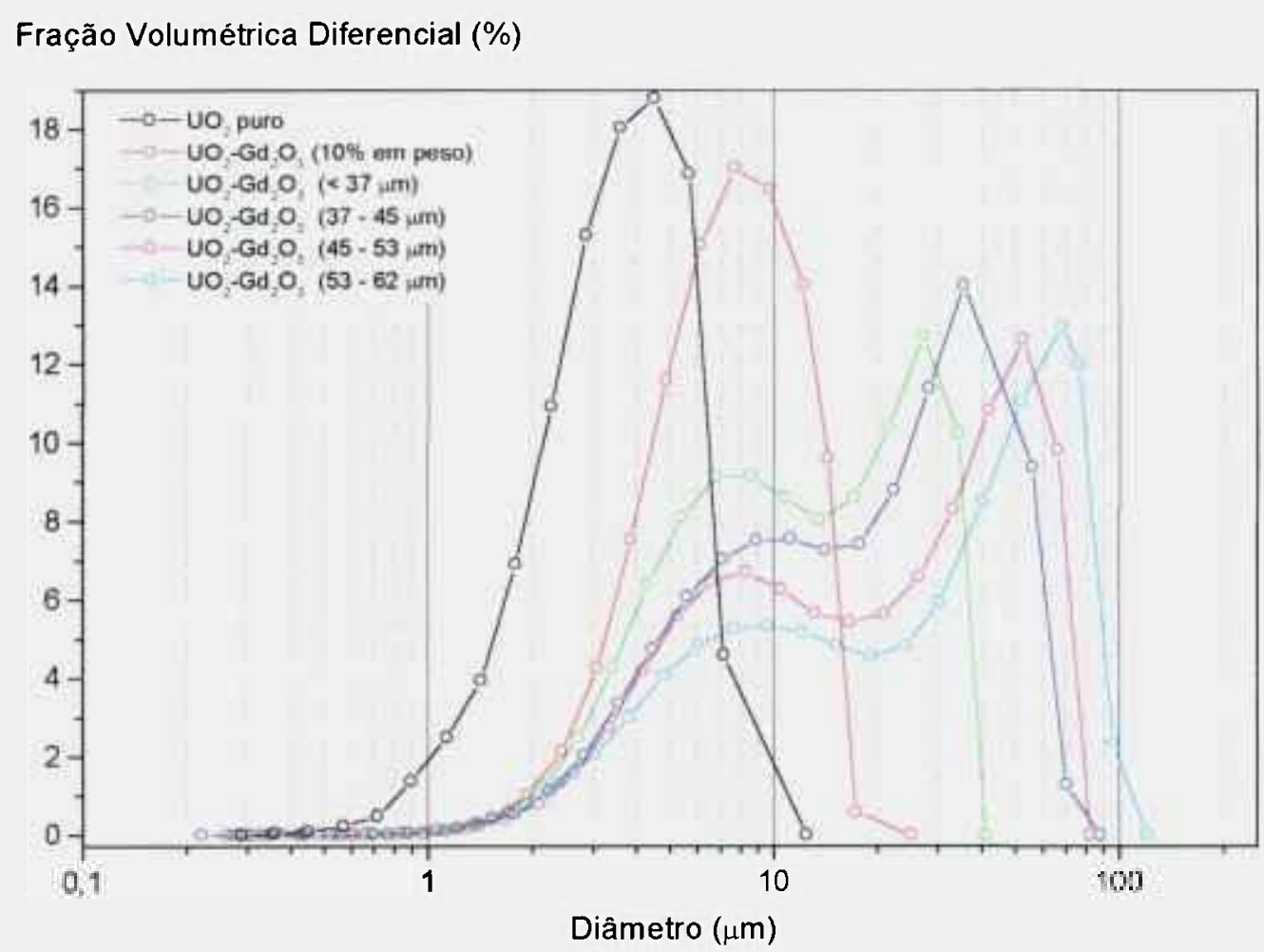

Figura 51 - Evolução da estrutura de poros de pastilhas sinterizadas $\mathrm{UO}_{2}-\mathrm{Gd}_{2} \mathrm{O}_{3}$ em função do tamanho de aglomerados de $\mathrm{Gd}_{2} \mathrm{O}_{3}$. (10\% em peso)

Observando-se a figura 51, pode-se inferir que se o tamanho do aglomerado de $\mathrm{Gd}_{2} \mathrm{O}_{3}$ é suficientemente pequeno, o vazio formado devido ao efeito Kirkendall é incorporado na primeira moda da distribuição bimodal, resultando numa distribuição monomodal deslocada na direção de maiores diâmetros. Isso dificulta a perfeita visualização do fenômeno, o que poderia explicar o fato da hipótese de ocorrência do efeito Kirkendall não ter sido anteriormente estudada. Apesar de não apresentarem micrografias, Yuda e Une ${ }^{(116)}$ mencionam a observação da ocorrência de poros de grande dimensão na sinterização de pastilhas $\mathrm{UO}_{2}-\mathrm{Gd}_{2} \mathrm{O}_{3}$ sinterizadas sob atmosfera de $\mathrm{CO} / \mathrm{CO}_{2}$, o que apóia a hipótese de que trata este item.

As micrografias eletrônicas de varredura apresentadas na figura 52 ilustram a formação de poros decorrentes do efeito Kirkendall, quando apenas parte do gadolínio do aglomerado difundiu-se para a matriz de $\mathrm{UO}_{2}$, não se completando a solubilização. Essa figura mostra detalhadamente aglomerados de $\mathrm{Gd}_{2} \mathrm{O}_{3}$ no interior de poros em formação. Isso foi comprovado por meio de microanálise, cujos resultados estão apresentados na figura 53. 

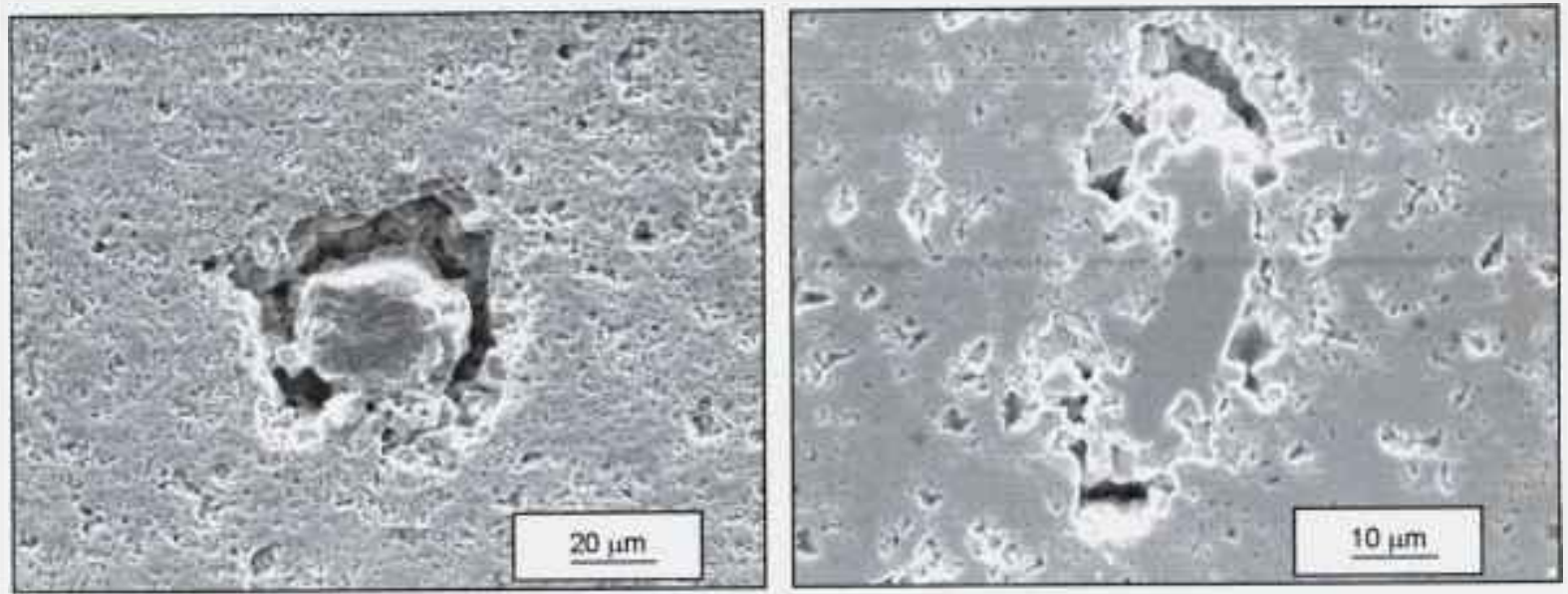

Figura 52 - Micrografias eletrônicas de varredura ilustrando poros em formação.

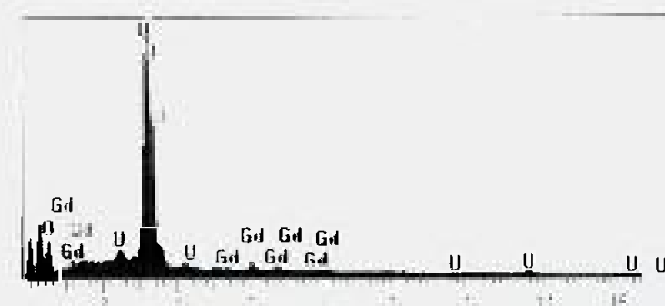

$A$

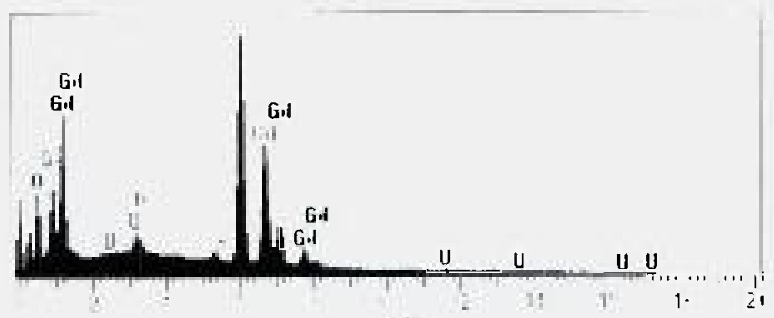

B

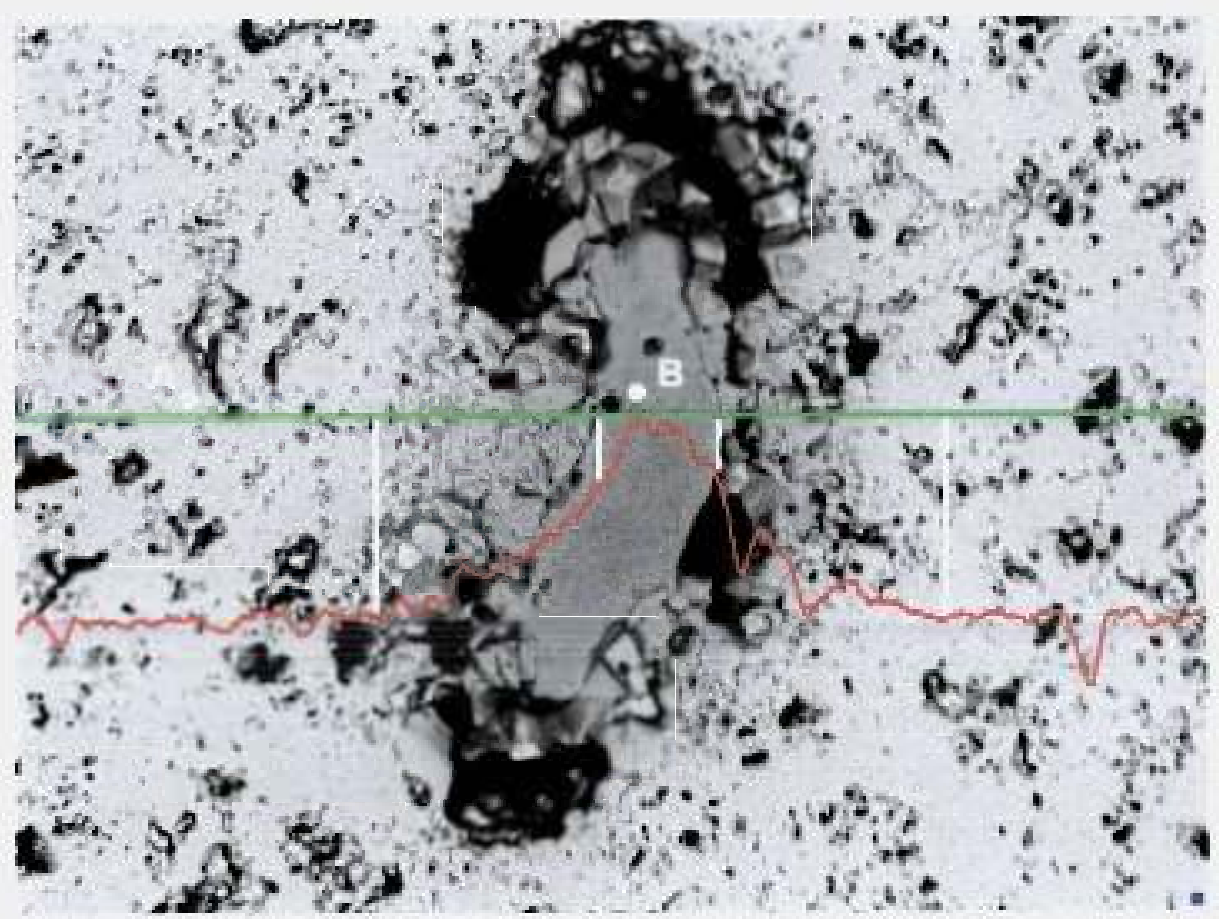

Figura 53 - Ilustração da formação de poros a partir de aglomerados de $\mathrm{Gd}_{2} \mathrm{O}_{3}$. $\left(1650^{\circ} \mathrm{C}, 3\right.$ horas, $\mathrm{H}_{2}$ ) 
A micrografia eletrônica de varredura apresentada na figura 53 foi obtida com elétrons retroespalhados. Como esse tipo de imagem é sensível ao número atômico médio, pode-se observar o tom de cinza escuro no interior do aglomerado tornar-se mais claro à medida que se penetra na matriz de $\mathrm{UO}_{2}$ que rodeia o aglomerado, que é mais clara devido ao maior número atômico. Essa é uma interessante ilustração da formação da solução sólida, revelando a frente de difusão do gadolínio no $\mathrm{UO}_{2}$. Microanálises realizadas nos pontos A e B indicados na figura comprovam que praticamente gadolínio puro está presente no interior do poro em formação. A concentração de gadolínio foi determinada (análise qualitativa) ao longo da linha verde indicada na figura. $\mathrm{O}$ resultado obtido (perfil de concentração em vermelho) demonstra mais uma vez que a penetração do gadolínio no $\mathrm{UO}_{2}$ é preferencial. Esse resultado confirma os resultados dos estudos de interdifusão apresentados e discutidos anteriormente no item 2.2.2 (ver figura 33).

A correlação entre o diâmetro de poros no segundo pico da distribuição bimodal, aliado à presença de $\mathrm{Gd}_{2} \mathrm{O}_{3}$ no interior de poros em formação, demonstra que esses poros de maior diâmetro são gerados a partir de aglomerados de $\mathrm{Gd}_{2} \mathrm{O}_{3}$ por ocasião da sua dissolução na rede cristalina do $\mathrm{UO}_{2}$ durante a sinterização, resultado do efeito Kirkendall. Como a formação da solução sólida ocorre em temperaturas em que a estrutura de poros provavelmente já está bastante fechada, durante o segundo estágio da sinterização, essa porosidade formada não pode ser eliminada, pelo menos não inteiramente, resultando num corpo sinterizado com uma maior porosidade residual.

Com base nas evidências experimentais obtidas pode-se considerar demonstrada a hipótese baseada na formação de poros estáveis. $\mathrm{O}$ mecanismo que explica o comportamento da sinterização do combustível $\mathrm{UO}_{2}-\mathrm{Gd}_{2} \mathrm{O}_{3}$, preparado por mistura mecânica de pós e utilizando pó de $\mathrm{UO}_{2}$ proveniente da tecnologia do TCAU, é baseado na ocorrência do efeito Kirkendall. Uma significativa diferença nos coeficientes de interdifusão do gadolínio no $\mathrm{UO}_{2}$ e do urânio no $\mathrm{Gd}_{2} \mathrm{O}_{3}$ causa um desbalanceamento no transporte de material durante a formação da solução sólida. Como decorrência deste fenômeno, a densificação durante a sinterização ocorre simultaneamente com a formação de poros nos locais onde originalmente estavam presentes aglomerados de $\mathrm{Gd}_{2} \mathrm{O}_{3}$, $\mathrm{O}$ diâmetro destes poros é proporcional ao diâmetro dos aglomerados inicialmente presentes e são estáveis por terem sido formados em alta temperatura, numa estrutura de poros essencialmente fechada, não sendo possível sua eliminação após a sua formação, no subseqüente processo de sinterização.

Além das evidências experimentais obtidas no estudo dessa hipótese diretamente, apresentadas e discutidas neste capitulo, outras evidências experimentais, obtidas neste 
trabalho e em outros trabalhos publicados, suportam esse mecanismo, como está discutido no próximo item.

\subsection{Revisão de resultados e da literatura sob a ótica da hipótese}

Segundo a literatura consultada, as densidades obtidas na sinterização de pastilhas $\mathrm{UO}_{2}-\mathrm{Gd}_{2} \mathrm{O}_{3}$ apresentam grande discordância, como foi anteriormente discutido no item 1.5 , cujos resultados estão aprtesentados na figura 5. Apesar de, em geral, a metodologia adotada na preparação dos pós mistos não ter sido apresentada com detalhes nos trabalhos obtidos na literatura, obteve-se fortes evidências de que o método de preparação influi decisivamente nas densidades finais obtidas após a sinterização. Isso foi confirmado experimentalmente neste trabalho, com base nos resultados apresentados no item 2.1.1, o que permitiu a proposição da hipótese da formação de uma barreira de difusão. $O$ mecanismo baseado na formação de poros estáveis, demonstrado neste capítulo, explica a forte influência que a homogeneidade da distribuição de $\mathrm{Gd}_{2} \mathrm{O}_{3}$ no pó misto exerce na densidade obtida após a sinterização ${ }^{(\mathbf{1 2 5})}$.

Quando o $\mathrm{Gd}_{2} \mathrm{O}_{3}$ está presente no nível macroscópico de homogeneidade, aglomerados de $\mathrm{Gd}_{2} \mathrm{O}_{3}$ de grande diâmetro estão presentes no pó misto, provavelmente superior a $20 \mu \mathrm{m}$, o que conduz à formação de poros durante a sinterização devido à ocorrência do efeito Kirkendall durante a formação da solução sólida. Esses poros não podem ser eliminados totalmente durante o processo de sinterização posterior à sua formação, resultando numa porosidade residual no corpo sinterizado, o que explica as baixas densidades observadas após a sinterização.

Quando o $\mathrm{Gd}_{2} \mathrm{O}_{3}$ está presente no nível microscópico de homogeneidade, ele não está presente na forma de aglomerados, mas sim na forma de partículas de pequeno diâmetro finamente dispersas. Nesse caso, os poros formados durante a sinterização devido ao efeito Kirkendall são de pequeno diâmetro, o que torna possível, em grande parte, a sua eliminação durante o processo de sinterização posterior à sua formação. Além disto, uma maior fração de matriz de solução sólida deve ser formada, a qual tem alta difusividade, resultando numa boa sinterabilidade que deve auxiliar o processo de eliminação dos poros formados segundo o mecanismo proposto.

Quando o $\mathrm{Gd}_{2} \mathrm{O}_{3}$ está presente no nível atômico de homogeneidade, o pó misto já é uma solução sólida, a qual apresenta alta difusividade cationica, segundo o modelo proposto por Ho e Radford ${ }^{(40)}$, o qual foi confirmado com base nos resultados obtidos neste trabalho, apresentados e discutidos nos itens 2.2.1 e 2.2.2. Como o pó é totalmente 
homogênio é alta a sua sinterabilidade e, não sendo possível a ocorrência do efeito Kirkendall, altas densidades são atingidas e a curva de sinterização mostra apenas uma etapa.

Assim como o mecanismo baseado na formação de poros estáveis explica, neste trabalho, a forma das curvas de sinterização de pastilhas de $\mathrm{UO}_{2}-\mathrm{Gd}_{2} \mathrm{O}_{3}$ preparadas pela técnica de mistura mecânica de pós, ele também pode explicar as curvas de sinterização obtidas por Manzel e Dörr ${ }^{(46)}$, uma vez que a técnica de preparação do pó misto é a mesma. Os resultados obtidos por Yuda e Une ${ }^{(116)}$ na sinterização de pastilhas $\mathrm{UO}_{2}$ $\mathrm{Gd}_{2} \mathrm{O}_{3}$ em atmosfera oxidante de $\mathrm{CO} / \mathrm{CO}_{2}$ também suporta o mecanismo da formação de vazios. Quando a sinterização ocorre em menores temperaturas, que é o caso da sinterização sob atmosfera oxidande, o fenômeno fica mais bem evidenciado e a densidade final obtida é ainda mais prejudicada, uma vez que os vazios derivados do efeito Kirkendall são formados numa estrutura de poros ainda mais fechada quando comparada àquela desenvolvida na sinterização sob atmosfera redutora. A observação por Yuda e Une de grandes poros nos corpos sinterizados sob atmosfera de $\mathrm{CO} / \mathrm{CO}_{2}$ também suportam o mecanismo.

O resultado obtido no teste da hipótese da formação da barreira de difusão, apresentado na figura 37, também pode ser explicado com base no mecanismo de formação de poros estáveis. Como nas amostras preparadas para este teste foi adicionado ao pó de $\mathrm{UO}_{2}$ pó misto $(\mathrm{U}, \mathrm{Gd}) \mathrm{O}_{2}$ contendo crescentes concentrações de gadolínio, em lugar de pó de $\mathrm{Gd}_{2} \mathrm{O}_{3}$ puro, a formação de vazios devido ao efeito Kirkendall foi tanto maior quanto maior a concentração de gadolínio no pó misto adicionado. Isto pode ser observado nas figuras 38 e 39, onde duas etapas de sinterização estão evidenciadas, mesmo quando o pó misto contendo apenas $20 \% \mathrm{em} \mathrm{mol} \mathrm{de} \mathrm{Gd}_{2} \mathrm{O}_{3}$ é utilizado na mistura de pós. Isso explica a razão da densidade final da pastilha sinterizada aumentar ligeiramente com a diminuição da concentração de gadolínio presente no pó misto adicionado ao pó de $\mathrm{UO}_{2}$, que é provavelmente devida à menor intensidade com que o efeito Kirkendall ocorre, uma vez que a diferença nos coeficientes de difusão entre as fases $\mathrm{UO}_{2}$ e $(\mathrm{U}, \mathrm{Gd}) \mathrm{O}_{2}$ deve diminuir à medida que a concentração de gadolínio na fase $(\mathrm{U}, \mathrm{Gd}) \mathrm{O}_{2}$ diminui. A confirmação desta proposição é sugestão para um trabalho futuro.

Outra importante evidência experimental que também suporta o mecanismo de formação de poros estáveis foi observada por Manzel e Dörr ${ }^{(+6)}$ durante a irradiação do combustível $\mathrm{UO}_{2}-\mathrm{Gd}_{2} \mathrm{O}_{3}$ preparado a partir de pó de $\mathrm{UO}_{2}$ proveniente do TCAU e adotando-se a técnica de mistura mecânica. Estes pesquisadores observaram a formação de poros de grande diâmetro em regiões onde inicialmente existia alta concentração de $\mathrm{Gd}_{2} \mathrm{O}_{3}$. Como a especificação do combustível fabricado segundo esse processo permite a 
existência de regiões de $\mathrm{Gd}_{2} \mathrm{O}_{3}$ puro com tamanho de até $220 \mu \mathrm{m}{ }^{(68,95)}$, nessas regiões ocorre a formação da solução sólida durante a irradiação, formando-se os grandes poros devido ao efeito Kirkendall. A formação destes poros cessa após um determinado nível de queima, já que a formação da solução sólida é completada, como observado experimentalmente. Portanto, o mecanismo demonstrado neste trabalho explica também a formação de poros de grande diâmetro durante a irradiação do combustivel $\mathrm{UO}_{2}-\mathrm{Gd}_{2} \mathrm{O}_{3}$ fabricado segundo a rota de mistura mecânica de pós.

Uma vez conhecido o mecanismo que explica a insuficiente densificação do combustivel $\mathrm{UO}_{2}-\mathrm{Gd}_{2} \mathrm{O}_{3}$ durante a sinterização, é possível propor linhas de ação para desenvolver possíveis soluções tecnológicas que possam minimizar ou eliminar o problema. Algumas propostas estão apresentadas e discutidas no próximo capítulo, algumas das quais baseadas em resultados experimentais, ainda que de caráter preliminar, os quais também sustentam o mecanismo da formação de poros estáveis devido ao efeito Kirkendall. 


\section{ANÁLISE TECNOLÓGICA}

Uma vez esclarecido o mecanismo responsável pelo comportamento do combustivel $\mathrm{UO}_{2}-\mathrm{Gd}_{2} \mathrm{O}_{3}$ preparado pela técnica de mistura de pós durante a sinterização; foi possivel propor, discutir e, em alguns casos, testar preliminarmente, possiveis ajustes nos procedimentos de fabricação que se acredita poderem minimizar, ou até mesmo compensar totalmente, os efeitos negativos da formação de poros devido ao efeito Kirkendall. Esses ajustes podem ser divididos em três classes, a saber:

a) atuação no ciclo de sinterização, ajustando-se a taxa de aquecimento e a temperatura de sinterização isotérmica;

b) atuação na superfície específica do pó de $\mathrm{UO}_{2}$ utilizado na preparação da mistura de pós, por meio do ajuste das condiçães de redução do TCAU;

c) atuação no procedimento de homogeneização dos pós de $\mathrm{UO}_{2}$ e $\mathrm{Gd}_{2} \mathrm{O}_{3}$, obtendo-se uma mistura com o nível microscópico de homogeneidade.

\subsection{Ajuste do ciclo de sinterização}

A formação de poros que acompanha a formação da solução sólida, devida à ocorrência do efeito Kirkendall, segundo os resultados apresentados nas figuras 15, 48 e 49 , começa a acontecer acima de $1000{ }^{\circ} \mathrm{C}$, durante o segundo estágio da sinterização, quando o processo de densificação já está iniciado, e termina ao redor de $1350^{\circ} \mathrm{C}$, quando o processo de densificação da matriz de $\mathrm{UO}_{2}$ já está bastante adiantada e a taxa de densificação está em declínio. Nestas condições, os poros formados são de dificil eliminação, principalmente se o nivel de homogeneidade na distribuição de $\mathrm{Gd}_{2} \mathrm{O}_{3}$ é macroscópico, onde estão presentes aglomerados de grande diâmetro.

A primeira possibilidade para atuação no processo seria a antecipação da formação da solução sólida, ou seja, atuar na formação de poros de maneira que ela ocorra em menores temperaturas, antes do início do segundo estágio da sinterização e da densificação. Dessa forma os poros dèrivados do efeito Kirkendall seriam formados numa estrutura de poros aberta e poderiam ser mais facilmente eliminados. Nesta linha, foram realizados tratamentos isotérmicos a $800{ }^{\circ} \mathrm{C}$ e $1200{ }^{\circ} \mathrm{C}$, por 4 e 12 horas, durante $\mathrm{o}$ aquecimento na sinterização. O objetivo foi completar a reação no estado sólido na 
temperatura a mais baixa possível, formando-se os poros decorrentes do efeito Kirkendall numa estrutura de poros a mais aberta possível. Nestes testes foram utilizados os mesmos pós de $\mathrm{UO}_{2}$ e $\mathrm{Gd}_{2} \mathrm{O}_{3}$ e os mesmos procedimentos de homogeneização descritos no item 2.1. Nas etapas de aquecimento foi mantida a taxa de $5{ }^{\circ} \mathrm{C} / \mathrm{min}$ e a atmosfera foi $\mathrm{H}_{2}$ puro. Os resultados estão apresentados na figura 54. Observa-se nessa figura que todos os tratamentos térmicos aplicados mostraram-se ineficazes, resultando em níveis de densificação muito próximos do nível obtido no ciclo de sinterização sem a aplicação do tratamento térmico. Os tratamentos térmicos a $800^{\circ} \mathrm{C}$ não impediram a formação de poros devido ao efeito Kirkendall, uma vez que a forma das curvas de sinterização não foi alterada, demonstrando que esta temperatura é muito baixa para que ocorra a formação da solução sólida, mesmo aplicando-se prolongados tempos de tratamento térmico. $\mathrm{O}$ tratamento térmico a $1200{ }^{\circ} \mathrm{C}$ também se mostrou ineficaz, uma vez que não ocorreu o esperado aumento da taxa de densificação quando foi retomado o programa de aquecimento. Isso é devido à formação da solução sólida numa estrutura de poros já muito fechada, mostrando que a temperatura do tratamento térmico foi demasiadamente elevada.

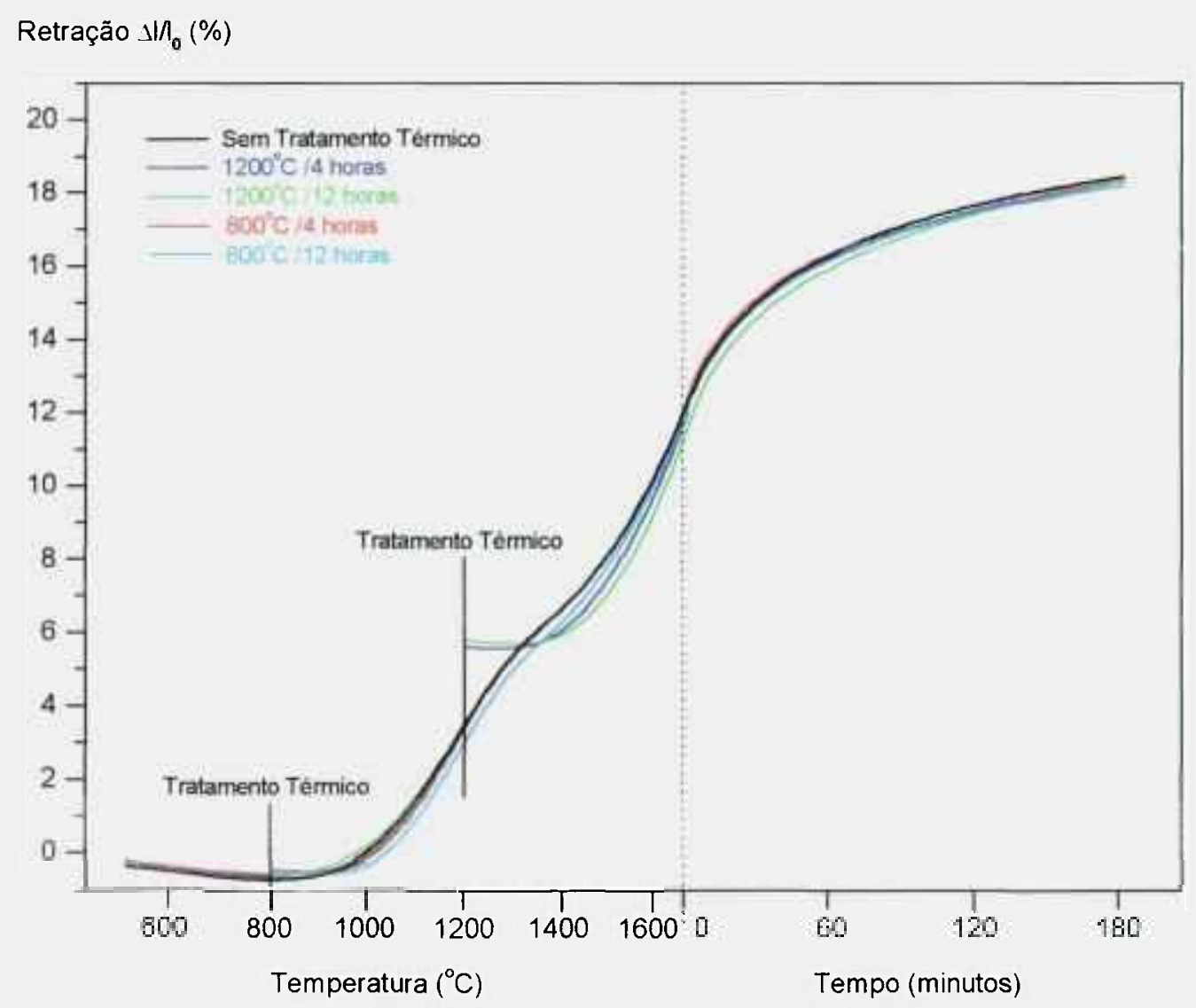

Figura 54 - Efeito de tratamentos térmicos na sinterização de pastilhas de $\mathrm{UO}_{2}-\mathrm{Gd}_{2} \mathrm{O}_{3}$. ( $10 \%$ em peso $\mathrm{Gd}_{2} \mathrm{O}_{3}, 5^{\circ} \mathrm{C} / \mathrm{min}, \mathrm{H}_{2}$ ) 
Outra possibilidade para atuação no processo seria o retardamento do processo de sinterização, ou seja, atuar na cinética de sinterização de maneira que ela ocorra em maiores temperaturas, depois da formação da solução sólida e da formação de poros. Como no caso anterior, dessa forma os poros derivados do efeito Kirkendall também poderiam ser formados numa estrutura de poros aberta e poderiam ser mais facilmente eliminados. O retardamento da sinterização possivelmente poderia ser compensado na etapa isotérmica do ciclo de sinterização. Uma forma de atingir este objetivo é aumentar a taxa de aquecimento no ciclo de sinterização. Atuando nesse parâmetro, se a cinética de formação da solução sólida, e, portanto, da formação de poros decorrente do efeito Kirkendall, for mais rápida do que a cinética de sinterização, o efeito seguramente seria benéfico em termos de porosidade residual, uma vez que uma maior fração de poros formados poderia ser eliminada na sinterização posterior. Para testar essa possibilidade, pastilhas de $\mathrm{UO}_{2}-\mathrm{Gd}_{2} \mathrm{O}_{3}$, contendo $10 \%$ em peso de $\mathrm{Gd}_{2} \mathrm{O}_{3}$, preparadas segundo a metodologia descrita no item 2.1 , foram sinterizadas sob atmosfera de $\mathrm{H}_{2}$ sob diferentes taxas de aquecimento, variando desde $1{ }^{\circ} \mathrm{C} / \mathrm{min}$ até $90^{\circ} \mathrm{C} / \mathrm{min}$. As curvas de sinterização obtidas estão apresentadas na figura 55. As taxas de densificação derivadas dessas curvas estão apresentadas na figura 56.

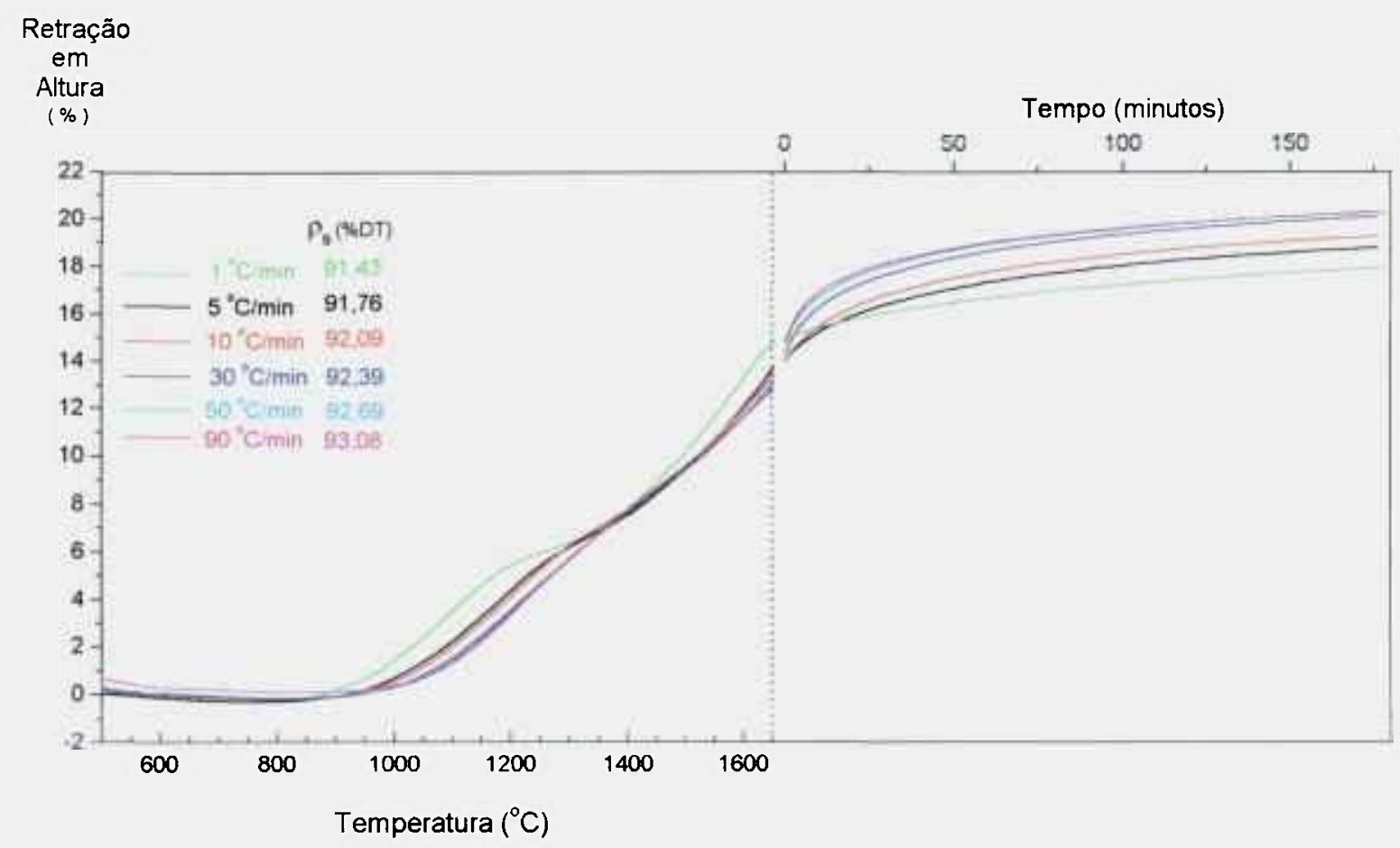

Figura 55 - Efeito da taxa de aquecimento na sinterização de pastilhas de $\mathrm{UO}_{2}-\mathrm{Gd}_{2} \mathrm{O}_{2}$. ( $10 \%$ em peso $\mathrm{Gd}_{2} \mathrm{O}_{3}, \mathrm{H}_{2}$ ) 


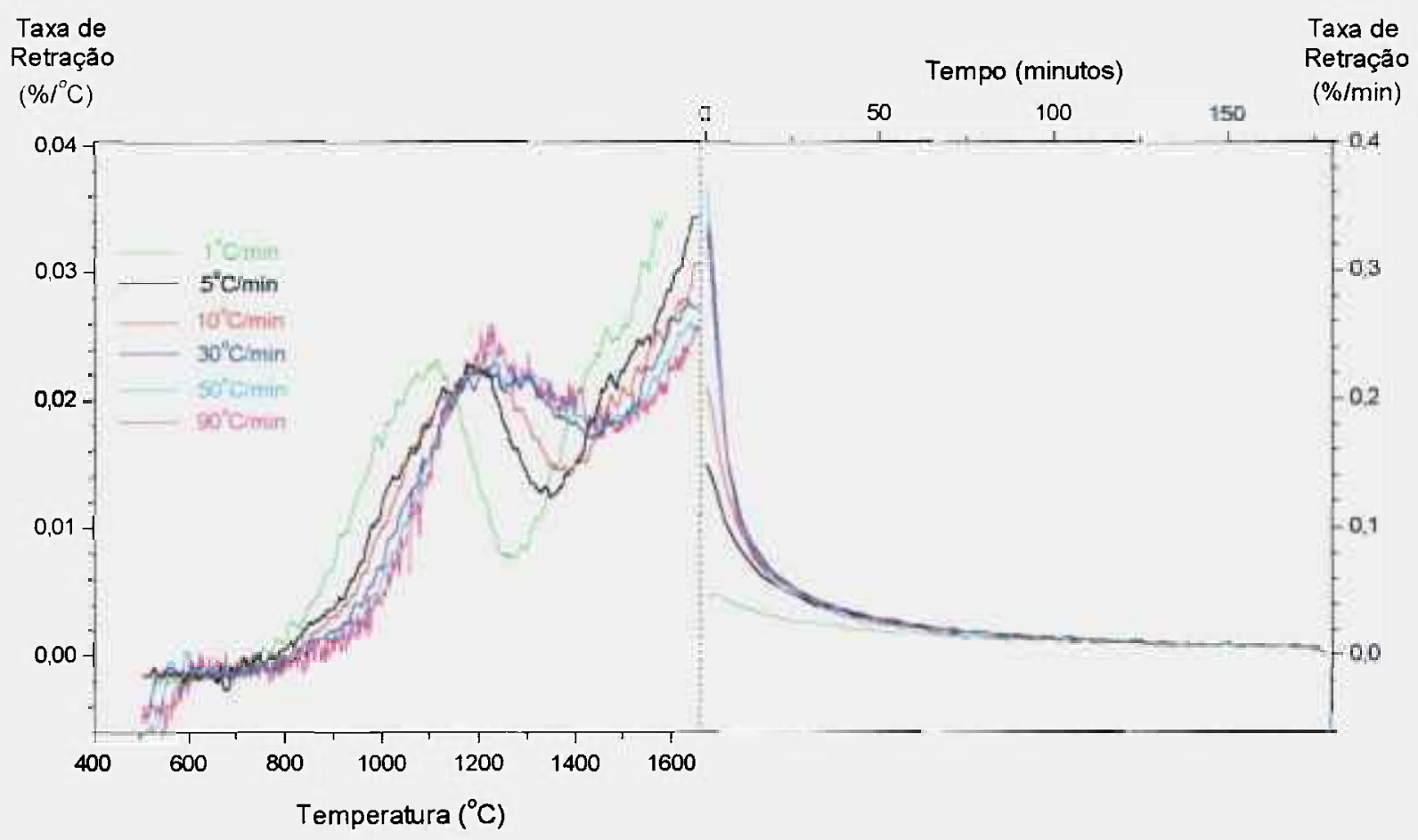

Figura 56 - Taxas de densificação derivadas das curvas apresentadas na figura 55.

Observando-se as figuras 55 e 56 pode-se verificar o efeito positivo do aumento da taxa de aquecimento na densidade final obtida após a sinterização. A elevação da taxa de aquecimento de $5{ }^{\circ} \mathrm{C} / \mathrm{min}$ para $90^{\circ} \mathrm{C} /$ min conduz à redução da porosidade final em quase $1,5 \%$ em volume. Quando a taxa de aquecimento é muito baixa, como $1{ }^{\circ} \mathrm{C} / \mathrm{min}$, a formação de poros durante a formação da solução sólida fica muito bem evidenciada e a densificação no período isotérmico é muito baixa. Por outro lado, quando a taxa de aquecimento é superior a $10^{\circ} \mathrm{C} / \mathrm{min}$, a diminuição da taxa de retração devida à formação de poros é menor e a densificação no início do tratamento isotérmico é bastante pronunciada, resultando num efeito benéfico na eliminação da porosidade, obtendo-se maiores densidades no corpo sinterizado.

As figuras 57 e 58 apresentam respectivamente a curva de sinterização e a correspondente taxa de densificação de uma pastilha $\mathrm{UO}_{2}-\mathrm{Gd}_{2} \mathrm{O}_{3}$ sinterizada sob argônio com taxa de aquecimento de $90^{\circ} \mathrm{C} / \mathrm{min}$. Essas figuras ilustram com mais clareza o efeito benéfico do aumento da taxa de aquecimento na sinterização do sistema. Quando a taxa de aquecimento é elevada, no caso $90{ }^{\circ} \mathrm{C} / \mathrm{min}$, a taxa máxima de formação de poros simultaneamente à sinterização é menor e a taxa de sinterização quando termina a formação de poros é consideravelmente maior, resultando numa maior recuperação na 
densificação do sistema, o que conseqüentemente conduz a uma porosidade residual menor após o ciclo de sinterização.

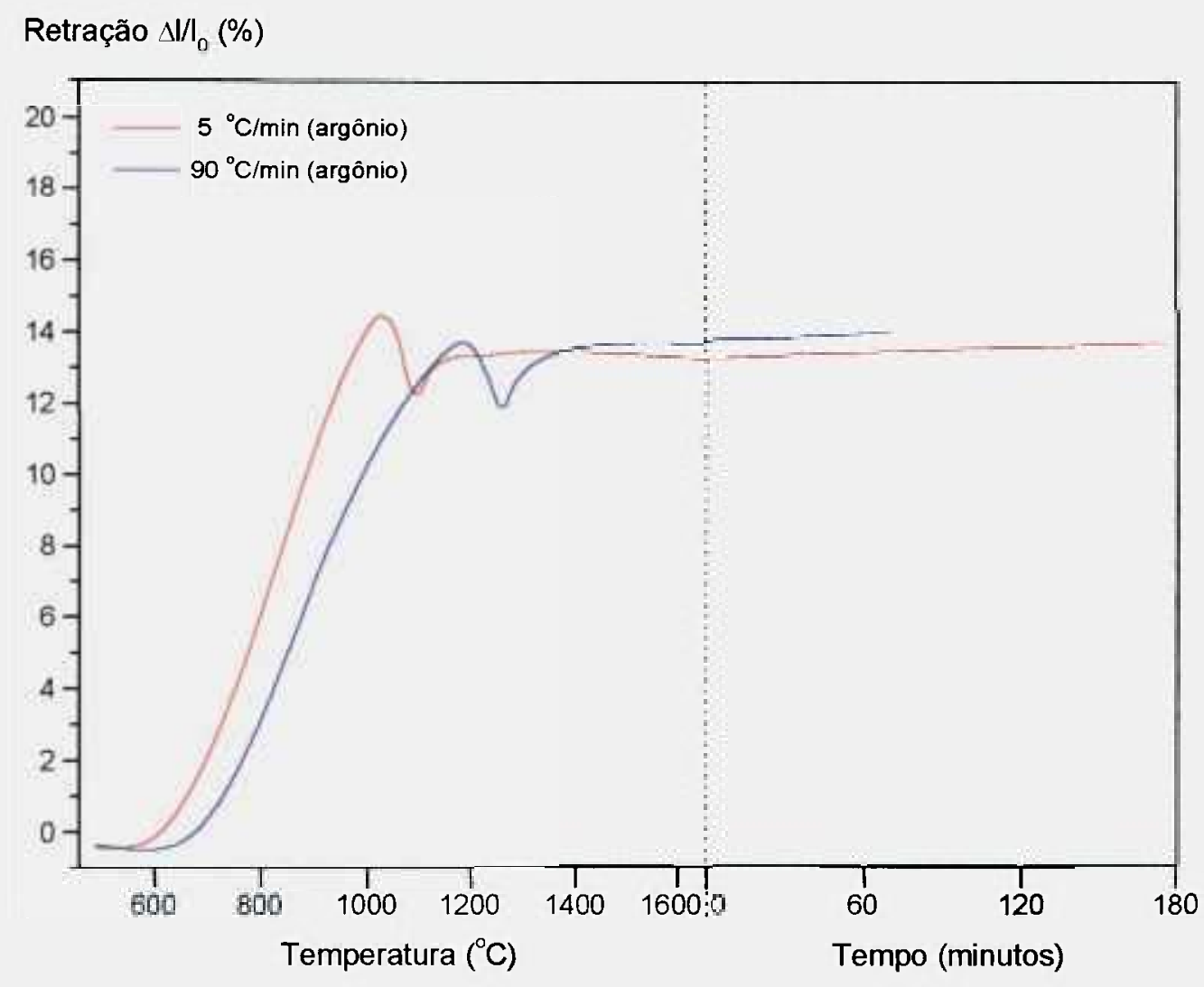

Figura 57 - Efeito da taxa de aquecimento na sinterização de pastilhas $\mathrm{UO}_{2}-\mathrm{Gd}_{2} \mathrm{O}_{3}$ sob atmosfera de argônio. ( $10 \%$ em peso de $\left.\mathrm{Gd}_{2} \mathrm{O}_{3}\right)$

Essas observações são evidências experimentais adicionais que comprovam o mecanismo de formação de poros estáveis. Convém mencionar que a temperatura de sinterização usualmente utilizada na sinterização do combustivel $\mathrm{UO}_{2}-\mathrm{Gd}_{2} \mathrm{O}_{3}$ é de 1700 a $1750{ }^{\circ} \mathrm{C}{ }^{(40,46,47,68,72.114)}$. Como neste trabalho a temperatura de sinterização adotada foi de $1650{ }^{\circ} \mathrm{C}$, devido a limitações experimentais, $\mathrm{o}$ aumento dessa temperatura para $1750{ }^{\circ} \mathrm{C} \mathrm{em}$ conjunto com o aumento da taxa de aquecimento possivelmente permitiria a obtenção da densidade mínima especificada para o combustível, de $93,5 \%$ da densidade teórica ${ }^{(11,95)}$. 


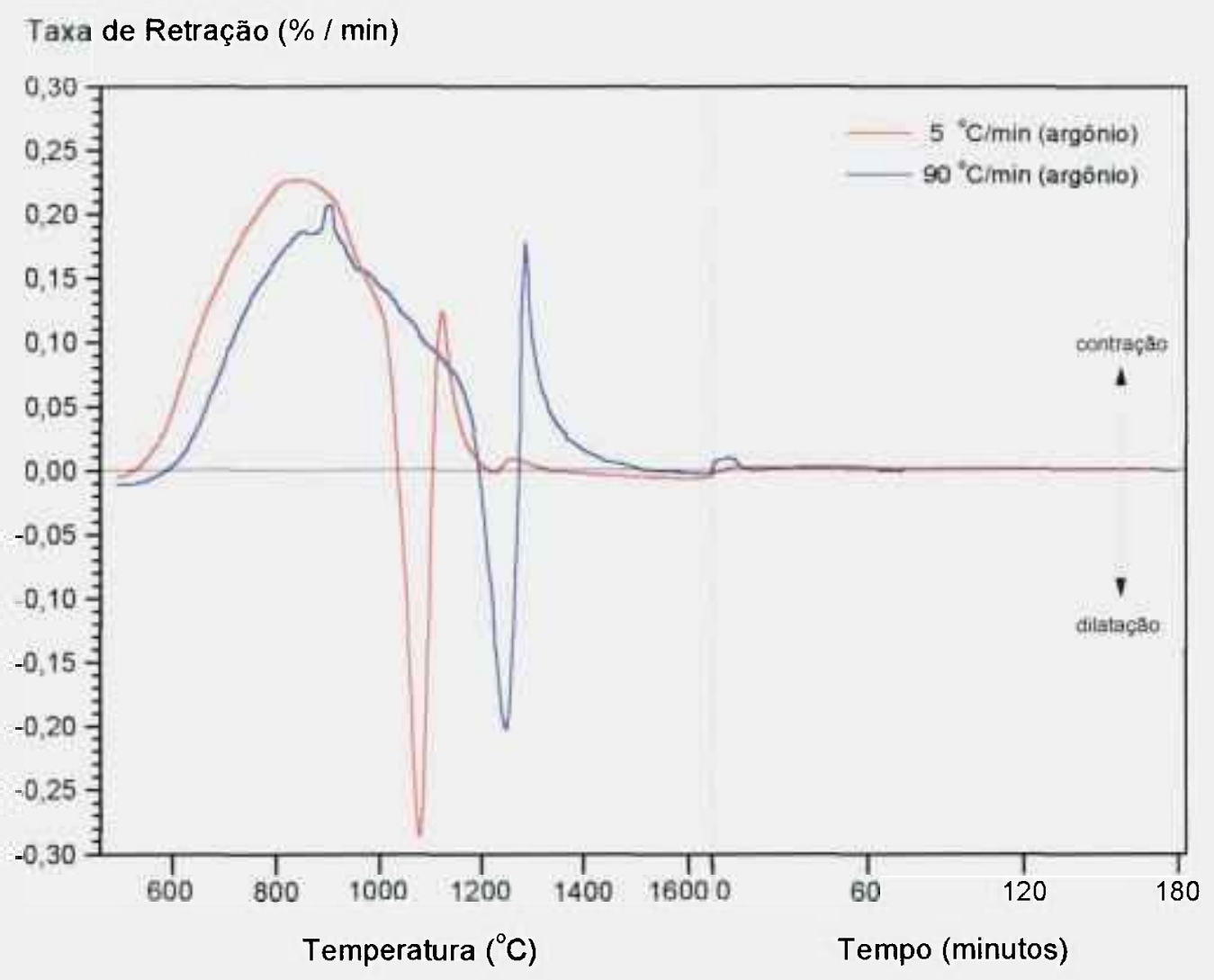

Figura 58 - Taxas de retração derivadas das curvas apresentadas na figura 57.

\subsection{Ajuste da superfície específica do pó de $\mathrm{UO}_{2}$}

Uma outra maneira de atuar na cinética de sinterização, de maneira que ela ocorra em maiores temperaturas, depois da formação da solução sólida e da formação de poros, é a diminuição da atividade do pó de $\mathrm{UO}_{2}$ utilizado na preparação da mistura de pós. Seguindo a mesma linha de raciocínio apresentada no item anterior, com o retardamento da sinterização os poros derivados do efeito Kirkendall seriam formados numa estrutura de poros ainda aberta e poderiam ser mais facilmente eliminados.

Essa possibilidade foi testada utilizando-se pó de $\mathrm{UO}_{2}$, proveniente do TCAU, com diferentes áreas de superficie específica. O controle da atividade do pó de $\mathrm{UO}_{2}$ é possível por meio do controle dos parâmetros de redução do TCAU. Pós menos ativos podem ser obtidos por meio do aumento da temperatura e/ou tempo de redução. Os resultados estão apresentados nas figuras 59 e 60 . Uma vez que os pós de $\mathrm{UO}_{2}$ com alta superfície específica iniciam a densificação em menores temperaturas, a formação da solução sólida, e a conseqüente formação de poros devido ao efeito Kirkendall, ocorre 
numa estrutura de poros bastante fechada, durante uma estapa já avançada do estágio intermediário da sinterização. Por esse motivo é dificil a eliminação dos poros formados. Por outro lado, quảndo a superficie específica do pó de $\mathrm{UO}_{2}$ utilizado é demasiadamente baixa, apesar do processo de formação de poros ocorrer numa estrutura de poros mais aberta, após a sua formação não existe disponível suficiente atividade no sistema para que ocorra uma boa densificação, resultando em densidades muito baixas. Parece, então, existir uma superficie específica ótima para o pó de $\mathrm{UO}_{2}$, não suficientemente alta para fechar demasiadamente a estrutura de poros antes da formação da solução sólida, e não muito baixa de forma que comprometa o processo de sinterização do sistema como um todo. A superficie especifica ótima deve ser aquela que confira ao pó de $\mathrm{UO}_{2}$ da mistura características de sinterabilidade de tal forma que na fase de densificação a alta temperatura, após a formação da solução sólida, ainda se tenha sinterabilidade suficiente para se eliminar em grande parte os poros formados pelo efeito Kirkendall, otimizando-se a densificação. Dessa forma é reforçada a densificação em temperaturas acima daquelas nas quais ocorre a formação de poros, ao redor de $1350{ }^{\circ} \mathrm{C}$, por meio de uma reserva de atividade para sinterização em temperaturas elevadas. Neste trabalho, o melhor resultado foi obtido utilizando-se pó de $\mathrm{UO}_{2}$ com superficie específica de $4,5 \mathrm{~m}^{2} / \mathrm{g}$. Observa-se nas figuras 59 e 60 que, no caso da utilização deste pó de $\mathrm{UO}_{2}$, a densificação durante o período isotérmico do ciclo de sinterização foi consideravelmente maior do que a observada no caso de utilização de pó de $\mathrm{UO}_{2}$ com maiores superficies específicas. Isso explica os resultados obtidos por Agueda et al ${ }^{(114)}{ }_{b}$ que obtiveram densidades após a sinterização sensivelmente superiores quando utilizaram pó de $\mathrm{UO}_{2}$ com menor área de superficie específica. Como discutido no item 1.5 e apresentado na figura 5 , estes pesquisadores obtiveram uma densidade final até $4 \%$ da densidade teórica superior quando a superficie específica do pó de $\mathrm{UO}_{2}$ foi diminuída de $6,65 \mathrm{~m}^{2} / \mathrm{g}$ para $4,37 \mathrm{~m}^{2} / \mathrm{g}$

Essas observações também são evidências experimentais adicionais que comprovam o mecanismo proposto de formação de poros estáveis. Como comentado no item anterior, a utilização de uma maior temperatura de sinterização, como a usualmente utilizada na sinterização do combustível $\mathrm{UO}_{2}-\mathrm{Gd}_{2} \mathrm{O}_{3}\left(1700\right.$ a $\left.1750{ }^{\circ} \mathrm{C}\right)$, certamente conduziria a resultados mais positivos, uma vez que a melhoria observada no comportamento da sinterização do sistema $\mathrm{UO}_{2}-\mathrm{Gd}_{2} \mathrm{O}_{3}$ em função do controle da superficie específica do pó de $\mathrm{UO}_{2}$ não permitiu, por si só, a obtenção da densidade mínima especificada para o combustível. Observando-se a densificação que ocorre na parte isotérmica do ciclo de sinterização, pode-se também concluir que o aumento do tempo de tratamento isotérmico deve conduzir à obtenção de maiores densidades nos corpos sinterizados. Isso é confirmado por resultados obtidos num trabalho anterior que estudou a sinterização do sistema $\mathrm{UO}_{2}-\mathrm{Gd}_{2} \mathrm{O}_{3}{ }^{(\mathbf{1 2 4})}$. Nesse trabalho, na faixa de concentração de 2 a 6 $\%$ em peso de $\mathrm{Gd}_{2} \mathrm{O}_{3}$, foi possível a eliminação adicional de aproximadamiente $2 \%$ em 
volume de porosidade com o aumento do tempo de tratamento isotérmico de 3 para 6 horas.

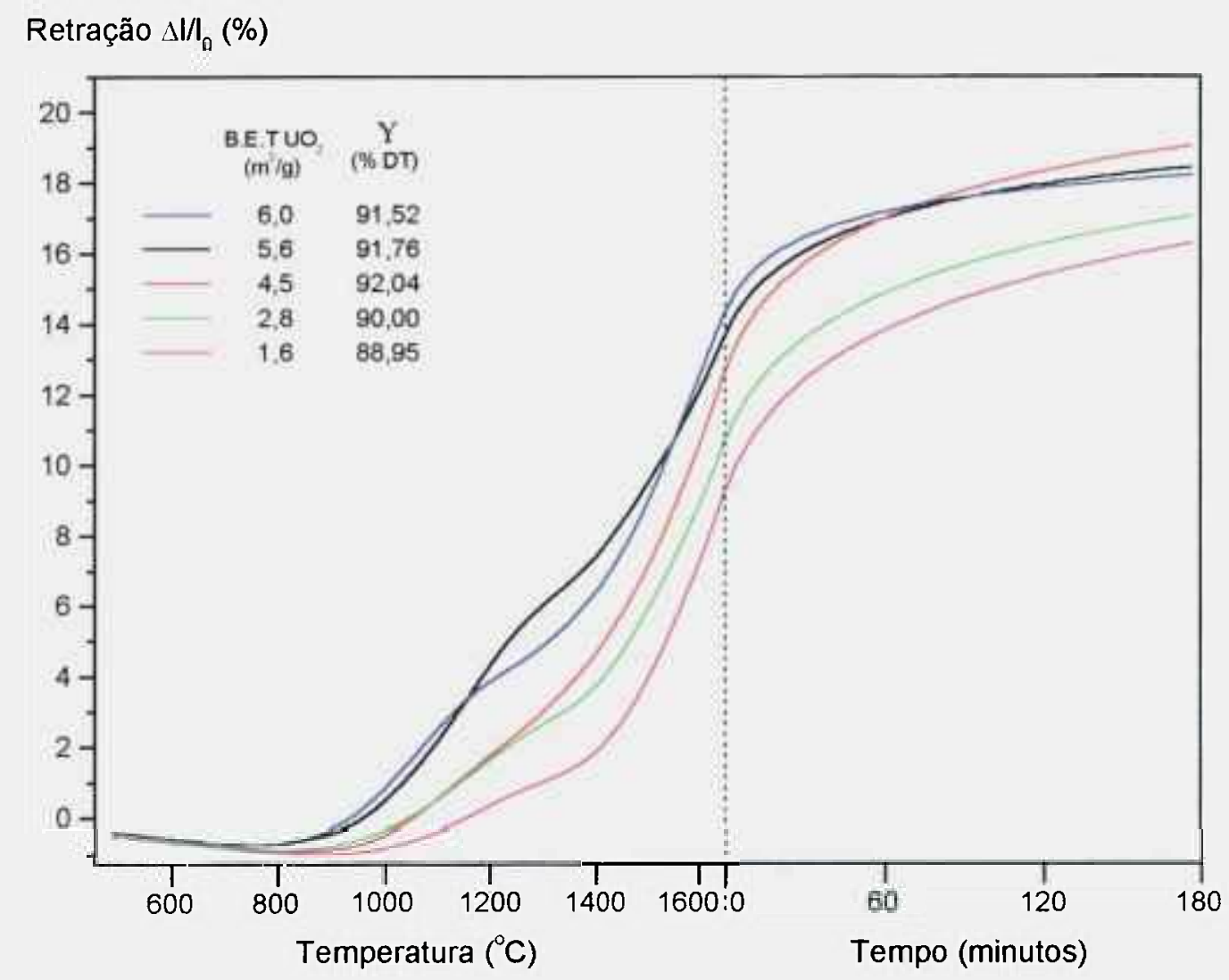

Figura 59 - Efeito da superfície específica do pó de $\mathrm{UO}_{2}$ na sinterização de pastilhas $\mathrm{UO}_{2}-\mathrm{Gd}_{2} \mathrm{O}_{3} .\left(10 \%\right.$ em peso de $\left.\mathrm{Gd}_{2} \mathrm{O}_{3}, 5{ }^{\circ} \mathrm{C} / \mathrm{min}, \mathrm{H}_{2}\right)$

\subsection{Desenvolvimento de métodos alternativos para incorporação do pó de $\mathrm{Gd}_{2} \mathrm{O}_{3}$}

Como foi discutido no item 2.1.1, verificou-se que a homogeneidade da distribuição do $\mathrm{Gd}_{2} \mathrm{O}_{3}$ no pó misto exerce uma decisiva influência na sinterização de pastilhas $\mathrm{UO}_{2}-\mathrm{Gd}_{2} \mathrm{O}_{3}$, ou seja, tanto maior é a densidade final obtida quanto maior é a homogeneidade na distribuição. Esse comportamento é explicado com base no mecanismo de poros estáveis. Quando o nível de homogeneidade é macroscópico, estão presentes aglomerados de $\mathrm{Gd}_{2} \mathrm{O}_{3}$ que conduzem à formação de grandes poros quando ocorre a sua solubilização na matriz de $\mathrm{UO}_{2}$, decorrente do efeito Kirkendall. Se o tamanho do aglomerado é suficientemente pequeno, ou se as partículas de $\mathrm{Gd}_{2} \mathrm{O}_{3}$ estão presentes individualmente, com diâmetro médio da ordem de $2,5 \mu \mathrm{m}$, como ilustra a figura 10 , os 


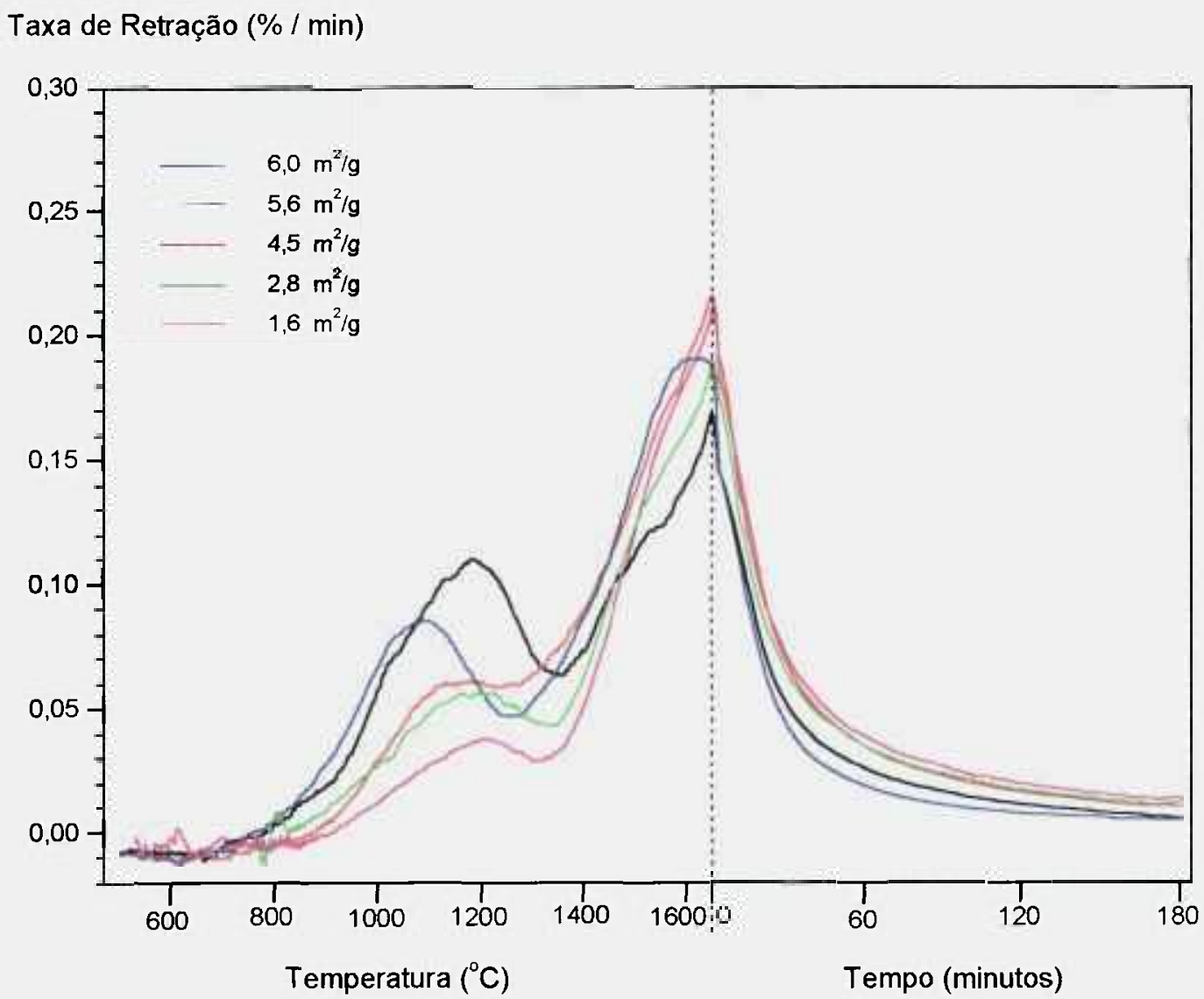

Figura 60 - Taxas de retração derivadas das curvas apresentadas na figura 59.

poros formados por estas partículas de pequeno tamanho possivelmente podem ser eliminados após a sua formação, nas etapas subseqüentes de sinterização. Essa situação ocorre quando é atingido o nível microscópico de homogeneidade na distribuição de $\mathrm{Gd}_{2} \mathrm{O}_{3}$ no pó misto. Essa afirmação é baseada nos resultados experimentais apresentados e discutidos no item 2.1.1 ${ }^{\text {(124,125) }}$. Quando a homogeneidade na distribuição de $\mathrm{Gd}_{2} \mathrm{O}_{3}$ atinge o nível atômico, o pó misto já se encontra na forma de solução sólida, não sendo possível a ocorrência do efeito Kirkendall, conduzindo à obtenção de altas densidades após a sinterização, uma vez que a sinterização é beneficiada pela presença dos cátions $\mathrm{Gd}^{3+}$ na rede cristalina do $\mathrm{UO}_{2}$. Portanto, o desenvolvimento de um método alternativo de homogeneização dos pós de $\mathrm{UO}_{2}$ e $\mathrm{Gd}_{2} \mathrm{O}_{3}$, o qual permita a obtenção do nível microscópico de homogeneidade, é uma possível solução para o problema observado na sinterização do sistema $\mathrm{UO}_{2}-\mathrm{Gd}_{2} \mathrm{O}_{3}$.

O método de homogeneização deve preservar a morfologia original das partículas de TCAU, a qual confere ao $\mathrm{UO}_{2}$ produzido a desejável boa escoabilidade que permite a compactação direta. A utilização do método de co-moagem, seja a úmido ou a seco, apesar 
de resultar em boas densidades após a sinterização (nível microscópico de homogeneidade), não é tecnologicamente interessante por destruir a morfologia original do pó de $\mathrm{UO}_{2}$, o que implica na necessária incorporação da etapa de granulação.

Como discutido anteriormente, o processo de coprecipitação via TCAU, que na verdade é uma precipitação simultânea, permite a obtenção do nível microscópico de homogeneidade na distribuição de $\mathrm{Gd}_{2} \mathrm{O}_{3}$ no pó misto $\mathrm{UO}_{2}-\mathrm{Gd}_{2} \mathrm{O}_{3}$, o que resulta num nível de densificação suficiente durante a sinterização. Contudo, a desvantagem da incorporação do gadolínio na etapa da precipitação é a contaminação do reator, exigindo equipamentos exclusivos. Como o combustível $\mathrm{UO}_{2}-\mathrm{Gd}_{2} \mathrm{O}_{3}$ é sempre utilizado em conjunto com o combustivel padrão de $\mathrm{UO}_{2}$, todà a instalação de precipitação deve ser necessariamente duplicada. Para evitar a duplicação da instalação, uma alternativa seria a incorporação do gadolínio, na forma de óxido, à suspensão de TCAU antes da filtração. Dessa forma seria realizada uma homogeneização em meio líquido, muito mais eficiente por permitir a desaglomeração do $\mathrm{Gd}_{2} \mathrm{O}_{3}$, dispersando-se as partículas individuais nos cristais de TCAU. Neste caso, após a precipitação do TCAU no reator tradicional, a suspensão seria bombeada para um tanque de homogeneização e, a partir daí, para um filtro especial, diferente do utilizado no processo de produção do combustivel $\mathrm{UO}_{2}$ padrão. Nesse caso seriam necessárias apenas a duplicação do sistema de filtração e a instalação de um tanque de homogeneização adicional.

Essa solução foi tentada no presente trabalho, em escala de laboratório. Contudo, os resultados obtidos não mostraram ser satisfatórios, uma vez que foi observada uma forte tendência à segregação do $\mathrm{Gd}_{2} \mathrm{O}_{3}$ na suspensão, assim como uma também acentuada tendência à aglomeração durante a filtração. É necessária a execução de um programa de pesquisa com o objetivo específico de encontrar meios que garantam uma boa homogeneidade na suspensão e filtração, possivelmente por meio da utilização de algum tipo de dispersante. Essa é uma das sugestões para futuros trabalhos.

Os métodos de sintese de $\mathrm{Gd}_{2} \mathrm{O}_{3}$ mais comuns são baseados na decomposição térmica de carbonatos e hidróxidos. A partir desses métodos, o mínimo tamanho de partícula obtido é limitado pela sensível tendência à aglomeração durante a decomposição térmica. Contudo, Mazdiyani e Brown ${ }^{(155)}$ desenvolveram uma técnica de calcinação dinâmica que previne a agregação durante a decomposição térmica, o que possibilitou a obtenção partículas finas de $\mathrm{Gd}_{2} \mathrm{O}_{3}$, ao redor de $28 \mathrm{~nm}$. Além disto, como novas aplicações do $\mathrm{Gd}_{2} \mathrm{O}_{3}$ têm sido recentemente investigadas, principalmente como aditivos e dopantes, novos métodos para a sua preparação também têm sido investigados. Pó de $\mathrm{Gd}_{2} \mathrm{O}_{3}$ ultrafino tem sido obtido por meio de síntese mecânico-química, resultando em partículas de $0,1 \mu \mathrm{m}^{(\mathbf{1 5 6 , 1 5 7})}$. A utilização de pós de $\mathrm{Gd}_{2} \mathrm{O}_{3}$ ultrafinos que exibem baixa 
tendência à aglomeração, adotando-se a técnica de homogeneização na suspensão de TCAU, ou mesmo a técnica de mistura mecânica a seco dos pós, provavelmente conduziria a um bom resultado, minimizando-se os efeitos do mecanismo demonstrado neste trabalho por meio da diminuição do diâmetro dos poros formados devido ao efeito Kirkendall. Também este trabalho fica como uma sugestão para trabalhos futuros. 


\section{CONCLUSÕES}

Foi realizada, neste trabalho, uma investigação sobre o mecanismo atuante no bloqueio da sinterização que ocorre no sistema $\mathrm{UO}_{2}-\mathrm{Gd}_{2} \mathrm{O}_{3}$. A partir dos resultados experimentais apresentados e discutidos anteriormente, podem ser elaboradas as seguintes conclusões:

1. O mecanismo responsável pelo comportamento da sinterização no sistema $\mathrm{UO}_{2}-\mathrm{Gd}_{2} \mathrm{O}_{3}$, quando o método de preparação do pó misto é a mistura mecânica a seco dos pós de $\mathrm{UO}_{2}$ e $\mathrm{Gd}_{2} \mathrm{O}_{3}$, é a formação de porosidade devido ao efeito Kirkendall, a qual é gerada em decorrência da formação da solução sólida, quando ocorre transporte preferencial de gadolínio para a matriz de $\mathrm{UO}_{2}$. Nos locais onde originalmente existiam aglomerados de $\mathrm{Gd}_{2} \mathrm{O}_{3}$ são formados poros ao mesmo tempo em que ocorre a sinterização do sistema. Como esses poros têm grande diâmetro e são formados numa temperatura elevada, numa estrutura de poros já relativamente fechada, durante o segundo estágio de sinterização, eles são de dificil eliminação, permanecendo, em grande parte, no corpo sólido após a sinterização, diminuindo a densidade final obtida.

2. Foi evidenciada a presença de fases de baixa difusividade, diferentes da fase fluorita do $\mathrm{UO}_{2}$, quando a fração molar de gadolínio ultrapassa o valor 0,5 . Essas fases não puderam ser identificadas neste trabalho, mas devem ser isoestruturais à série de fases recentemente identificadas nos sistemas $\mathrm{Ce}-\mathrm{O}, \mathrm{Pr}-\mathrm{O}$ e Tb-O. Apesar dessa evidência experimental, a hipótese mais freqüentemente proposta, baseada na formação de uma barreira de difusão ao redor de aglomerados de $\mathrm{Gd}_{2} \mathrm{O}_{3}$, pela formação dessas fases de baixa difusividade ricas em gadolínio, não foi comprovada experimentalmente neste trabalho. O bloqueio na sinterização ocorre mesmo quando a fração molar de gadolinio, adicionado na forma de solução sólida $(\mathrm{U}, \mathrm{Gd}) \mathrm{O}_{2}$, é menor do que 0,5 , quando o sistema é comprovadamente monofásico com alta difusividade, com estrutura cristalina do tipo fluorita. Segundo os resultados obtidos, o fenômeno é mais bem caracterizado como uma concorrência entre formação e eliminação de poros durante a sinterização do que como um bloqueio da sinterização.

3. A transformação de fase do $\mathrm{Gd}_{2} \mathrm{O}_{3}$ que ocorre a aproximadamente $1260{ }^{\circ} \mathrm{C}$, passando da forma $\mathrm{C}$ cúbica de corpo centrado para a forma $\mathrm{B}$ monoclinica, não afeta $\mathrm{o}$ comportamento da sinterização do sistema $\mathrm{UO}_{2}-\mathrm{Gd}_{2} \mathrm{O}_{3}$. 
4. Foi observado experimentalmente que o aumento da taxa de aquecimento no ciclo de sinterização e a diminuição da atividade do pó de $\mathrm{UO}_{2}$ exercem uma influência positiva no processo de densificação. Esse comportamento está em acordo com o mecanismo demonstrado neste trabalho e, mantendo-se o método de mistura mecânica a seco para a incorporação de $\mathrm{Gd}_{2} \mathrm{O}_{3}$, essas observações direcionam possíveis ações de ajuste nos procedimentos de fabricação para minimização dos efeitos do mecanismo e, portanto, para otimização da densidade final das pastilhas $\mathrm{UO}_{2}-\mathrm{Gd}_{2} \mathrm{O}_{3}$ sinterizadas, a saber:

a) utilização da taxa de aquecimento no ciclo de sinterização a mais alta aplicável tecnologicamente, a ser definida com base na microestrura resultante da pastilha sinterizada. É recomendada uma taxa de aquecimento superior a $30^{\circ} \mathrm{C} /$ minuto;

b) utilização de um pó de $\mathrm{UO}_{2}$ com atividade ajustada de tal forma que o início da densificação seja retardado sem comprometer a densificação nos estágios finais do processo de sinterização, mantendo-se uma reserva de atividade para a sinterização em altas temperaturas. A superficie específica pode ser controlada por meio do ajuste das condições de redução do pó de TCAU precursor. A superficie específica ideal não foi precisamente determinada neste trabalho, mas deve estar situada na faixa entre $4 \mathrm{~m}^{2} / \mathrm{g}$ e $5 \mathrm{~m}^{2} / \mathrm{g}$;

c) aumento da temperatura de sinterização para $1750^{\circ} \mathrm{C}$, que é a temperatura de sinterização usualmente adotada no processo de fabricação do combustível $\mathrm{UO}_{2}$ a partir da tecnologia do TCAU;

d) aumento do tempo de sinterização para maximização da densificação na etapa isotérmica da sinterização, utilizando-se ao máximo a reserva de atividade mencionada no item $b$.

Provavelmente, uma combinação dos ajustes nos parâmetros de sinterização e do ajuste na atividade do pó de $\mathrm{UO}_{2}$ irão resultar na obtenção de pastilhas $\mathrm{UO}_{2}-\mathrm{Gd}_{2} \mathrm{O}_{3}$ com a mínima densidade requerida pela especificação. Contudo, um trabalho complementar com esse objetivo específico ainda deve ser realizado.

5. Finalmente, os resultados experimentais demonstraram que a causa primária da insuficiente densificação observada no sistema $\mathrm{UO}_{2}-\mathrm{Gd}_{2} \mathrm{O}_{3}$ é a má qualidade da homogeneidade da distribuição de $\mathrm{Gd}_{2} \mathrm{O}_{3}$ no pó misto preparado pela técnica de 
mistura mecânica a seco, da qual o mecanismo de formação de poros estáveis é conseqüência. Umạ vez conhecido o mecanismo que explica o comportamento da sinterização do sistema $\mathrm{UO}_{2}-\mathrm{Gd}_{2} \mathrm{O}_{3}$, e sua causa primária, pode-se também concluir que o desenvolvimento de técnicas alternativas de homogeneização, em conjunto com a utilização de pó de $\mathrm{Gd}_{2} \mathrm{O}_{3}$ com características especiais, provavelmente permitiriam a obtenção de pastilhas $\mathrm{UO}_{2}-\mathrm{Gd}_{2} \mathrm{O}_{3}$ com a densidade mínima especificada. Porém, um trabalho específico nessa área ainda deve ser conduzido. 


\section{PROPOSTAS PARA TRABALHOS FUTUROS}

Os estudos efetuados neste trabalho e as observações experimentais permitem a proposição de trabalhos adicionais, de caráter científico e tecnológico, que ampliariam o conhecimento do sistema $\mathrm{UO}_{2}-\mathrm{Gd}_{2} \mathrm{O}_{3}$ e poderiam ser valiosas contribuições para a tecnologia de fabricação deste tipo de combustivel nuclear, cuja utilização nos dias de hoje é tão importante sob o ponto de vista econômico e estratégico.

1. Quase nenhuma informação sobre fases no sistema U-Gd-O está disponível na literatura. É proposto um estudo sistemático desse sistema, identificando-se e caracterizando-se as fases existentes. Como a primeira etapa desse estudo, propõese a complementação dos estudos realizados neste trabalho, incluindo a análise microestrutural de pastilhas sinterizadas obtidas a partir de pós preparados por coprecipitação e a aplicação do método de Rietveld para a análise dos perfis de difração de raios- $\mathrm{X}$ derivados dessas pastilhas.

2. Complementação dos estudos de interdifusão preliminares realizados neste trabalho, buscando a determinação dos coeficientes de interdifusão com maior exatidão e precisão, em função da concentração de gadolinio, determinando-se a influência dessa concentração na magnitude do efeito Kirkendall. Esses estudos, em conjunto com os estudos da cinética de formação da solução sólida e cinética de sinterização, também propostos, permitiriam desenvolver um modelo do mecanismo, o que possibilitaria o desenvolvimento de um ciclo de sinterização otimizado.

3. Estudar um método alternativo de incorporação do pó de $\mathrm{Gd}_{2} \mathrm{O}_{3}$ com o objetivo de atingir-se o nível microscópico de homogeneidade. Propõe-se o método de homogeneização em fase líquida, no qual o pó de $\mathrm{Gd}_{2} \mathrm{O}_{3}$ é incorporado na suspensão de TCAU antes da filtração. O objetivo é obter-se uma dispersão de partículas individuais de $\mathrm{Gd}_{2} \mathrm{O}_{3}$ no pó de $\mathrm{UO}_{2}$, após a redução. Como o tamanho médio dessas partículas é de apenas $2,5 \mu \mathrm{m}$, os poros formados devido ao efeito Kirkendall podem ser suficientemente pequenos para serem eliminados após a sua formação, no processo subseqüente de sinterização.

4. Estudar a substituição do pó de $\mathrm{Gd}_{2} \mathrm{O}_{3}$ comercial, utilizado neste trabalho, por pó de $\mathrm{Gd}_{2} \mathrm{O}_{3}$ ultrafino com pouca tendência à aglomeração, incorporado ao combustivel $\mathrm{UO}_{2}$ na forma de mistura mecânica de pós e em fase líquida, como descrito no trabalho proposto no item anterior. Isso provavelmente resultará num impacto muito positivo no comportamento da sinterização do sistema $\mathrm{UO}_{2}-\mathrm{Gd}_{2} \mathrm{O}_{3}$. 


\section{REFERÊNCIAS BIBLIOGRÁFICAS}

1 - ANDERSON, W. K.; THEILACKER, J. S. Neutron absorber materials for reactor control. Naval Reactors Handbooks. USAEC, Washington, DC. 1962.

2 - MURGATROYD, R. A; KELLY, B. T. Technology and assessment of neutron absorbing materials. Atomic Energy Review, vol. 15, n. 1, 1977.

3 - STRASSER, A. A.; SHEPPARD, K. D. Light water reactor reactivity control. Nucl. Energy, v. 23, n. 3, p. 169-178, 1984.

4 - RADFORD, K. C.; ARGALL, B. M; KELLER, H. W; GOODSPEED, R. C. Fabrication, development and application of an annular $\mathrm{Al}_{2} \mathrm{O}_{3}-\mathrm{B}_{4} \mathrm{C}$ burnable absorber. Nucl. Technology, v. 60, p.344-351, 1983.

5 - INTERNATIONAL ATOMIC ENERGY AGENCY. Water reactor fuel extended burnup study. Technical reports series, v. 343. Vienna, Austria: IAEA, 1992.

6 - BARRE, B. The future of nuclear energy in the world. Journal of Alloys and Compounds, v. 271, p. 1-5, 1998.

7 - COCHRAN, R. G.; TSOULFANIDIS, N. The nuclear fuel cycle: analysis and management. La Grange Park, Ill: American Nuclear Society, 1992.

8 - MÄRKL, H.; HOLZER, R. Advanced core and fuel design for light water reactors. Kerntechnik, v. 50, n. 4, p. 241-248, 1987.

9 - DOSHI, P. K ; CHAPIN, D. L.; SCHERPEREEL, L. R. Westinghouse VANTAGE+ fuel assembly to meet future PWR operating requirements. Trans. Am. Nucl. Soc, v. 56 , p. $118-119,1988$.

10 - INTERNATIONAL ATOMIC ENERGY AGENCY. Nuclear power reactors in the world. Reference Data Series, n. 2. Vienna, Austria: IAEA, 1997.

11 - INTERNATIONAL ATOMIC ENERGY AGENCY. Characteristics and use of urania-gadolinia fuels. Relatório IAEA-TECDOC-844. Vienna, Austria: IAEA, 1995. 
12 - $\mathrm{HOVE}, \mathrm{C} . \mathrm{M}$. Use of $\mathrm{UO}_{2}-\mathrm{Gd}_{2} \mathrm{O}_{3}$ in very low leakage, extended burnup fuel cycles. Trans. Am. Nucl. Soc., v. 50, p. 555-555, 1985.

13 - ROTHLEDER, B. M. Feasibility of using gadolinium as a burnable poison in PWR cores. Relatório EPRI NP-1663. Electric Power Research Institute, 1981.

14 - BÖHM, W.; KIEHLMANN, H. D. $\mathrm{UO}_{2}-\mathrm{Gd}_{2} \mathrm{O}_{3}$ burnable poison reactivity control in PWRs. Trans. Am. Nucl. Soc., v. 40, p. 185-188, 1982.

15 - GOLDSTEIN, L.; STRASSER, A. A. A comparasion of gadolinia and boron for burnable poison applications in pressurized water reactors. Nucl. Technology, v.60, p. 352-361, 1983.

16 - ROTHLEDER, B. M.; EICH, W. J. Use of godolinium in PWR cores for reactivity parameter and power distribution control. Trans. Am. Nucl. Soc., v. 41, p. 596-597, 1982.

17 - ROTHLEDER, B. M. Reduction of moderator temperature coefficient by gadolinium substitution for PWR application. Trans. Am. Nucl. Soc., v. 39, p. 616-618, 1981.

18 - GALPERIN, A.; SEGEV, M.; RADKOWSKY A. Substitution of the soluble boron reactivity control system of a pressurized water reactor by gadolinium burnable poisons. Nucl. Technology, v.75, p. 127-133, 1986.

19 - CRUMP, M. W.; HARRIS, R. P.; JONSSON, A.; LORETZ, R. A.; MATZIE, R. A.; REC, J. R. Modeling features in the analysis of gadolinia-bearing fuel. Trans. Am. Nucl. Soc., v. 41, p. 593-594, 1982.

20 - CHAUCHEPRAT, P.; MARTIN-DEIDIER, L.; SANTAMARINA, A.; DOUTRIAUX, D.; ROSHD, M.; ZERO, S. GEDEON 1: a benchmark experiment for the $\mathrm{UO}_{2}-\mathrm{Gd}_{2} \mathrm{O}_{3}$ depletion in PWR assemblies. Trans. Am. Nucl. Soc, v. 47, p. $418-$ 420,1984

21 - DO, Q. Q.; DOUTRIAUX, D.; ZERO, S. GEDEON 1: a first interpretation of a benchmark experiment for $\mathrm{UO}_{2}-\mathrm{Gd}_{2} \mathrm{O}_{3}$ depletion in PWR assemblies. Trans. Am. Nucl. Soc., v. 50, p. 560-562, 1985. 
22 - CHAUCHEPRAT, P.; MARTIN-DEIDIER, L.; SANTAMARINA, A.; DO, Q. Q.; DOUTRIAUX, D.; ZERO, S. GEDEON II: a benchmark experiment for $\mathrm{UO}_{2}-\mathrm{Gd}_{2} \mathrm{O}_{3}$ depletion in realistic PWR designs. Trans. Am. Nucl. Soc., v. 52, p. 651-652, 1986.

23 - BÖHM, W.; KIEHLMANN, H. D.; NEUFERT, A.; PEEHS, M. $\mathrm{Gd}_{2} \mathrm{O}_{3}$ up to 9 weight percent, na established burnable poison for advanced fuel management in pressurized water reactors. Kerntechnik, v. 50, n. 4, p. 234-240, 1987.

24 - STOUT, R. B.; SOFER, G. A. Experience with gadolinia burnable absorbers in light water reactors. Trans. Am. Nucl. Soc., v. 39, p. 401-402, 1981.

25 - STOGEN, F. B.; NIELSEN, L. A.; GRUMMER, R. G. Operating experience with Exxon nuclear-supplied gadolinia in pressurized water reactors. Trans. Am. Nucl. Soc., v. 40, p. 194-198, 1982.

26 - ROTHLEDER, B. M.; EICH, W. J. Global effects of axially zoned gadolinium in PWR cores. Trans. Am. Nucl. Soc., v. 35, p. 97-99, 1980.

27 - LINDELÖW, U.; BERNANDER, O.; OEHMAN, L.; LINDNER, J. Asea-Atom advanced PWR reload fuel assembly design. Nuclear Europe, v. 5, p. 16-19, 1985.

28 - DRUMM, C. R.; LEE, J. C. Gadolinium burnable absorber optimization by the method of conjugate gradients. Nucl. Sci. Engineering, v. 96, p. 17-29, 1987.

29 - HIDA, K.; YOSHIOKA, R. Optimization of axial enrichment and gadolinia distributions for BWR fuel under control rod programing. J. Nucl. Sci. Technol., v. 29, n. 4, p. 313-324, 1992.

30 - COLLETE, C.; FRANCILLON, G.; OBADIA, F. Operating experience of the Fragema gadolinia bearing fuel assembly. In: IMPROVEMENTS IN WATER REACTOR FUEL TECHNOLOGY AND UTILIZATION. PROCEEDINGS OF INTERNATIONAL SYMPOSIUM, 15-19 September, 1986, Stockholm. Anais... Vienna: IAEA, 1987. 621 p. p. 255-269. (IAEA-SM-288/6)

31 - SECKER, J. R.; ERWIN, R. D. $\mathrm{ZrB}_{2}$ : the optimun integral fuel burnable absorber for PWRs. Trans. Am. Nucl. Soc., v. 62, p. 555-556, 1990. 
32 - SIMMONS, R. L.; JONES, N. D.; POPA, F. D.; MUELLER, D. E.; PRITCHETT, J. E. Integral fuel burnable absorbers with $\mathrm{ZrB}_{2}$ in pressurized water reactors. Nucl. Technology, v. 80, p. 343-348, 1988

33 - PRITCHET, J. E.; MUELLER, D. E. Operational experience with $\mathrm{ZrB}_{2}$ integral fuel burnable absorbers. Trans. Am. Nucl. Soc., v. 55, p. 117-118, 1987.

34 - SRINILTA, S.; SCHMIDT, R. F.; PRITCHETT, J. E. A comparison of gadolinium and $\mathrm{ZrB}_{2}$ as integral burnable absorbers in PWRs. Trans. Am. Nucl. Soc., v. 55, p 124-126, 1987.

35-JONSSON, A. Initial physics evaluation of erbium as burnable absorber in a PWR. Trans. Am. Nucl. Soc., v. 61, p. 340-341, 1990.

36 - GAVIN, P. H; Jonsson, A; SWOOPE, S.; CHANG, R. Y.; THOMSEN, O. J. Lead test fuel assembly physics for erbium fuel at San Onofre nuclear generating station. Trans. Am. Nucl. Soc., v. 68, part A, p. 443-445, 1993.

37 - ASOU, M; PORTA, J. Prospects for poisoning reactor cores of the future. Nucl. Eng. Design, v.168, p. 261-270, 1997.

38 - JONSSON, A. Comparison of the relative importance of constraints in the design of burnable absorbers for 17 X 17 PWR fuel in a 18-month cycle. Trans. Am. Nucl. Soc., v. 75, p. 355-356, 1996.

39 - CACCIAPOUTI, R. J.; WEADER, R. J.; MALONE, J. P. PWR burnable absorber evaluation. Nucl. Energy, v. 34, n. 5, p. 303-305, 1995

40 - HO, S. M.; RADFORD, K. C. Structural chemistry of solid solutions in the $\mathrm{UO}_{2}$ $\mathrm{Gd}_{2} \mathrm{O}_{3}$ system. Nucl. Technology, v. 73, p. 350-360, 1986.

41 - KEMPTER, C. P.; ELLIOTT, R. O. Thermal expantion of $\mathrm{UN}, \mathrm{UO}_{2}, \mathrm{UO}_{2}$. $\mathrm{ThO}_{2}$, and $\mathrm{ThO}_{2}$. J. Chem. Phys., v. 30, n. 6, p. 1524-1526, 1959

42 - LYNDS, L. Preparation of stoichiometric $\mathrm{UO}_{2}$ by thermal decomposition of $\mathrm{UO}_{2} \mathrm{I}_{2}$. J. Inorg. Nucl. Chem., v. 24, p. 1007-1020, 1962

43 - GRONVOLD, F. High-temperature x-ray study of uranium oxides in the $\mathrm{UO}_{2}-\mathrm{U}_{3} \mathrm{O}_{8}$ region. J. Inorg. Nucl. Chem., v. 1, p. 357-370, 1955. 
44 - INTERNATIONAL ATOMIC ENERGY AGENCY. Thermodynamic and transport properties of uranium dioxide and related phases. Technical reports series, v. 39. Vienna, Austria: IAEA, 1965.

45 - LITTLECHILD, J. E.; BUTLER, G. G.; LESTER, G. W. The production of burnable poison oxide fuel. In: NUCLEAR FUEL PERFORMANCE. PROCEEDINGS OF INTERNATIONAL CONFERENCE, 15-19 October, 1973, London. Anais... London: The British Nuclear Energy Society, 1973. p. 65.1-65.4.

46 - MANZEL, R.; DÖRR, W. O. Manufacturing and irradiation experience with $\mathrm{UO}_{2} / \mathrm{Gd}_{2} \mathrm{O}_{3}$ fuel. Am. Ceram. Soc. Bull., v. 59, n. 6, p. 601-603, 1980.

47 - FUKUSHIMA, S.; OHMICHI, T.; MAEDA, A.; WATANABE, H. The effect of gadolinium content on the thermal conductivity of near-stoichiometric (U, Gd) $\mathrm{O}_{2}$ solid solutions. J. Nucl. Mater., v. 105, p. 201-210, 1982.

48 - OHMICHI, T.; FUKUSHIMA, S.; MAEDA, A.; WATANABE, H. On the relation between lattice parameter and $\mathrm{O} / \mathrm{M}$ ratio for uranium dioxide-trivalente rare earth oxide solid solution. J. Nucl. Mater., v. 102, p. 40-46, 1981.

49 - BEALS, R. J.; HANDWERK, J. H. Solid solutions in the system urania-rare-earth oxides: I, $\mathrm{UO}_{2}-\mathrm{GdO}_{1.5}$. J. Am. Ceram. Soc., v.48, n. 5, p. 271-274, 1965.

50 - ARGONNE NATIONAL LABORATOY. Annual report for 1963. Metallurgy Division. Argonne, Ill. 1963. p.158-161. (ANL-6868)

51 - UNE, K; OGUMA, M. Thermodynamic properties of nonstoichiometric uraniagadolinia solid solutions in the temperature range $700-1100^{\circ} \mathrm{C}$. J. Nucl. Mater, v. 110, p. $215-222,1982$.

52 - WADA, T; NORO, K; TSUKUT, K. Behaviour of $\mathrm{UO}_{2}-\mathrm{Gd}_{2} \mathrm{O}_{3}$ fuel. In: NUCLEAR FUEL PERFORMANCE. PROCEEDINGS OF INTERNATIONAL CONFERENCE, 15-19 October, 1973, London. Anais... London: The British Nuclear Energy Society, 1973. p. 63.1-63.3.

53 - SALOMON, V. A. A.; SABIONI, A. C. S.; BRITO, W.; FERRAZ, W. B. Determinação do parâmetro de rede da solução sólida $\mathrm{U}_{1-\mathrm{x}} \mathrm{Gd}_{\mathrm{x}} \mathrm{O}_{2}(\mathrm{x} \leq 0,21)$. In: VI CGEN. CONGRESSO GERAL DE ENERGIA NUCLEAR, 27 out.- 1 nov. 1996, Rio de Janeiro. Anais... Associação Brasileira de Energia Nuclear, 1996. pp. 5.17. 
54 - CHOTARD, A; MELIN, P.; BRUET, M.; FRANÇOIS, B. Out of pile physical properties and in pile thermal conductivity of $(\mathrm{U}, \mathrm{Gd}) \mathrm{O}_{2}$. In: PROPERTIES OF MATERIALS FOR WATER REACTOR FUEL ELEMENTS AND METHODS OF MEASUREMENT. PROCEEDINGS OF A TECHNICAL COMMITTEE MEETING, 13-16 October, 1986, Vienna. Anais... Vienna: IAEA, 1987. p. 77-87. (IWGFPT/26)

55 - MIYAKE, C.; KANAMARU, M.; IMOTO, S. X-Ray photoelectron spectroscopy of $\mathrm{U}_{1-\mathrm{x}} \mathrm{Gd}_{\mathrm{x}} \mathrm{O}_{2}$ solid solution. J. Nucl. Mater., v. 138, p. 36-39, 1986.

56 - SHANNON, R. D. Revised effective ionic radii and systematic studies of interatomic distances in halides and chalcogenides. Acta Cryst., v. A32, p. 751-767, 1976.

57 - BEALS, R. J.; HANDWERK, J. H.; WRONA, B. J. Behavior of urania-rare-earth oxides at high temperatures. J. Am. Ceram. Soc., v. 52, n. 11, p. 578-581, 1969.

58 - AITKEN, E. A.; BARTRAM, S. F.; JUENKE, E. F. Crystal chemistry of the rhombohedral $\mathrm{MO}_{3} .3 \mathrm{R}_{2} \mathrm{O}_{3}$ compounds. Inorg. Chem., v. 3, n. 7, p. 949-954, 1964.

59 - CHASE, G. A. On the existence of a compound in the system yttrium-uraniumoxygen. Acta Cryst., v. 15, p. 91, 1962.

60 - STADLBAUER, E.; WICHMANN, U.; LOTT, U.; KELLER, C. Thermodinamics and phase relationships of the ternary lanthanum-uranium-oxigen system. J. Solid State Chem., v. 10, p. 341-350, 1974.

61 - TAGAWA, H.; FUJINO, T.; OUCHI, K.; WATANABE, K.; SAITA, K.; MORIMOTO, T. Oxidation-reduction properties of mixed oxides in lanthanumuranium-oxigen system. J. Nucl. Science Technology, v. 20, n. 6, p. 467-474, 1983.

62 - HINATSU, Y.; MASAKI, N.; FUJINO, T. The crystal structure of $\mathrm{La}_{6} \mathrm{UO}_{12}$. J. Solid State Chem., v. 73, p. 567-571, 1988.

63 - BERNDT, U.; TANAMAS, R.; KELLER, C. Ternary $\mathrm{UO}_{2}-\mathrm{UO}_{3}-\mathrm{EuO}_{1,5}(\mathrm{EuO})$ system and investigation of Eu(II)-actinide(IV)-perovskites. J. Solid State Chem., v. 17, p. 113-120, 1976.

64 - FUJINO, T; OUCHI, K.; MOZUMI, Y.; UEDA, R.; TAGAWA, H. Composition and oxygen potential of cubic fluorite-type solid solution $\mathrm{Eu}_{\mathrm{y}} \mathrm{U}_{1-\mathrm{y}} \mathrm{O}_{2+\mathrm{x}}(\mathrm{x}>=<0)$ and rhombohedral Eu $\mathrm{UO}_{12+\mathrm{x}}\left(\mathrm{x}^{\prime}<0\right)$. J. Nucl. Mater., v. 174, p. 92-101, 1990. 
65 - WICHMANN, U.; BERNDT, U.; KELLER, C. Phase equilibria and thermodinamic data for the ternary $\mathrm{UO}_{2}-\mathrm{UO}_{3}-\mathrm{REO}_{1,5}(\mathrm{Ho}, \mathrm{Tm}, \mathrm{Lu})$ systems. Rev. Chim. Miner., v. 14, p. $105-118,1977$.

66 - WADIER, J. F. Diagramme de phases et proprietes thermodynamiques du systeme uranium-neodyme-oxygene. These presentee a l'Úniversite Paris VI pour obtenir le grade de Docteur es Sciences Physiques. Commissariat a L'Energie Atomique. CEAR-4507. 1973.

67 - PEEHS, M.; DÖRR, W.; GRADEL, G.; MAIER, G. Zur wärmeleitfähigkeit und plastizität von $\mathrm{UO}_{2}$ mit Gd-zusätzen. J. Nucl. Mater., v. 106, p. 221-230, 1982.

68 - ASSMANN, H; PEEHS, M; ROEPENACK, H. Survey of binary oxide fuel manufacturing and quality control. J. Nucl. Mater., v. 153, p. 115-126, 1988.

69 - BARTRAM, S. F.; FITZSIMMONS, E. S. Studies on a new ordered oxide of uranium and yttrium. J. Nucl. Mater., v. 35, p. 126-130, 1970.

70 - GROSSMAN, L. N.; PACKARD, D. R.; HILL, H. W. (U,Gd)O $\mathrm{O}_{2}$ phase equilibria at high temperatures. Colloques Internationaux C.N.R.S., n. 205, p. 453-458. Paris, 1972.

71 - UNE, K; OGUMA, M. Oxygen potentials of $(\mathrm{U}, \mathrm{Gd}) \mathrm{O}_{2 \pm \mathrm{x}}$ solid solutions in the temperature range $1000-1500^{\circ} \mathrm{C}$. J. Nucl. Mater., v. 115, p. 84-90, 1983.

72 - UNE, K; OGUMA, M. Oxygen potential of $\mathrm{U}_{0,96} \mathrm{Gd}_{0,04} \mathrm{O}_{2}\left(\mathrm{UO}_{2}-3 w t \% \mathrm{Gd}_{2} \mathrm{O}_{3}\right)$ solid solution. J. Nucl. Mater., v. 131, p. 88-91, 1985.

73 - THORNTON, T. A.; EWANICH, J. A.; LAGEDROST, J. F.; ELDRIDGE, E. A. Thermal conductivity of sintered urania-gadolinia. Trans. Am. Nucl. Soc., v. 43, p. 348-349, 1982.

74 - PRESTON, S. D.; BARRET, C.; FASSINA, P.; MILLS, K. C.; ZAGHINI, N. Thermal diffusivities and thermal conductivities of $\mathrm{UO}_{2}$ and $\mathrm{U}_{1-\mathrm{x}} \mathrm{Gd}_{\mathrm{x}} \mathrm{O}_{2}$ solid solutions. High Temperatures-High Pressures, v. 21, n. 3, p. 287-295, 1989.

75 - HIRAI, M; ISHIMOTO, S. Thermal diffusivities and thermal contutivities of $\mathrm{UO}_{2}$ $\mathrm{Gd}_{2} \mathrm{O}_{3}$. J. Nucl. Science Technology, v. 28, n. 11, p. 995-1000, 1991. 
76 - UNE, K. Thermal expansion of $\mathrm{UO}_{2}-\mathrm{Gd}_{2} \mathrm{O}_{3}$ fuel pellets. J. Nucl. Science Technology, v. 23, n. 11, p. 1020-1022, 1986.

77 - AMAYA, M.; HIRAI, M. The effects of oxidation on the thermal conductivity of $(\mathrm{U}, \mathrm{M}) \mathrm{O}_{2}$ pellets (M=Gd and/or simulated soluble FPs). J. Nucl. Mater., v. 246, p. 158-164, 1997.

78 - INABA, H.; NAITO, K; OGUMA, M. Heat capacity measurement of $\mathrm{U}_{1-\mathrm{y}} \mathrm{Gd}_{\mathrm{y}} \mathrm{O}_{2}$ $(0.00 \leq \mathrm{y} \leq 0.142)$ from 310 to 1500 K. J. Nucl. Mater., v. 149, p. 341-348, 1987.

79 - MILLS, K. C.; PONSFORD, F. H.; RICHARDSON, M. J.; ZAGHINI, N.; FASSINA, P. Heat-capacity and entalphy of $\mathrm{UO}_{2}$ and gadolinia-doped $\mathrm{UO}_{2}$. Thermoch. Acta, v. 139, p. 107-120, 1989.

80 - YAMANOUCHI, S.; TACHIBANA, T.; TSUKUI, K.; OGUMA, M. Melting temperature of irradiated $\mathrm{UO}_{2}$ and $\mathrm{UO}_{2}-2 \mathrm{wt} \% \mathrm{Gd}_{2} \mathrm{O}_{3}$ fuel pellets up to burnup of about $30 \mathrm{GWd} / \mathrm{tU}$. J. Nucl. Science Technology, v. 25, n. 6, p. 528-533, 1988.

81 - BLANPAIN, P.; HAAS, D.; MOTTE, F. High rated and high burnup gadolinia fuel irradiated in the BR3 17 x 17 PWR. In: IMPROVEMENTS IN WATER REACTOR FUEL TECHNOLOGY AND UTILIZATION. PROCEEDINGS OF INTERNATIONAL SYMPOSIUM, 15-19 September, 1986, Stockholm. Anais... Vienna: IAEA, 1987.621 p. p. 305-317. (IAEA-SM-288/40)

82 - SKOGEN, F. B.; VAN SWAM, L. F. B. High burnup, high gadolinia content fuel for PWRs. In: FUEL ELEMENTS AND NUCLEAR MATERIALS. PROCEEDINGS OF ANNUAL MEETING ON NUCLEAR TECHNOLOGY ‘87, 2-4 June, 1987, Karlsruhe. Anais.. 829 p. p. 507-510.

83 - SKOGEN, F. B.; KEMPF, F. J. Advanced nuclear fuels corporation's achievements with gadolinia integral burnable absorbers. Trans. Am. Nucl. Soc., v. 57, p. 36, 1988.

84 - ASSMANN, H. Überblick über zusammenhänge zwischen LWR-BrennstoffEigenschaften und verfahrensabläufen bei der brennstoffproduktion. J. Nucl. Mater., v. 106, p. $15-33,1982$. 
85 - ASSMANN, H.; DÖRR, W. Microstructure and density of $\mathrm{UO}_{2}$ pellets for light water reactors as related to powder properties. Materials Science Monographs, n. 16, Ceramic Powders. Elsevier Scientific Publishing Company, Amsterdan. 1983. p. 707718 .

86 - BRANDBERG, S. G. The conversion of uranium hexafluoride to uranium dioxide. Nucl. Technology, v. 18, p. 177-184, 1973.

87 - HAAS, P. A. A comparasion of process for the conversion of uranyl nitrate into ceramic-grade $\mathrm{UO}_{2}$. Nucl. Technology, v. 81, p. 393-406, 1988.

88 - PLÖGER, F.; VIETZKE, H. Gewinnung von kernbrennstoffen. Chemie Ing. Techn., v. 37, n. 7, p. 692-699, 1965.

89 - MATHIEU, V. $\mathrm{UO}_{2}$ fuel fabrication by means of the AUC powder process. Trans. Am. Nucl. Soc., v. 28, p. 327-328, 1978.

90 - ASSMANN, H.; BECKER, M. Technology of $\mathrm{UO}_{2}$ fuel fabrication by the AUC powder process. Trans. Am. Nucl. Soc., v. 31, p. 147-148, 1979.

91 - KNUDSEN, I. E.; LEVITZ, N. M.; JONKE, A. A. Engineering development of fluid-bed fluoride volatility processes. Part 6: Preparation of dense uranium dioxide particles from uranium hexafluoride ia a fluidized bed. Argonne National Laboratory, Chemical Engineering Division. Argonne, Illinois. 1964. (ANL-6902)

92 - RADFORD, K. C.; LYON, W. L.; HART, J. E. Fluid-bed conversion of $\mathrm{UF}_{6}$ to $\mathrm{UO}_{2}$. Am. Ceram. Soc. Bull., v. 58, n. 2, p. 219-222,232, 1979.

93 - COLTER, J. C.; JAMES, D. B.; KEITH, W. G.; AKBARI-KENARI, R. Process for producing uranium oxide rich compositions from uranium hexafluoride using fluid injection into the reaction zone. United States Patent 4.031.029. June, 1977.

94 - HEAL, T. J.; LITTLECHILD, J. E. Fabrication of $\mathrm{UO}_{2}$ powder and pellets (IDR process). Trans. Am. Nucl. Soc, v. 28, p. 326-327, 1978.

95 - INTERNATIONAL ATOMIC ENERGY AGENCY. Guidebook on quality control of mixed oxides and gadolinium bearing fuels for light water reactors. Relatório LAEATECDOC-584. Vienna, Austria: IAEA, 1991. 
96 - HÄLLDAHL, L.; ERIKSSON, S. Characterization of homogeneity in (U, Gd)O pellets. J. Nucl. Mater., v. 153, p. 66-70, 1988.

97 - MIYAKE, C.; KANAMARU, M.; IMOTO, S. Formation of a solud solution of $\mathrm{U}_{1-\mathrm{x}} \mathrm{Gd}_{\mathrm{x}} \mathrm{O}_{2}$ by a co-precipitation method. J. Nucl. Mater., v. 138, p. 142-144, 1986.

98 - MIYAKE, C.; KANAMARU, M; IMOTO, S. Microcharacterization of gadolinium in $\mathrm{U}_{1-\mathrm{x}} \mathrm{Gd}_{\mathrm{x}} \mathrm{O}_{2}$ by means of electron spin resonance. J. Nucl. Mater., v. 137, p. $256-$ $260,1986$.

99 - TURNER, C. W. Sol-gel process - principles and applications. Am. Ceram. Soc. Bull., v. 70, n. 9, p. 1487-1490, 1991.

100 - HAAS, P. A.; CLINTON, S. D.; KLEINSTEUBER, A. T. Preparation of urania and urania-zirconia microspheres by a sol-gel process. Can. J. Chem. Eng., v. 44, p. 348-353, 1966.

101 - GANGULY, C.; BASAK, U. Fabrication of high density $\mathrm{UO}_{2}$ fuel pellets involving sol-gel microsphere pelletisation and low temperature sintering. J. Nucl. Mater., v. 178, p. $179-183,1991$.

102 - RINGEL, H. D.; ZIMMER, E. The external gelation of thorium process for preparation of $\mathrm{ThO}_{2}$ and $(\mathrm{Th}, \mathrm{U}) \mathrm{O}_{2}$ fuel kernels. Nucl. Technology, v. 45, p. 287 $298,1979$.

103 - NAEFE, P.; ZIMMER, E. Preparation of uranium kernels by na external gelation process. Nucl. Technology, v. 42, p. 163-171, 1979.

104 - YAMAGISHI, S.; TAKAHASHI, Y. Sol-gel method using carbon tetrachloride as drop-formation medium for producing large $\mathrm{ThO}_{2}$-base microspheres. J. Nucl. Science Technology, v. 22, n. 12, p. 995-1000, 1985.

105 - ZIMMER, E.; NAEFE, P.; RINGEL, H. Continuous working process for the production of $\mathrm{ThO}_{2}$ and $(\mathrm{Th}, \mathrm{U}) \mathrm{O}_{2}$ fuel kernels. Trans. Am. Nucl. Soc., v. 20, p. 591$593,1975$.

106 - MATTHEWS, R. B; HART, P. E. Nuclear fuel pellets fabricated from gel-derived microspheres. J. Nucl. Mater., v. 92, p. 207-216, 1980. 
107 - ZIMMER, E.; GANGULY, C.; BORCHARDT, J.; LANGEN, H. SGMP-na advanced method for fabrication of $\mathrm{UO}_{2}$ and MOX fuel pellets. $J$. Nucl. Mater., v. 152, p. 169-177, 1988.

108 - GÜNDÜZ, G.; USLU, I. Powder characteristics and microstructure of uranium dioxide and uranium dioxide - gadolinium oxide fuel. J. Nucl. Mater., v. 231, p. 113-120, 1996.

109 - GÜNDÜZ, G.; USLU, I.; ÖNAL, I.; DURMAZUÇAR, H. H.; ÖZTÜRK, T.; AKSIT, A. A.; KOPUZ, B.; CAN, F.; CAN, S.; UZMEN, R. Effects of different parameters on the densities of uranium dioxide and uranium dioxide- gadolinium oxide fuels produced by the sol-gel technique. Nucl. Technology, v. 111, p. 63-69, 1995.

110 - GERMAN, R. M. Sintering theory and practice. New York, NY. John Wiley \& Sons, 1996.

111 - MOHAN, A.; SONI, N. C.; MOORTHY, V. K. Mechanisms of sintering. Trans. Indian Institute of Metals, v. 33, n. 6, p.423-430, 1980.

112 - FOGAÇA FILHO, N. Estudo da sinterização de pós de $U_{3} O_{8}$ por dilatometria. São Paulo, 1977. Dissertação (Mestrado) - Escola Politécnica da Universidade de São Paulo.

113 - DAVIS, H.; POTTER, R. A. $\mathrm{UO}_{2}-\mathrm{Gd}_{2} \mathrm{O}_{3}$ sintering behavior. Mater. Sci. Res., v. 11, p. $515-524,1977$.

114 - AGUEDA, H. C.; HEREDIA, A. D.; AMAYA, D. C.; STERBA, M. E.; RUSSO, D. O. Efectos del oxido de gadolinio en la sinterizacion de dioxido de uranio. In: $5^{\text {th }}$ GENERAL CONGRESS ON NUCLEAR ENERGY. Associação Brasileira de Energia Nuclear; 28 Aug-2 Sep, 1994, Rio de Janeiro. Anais... v. 2, p. 567-571, 1994. (CONF-9408187)

115 - HIRAI, M. Thermal diffusivity of $\mathrm{UO}_{2}-\mathrm{Gd}_{2} \mathrm{O}_{3}$ pellets. $J$. Nucl. Mater., v. 173, p. 247-254, 1990.

116 - YUDA, R.; UNE, $\mathrm{K}$. Effect of sintering atmosphere on the densification of $\mathrm{UO}_{2}$ $\mathrm{Gd}_{2} \mathrm{O}_{3}$ compacts. J. Nucl. Mater., v. 178, p. 195-203, 1991. 
117 - DÖRR, W; GRADEL, G.; PEEHS, M. Process for preparing high-density oxidic nuclear-fuel bodies and apparatus for carrying out this process. European Patent 0 026 389. April, 1981.

118 - DÖRR, W; GRADEL, G.; PEEHS, M. Method for the manufacture of very dense oxidic nuclear fuel bodies. U. S. Patent 4,438,050. March, 1984.

119 - PEEHS, M.; ASSMANN, H.; MANZEL, R.; MATHIEU, V. Progress in oxidative sintering of $\mathrm{UO}_{2}$ fuel pellets (NIKUSI Process). In: IMPROVEMENTS IN WATER REACTOR FUEL TECHNOLOGY AND UTILIZATION. PROCEEDINGS OF INTERNATIONAL SYMPOSIUM, 15-19 September, 1986, Stockholm. Anais... Vienna: IAEA, 1987. 621 p. p. 481-491. (IAEA-SM-288/23)

120 - DÖRR, W; GRADEL, G.; PEEHS, M. Method for the manufacture of oxidic nuclear fuel sintered bodies. European Patent 0156018 . October, 1985.

121 - DÖRR, W; GRADEL, G.; PEEHS, M. Method for producing oxidic sintered nuclear fuel bodies. U. S. Patent 4,671,904. June, 1987.

122 - AMATO, I.; FACCHINI, A.; GERONTOPOULOS, P.; NERI, D.; BOCCALARI, M.; COGLIATI, G.; DALMASTRI, B.; DUSI, G. B.; FERRARI, S.; GABAGLIO, M.; GIAQUINTO, L.; LISCIA, A. Italian activities in the fuel manufacturing field. In: PEACEFUL USES OF ATOMIC ENERGY. PROCEEDINGS OF $4^{\text {th }}$ UNITED NATIONS INTERNATIONAL CONFERENCE, 6 September, 1971, Geneva. Anais... 1987. Paper 181. p. 225-243. (A/CONF.49/P--181)

123 - SCHÄFER, R.; MATHIEU, V.; GRADEL, G.; DÖRR, W.; PEEHS, M.; ASSMANN, $H$. Verfahren zum Herstellen von oxidischen Kernbrennstoffsinterkörpen. European Patent 0136 665. April, 1985.

124 - RIELLA, H. G.; DURAZZO, M.; HIRATA, M.; NOGUEIRA, R. A. $\mathrm{UO}_{2}-\mathrm{Gd}_{2} \mathrm{O}_{3}$ solid solution formation from wet and dry processes. J. Nucl. Mater., v. 178, p. 204211, 1991.

125 - DURAZZO, M.; RIELLA, H.G. Effect of mixed powder homogeneity on the $\mathrm{UO}_{2}$ $\mathrm{Gd}_{2} \mathrm{O}_{3}$ nuclear fuel sintering behavior. Key Eng. Materials, v. 189-191, p. 60-66, 2001. 
126 - SANTOS, L. R. Unidade piloto de obtenção do tricarbonato de amônio e uranilo. São Paulo, 1989. Dissertação (Mestrado) - Instituto de Pesquisas Energéticas e Nucleares.

127 - SABATO, S. F. Determinação espectrográfica de impurezas em urânio e seus compostos. São Paulo, 1989. Procedimentos de Análises Químicas - Instituto de Pesquisas Energéticas e Nucleares. (IPEN-QI-001)

128 - GRIGOLETTO, T. Determinação da concentração de urânio total por volumetria. São Paulo, 1989. Procedimentos de Análises Químicas - Instituto de Pesquisas Energéticas e Nucleares. (IPEN-QI-042)

129 - GRIGOLETTO, T. Determinação volumétrica da razão estequiométrica O/U nos óxidos de urânio $\mathrm{UO}_{2}$ e $\mathrm{U}_{3} \mathrm{O}_{8}$. São Paulo, 1989. Procedimentos de Análises Químicas - Instituto de Pesquisas Energéticas e Nucleares. (IPEN-QI-043)

130 - BUSTLLOS, J. O. W. V. Determinação de carbono em urânio metálico e nos óxidos $\mathrm{U}_{3} \mathrm{O}_{8}$ e $\mathrm{UO}_{2}$. São Paulo, 1989. Procedimentos de Análises Químicas Instituto de Pesquisas Energéticas e Nucleares. (IPEN-QI-024)

131 - BUSTILLOS, J. O. W. V. Determinação de hidrogênio, nitrogênio e oxigênio em compostos de urânio. São Paulo, 1989. Procedimentos de Análises Químicas Instituto de Pesquisas Energéticas e Nucleares. (IPEN-QI-025)

132 - GRIGOLETTO, T. Determinação dos ânions cloreto e fluoreto em compostos de urânio por eletrodos seletivos de ions. São Paulo, 1989. Procedimentos de Análises Químicas - Instituto de Pesquisas Energéticas e Nucleares. (IPEN-QI-049)

133 - FERREIRA, R. A. N.; MIRANDA, O.; REIS, S. C.; MANSUR, T. R.; ALENCAR, D. A; TERRA, J. L.; LAMEIRAS, F. S. Desenvolvimento de um equipamento para medição de superficie específica. . In: $34^{\text {th }}$ CONGRESSO BRASILEIRO DE CERÂMTCA. Associação Brasileira de Cerâmica, 20-23 Maio, 1990, Blumenau, SC. Anais.. v. II, p. 530-537, 1990.

134 - BRUNAUER, S.; EMMET, P. H.; TELLER, E. Adsorption of gases in multimolecular layers. J. Am. Chem. Soc., v.60, p. 309-321, 1938. 
135 - AMERICAN SOCIETY FOR TESTING AND MATERIALS. Standard methods for analysis of sintered gadolinium oxide - uranium dioxide pellets. Annual Book of ASTM Standards, v. 12.01, ASTM C 968-81.

136 - CARDOSO, P.E. Caracterização de materiais cerâmicos - Alguns métodos empregados no controle da qualidade de combustíveis nucleares. In: $30^{\circ}$ Congresso Brasileiro de Cerâmica. Anais... Rio de Janeiro, 20 a 23 Abril, 1986.

137 - REVINDRAN, P. V.; RAJAGOPALAN, K. V.; MATHUR, P. K. A feasibility study of the preparation of $(\mathrm{U}, \mathrm{Gd})_{3} \mathrm{O}_{8}$ solid solutions by thermal decomposition of coprecipitated carbonate mixtures. J. Nucl. Mater., v. 257, p. 189-193, 1998.

138 - HAMMERSCHMIDT, H.; SAIGER, S. Homogenitätsbestimmung an (U,Gd)O mischoxid-sinterkörpern. J. Nucl. Mater., v. 81, p. 153-158, 1979.

139 - DA SILVA, C. M. Coordenação de Caracterização de Materiais. Instituto de Pesquisas Energéticas e Nucleares. Comunicação Pessoal.

140 - INTERNATIONAL CENTER FOR DIFFRACTION DATA.Joint Committee of Powder Diffraction Standards. Gadolinium Oxide. $\mathrm{Gd}_{2} \mathrm{O}_{3}$. Card $\mathrm{N}^{\mathrm{o}} 12-474$.

141 - BEIS, A. Programme D'affinement de parametres de maille - Version 88.1. Laboratoire des Matériaux et du Génie Physique. Doado ao IPEN pelo Prof. M. Bochu. Institut National Polytéchnique. Grenoble, França.

142 - GSCHNEIDER Jr., K. A.; EYRING, L. Handbook on the physics and chemistry of rare earths. Non-Metallic Compounds - I, v. 3. North-Holand Physics Publishing, Amsterdam. 1979. p. 444.

143 - KANG, Z. C.; EYRING, L. A compositional and structural rationalization of the higher oxides of $\mathrm{Ce}, \mathrm{Pr}$, and $\mathrm{Tb}$. Journal of Alloys and Compounds, v. 249, p. 206$212,1997$.

144 - KANG, Z. C.; EYRING, L. The prediction of the structure of members of the homologous series of the higher rare earth oxides. Journal of Alloys and Compounds, v. 275-277, p. 30-36, 1998. 
155 - MAZDIYASNI, K. S.; BROWN, L. M. Influence of dynamic calcination on crystallite growth of submicron rare-earth oxides. J. Am. Ceram. Soc., v. 54, n. 10, p. $479-483,1971$.

156 - TSUZUKI, T.; HARRISON, W. T. A.; McCORMICK, P. G. Synthesis of ultrafine gadolinium oxide powder by mechanochemical processing. . Journal of Alloys and Compounds, v. 281, p. 146-151, 1998.

157 - TSUZUKI, T.; PIRAULT, E.; McCORMICK, P. G. Mechanochemical synthesis of gadolinium oxide nanoparticles. Nanostructured Materials, v. 11, n. 1, p. 125-131, 1999. 


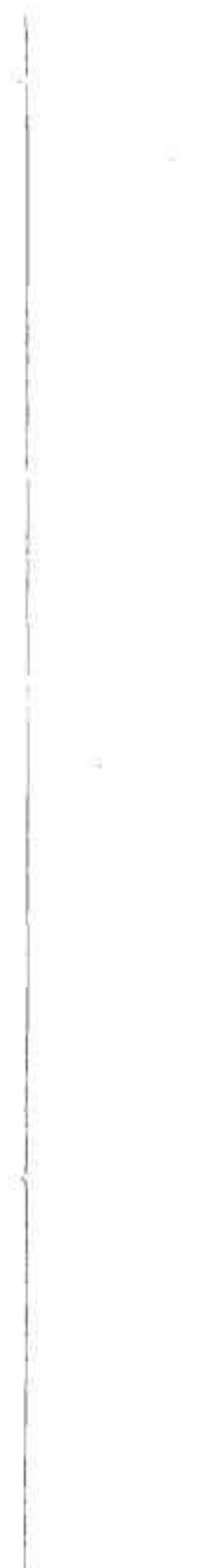

.

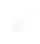

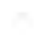

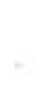

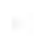

. 